\title{
The Synthesis of Novel Gallium Carbenes, Nitrenes, Phosphinidenes and Alkoxides
}

By

Struan John Wright Cummins

\author{
A thesis \\ submitted to Victoria University of Wellington \\ in partial fulfilment of the \\ requirements for the degree of \\ Masters of Science \\ in Chemistry
}

Victoria University of Wellington 


\begin{abstract}
In the present study, synthetic routes to formal double bonds between gallium and carbon (1), nitrogen (2), and phosphorus (3) have been investigated. These synthetic routes utilised the monoanionic, four electron donor, $\beta$-diketiminate (BDI) ligand to provide both steric and electronic stabilisation to three coordinate gallium complexes. The known di-substituted $\beta$-diketiminatogallium complexes: [(BDI)GaMe $)_{2}$ and [(BDI)Ga(NHPh) $)_{2}$, as well the new complexes: [(BDI)GaBn $\left.\mathrm{Ga}_{2}\right]$, [(BDI)Ga(NHDMP) $)_{2}\left(\mathrm{DMP}=2,6-\mathrm{Me}_{2} \mathrm{C}_{6} \mathrm{H}_{3}\right),\left[(\mathrm{BDI}) \mathrm{Ga}(\mathrm{NHDIPP})_{2}\right]\left(\mathrm{DIPP}=2,6-\mathrm{Pr}_{2} \mathrm{C}_{6} \mathrm{H}_{3}\right),\left[(\mathrm{BDI}) \mathrm{Ga}(\mathrm{PHPh})_{2}\right]$ were examined for their reactivity towards the $\alpha$-proton elimination mechanism for the formation of multiple bonds that is observed in transition metals. All of these complexes were shown to be unreactive towards $\alpha$-proton elimination.
\end{abstract}

The di-substituted $\beta$-diketiminato-gallium complex $\left[(\mathrm{BDI}) \mathrm{GaMe}_{2}\right]$ was subjected to various aniline derivatives to investigate if the methyl ligands exhibited the same reactivity as di-methyl transition metal complexes, where the methyl ligands could deprotonate the aniline to form a metal-imido complex. This complex was found to have no reactivity with anilines.

The mono-substituted $\beta$-diketiminato-gallium complex [(BDI)Ga(NHDMP)Cl] was tested for its reactivity with ${ }^{\mathrm{n}} \mathrm{BuLi}$ to abstract the amide proton and eliminate $\mathrm{LiCl}$ to form a gallium imido complex. While the ${ }^{1} \mathrm{H}$ NMR spectrum of the reaction mixture showed that a reaction had occurred, the products could not be isolated for characterisation.

Another mono-substituted $\beta$-diketiminato-gallium complex [(BDI)Ga(PHPh)Cl] was also tested for its reactivity with ${ }^{\mathrm{n}} \mathrm{BuLi}$ to abstract the phosphide proton and eliminate $\mathrm{LiCl}$ to form a gallium phosphinidene complex. The ${ }^{1} \mathrm{H}$ NMR spectrum and ${ }^{31} \mathrm{P}$ NMR spectrum of the isolated complex revealed that it still contained a phosphide proton, however the gallium centre now appeared to be bonded to a former methine carbon of an isopropyl group of the BDI ligand (32). This bond may have formed through metathesis between an intermediate containing a gallium-phosphorus double bond, and the $\mathrm{C}-\mathrm{H}$ bond of the isopropyl group. Further mechanistic studies could confirm if an intermediate such as $\mathbf{3}$ is formed, and the synthetic strategy altered to isolate it.

The synthesis of $\beta$-diketiminato-gallium-alkoxide complexes was also attempted, however the products of these synthesises could not be isolated due to solubility issues, potentially due to polymerisation. 

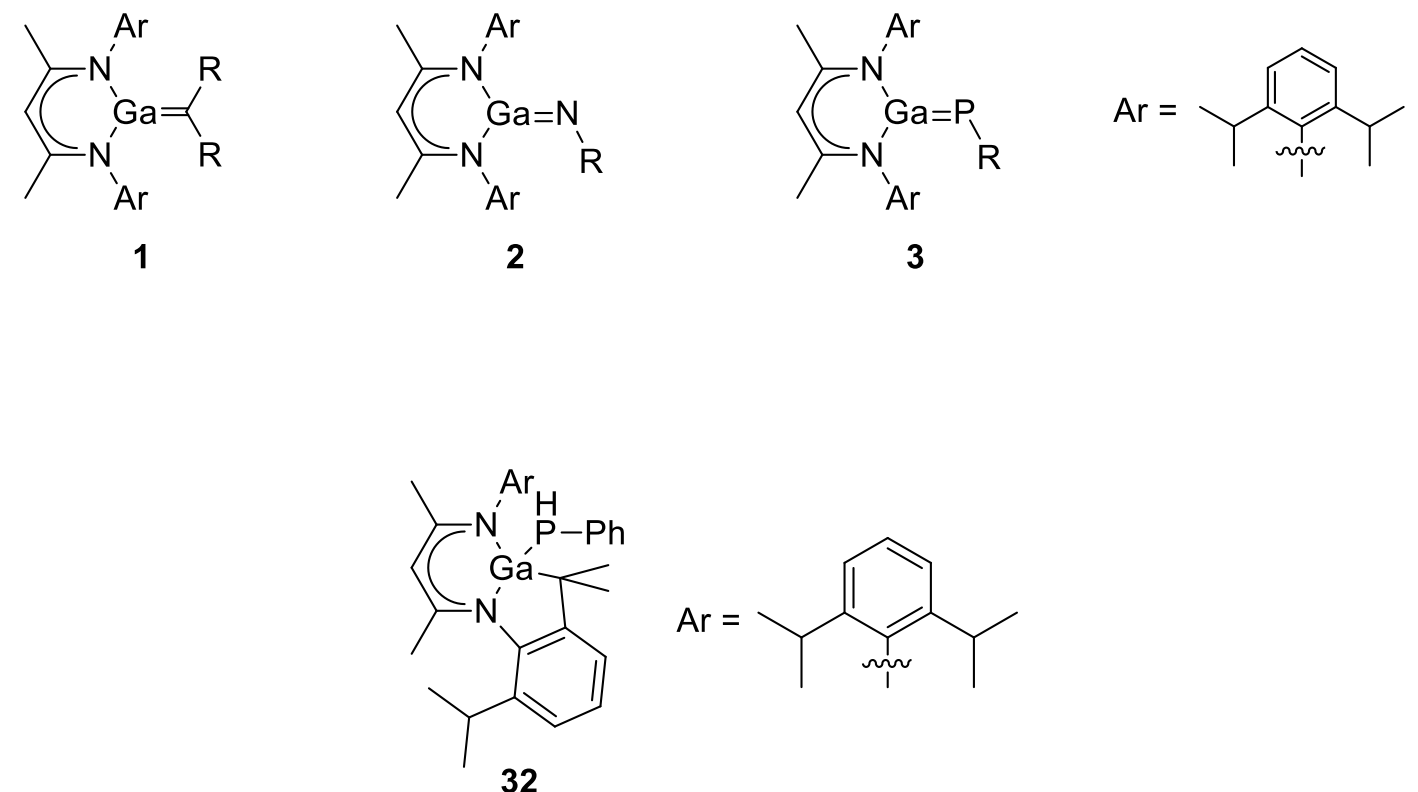

32 


\section{Acknowledgements}

Over the course of the past two years there have been many wonderful and knowledgeable people who have contributed greatly to the completion of this thesis, many of which it would not have been possible without.

To my supervisor Dr. Robin Fulton, thank you very much for your time, support, patience, guidance, constant enthusiasm, positive attitude, and your overall awesome personality for making this study so enjoyable. Thank you for all the encouragement and knowledge you have provided over the years, and for always being available when seeking your wisdom. To my lab mates Ryan Schwamm, Elliot Borren, Putri Fraser and Evan Playle, thank you for all of your input over the last two years in making the lab a humorous place to work, the jokes, peggings, drawings, stories, and videos of the day made the time in the lab fly, much faster than the toluene on the vacuum ever did.

To Associate Professor Martyn Coles, thank you for all your help and input over the years. You have been a fountain of knowledge in many areas, most of all with crystal structures and solving crystal data. To the organometallics research group headed by Professor John Spencer, thank you for all your help, advice, and difficult to synthesise chemicals that you donated to this research. In particular, thank you to Kathryn Allan for all your help running variable temperature NMR spectroscopy and being a continuing source of wisdom on phosphorus NMR.

To fellow masters students Shyamal Prasad and Amy Foster, thank you for making what little free time we've had over the past two years fun and enjoyable, good friends like you are hard to come by. To everyone that has had to put up with me annoying them over the last few years while waiting for toluene to vac off, thanks heaps. Especially Teresa Gen, Jackie King, and Jaime-Ann Elliot who not only put up with me but always lent me chemicals, equipment, and the occasional nitrogen cylinder when we forgot to order one.

I would like to gratefully acknowledge the Curtis-Gordon Research Scholarship in Chemistry for providing funding.

To my sister, thank you for the food during the weeks where there wasn't any work, and for all your support over the past two years. To my mum and dad, thank so very much for everything you've done, the care packages, the financial aid, the occasional haircut and most importantly the unconditional love and support you've provided over the years have got me this far, and this thesis couldn't have been completed without you. 


\section{Table of Contents}

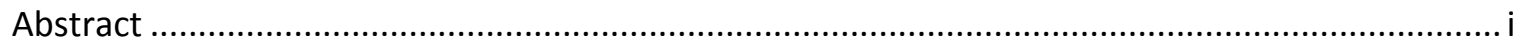

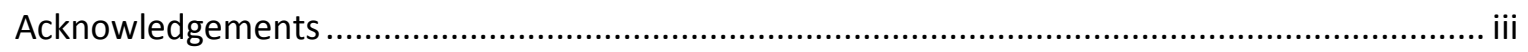

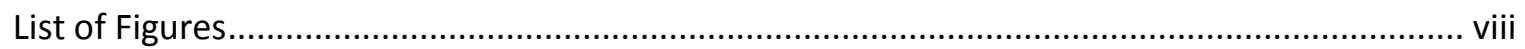

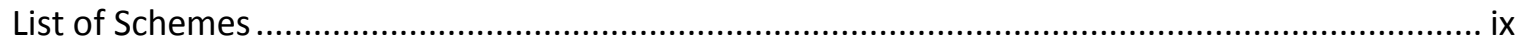

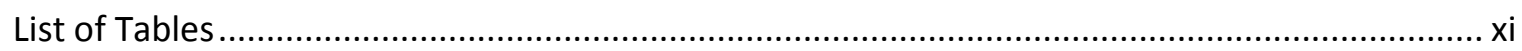

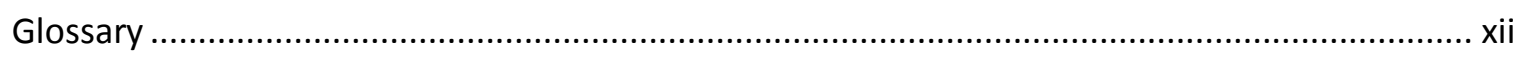

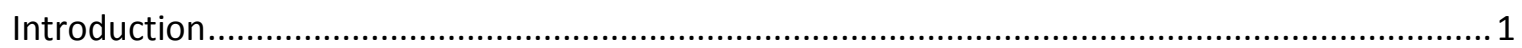

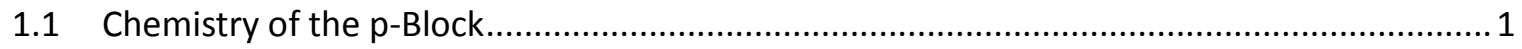

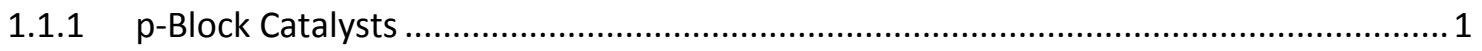

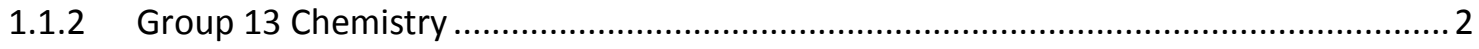

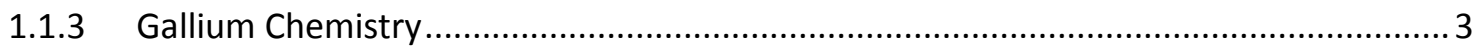

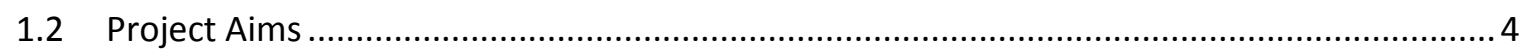

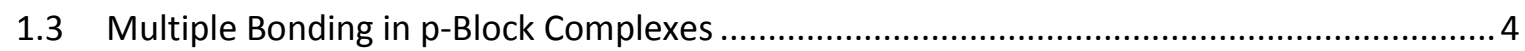

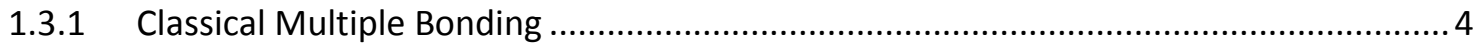

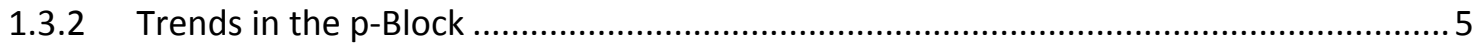

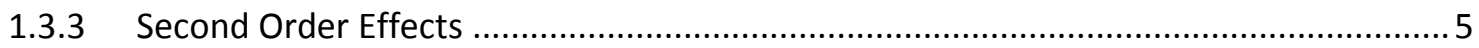

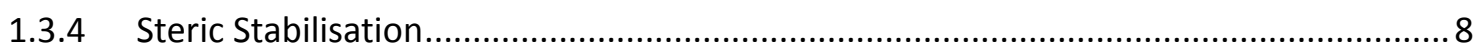

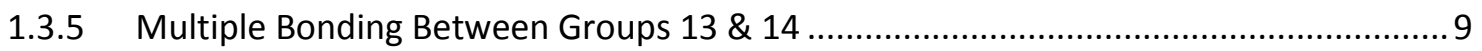

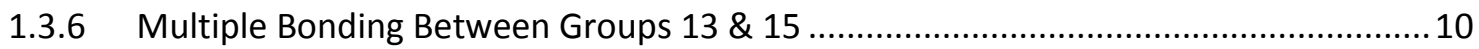

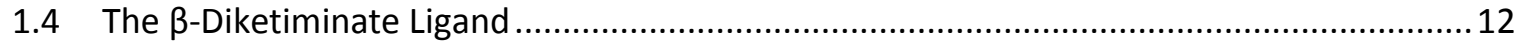

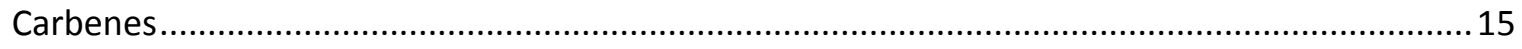

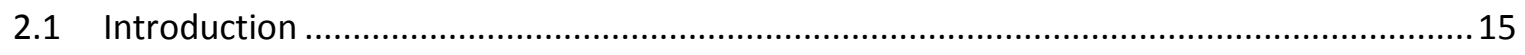

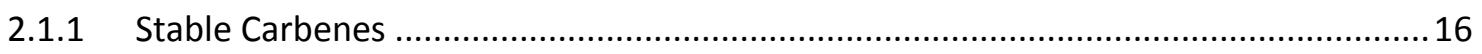

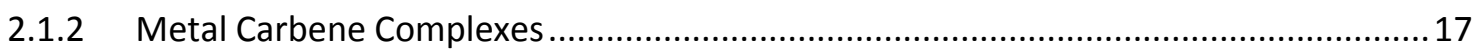

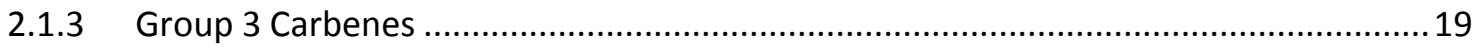

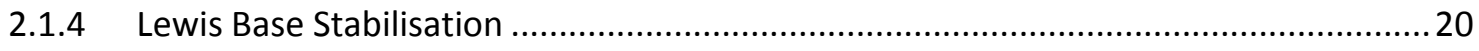

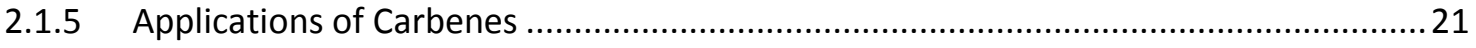




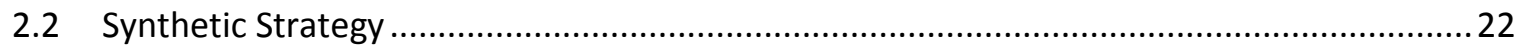

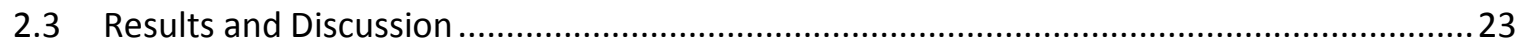

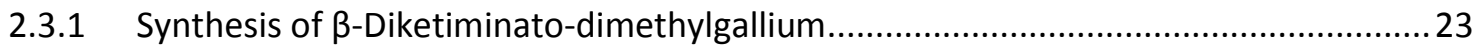

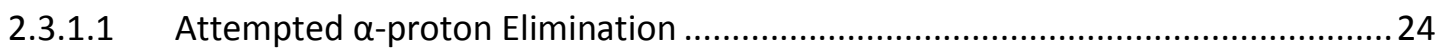

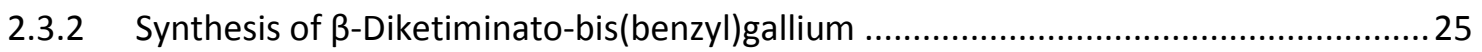

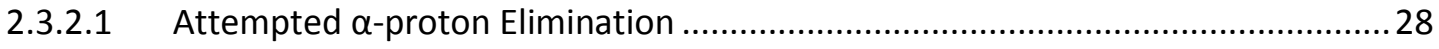

2.3.3 Attempted Synthesis of $\beta$-Diketiminato-benzyl-chlorogallium ...................................29

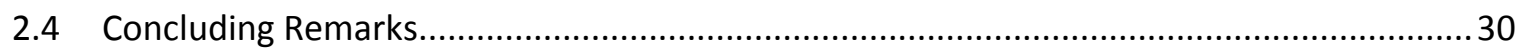

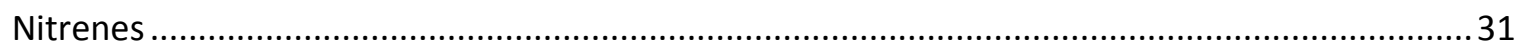

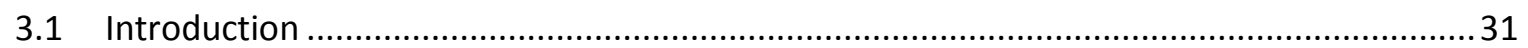

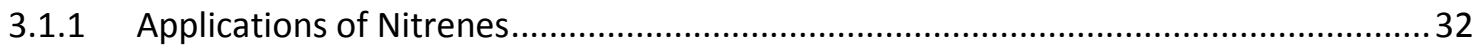

3.1.2 Existing $\beta$-Diketiminatogallium Imido Complexes …................................................... 33

3.1.3 Existing $\beta$-Diketiminatogallium Diamido Complexes .................................................... 34

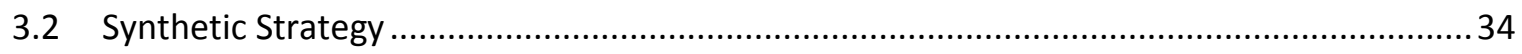

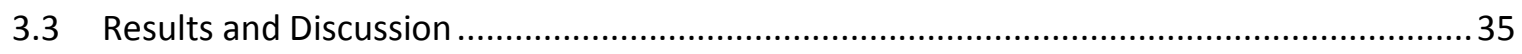

3.3.1 Reactivity of $\beta$-Diketiminato-dimethylgallium with Anilines ........................................35

3.3.2 Attempted Synthesis of $\beta$-Diketiminato-bis(hexamethyldisilazane)gallium .................36

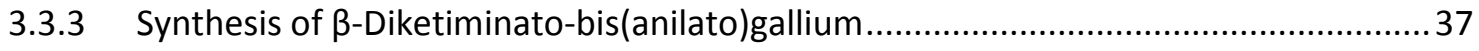

3.3.3.1 Attempted $\alpha$-proton Elimination ………..................................................... 37

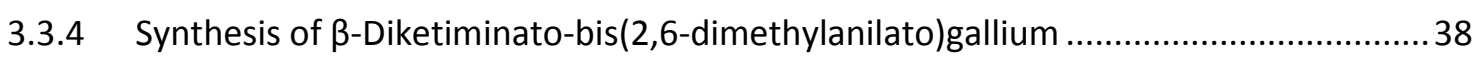

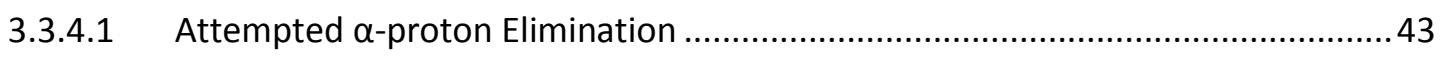

3.3.5 Synthesis of $\beta$-Diketiminato-bis(2,6-diisopropylanilato)gallium ............................... 44

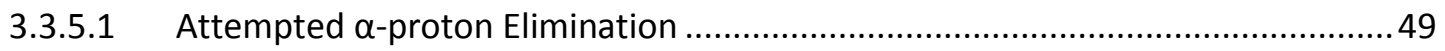

3.3.6 Synthesis of $\beta$-Diketiminato-anilato-chlorogallium Complexes...................................50

3.3.6.1 Addition of $n$-Butyllithium to $\beta$-Diketiminato-chloro-(2,6-dimethylanilato)gallium 51

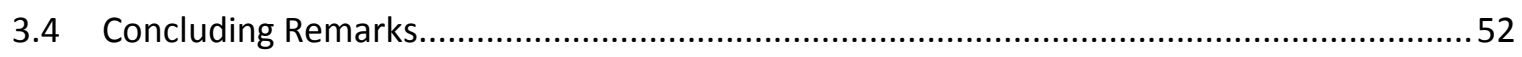

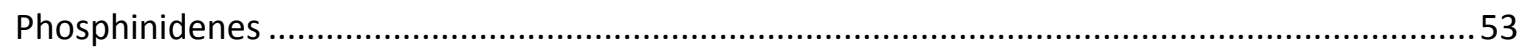


4.1 Introduction

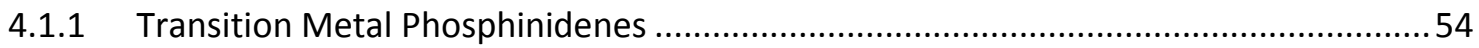

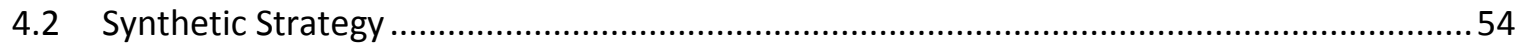

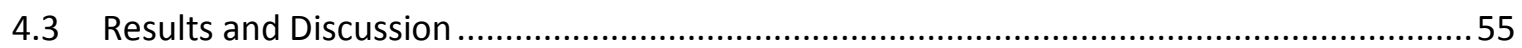

4.3.1 Attempted Synthesis of $\beta$-Diketiminato-bis(dicyclohexylphosphanido)gallium............55

4.3.2 Synthesis of $\beta$-Diketiminato-bis(phenylphosphanido)gallium ....................................56

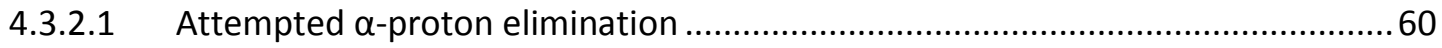

4.3.3 Synthesis of $\beta$-Diketiminato-chloro-phenylphosphanidogallium ...............................61

4.3.3.1 Addition of $n$-Butyllithium to $\beta$-Diketiminato-chloro-phenylphosphanidogallium .. 62

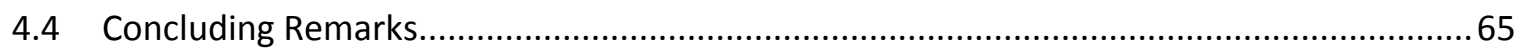

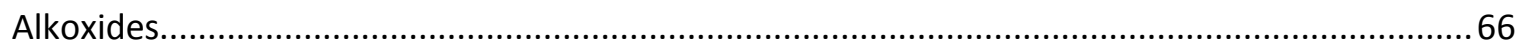

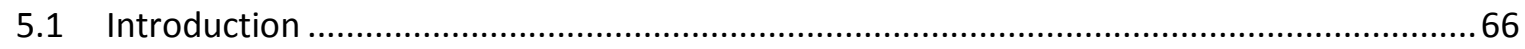

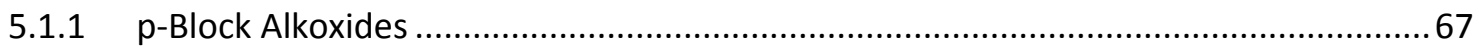

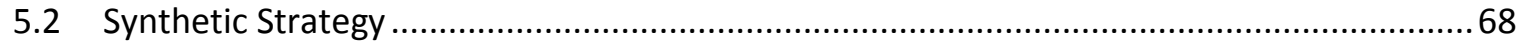

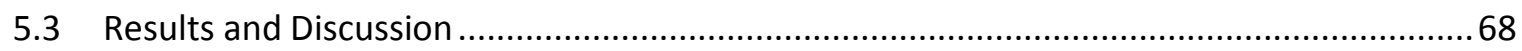

5.3.1 Attempted Synthesis of $\beta$-Diketiminato-bis(isopropoxido)gallium ..............................68

5.3.2 Attempted Synthesis of $\beta$-Diketiminato-bis(tert-butoxido)gallium............................69

5.3.3 Attempted Synthesis of $\beta$-Diketiminato-bis(phenoxido)gallium .................................. 70

5.3.4 Attempted Synthesis of $\beta$-Diketiminato-bis(2,6-di-tert-butylphenoxido)gallium ........ 71

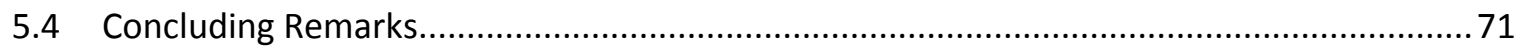

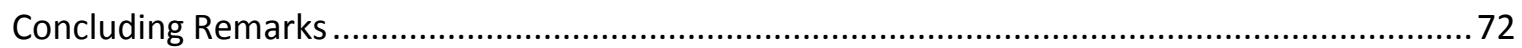

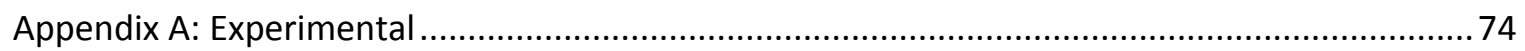

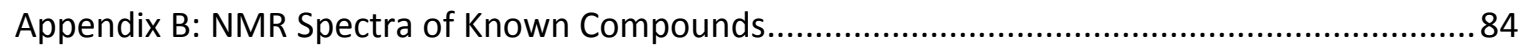

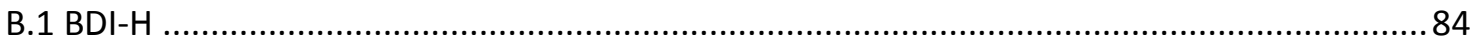

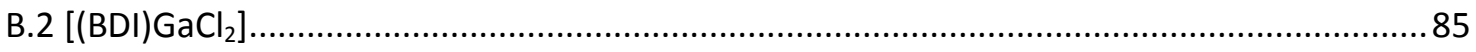

B.3 [(BDI)GaMe $]$.

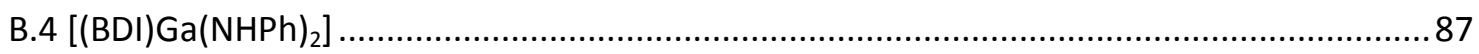

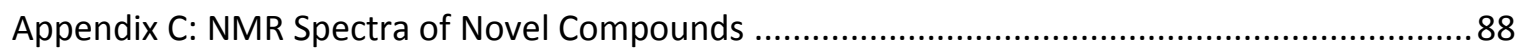




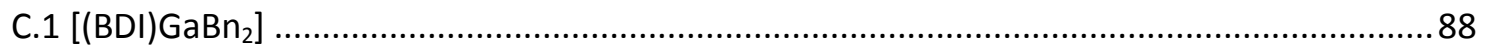

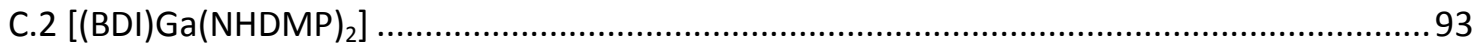

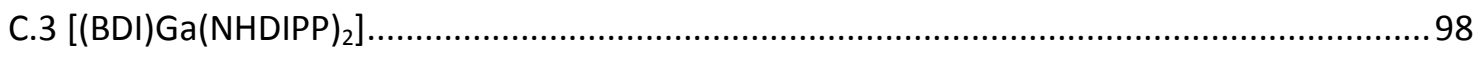

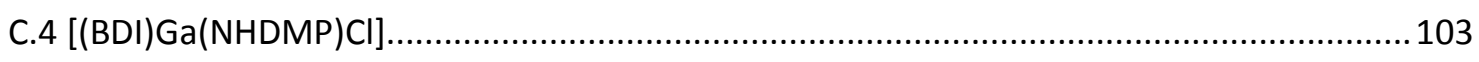

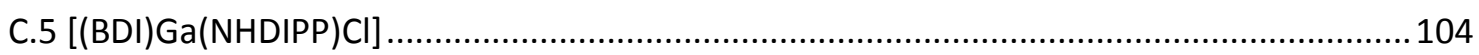

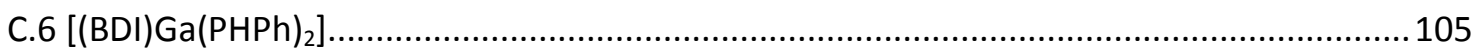

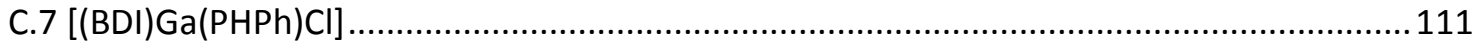

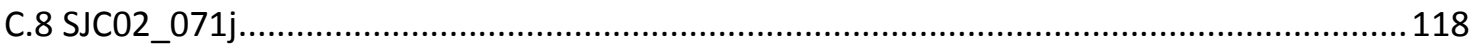

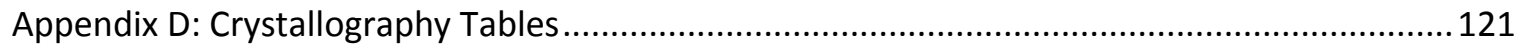

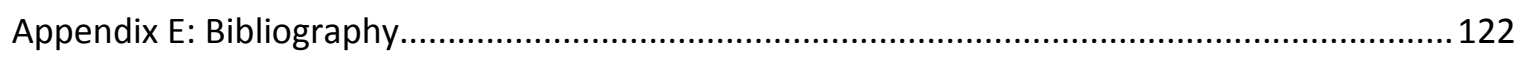




\section{List of Figures}

Figure 1: Tin(II) octanoate.

Figure 2: The $\beta$-diketiminiate-gallium -carbene, -nitrene, and -phosphinidene synthetic targets. . 4

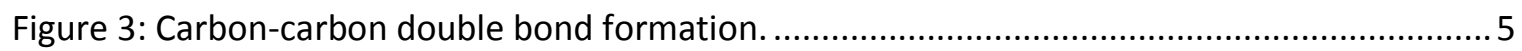

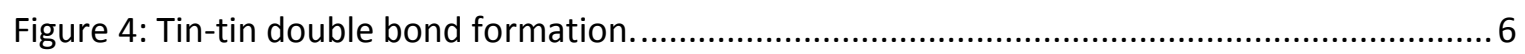

Figure 5: Energy level diagram illustrating second order Jahn-Teller orbital mixing ....................... 7

Figure 6: The dihedral angle between the double bond plane and substituents, $\alpha$...................... 8

Figure 7: Known complexes possessing boron-carbon and boron-silicon double bonds. ............... 9

Figure 8: Generic structure of the $\beta$-diketiminate ligand.............................................................. 12

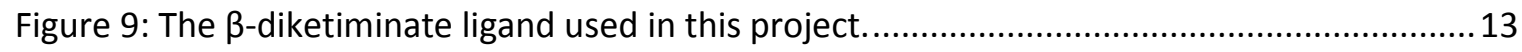

Figure 10: $\beta$-diketiminato- $N$-heterocyclic gallene and its use as a ligand.................................... 14

Figure 11: The singlet and triplet electronic states of carbenes................................................ 15

Figure 12: Cyclic amino-alkyl and phosphorus stabilised carbenes. ........................................... 16

Figure 13: The bonding configuration of both Fischer and Schrock carbenes............................. 17

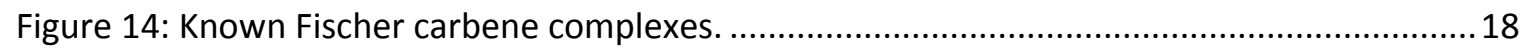

Figure 15: Stabilised carbenes have been previously used as ligands on gallium trichloride........19

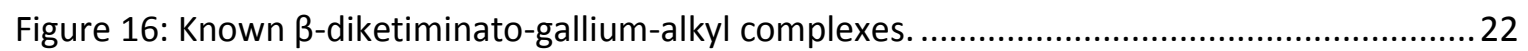

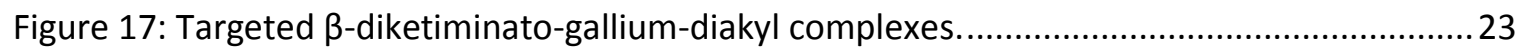

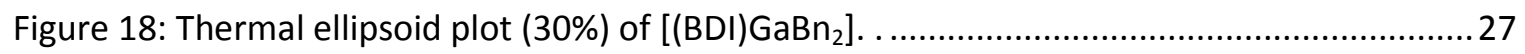

Figure 19: Catalytic cycle of hydroaminiation proposed by Bergman et al. ................................... 32

Figure 20: Targeted $\beta$-diketiminato-gallium-diamido complexes................................................. 35

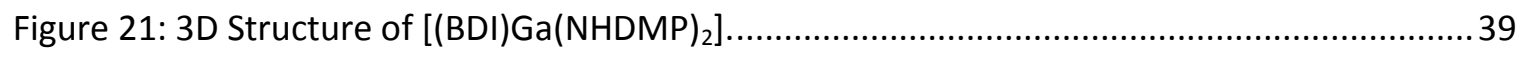

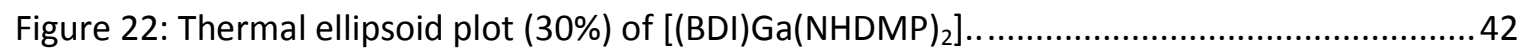

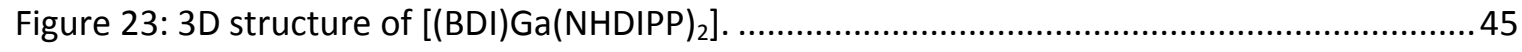

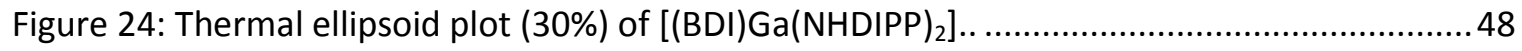

Figure 25: Targeted $\beta$-diketiminato-gallium -diphosphido and -alkylphosphido complexes......... 55

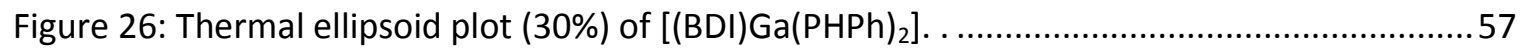

Figure 27: Proposed product of gallium-carbon bond formation...............................................65

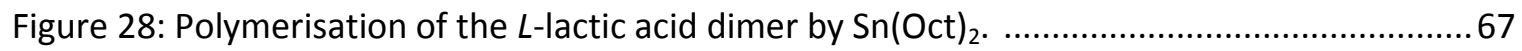

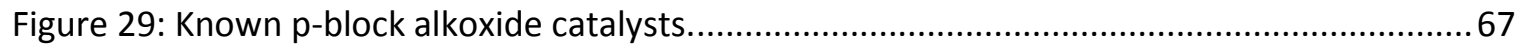

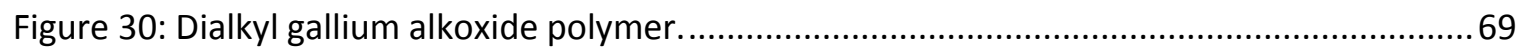




\section{List of Schemes}

Scheme 1: Reversible cleavage of dihydrogen by frustrated Lewis pairs. ..................................... 3

Scheme 2: Synthesis of multiple bonds between heavier group 13 and group 14 elements........ 10

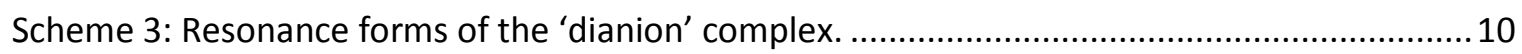

Scheme 4: Resonance forms of a metal-phosphanido complex ................................................. 11

Scheme 5: Synthesis of gallium and indium phosphinidene complexes...................................... 11

Scheme 6: Synthesis of known $\beta$-diketiminate gallium dichloride complexes. ............................ 12

Scheme 7: Synthesis of a $\beta$-diketiminate gallium dimethyl complex.............................................13

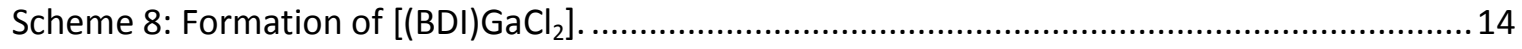

Scheme 9: The synthesis of a cyclopropane derivative using a carbene intermediate. .................16

Scheme 10: Resonance structures of $\mathrm{N}$-heterocyclic carbenes. ..................................................... 16

Scheme 11: $\alpha$-proton elimination by the neopentyl ligand to give a carbene and neopentane...18

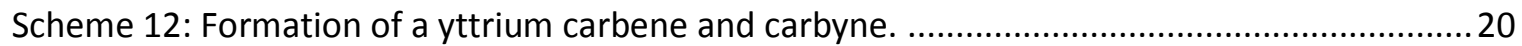

Scheme 13: Lewis base stabilised titanocene-carbene complexes................................................ 20

Scheme 14: Formation of a $\beta$-diketiminato-scandium-imido complex......................................... 21

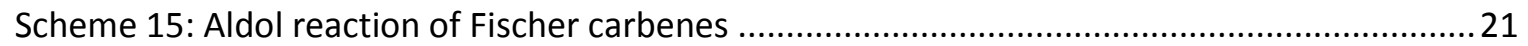

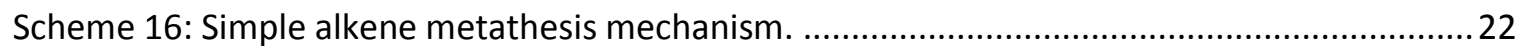

Scheme 17: $\alpha$-proton elimination of [(BDI)GaMe $\left.{ }_{2}\right]$ to give a gallium carbene. ..............................23

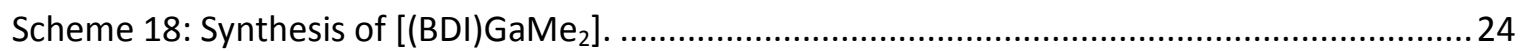

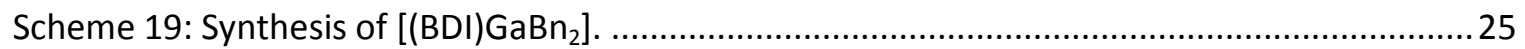

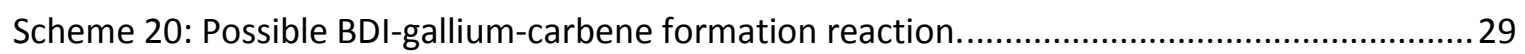

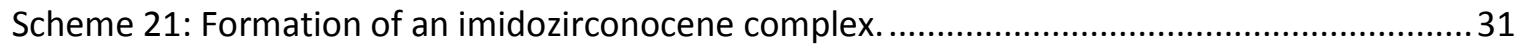

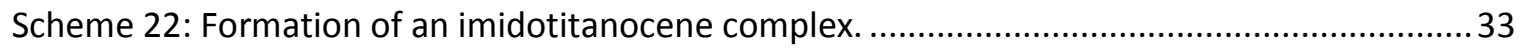

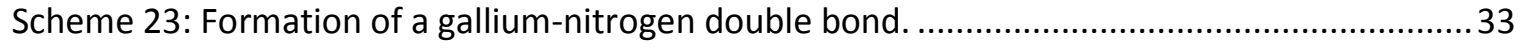

Scheme 24: Formation of $\beta$-diketiminato-gallium-diamide complexes...........................................34

Scheme 25: Proposed reaction mechanism of $\left[(\mathrm{BDI}) \mathrm{GaMe}_{2}\right]$ and aniline..................................... 35

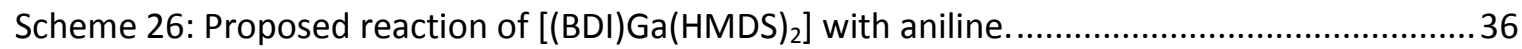

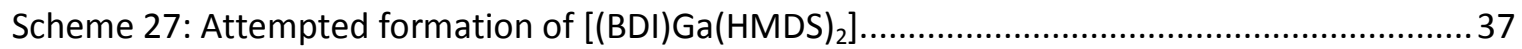

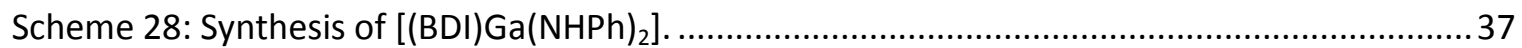

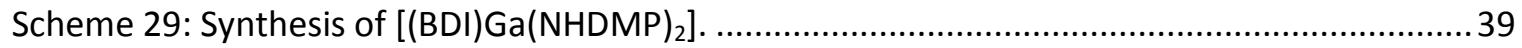

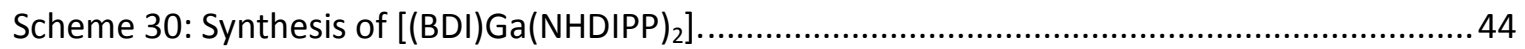

Scheme 31: Possible $\beta$-diketiminato-gallium-imide formation reaction. ........................................50

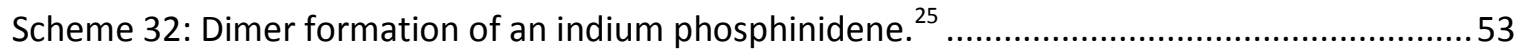

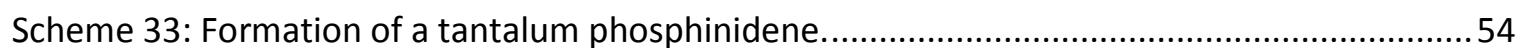




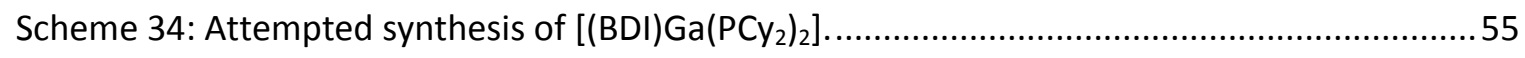

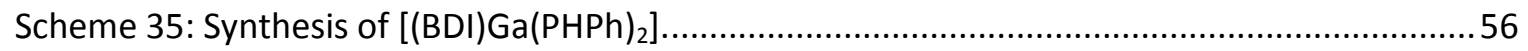

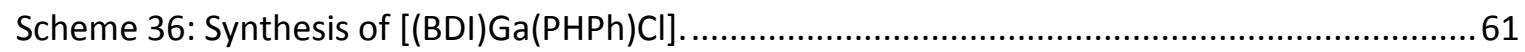

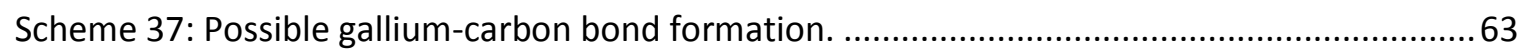

Scheme 38: Formation of titanium-carbon bonds using the BDI ligand. .......................................... 64

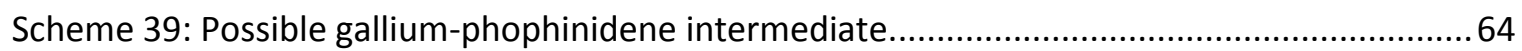

Scheme 40: Two potential routes to $\beta$-diketiminato-gallium alkoxides. ......................................68 


\section{List of Tables}

Table 1: Reaction conditions for the attempted $\alpha$-proton elimination of [(BDI)GaMe $\left.\mathrm{Ge}_{2}\right] \ldots \ldots \ldots \ldots \ldots . . . .25$

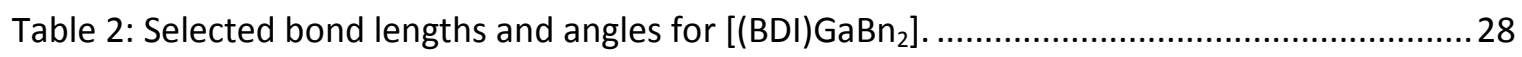

Table 3: Reaction conditions for the attempted $\alpha$-proton elimination of [(BDI)GaBn $\left.G_{2}\right] \ldots \ldots \ldots \ldots \ldots . . . . .29$

Table 4: Reaction conditions for the attempted $\alpha$-proton elimination of [(BDI)Ga(NHPh) $\left.{ }_{2}\right]$........ 38

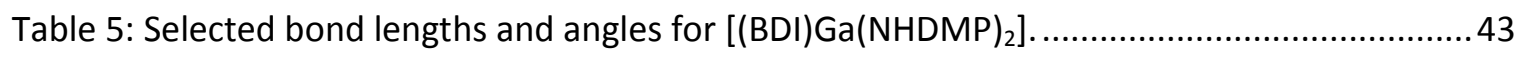

Table 6: Reaction conditions for the attempted $\alpha$-proton elimination of [(BDI)Ga(NHDMP) $\left.{ }_{2}\right] \ldots . .44$

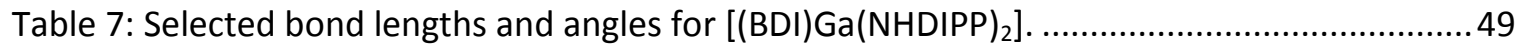

Table 8: Reaction conditions for the attempted $\alpha$-proton elimination of $\left[(\mathrm{BDI}) \mathrm{Ga}(\mathrm{NHDIPP})_{2}\right] \ldots . .50$

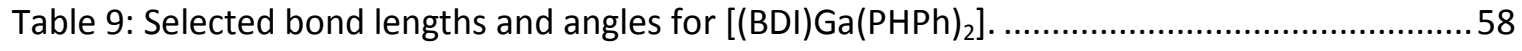

Table 10: Reaction conditions for the attempted $\alpha$-proton elimination of $\left[(\mathrm{BDI}) \mathrm{Ga}(\mathrm{PHPh})_{2}\right] \ldots \ldots . .61$ 


\section{Glossary}

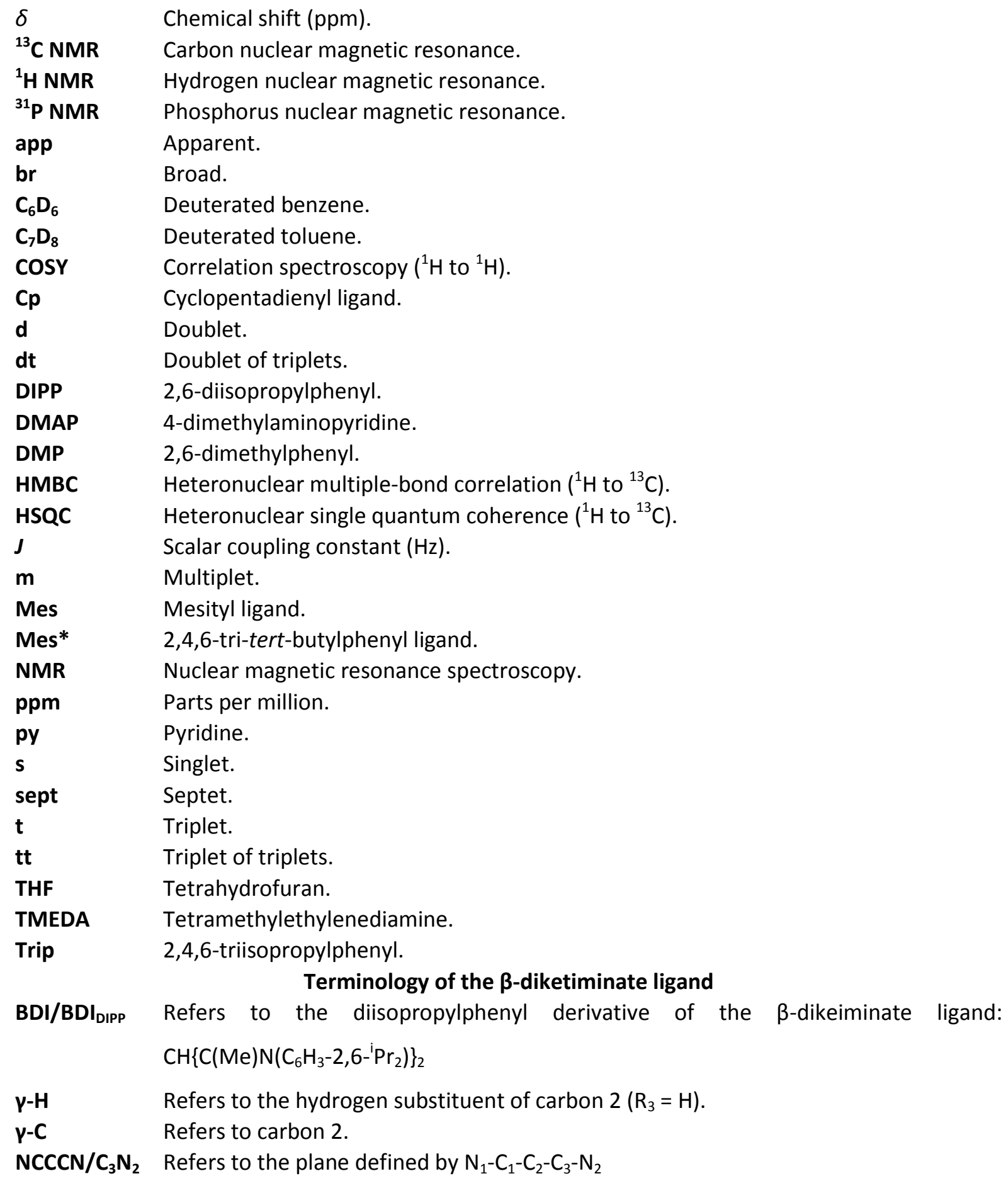<smiles>[R5]N=C([R])/C([R])=C(/[R])N([R7])[Y]</smiles> 


\section{Chapter 1}

\section{Introduction}

\subsection{Chemistry of the p-Block}

Life on Earth is dominated heavily by the chemistry of the p-block elements, with the human body containing an abundance of carbon, nitrogen, oxygen and phosphorus in its elemental composition. There are a wide variety of biologically and industrially important compounds that contain formal multiple bonds between elements of the p-block, such as alkenes and alkynes, ketones and other carbonyls, imines and cyanides, phosphates and many others. ${ }^{1,2}$ As many of these functionalities play crucial roles in biological systems, as well as industry, understanding the analogues of these systems with heavier p-block elements could lead to the discovery of new biologically active or catalytically active compounds, or allow for the improvement of existing ones.

\subsection{1 p-Block Catalysts}

The use of oil or petroleum based polymers has several downsides, most notably the limited supply of oil and the ecological problems arising from their disposal. Alternative polymers such as polylactic acid (PLA) and polyglycolic acid (PGA), which are biodegradable and made from readily renewable materials, offer the solution to these problems. While the elements of the $d$-block are the industrial standard for the catalysis of petroleum based polymers, $\operatorname{tin}(\mathrm{II})$ octanoate ( $\mathrm{Sn}(\mathrm{Oct})_{2}$, Figure 1 ) is the benchmark for the polymerisation of both PLA and the co-polymer of lactic acid and glycolic acid (PLGA), as it is both highly active in polymerisation and air stable. ${ }^{3}$ 


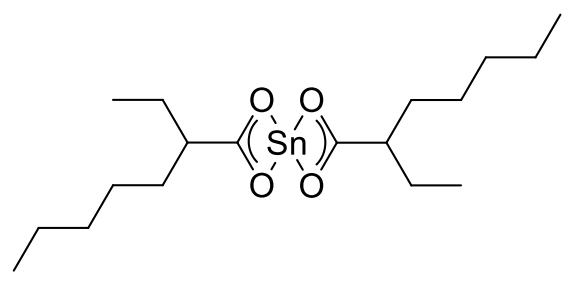

Figure 1: Tin(II) octanoate.

Unfortunately, tin(IV) is toxic to humans, especially tri-alkyl tin complexes, and therefore it is not ideal for the production of polymers used in food packaging. Other p-block complexes that have been shown to be catalytically active for the polymerisation of PLA are aluminium, germanium, and bismuth alkoxide complexes, along with catalysts using calcium, magnesium, titanium, and zinc centres. ${ }^{4}$ Aluminium has also been shown to be effective at the polymerisation of ethylene, using the complex $\left\{\mathrm{RC}\left(\mathrm{NR}^{\prime}\right)_{2}\right\} \mathrm{AlMe}_{2}{ }^{5}$ While polyethylene is not as environmentally friendly as PLA, this does show that $p$-block elements can be useful in catalysis reactions previously limited to $d$-block elements.

\subsubsection{Group 13 Chemistry}

The chemistry of the group 13 elements derives from their three valence electrons, with the +3 oxidation state being the highest accessible state. This makes the group 13 elements highly complementary to the group 15 elements, with five valence electrons, which readily form Lewis pairs. Recently this pairing has been utilised as a new method of hydrogen storage, through the use of 'frustrated Lewis pairs'. These pairs utilise the steric hindrance of large, bulky ligands, such as the mesityl and pentaflurophenyl ligands, to generate a molecule containing both a borane and phosphine functionality that are unable to interact with each other, creating both Lewis acid and base functionalities in the same molecule. These frustrated Lewis pairs have been shown to cleave dihydrogen (Scheme 1 ) at room temperature, and reversibly liberate dihydrogen under thermal conditions. $^{6}$ 


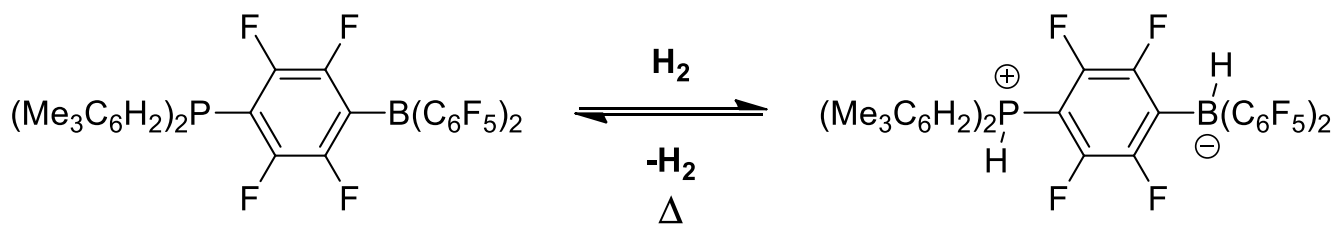

Scheme 1: Reversible cleavage of dihydrogen by frustrated Lewis pairs.

Organoboron and organoaluminium reagents are also used heavily in synthetic chemistry in a variety of roles, including as reducing agents $\left(\mathrm{LiAlH}_{4}\right.$ and $\left.\mathrm{NaBH}_{4}\right)$ and in hydroboration reactions $\left(\mathrm{B}_{2} \mathrm{H}_{6}\right)$. Elemental boron forms covalent networks similar to carbon, while boron-hydride compounds form clusters such as borane $\left(\mathrm{B}_{2} \mathrm{H}_{6}\right)$ that have bridging hydrogen atoms between the boron atoms in the cluster. Aluminium is the third most abundant element on Earth, and is highly reactive in its elemental state. ${ }^{2}$ Alloys of aluminium are lightweight and resistant to corrosion, which makes them useful substitutes for iron and steel in many roles that require these properties, such as the manufacture of aircraft and cars, construction, packaging and household items. ${ }^{2}$ Indium and thallium adopt both the +1 and +3 oxidation state, with indium favouring +3 and thallium favouring +1 , making indium(I) complexes good reducing agents and thallium(III) complexes good oxidants. ${ }^{2}$

\subsubsection{Gallium Chemistry}

Although gallium is a group 13 element like boron and aluminium, it has significantly different physical properties, including a smaller atomic radius than aluminium and a melting point of just $303 \mathrm{~K}$. The primary use of gallium industrially is as a component of semiconductors, with gallium nitride ( $\mathrm{GaN}$ ) and gallium arsenide (GaAs), used in circuitry, photovoltaics, and LEDs. The radioactive isotope ${ }^{67} \mathrm{Ga}$ has been used as a commercial magnetic resonance imagery agent as gallium(III) exhibits similar biological activity to iron(III), allowing it to substitute with iron in the blood. Gallium nitrate (brand name Ganite ${ }^{\circledR}$ ) is a metallopharmaceutical agent that is used to treat both lymphomas and bladder cancer by competing with iron(III) for the protein transferrin, which transfers iron into cells. This reduces the amount of iron(III) transported into cells, resulting in an iron deficiency in the tumour cells, as iron is essential for cell growth, this inhibits further growth of the tumour. ${ }^{7}$ 


\subsection{Project Aims}

The aim of this project was a proof-of-concept that the $\left[\mathrm{CH}\left\{\mathrm{N}\left(\mathrm{C}_{6} \mathrm{H}_{3}-2,6-\mathrm{i} \mathrm{Pr}\right) \mathrm{C}(\mathrm{Me})\right\}_{2}\right](\mathrm{BDI})$ ligand could be used to stabilise low co-ordinate gallium complexes possessing some degree of multiple bonding with lighter group 14 and 15 elements, specifically, carbon, nitrogen and phosphorous. In particular the focus of this research was the formation of formal gallium-carbon, -nitrogen, and -phosphorus double bonds, of which to date only gallium-nitrogen double bonds have been reported. The BDI ligand was chosen as an ancillary ligand to stabilise three-coordinate gallium complexes, as it was theorised that this ligand would provide enough steric bulk to stabilise the resulting carbene, nitrene and phosphinidene complexes. Synthetic targets are outlined in Figure 2.<smiles></smiles>

1<smiles></smiles>

2

a) $R_{1}=H R_{2}=H$

b) $R_{1}=P h R_{2}=H$

c) $R_{1}=P h R_{2}=P h$ a) $R_{1}=P h$

b) $\mathrm{R}_{1}=2,6-\mathrm{MeC}_{6} \mathrm{H}_{3}$

c) $\mathrm{R}_{1}=2,6-\mathrm{PrC}_{6} \mathrm{H}_{3}$<smiles></smiles><smiles>CC(C)c1cccc(C(C)C)c1C(C)(C)C</smiles>

a) $R_{1}=C y$

b) $\mathrm{R}_{1}=\mathrm{Ph}$

Figure 2: The $\beta$-diketiminiate-gallium -carbene, -nitrene, and -phosphinidene synthetic targets.

\subsection{Multiple Bonding in p-Block Complexes}

\subsubsection{Classical Multiple Bonding}

Multiple bonding between the p-block elements of period two and three is prevalent due to the smaller relative energy difference and large degree of physical overlap between the $s$ and $p$ orbitals in each element; combined with the small relative energy difference between the elements, compared to the elements of period 4 onwards. ${ }^{8}$ These properties allow for the creation of both $\sigma$ and $\pi$ bonds, with a typical double bond consisting of two elements in triplet states having $\sigma$ overlapping $s p$ hybrid orbitals and $\pi$ overlapping of a perpendicular $p$ orbital (Figure 3 ). The strength 
of the $\sigma$ and $\pi$ bonds typically decreases going down a group, usually with a decrease of at least $50 \%$ observed in the first jump down from period 2 to period $3 .{ }^{9}$

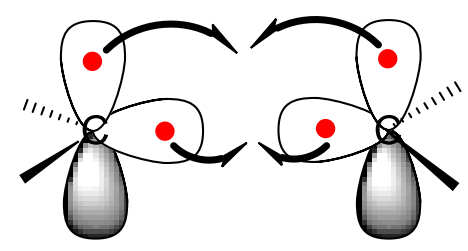

Figure 3: Carbon-carbon double bond formation.

\subsubsection{Trends in the p-Block}

In the p-block, the ability of the $s$ and $p$ orbitals to hybridise decreases going down the group, and there are several theories to explain this. Kutzelnigg ${ }^{10}$ postulates that the valence $p$ orbitals are further extended into space than their corresponding $s$ orbitals, except in period 2, where there are no core $p$ electrons to induce Pauli repulsion. ${ }^{10}$ As the orbitals physically overlap less, their ability to hybridise decreases, which is a simple, logical theory. While the energy difference between the $s$ and $p$ orbitals does increase going down a group, the energy difference is only significant in the heaviest elements, where relativistic effects stabilise $s$ orbitals to a greater extent than $p$ orbitals. ${ }^{10,11}$ For example the $6 s$ orbital of lead shows almost no ability to hybridise, with the molecular orbital exhibiting $>90 \% s$ character and $<10 \% p .^{12}$ This causes the $6 s$ electrons to exhibit the 'inert pair effect', where the $6 s$ electrons behave more like a lone pair of core electrons than valence bonding electrons.

\subsubsection{Second Order Effects}

From gallium onwards, the p-block elements have fully occupied $d$ orbitals in their electronic core, which further increases the relative energy difference between the $s$ and $p$ energy levels. Consequently the heavier $p$-block elements do not exhibit the same type of bonding seen in their lighter second and third period counterparts. The heavier elements of the $p$-block prefer to adopt a singlet electronic state rather than a triplet, depending on the oxidation state of the metal, as the energy difference between the $s p^{2}$ hybrid orbital and the free $p$ orbital is larger than the pairing energy. ${ }^{13}$ As such, classical $\sigma$-bonding cannot occur between these occupied orbitals due to both $s p^{2}$ 
orbitals being fully occupied. Thus these orbitals combine through polar dative bonding where the $s p^{2}$ hybridised orbital overlaps with an empty $p$ orbital (Figure 4). ${ }^{14}$
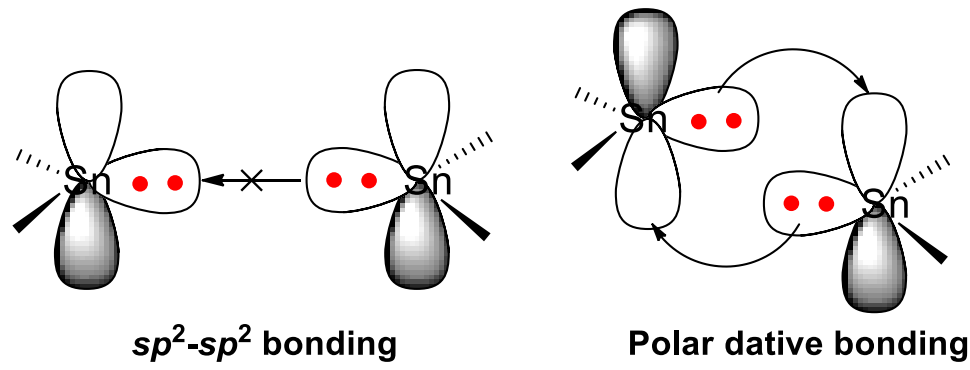

Figure 4: Tin-tin double bond formation. ${ }^{15}$

This combination of two different types of orbitals causes second order Jahn-Teller orbital mixing to occur in the bonding of heavier p-block elements. ${ }^{16}$ This mixing occurs between bonding orbitals with non-bonding or anti-bonding orbitals, resulting in the distortion of the bonding plane. ${ }^{16}$ This distortion manifests in a 'bending' of the bonding plane so that the substituents on either side of the bond are either above or below the bonding plane. In formally double bonded complexes, this results in a mixing of the $\sigma$-orbital with the $\pi^{*}$-orbitals, and the $\pi$-orbital with the $\sigma^{*}$-orbital (Figure $5)^{14}$ resulting in the distortion of the typically planar double bond structure into a transpyramidalized geometry. These second order effects are also present in the alkyne analogues of heavier p-block elements resulting in a trans-bent geometry, as opposed to a linear one. ${ }^{14}$ 

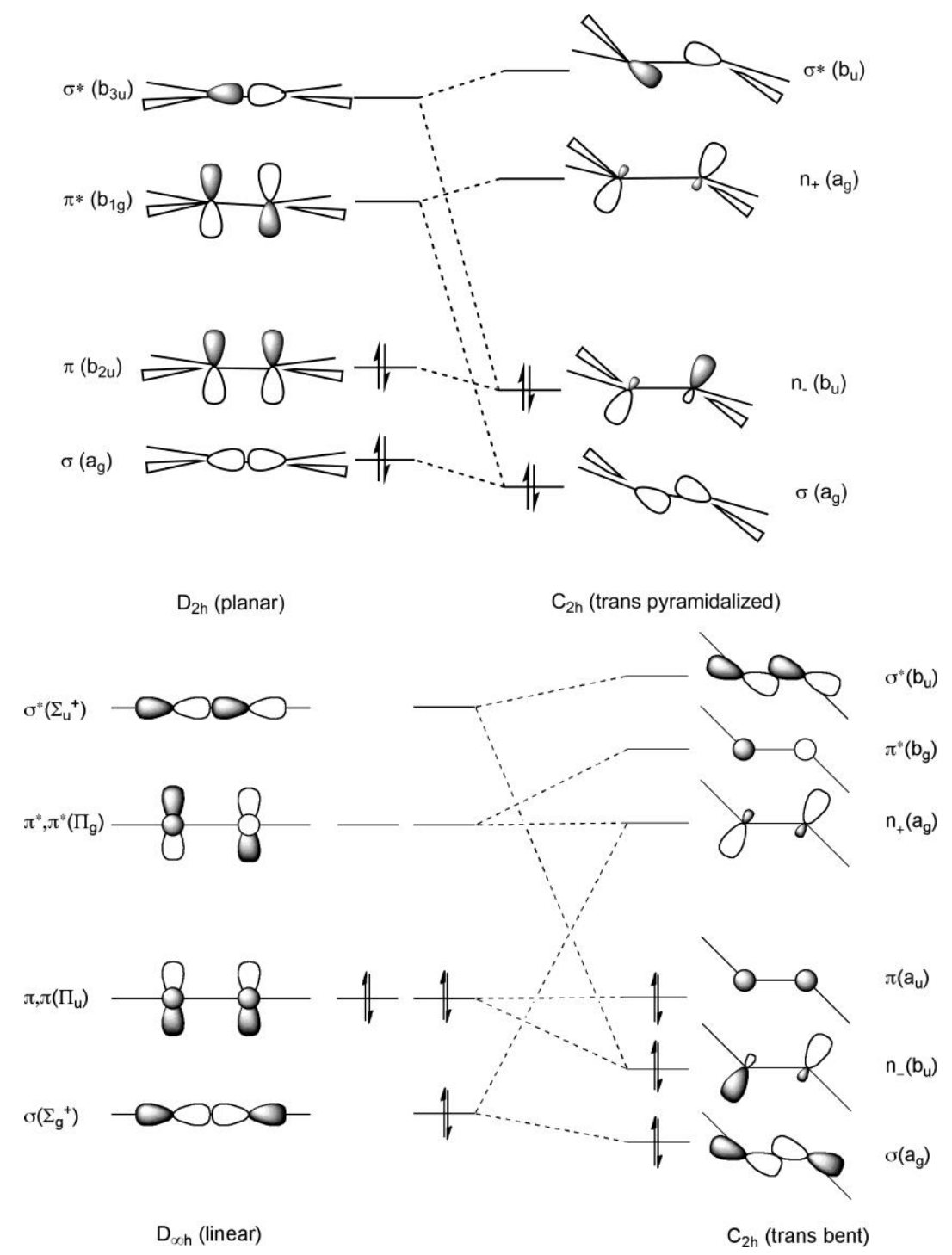

Figure 5: Energy level diagram illustrating second order Jahn-Teller orbital mixing for double bonded (top) and triple bonded (bottom) complexes. Figure reproduced from Fischer and Power. ${ }^{14}$

The degree of Jahn-Teller orbital mixing can be assessed through the out of plane angle of the substituents relative to the bonding plane, otherwise known as the angle $\alpha$ (Figure 6). This angle increases as the degree of orbital mixing increases, which is observed in group 14 complexes. A traditional carbon-carbon double bond has an $\alpha$ angle of $0^{\circ}$, indicating no second order orbital mixing. With disilenes, this angle can range from $0-23^{\circ}$ depending on the ligand system. ${ }^{14}$ Larger, more sterically bulky substituents on the ligand give the complexes an angle closer to $0^{\circ}{ }^{14}$ Further down the periodic table, digermenes exhibit angles of around $50^{\circ}$, distannes (Figure 6) around $55^{\circ},{ }^{14}$ however this effect is best observed in the diplumbenes, which can have angles of up to $71^{\circ},{ }^{17}$ indicating a high degree of orbital mixing. 


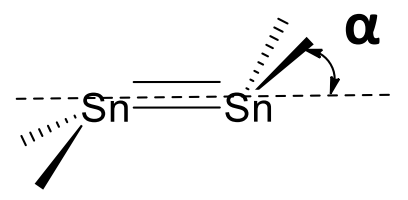

Figure 6: The dihedral angle between the double bond plane and substituents, $\alpha$.

\subsubsection{Steric Stabilisation}

One major difference between the heavier p-block elements and their lighter counterparts is that their ionic radii increases significantly moving down the period. This is due to the changes in their core electronic structure, with period 4 elements onwards possessing core $d$ electrons and period 5 elements onward possessing both core $d$ and $f$ electrons. Due to the Pauli exclusion principle, these extra $d$ and $f$ core electrons force the valence electrons to occupy space further away from the nucleus. ${ }^{15}$ This increased size allows for co-ordination numbers similar to that of transition metals, but without the oxidation/reduction reactivity of analogous transition metal complexes. ${ }^{15}$ In 1973, Lappert et al. ${ }^{18}$ used the steric bulk of the 'Big R' (-CH(SiMe $\left.)_{2}\right)$ ligand to prepare the tin analogues of alkenes and carbenes (distannenes and stannenes respectively) of the structure $\mathrm{R}_{2} \mathrm{SnSnR}_{2}{ }^{18}$ This lead to the realisation that sterically bulky ligands were the key to isolating low co-ordinate $\mathrm{p}$-block complexes by providing the kinetic stability required for their formation. ${ }^{15}$ As stated in Section 1.3.3, more sterically bulky ligands (e.g. 2,4,6,-trimethylphenyl (Mes), $\left.\mathrm{SiMe}\left({ }^{\mathrm{t}} \mathrm{Bu}\right)_{2}\right)$ reduced the $\alpha$-angle of disilene complexes more than less bulky ones like $\mathrm{Si}\left({ }^{\mathrm{i}} \mathrm{Pr}\right)_{3}{ }^{14}$ Consequently, Lappert's synthesis was quickly followed by the synthesis of disilenes, digermenes, and diplumbenes, which all used bulky $R$ groups. At the same time, sterically bulky ligands were being used to synthesise previously unheard of double bonds between different groups of heavier $p$ block elements, such as a lead bismuth double bond. ${ }^{14}$ 


\subsubsection{Multiple Bonding Between Groups 13 \& 14}

Currently there are very few examples of multiple bonding between groups $13 \& 14 .{ }^{14}$ Fischer and Power ${ }^{14}$ divided known compounds into two classes, neutral complexes of $R E=E^{\prime} R_{2}$ (where $E=$ group 13 element and $E^{\prime}=$ group 14 element) and monoanionic complexes $\left[R_{2} E=E^{\prime} R_{2}\right]^{-}$. Of the neutral complexes $\left(R E=E^{\prime} R_{2}\right)$, known compounds only include formal boron double bonds with either carbon $^{19}(\mathbf{4})$ or silicon ${ }^{20}$ (5, Figure 7). In both cases, the boron-carbon and boron-silicon double bonds were identified to be $10 \%$ shorter than their respective standard single bonds. ${ }^{19,20}$ In the case of the B-Si complex (5) computational studies identified that there was some resonance bonding with the ring nitrogen that also contributed to the bonding structure. ${ }^{20}$
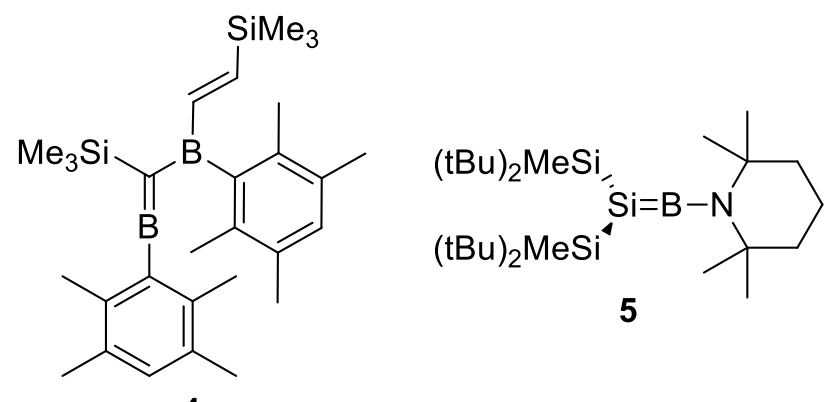

4

Figure 7: Known complexes possessing boron-carbon and boron-silicon double bonds. ${ }^{19,20}$

Examples of the monoanionic complexes $\left(\left[R_{2} E=E^{\prime} R_{2}\right]^{-}\right)$are slightly more numerous, the most common type of compounds are boron-carbon complexes, where the boron is considered to be stabilising a carbanion. ${ }^{14}$ Recent work by Nakata et al. ${ }^{21,22}$ utilised a new synthetic approach (Scheme 2) to form complexes with multiple bonds between Ga-Si (6a), Ga-Ge (6b), In-Si (6c), and In-Ge (6d). By using the bulky SiMe $\left({ }^{t} \mathrm{Bu}\right)_{2}$ ligand to stabilise either silicon or germanium lithium salts, Nakata et al. were able to react these with either gallium or indium trichlorides to produce the monoanionic disila- and digerma- gallium and indium complexes. ${ }^{21,22}$ These complexes spontaneously formed dimers to give an alkene like 'dianion' complex, ${ }^{14}$ which showed a shortening of about $9 \%$ in both $\mathrm{M}$ $E$ bonds (where $M=G a$, In and $E=S i, G e$ ). These 'dianions' possessed $\alpha$ angles of $43^{\circ}$ and $55^{\circ}$ for the complexes $(\mathbf{6 a})$ and $(\mathbf{6 c})$, respectively, ${ }^{21}$ consistent with dative bonding involving a large degree of orbital mixing. The similarity in the length of both bonds in the complexes can be explained through resonance structures, in which the negative charge can be located on any of the three central atoms (Scheme 3). ${ }^{21}$ This also explains the bent conformation of the complex, as the delocalisation of the 
negative charge does not lock the molecule in a planar conformation. The complex may also exhibit some degree of orbital mixing in the bonding, as the $\mathrm{SiMe}\left({ }^{\mathrm{t}} \mathrm{Bu}\right)_{2}$ groups are not fully perpendicular across the EME plane.

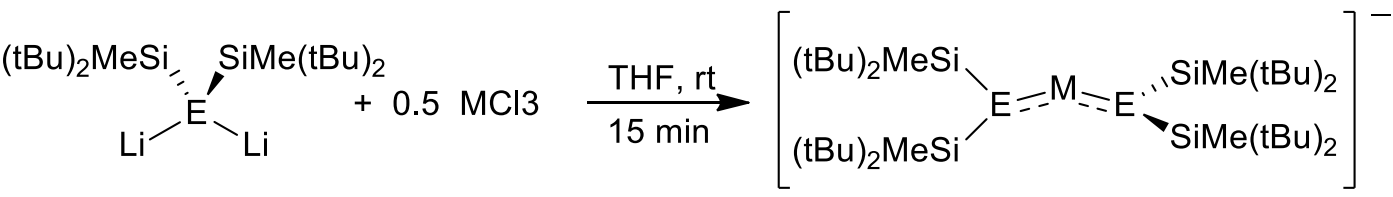

$$
\begin{aligned}
& M=G a, \ln E=S i, G e \quad 6 \text { a) } M=G a E=S i \\
& \text { b) } M=\mathrm{GaE}=\mathrm{Ge} \\
& \text { c) } M=\ln E=S i \\
& \text { d) } M=\ln E=G e
\end{aligned}
$$

Scheme 2: Synthesis of multiple bonds between heavier group 13 and group 14 elements.

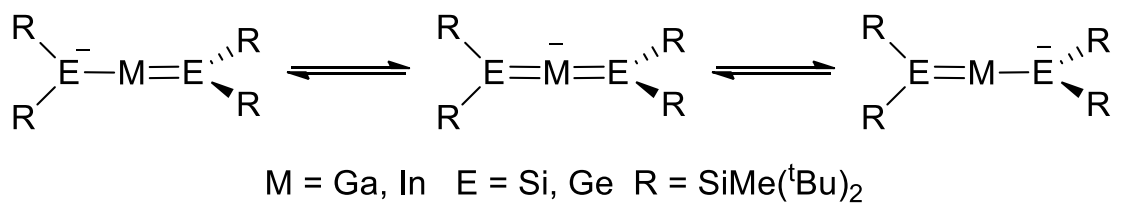

Scheme 3: Resonance forms of the 'dianion' complex.

\subsubsection{Multiple Bonding Between Groups 13 \& 15}

Compounds involving multiple bonds between group 13 and 15 elements are more common ${ }^{14}$ due to the complimentary nature of the electronic structures of the two groups, possessing three and five valence electrons respectively. This creates excellent Lewis pairs, with nitrogen or phosphorous commonly acting as the Lewis base, while boron or aluminium are often found as the corresponding Lewis acid. However, this also leads to debate over whether the shortening of the group 13-group 15 bond, relative to their calculated single bond length, is due to a formal double bond or donation of a lone electron pair from the group 15 element into an empty orbital on the group 13 element (Scheme 4). One way of resolving this and forming a true double bond is to synthesise either a nitrene or phosphinidene complex through the elimination of an alkyl and hydrogen substituent (Scheme 4). This reaction has previously been used to isolate phosphinidenes 
of zirconium ${ }^{23}$ and molybdenum ${ }^{24}$ through the elimination of the methyl ligand from the metal centre by a neighbouring phosphanide ligand.

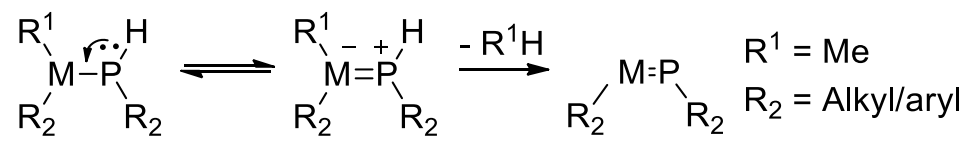

Scheme 4: Resonance forms of a metal-phosphanido complex (left), versus formation of a metal phosphinidene (right).

One system that came close to achieving gallium and indium phosphinidenes was explored by Rotter et al. ${ }^{25}$ who treated $\left(\mathrm{Mes}^{*}\right)_{2} \mathrm{E}-\mathrm{X}\left(\mathrm{Mes}^{*}=2,4,6{ }^{\mathrm{t}} \mathrm{Bu}_{3} \mathrm{C}_{6} \mathrm{H}_{2} ; \mathrm{E}=\mathrm{Ga}, \mathrm{In} ; \mathrm{X}=\mathrm{Cl}, \mathrm{Br}\right.$ ) with $\mathrm{KP}(\mathrm{H}) \mathrm{SiR}_{3}$ $\left(R={ }^{i} \mathrm{Pr},{ }^{\mathrm{t}} \mathrm{Bu}\right)$ to form $\left(\mathrm{Mes}^{*}\right)_{2} \mathrm{M}-\mathrm{P}(\mathrm{H}) \mathrm{SiR}_{3}$ (Scheme 5). ${ }^{25}$ These compounds readily eliminated tri-(tert-butyl)benzene to give the proposed intermediate gallium and indium phosphinidene complexes (7), however, dimerisation of the resulting phosphinidenes occurred to give (8), presumably due to the insufficient steric bulk around the group 13 centre (Scheme 5). ${ }^{25}$

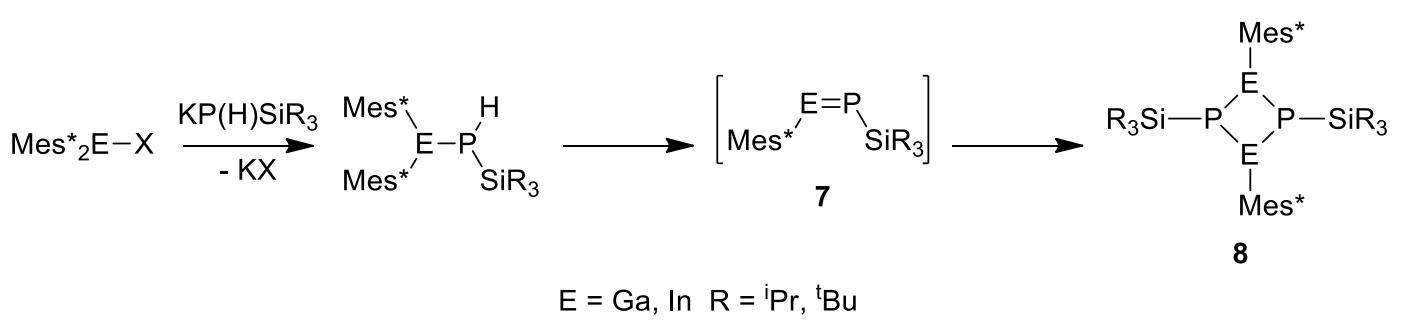

Scheme 5: Synthesis and subsequent dimerisation of gallium and indium phosphinidene complexes. ${ }^{25}$ 


\subsection{The $\beta$-Diketiminate Ligand}

One ligand that has been extensively investigated for both its steric and electronic stabilisation properties is the $\beta$-diketiminate ligand (Figure 8 ). All of the various substituents $R_{1}-R_{5}$ can be individually modified to fine tune the steric and electronic properties of the ligand, as well as the chirality of the ligand. ${ }^{26}$<smiles>[R5]N=C([R])/C([R])=C(/[R])N[R7]</smiles>

Figure 8: Generic structure of the $\beta$-diketiminate ligand.

The $\beta$-diketiminate ligand behaves as a monoanionic, $4 \mathrm{e}^{-}$donor ligand that, upon co-ordination to a metal centre, delocalises its $\pi$ electrons over the $\mathrm{C}_{3} \mathrm{~N}_{2}$ ligand backbone, creating a planar structure. This planarity has been used to compare the bonding geometry of the ligand to various metal centres. ${ }^{8,27}$ This aromatic NCCCN backbone, combined with the use of substituted phenyl rings at $R_{1}$ and $R_{5}$, allows for the formation of intermolecular $\pi-\pi$ interactions that increase the likelihood of coordination compounds using the $\beta$-diketiminate ligand forming crystals with regular lattice patterns that can be analysed by single crystal X-ray diffraction. ${ }^{26}$ Several derivatives of the $\beta$-diketiminate ligand have been previously added to gallium trichloride, resulting in the formation of $\beta$-diketiminato- $\mathrm{GaCl}_{2}$ complexes (9) in relatively good yields. These complexes are formed simply through the use of a strong base such as triethyl amine $\left(\mathrm{NEt}_{3}\right)$ to deprotonate the amine and allow coordination of the $\beta$-diketiminate ligand to the metal centre (Scheme 6$)^{28}$

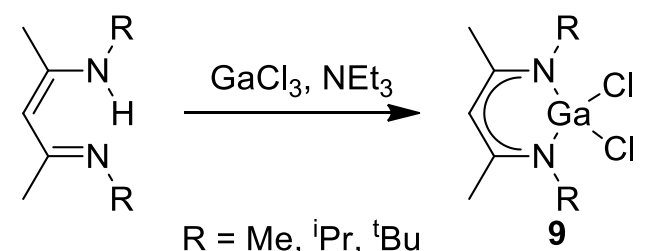

Scheme 6: Synthesis of known $\beta$-diketiminate gallium dichloride complexes. 
The first gallium $\beta$-diketiminate complex was synthesised in 1994 using the bis(2-pyridyl)methane ligand. This reaction was tailored to produce the dimethyl gallium derivative (10) through the use of chloro-dimethylgallium as the gallium source (Scheme 7). ${ }^{29}$

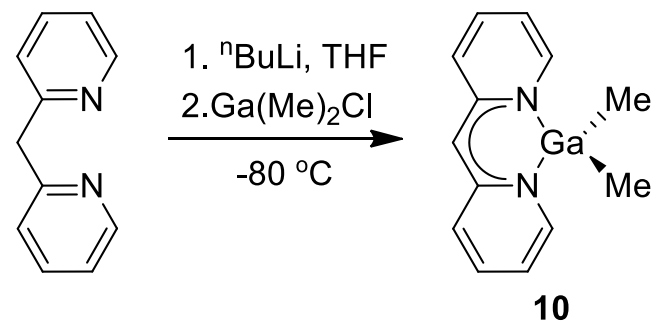

Scheme 7: Synthesis of a $\beta$-diketiminate gallium dimethyl complex.

The current study investigates using the di-isopropylphenyl (DIPP) $\beta$-diketiminate derivative $\left[\mathrm{CH}\left\{\mathrm{C}(\mathrm{Me}) \mathrm{N}\left(\mathrm{C}_{6} \mathrm{H}_{3}-2,6-{ }^{\prime} \mathrm{Pr}_{2}\right)\right\}_{2}\right]$ (acronyms $\mathrm{BDI}_{\mathrm{DIPP}}$ and $\mathrm{BDI}$ refer to this particular ligand) to provide steric stabilisation. This ligand provides sufficient steric bulk to prevent the dimerisation or oligomerisation of metal complexes. ${ }^{26}$ In addition, the synthesis of the protonated version, BDI-H (11, Figure 9), is a facile reaction that proceeds in high yields from readily available starting materials. ${ }^{30}$<smiles>C/C(=C/C(C)=N/[Ga])NN=[Al]</smiles>

11<smiles>CC(C)c1cccc(C(C)C)c1C(C)C</smiles>

$m_{1}$

Figure 9: The $\beta$-diketiminate ligand used in this project.

The $\beta$-diketiminate ligand is a versatile ligand that can be coordinated to a metal centre through a variety of different routes, with the two main ones being: formation of the alkali salt of BDI (BDI-Li/Na/K) and addition to a metal halide $\left(\mathrm{MX}_{n}\right)$, or addition of $\mathrm{BDI}-\mathrm{H}$ to metals coordinated to labile, readily protonated ligands such as methyl and HMDS ligands. 
The BDI ligand has been extensively coordinated to gallium previously, including in the isolation of $\mathrm{N}$-heterocyclic gallenes (Figure 10 ), which are the gallium(I) analogues of $\mathrm{N}$-heterocyclic carbenes. ${ }^{31}$ These complexes have been used as carbene-analogous ligands on transition metals such as gold, silver and copper to form cationic metal complexes (Figure 10). ${ }^{32}$
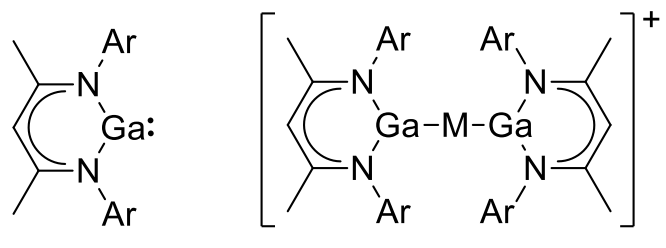<smiles>CC(C)c1cccc(C(C)C)c1C(C)(C)C</smiles>

$$
M=A u, A g, C u
$$

Figure 10: $\beta$-diketiminato- $N$-heterocyclic gallene and its use as a ligand.

The BDI ligand has also previously been used in the formation of the main starting material of this project, $\left[(\mathrm{BDI}) \mathrm{GaCl}_{2}\right]$ (12), which can be prepared through the reaction of $\mathrm{BDI}-\mathrm{H}$ with ${ }^{\mathrm{n}} \mathrm{BuLi}$ to generate $\mathrm{BDI}$-Li in-situ, which can be added stoichiometrically to $\mathrm{GaCl}_{3}$ to generate $\left[(\mathrm{BDI}) \mathrm{GaCl}_{2}\right]$ and precipitate LiCl (Scheme 8).<smiles>C/C(=C/C(C)=N/Br)NN=[Al]</smiles>

11

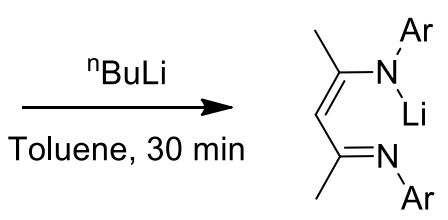

$\mathrm{Ar}$<smiles></smiles>

12<smiles>CC(C)c1cccc(C(C)C)c1C(C)(C)C</smiles>

Scheme 8: Formation of $\left[(\mathrm{BDI}) \mathrm{GaCl}_{2}\right]$.

$\left[(\mathrm{BDI}) \mathrm{GaCl}_{2}\right]$ is a useful starting material as it can be readily converted to mixed $[(\mathrm{BDI}) \mathrm{Ga}(\mathrm{R}) \mathrm{Cl}]$ and di-substituted [(BDI)GaR $\mathrm{G}_{2}$ ] complexes. This can be achieved as the $\mathrm{Ga}-\mathrm{Cl}$ bonds can undergo salt metathesis with lithium, sodium, potassium and magnesium reagents through $\sigma$-bond metathesis reactions to form the corresponding alkali salt and Ga-R bond, where $\mathrm{R}$ is an organic compound. 


\section{Chapter 2}

\section{Carbenes}

One of the main synthetic targets of this study is a $\beta$-diketiminato-gallium carbene complex (1), as to date a formal gallium-carbon double bond has never been reported. As such, the properties of the three main types of carbenes have been reviewed, along with known reactions for the formation of transition metal carbene complexes. Group 3 transition metal carbene complexes are used as a base to formulate synthetic strategies for analogous $\beta$-diketiminato-gallium carbene complexes, due to the isoelectronic properties of group 3 and 13 elements.

\subsection{Introduction}

Carbenes are a neutral species of divalent carbon with the generic formula :CR ${ }^{1}{ }^{2}$. The carbon possesses two free electrons in either a singlet state (where the electrons are paired in the $s p^{2}$ hybrid orbital) or triplet state (where the electrons are unpaired, with one in an $s p^{2}$ hybrid orbital and the other in a $p$ orbital), depending on the relative energies of the two states (Figure 11). The simplest known carbene species, $\mathrm{CBr}_{2}$, can be formed in situ from bromoform $\left(\mathrm{CHBr}_{3}\right)$ by the base catalysed elimination of $\mathrm{HBr}$. Although this carbene (13) is not stable, it can be readily trapped by ethene to form cyclopropane (Scheme 9). ${ }^{1}$

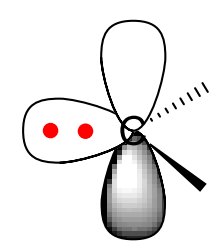

Singlet

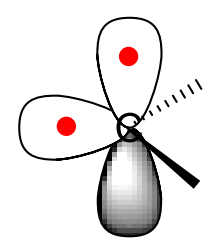

Triplet

Figure 11: The singlet and triplet electronic states of carbenes. 


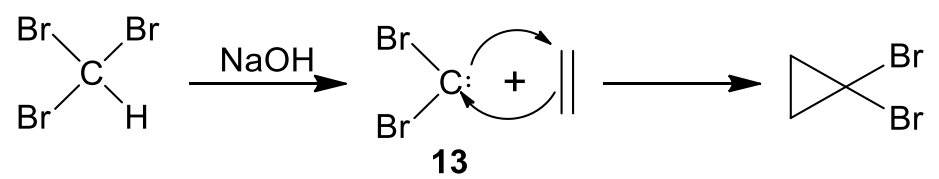

Scheme 9: The synthesis of a cyclopropane derivative using a carbene intermediate.

\subsubsection{Stable Carbenes}

Stable carbene species were not isolated prior to the use of stabilising nitrogen or phosphorous groups at the $\alpha$-position to the carbene. In 1991, Arduengo et al. ${ }^{33}$ generated the first stable or 'free' carbene (14) by positioning the carbene between two nitrogen atoms. It is proposed that each of the lone electron pairs on the two nitrogen atoms help stabilise the empty $p$ orbital on the carbene carbon through donation of electron density to the carbon (Scheme 10). This chemistry was expanded to encompass a range of $\mathrm{N}$-heterocyclic carbenes, as well as cyclic amino-alkyl carbenes and a variety of phosphorous stabilised carbenes (Figure 12). ${ }^{14}$

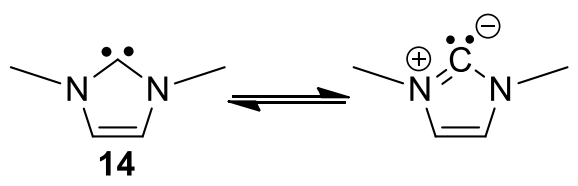

Scheme 10: Resonance structures of $N$-heterocyclic carbenes. ${ }^{33}$<smiles>CC1(C)C=CN([Ga])C1(C)C</smiles>

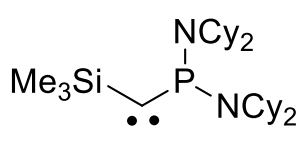<smiles>CC(C)c1cccc(C(C)C)c1N(C)C</smiles>

Figure 12: Cyclic amino-alkyl and phosphorus stabilised carbenes. 


\subsubsection{Metal Carbene Complexes}

While the term 'carbene' is generally used to describe the free $\mathrm{R}_{2} \mathrm{C}$ : species, there are also two types of transition metal carbenes. These carbenes refer to divalent carbon bound to a metal centre $\left(M=C R_{2}\right)$. Unlike stabilised carbene species, these compounds have a formal double bond between the metal and carbon atoms, giving the carbon a full valence count of 8 . This type of bonding can occur in one of two ways: via a Fischer or a Schrock carbene. In a Fischer carbene the electrons on the carbon are paired (singlet state), and donate electron density into a vacant orbital on the metal. The metal then donates electron density from one of its full orbitals into the vacant $p$ orbital of the carbene via $\pi$-back bonding to create a formal double bond. In contrast, Schrock carbenes have unpaired electrons (triplet state) which form bonds through interactions with a triplet state metal (Figure 13). ${ }^{33}$

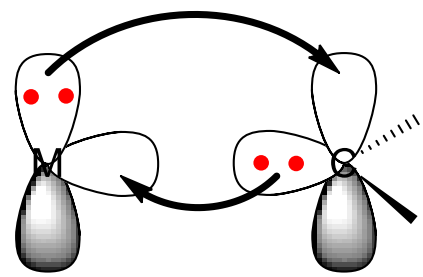

Fischer (singlet)

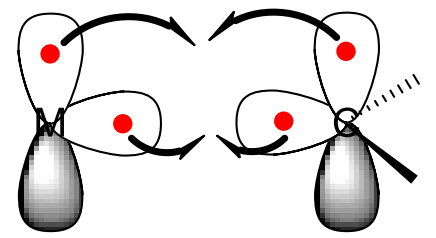

Schrock (triplet)

Figure 13: The bonding configuration of both Fischer and Schrock carbenes.

The stable carbene species described in section 2.1.1 form Fischer carbene complexes, as the presence of electron donating heteroatoms such as nitrogen and phosphorus stabilises the singlet state of the carbene. Known $\mathrm{N}$-heterocyclic carbene complexes of platinum ${ }^{34}$ and scandium ${ }^{35}$ (Figure 14) are just the tip of the iceberg, with thousands of transition metal Fischer type carbene complexes known. 

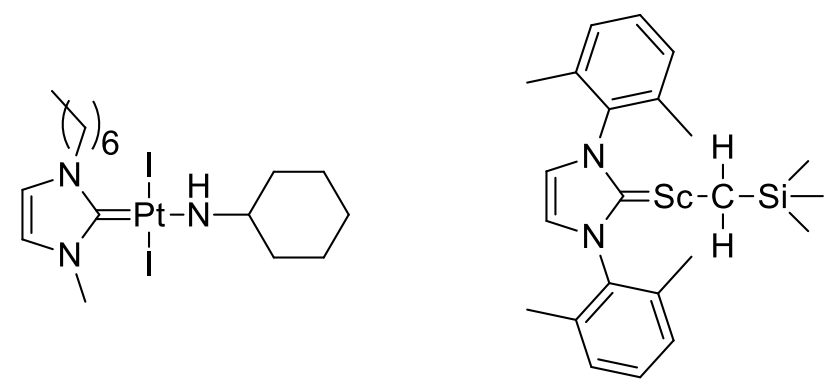

Figure 14: Known Fischer carbene complexes.

Prior to 1974, most transition metal carbenes used at least one heteroatom (at the $\alpha$-position) to stabilise the carbene carbon. ${ }^{36}$ In 1974, Schrock showed that stable 'alkylcarbene' complexes, or Schrock carbenes, could also be formed through abstraction of the $\alpha$-proton by neopentyl (Np) ligands. This was achieved through the reaction of two equivalents of neopentyllithium with $\mathrm{Ta}(\mathrm{Np})_{2} \mathrm{Cl}_{2}$ to give the complex $\mathrm{Ta}(\mathrm{Np})_{3}\left(\mathrm{CHC}\left(\mathrm{CH}_{3}\right)_{3}\right)(\mathbf{1 5}) \cdot{ }^{37}$ Schrock proposed a mechanism based on observations using isotopically labelled neopentane that supported the abstraction of an $\alpha$-proton by another neopentyl ligand (Scheme 11). Thus not only could stable carbenes be formed without the heteroatom stabiliser used in Fischer carbenes, but hydrogen could also be one of the substituents on the carbene carbon. ${ }^{37}$

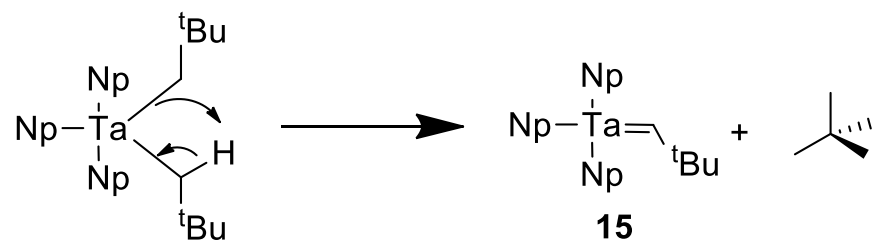

Scheme 11: $\alpha$-proton elimination by the neopentyl ligand to give a carbene and neopentane.

Carbenes stabilised by either phosphorous ${ }^{38}(\mathbf{1 6})$ or nitrogen $^{39}(\mathbf{1 7})$ groups at the $\alpha$-position can also be used as neutral ligands for a variety of metal centres, as they typically adopt a singlet state, donating an electron pair into an unoccupied orbital on the metal centre. Stabilised carbenes have been used previously as ligands on gallium trichloride (Figure 15), with the addition of $\mathrm{Me}_{3} \mathrm{SiCP}\left(\mathrm{NCY}_{2}\right)_{2}$ to gallium trichloride resulting in the formation of a tetrahedral gallium compound (16), where the carbene has donated its free electron pair into the empty $p$ orbital on gallium. This 
results in the formation of a gallium-carbon single bond rather than the metal-carbon double bonds that can be observed between transition metals and un-stabilised carbenes. As such, stabilised carbenes act as a neutral two electron donating ligand as opposed to the desired four electron monoanionic ligand that provides extra electron density to the gallium centre, in order to stabilise double bond formation.
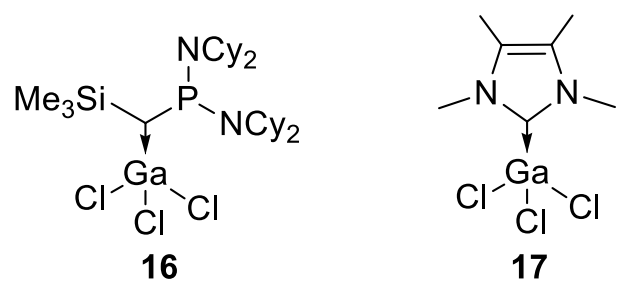

Figure 15: Stabilised carbenes have been previously used as ligands on gallium trichloride.

\subsubsection{Group 3 Carbenes}

Group 3 transition metals potentially provide a good model for the reactivity of group 13 metals because the chemistry of both groups is dominated by the +3 oxidation state, and neither group possesses any reactive $d$ electrons in this oxidation state. Group 3 metals can spontaneously form carbene complexes when bound to two alkyl substituents when at least one possesses a hydrogen atom at the metal-carbon bond, with theory and experimental observations strongly supporting an $\alpha$-proton elimination mechanism. These carbenes can be further transformed to carbynes, though this may require thermal conditions (Scheme 12$).{ }^{40}$ For instance, salt metathesis occurs on addition of yttrium trichloride to benzyllithium, however the expected tris-benzyl complex is not observed. Instead alkylidene compound (18) is formed, with the presence of toluene in the reaction mixture supporting $\alpha$-elimination of a benzyl group. Heating the alkylidene complex (18) resulted in the formation of carbyne (19) and a second equivalent of toluene. ${ }^{40}$ The neodymium trichloride salt was also reacted in this manner with benzyllithium to give a neodymium carbyne complex and two equivalents of toluene. ${ }^{40}$ 


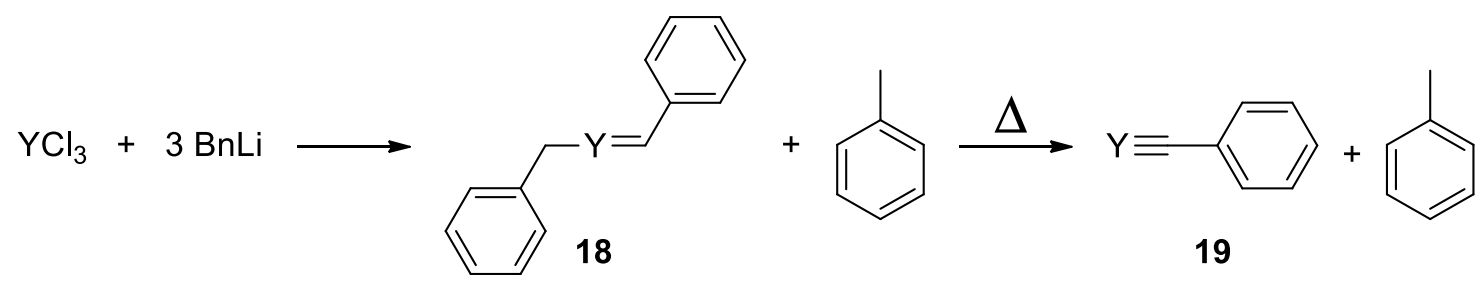

Scheme 12: Formation of a yttrium carbene and carbyne. ${ }^{40}$

\subsubsection{Lewis Base Stabilisation}

A potential hindrance to the formation of any metal-carbene complex is their tendency to dimerise due to lack of electron density at the metal centre, and this has been observed in carbene complexes of group 4 metals such as titanium. ${ }^{41,42}$ It was found that the addition of a Lewis base to either the precursor during the reaction or the dimer complex resulted in the formation of the free carbene monomer complex. An example of this is the formation of $\mathrm{Cp}_{2} \mathrm{Ti}=\mathrm{CH}_{2}$ from the methylene bridged $\left[\mathrm{Cp}_{2} \mathrm{TiCH}_{2}\right]_{2}$ through the addition of trimethylphosphine ${ }^{42}$ or triethylphosphine ${ }^{41}$ (Scheme $13)$, as the extra electron density provided by the Lewis base is able to stabilise the metal-carbene complex.

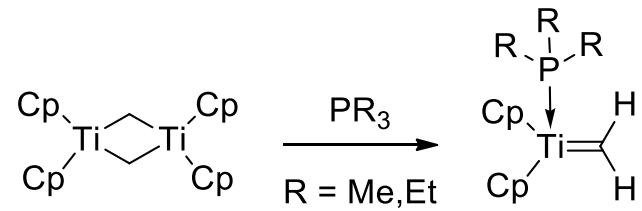

Scheme 13: Lewis base stabilised titanocene-carbene complexes.

Group 3 imides can be prepared using the same principle, however the Lewis base also plays the role of facilitating proton transfer between ligands to allow for the formation of the imide. ${ }^{43,44}$ In the formation of scandium imido complexes, the base DMAP is used to transfer an amide proton to an alkyl ligand, however the DMAP remains coordinated to the resulting scandium imido complex to stabilise it (Scheme 14). ${ }^{44}$ 
<smiles>[R]N=[As](Cc1ccccc1)[n+]1ccc(N(C)C)cc1</smiles>

Scheme 14: Formation of a $\beta$-diketiminato-scandium-imido complex.

\subsubsection{Applications of Carbenes}

Metal carbene complexes have a diverse range of uses across many chemistry disciplines. The reactivity of the metal-carbon double bond generally depends on whether the carbene is a Fischer or Schrock carbene. Fischer carbenes tend to be electrophilic and, when they contain $\beta$-protons, will undergo Aldol reactions with aldehydes under strongly basic conditions to form $\alpha, \beta$-unsaturated ketone-transition metal complexes (Scheme 15). ${ }^{45}$ Schrock carbenes are more nucleophilic and, as such, are good catalysts for metathesis reactions. ${ }^{46}$ Schrock carbene complexes form the basis for some of the most important transition metal carbenes used in synthetic chemistry, in the form of Grubbs' ruthenium catalysts ${ }^{47}$ and Schrocks' molybdenum catalysts. ${ }^{48}$ The metal-carbon double bond can undergo $2+2$ cycloaddition and cyclo-reversion reactions, which can be used for a range of different metathesis reactions where an existing double bond is 're-arranged' by the metal-carbon double bond (Scheme 16). Examples of this rearrangement include alkene and alkyne metathesis (cross metathesis), ring closing metathesis, ring opening metathesis, and ring opening polymerisation metathesis.<smiles>[R]C=C(C=CC([R])=O)OC</smiles>

Scheme 15: Aldol reaction of Fischer carbenes 


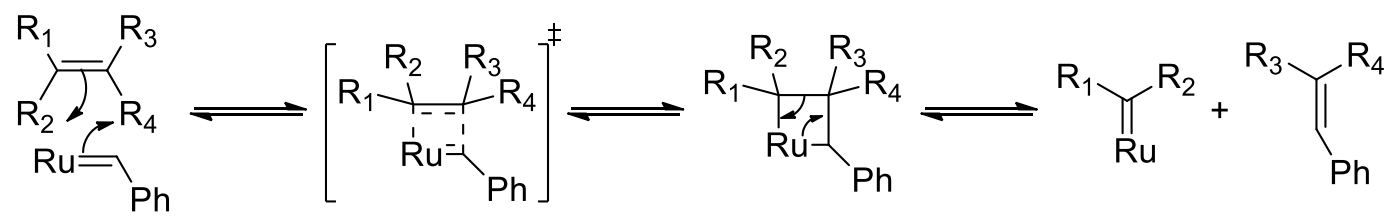

Scheme 16: Simple alkene metathesis mechanism.

\subsubsection{Known $\beta$-Diketiminatogallium Alkyl Complexes}

While there are no reported gallium-carbon double bonds, there are many examples of gallium mono-, di-, and tri- alkyl complexes, including several organo-gallium complexes bearing the BDI ligand. ${ }^{30}$ Currently the longest alkyl substituent using the BDI ligand is a methyl ligand, with the main examples consisting of $\left[(\mathrm{BDI}) \mathrm{GaMe}_{2}\right]{ }^{27}[(\mathrm{BDI}) \mathrm{Ga}(\mathrm{H}) \mathrm{Me}],{ }^{49}[(\mathrm{BDI}) \mathrm{Ga}(\mathrm{Me}) \mathrm{OH}]^{50}$ and $[(\mathrm{BDI}) \mathrm{Ga}(\mathrm{Me}) \mathrm{Cl}]^{49}$ (Figure 16). Previous work in this group has since isolated [(BDI)Ga $\left.\mathrm{Gu}_{2}\right]\left[(\mathrm{BDI}) \mathrm{GaNp}_{2}\right]$ and $\left[(\mathrm{BDI}) \mathrm{GaPh}_{2}\right]$, though only [(BDI) $\left.\mathrm{Ga}^{\mathrm{n}} \mathrm{Bu}_{2}\right]$ has been fully characterised. ${ }^{30}$
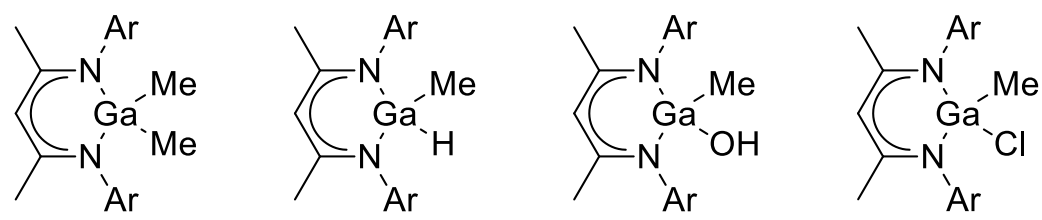<smiles>CC(C)c1cccc(C(C)C)c1C(C)C</smiles>

Figure 16: Known $\beta$-diketiminato-gallium-alkyl complexes.

\subsection{Synthetic Strategy}

The synthetic strategy for a $\beta$-diketiminato-gallium-carbene complex explored the ability of $\beta$-diketiminato-gallium-dialkyl complexes to undergo an $\alpha$-proton elimination reaction similar to those observed in the group three transition metal dialkyl complexes. As there is only one known $\beta$-diketiminato-gallium-dialkyl complex, [(BDI)GaMe $\mathrm{Ga}_{2}$, the reactivity of this complex towards a-proton elimination was examined. However, as gallium(III) will theoretically adopt a singlet electronic state in the formation of a carbene, the carbene carbon may require $\pi$-donor substituents to favour the formation of a Fischer type carbene. In order to avoid forming a stabilised carbene using nitrogen or phosphorus, where resonance structures could influence the degree of multiple 
bonding in a gallium-carbene complex, weaker $\pi$-donor substituents such as phenyl groups can be used to tune the electronic state of the carbene carbon. [(BDI) $\left.\mathrm{GaBn}_{2}\right]$ is another target to examine the effects of phenyl substituents on the $\alpha$-proton elimination reaction. Synthetic targets are outlined in Figure 17.

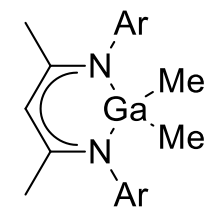

20<smiles></smiles>

21<smiles>CC(C)c1cccc(C(C)C)c1N(C)C</smiles>

Figure 17: Targeted $\beta$-diketiminato-gallium-diakyl complexes.

\subsection{Results and Discussion}

\subsubsection{Synthesis of $\beta$-Diketiminato-dimethylgallium}

The simplest $\beta$-diketiminato-gallium-dialkyl complex that could potentially undergo $\alpha$-proton elimination is the known compound [(BDI)GaMe $\mathrm{Ga}_{2}$ (20). This complex could potentially eliminate methane to form a gallium carbon double bond (Scheme 17).

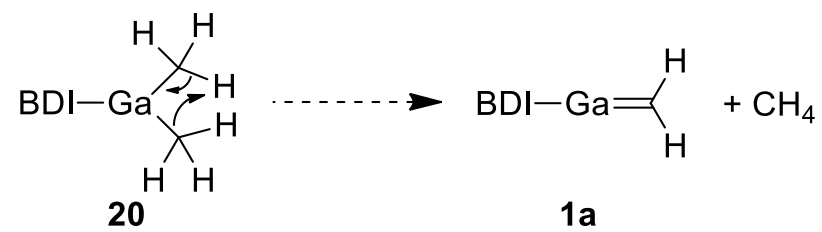

Scheme 17: $\alpha$-proton elimination of [(BDI)GaMe $\mathrm{Ga}_{2}$ to give a gallium carbene.

The synthesis of $\left[(\mathrm{BDI}) \mathrm{GaMe}_{2}\right]$ was attempted via the known literature procedure. This involved the in-situ generation of $\mathrm{GaMe}_{3}$ from $\mathrm{GaCl}_{3}$, followed by the addition of $\mathrm{BDI}-\mathrm{H} .{ }^{27}$ Unfortunately, 
despite repeated attempts, the product could not be obtained in sufficient yields. However [(BDI) $\left.\mathrm{GaMe}_{2}\right]$ could also be generated through the addition of either MeLi or $\mathrm{MeMgBr}$ to [(BDI) $\left.\mathrm{GaCl}_{2}\right]$. Treatment of $\left[(\mathrm{BDI}) \mathrm{GaCl}_{2}\right]$ with two equivalents of $\mathrm{MeMgBr}$ in toluene at $60{ }^{\circ} \mathrm{C}$ for 12 hours (Scheme 18 ) gave [(BDI)GaMe ${ }_{2}$ in $81.6 \%$ isolated yield. The ${ }^{1} \mathrm{H}$ NMR data of the recrystallised product matched those reported previously. ${ }^{27}$<smiles>Cc1cc(C)[n+](Cl)n1[Al]</smiles>

12

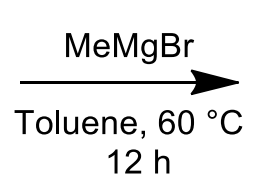

$12 \mathrm{~h}$<smiles></smiles>

20<smiles>CC(C)c1cccc(C(C)C)c1C(C)(C)C</smiles>

Scheme 18: Synthesis of $\left[(\mathrm{BDI}) \mathrm{GaMe}_{2}\right]$.

\subsubsection{Attempted $\alpha$-proton Elimination}

The $\alpha$-proton elimination reaction of $\left[(\mathrm{BDI}) \mathrm{GaMe}_{2}\right]$ was first attempted on a $20 \mathrm{mg}$ scale in deuterated benzene. No reaction was observed by ${ }^{1} \mathrm{H}$ NMR spectroscopy at either room temperature or at $80^{\circ} \mathrm{C}$. To attempt to facilitate the transfer of the $\alpha$-proton, the Lewis bases DMAP and TMEDA were independently added to the reaction mixture, however only on a $1 \%$ loading to determine if the base could catalytically facilitate the transfer of the $\alpha$-proton without coordinating to the resulting carbene as previously observed with transition metal carbenes ${ }^{41}$ and imides. ${ }^{44}$ The two bases DMAP and TMEDA were independently added to the solution and the samples monitored for two hours, then heated to $80^{\circ} \mathrm{C}$ after no reaction was observed by ${ }^{1} \mathrm{H}$ NMR spectroscopy. Upon the failure of both bases to catalyse proton transfer, the reaction was repeated on a $100 \mathrm{mg}$ scale in THF to determine if a coordinating solvent could stabilise the resulting carbene complex instead of a coordinating base. No reaction was observed, even when TMEDA or DMAP were added to the reaction mixture. Finally, the reactions were repeated in toluene to increase the reflux temperature to $110^{\circ} \mathrm{C}$, however again no reaction was observed, including when TMEDA or DMAP were added to the reaction mixture. These results are summarised in Table 1. 
Table 1: Reaction conditions for the attempted $\alpha$-proton elimination of [(BDI)GaMe $\mathrm{Ge}_{2}$.

\begin{tabular}{|l|l|l|l|l|}
\hline Solvent & Temp. $\left({ }^{\circ} \mathrm{C}\right)$ & Time & Base & Observations \\
\hline $\mathrm{C}_{6} \mathrm{D}_{6}$ & 25 & $2 \mathrm{~h}$ & - & No Reaction \\
\hline $\mathrm{C}_{6} \mathrm{D}_{6}$ & 80 & $12 \mathrm{~h}$ & - & No Reaction \\
\hline $\mathrm{C}_{6} \mathrm{D}_{6}$ & 25 & $2 \mathrm{~h}$ & TMEDA & No Reaction \\
\hline $\mathrm{C}_{6} \mathrm{D}_{6}$ & 80 & $12 \mathrm{~h}$ & TMEDA & No Reaction* \\
\hline $\mathrm{C}_{6} \mathrm{D}_{6}$ & 25 & $2 \mathrm{~h}$ & DMAP & No Reaction \\
\hline $\mathrm{C}_{6} \mathrm{D}_{6}$ & 80 & $12 \mathrm{~h}$ & DMAP & No Reaction* \\
\hline THF & 25 & $2 \mathrm{~h}$ & - & No Reaction \\
\hline THF & 60 & $12 \mathrm{~h}$ & - & No Reaction \\
\hline THF & 25 & $2 \mathrm{~h}$ & TMEDA & No Reaction \\
\hline THF & 60 & $12 \mathrm{~h}$ & TMEDA & No Reaction* \\
\hline THF & 25 & $2 \mathrm{~h}$ & DMAP & No Reaction \\
\hline THF & 60 & $12 \mathrm{~h}$ & DMAP & No Reaction* \\
\hline Toluene & 25 & $2 \mathrm{~h}$ & - & No Reaction \\
\hline Toluene & 110 & $12 \mathrm{~h}$ & - & No Reaction \\
\hline Toluene & 25 & $2 \mathrm{~h}$ & DMAP & No Reaction \\
\hline Toluene & 110 & $12 \mathrm{~h}$ & DMAP & No Reaction* \\
\hline Toluene & 25 & $2 \mathrm{~h}$ & TMEDA & No Reaction \\
\hline Toluene & 110 & $12 \mathrm{~h}$ & TMEDA & No Reaction* \\
\hline
\end{tabular}

Base loaded at $1 \%$

*The ${ }^{1} \mathrm{H}$ NMR spectrum showed traces of protonated ligand (BDI-H)

\subsubsection{Synthesis of $\beta$-Diketiminato-bis(benzyl)gallium}

Upon failure to generate a carbene complex from [(BDI)GaMe $\left.{ }_{2}\right]$, [(BDI)GaBn ${ }_{2}$ ] was tested for its reactivity in $\alpha$-proton elimination reactions. The benzyl ligand was chosen due to the presence of the phenyl ring, which should increase the acidity of the $\alpha$-proton, and the stability of the toluene produced by the elimination reaction should provide a driving force, as shown previously using yttrium and neodymium (Scheme 12, section 2.1.3). ${ }^{40}$ The synthesis was achieved through the treatment of $\left[(\mathrm{BDI}) \mathrm{GaCl}_{2}\right]$ with two equivalents of $\mathrm{BnMgCl}$ in THF (Scheme 19), to give the novel compound [(BDI) $\left.\mathrm{GaBn}_{2}\right](\mathbf{2 1})$ in $65.8 \%$ isolated yield.<smiles></smiles>

12

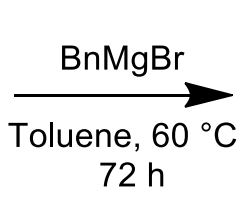

$72 \mathrm{~h}$<smiles></smiles>

21<smiles>CC(C)c1cccc(C(C)C)c1C(C)C</smiles>

Scheme 19: Synthesis of [(BDI)GaBn $]$. 
Following purification of the crude product by crystallisation from toluene/hexane at $-30{ }^{\circ} \mathrm{C}$, the crystals were analysed by ${ }^{1} \mathrm{H}$ and ${ }^{13} \mathrm{C}$ NMR, elemental analysis, and single crystal $\mathrm{X}$-ray diffraction. The ${ }^{1} \mathrm{H}$ NMR spectrum of the product showed a new resonance for the BDI $\mathrm{\gamma}-\mathrm{H}$ proton $(\delta 4.93 \mathrm{ppm}$, $s, 1 \mathrm{H})$ downfield compared to the starting material resonance $(\delta 4.75 \mathrm{ppm})$. A resonance at $\delta 2.03 \mathrm{ppm}(\mathrm{s}, 4 \mathrm{H})$ corresponding to the benzyl $\mathrm{CH}_{2}$ protons was also observed. The support for a di-substituted product was boosted by the para- and ortho- benzyl hydrogen resonances $(\delta 6.92 \mathrm{ppm}, t, 2 \mathrm{H} ; 6.86 \mathrm{ppm}, d, 4 \mathrm{H}$ ) having an integration of two and four respectively, compared with one for the $\mathrm{p}-\mathrm{H}$. The presence of only one methine resonance $(\delta 3.31 \mathrm{ppm}$, app. sept, $6.6 \mathrm{~Hz}$, $4 \mathrm{H})$ and the two isopropyl methyl resonances $(\delta 1.54 \mathrm{ppm}, d, 12 \mathrm{H} ; 1.20 \mathrm{ppm}, d, 12 \mathrm{H})$ for the BDI ligand isopropyl groups indicated that the molecule is highly symmetrical in solution. Elemental analysis of the purified product showed that they were within experimental error of the proposed chemical formula.

The crystal structure of $\left[(\mathrm{BDI}) \mathrm{GaBn}_{2}\right]$ revealed a pseudo-tetrahedral gallium centre, similar to that observed in $\left[(\mathrm{BDI}) \mathrm{GaMe}_{2}\right]$, with the $\mathrm{BDI}$ ligand of $\left[(\mathrm{BDI}) \mathrm{GaBn}_{2}\right]$ possessing a similar but slightly larger bite angle $\left(94.69(7)^{\circ}\right)$ than observed in [(BDI)GaMe ${ }_{2}\left(93.92(7)^{\circ}\right)\left(\right.$ Figure 18). ${ }^{27}$ However the angle between the two alkyl substituents is $111.03(9)^{\circ}$ in $\left[(\mathrm{BDI}) \mathrm{GaBn}_{2}\right]$ compared with $122.44(9)^{\circ}$ in [(BDI)GaMe ${ }_{2}$, which can be attributed to the steric repulsion between the aromatic groups of both the BDI ligand and the benzyl substituents forcing the two benzyl ligands closer together. The Ga-N bond lengths $(1.970(2) \& 1.986(2) \AA)$ are nearly identical to those observed in [(BDI)GaMe $\mathrm{Ge}_{2}$ (1.979(2) \& 2.001(2) $\AA$ ), the Ga-C bond lengths $(1.990(2) \& 1.992(2) \AA$ ) are marginally longer than those

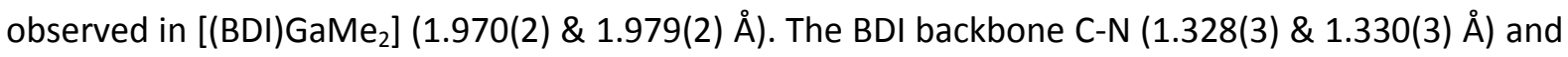
C-C bond lengths $\left(1.403(3) \& 1.405(3) \AA\right.$ ) are nearly identical to those observed in [(BDI)GaMe $\left.\mathrm{Ga}_{2}\right]$ (C-N: $1.333(3) \& 1.325(2) \AA$; C-C: $1.400(3) \& 1.415(3) \AA ̊$ ), as are the N-C-C angles of $123.5(2)^{\circ}$ \& $123.9(2)^{\circ}\left(\left[(\mathrm{BDI}) \mathrm{GaMe}_{2}\right]-123.3(2)^{\circ} \& 123.8(2)^{\circ}\right)$, however the Ga-N-C bond angles of $120.8(1)^{\circ} \&$ $120.3(1)^{\circ}$ are slightly larger than the $118.5(1)^{\circ}$ observed in $\left[(\mathrm{BDI}) \mathrm{GaMe}_{2}\right]$, reflecting the larger bite angle in the $\left[(\mathrm{BDI}) \mathrm{GaBn}_{2}\right]$ complex. Similar to $\left[(\mathrm{BDI}) \mathrm{GaMe}_{2}\right]$, the gallium centre does not sit in the plane of the BDI backbone, but instead adopts a pseudo-boat configuration with $C(2)$ and gallium sitting above $\mathrm{C}(1)-\mathrm{C}(3)-\mathrm{N}(1)-\mathrm{N}(2)$. The distance of gallium above the $\mathrm{BDI}$ backbone $\mathrm{C}_{3} \mathrm{~N}_{2}$ plane $(0.60 \AA)$ is less than those observed in [(BDI)GaMe $)_{2}$ (0.76 $\AA$ ) and the group 13 analogues [(BDI)AIMe $\left.{ }_{2}\right](0.72 \AA)$ and [(BDI)InMe $\mathrm{n}_{2}$ (0.89 $\AA$ ). ${ }^{27}$ This is potentially due to the steric interaction of the benzyl groups with each other and with the BDI ligand. 


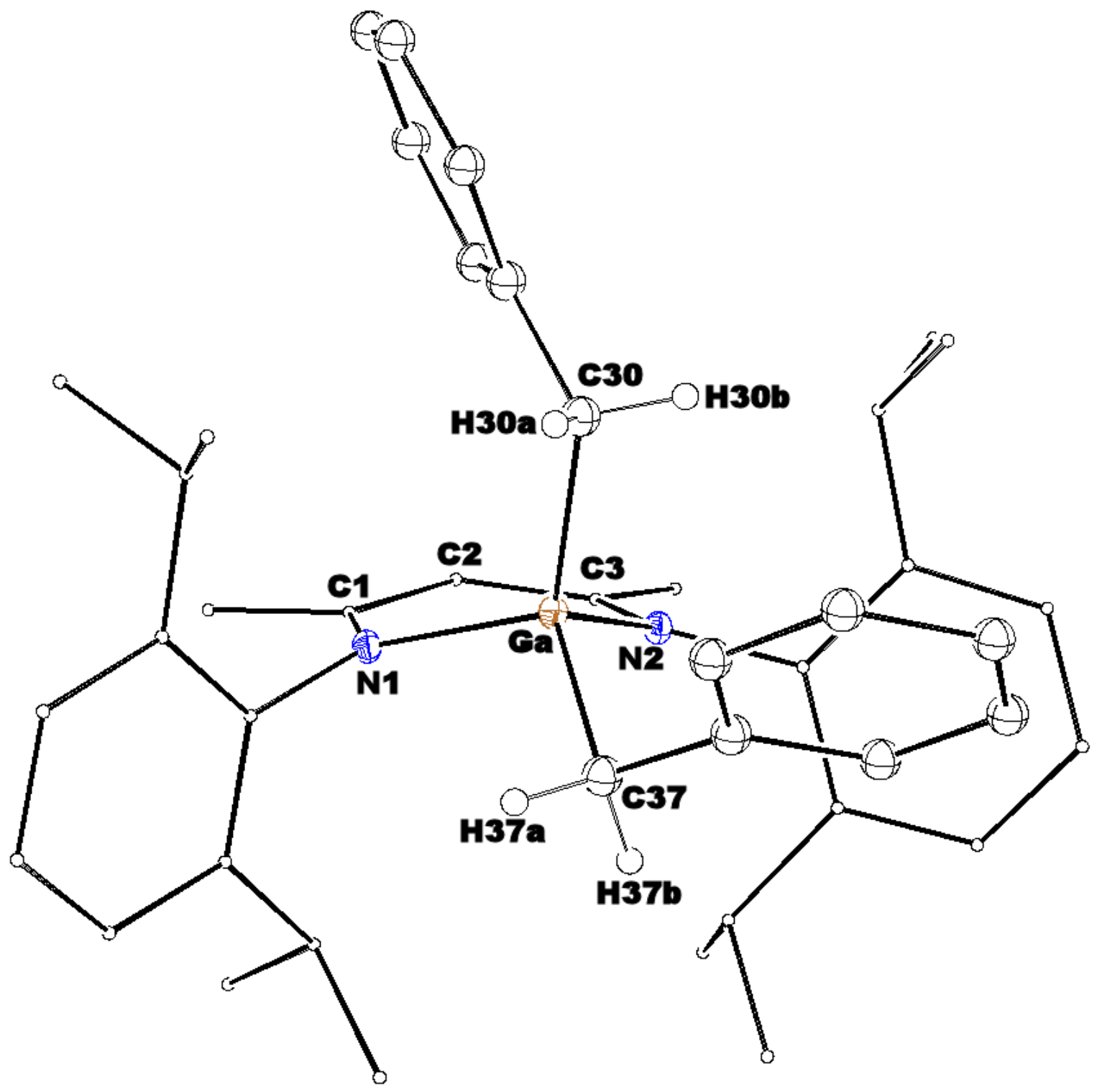

Figure 18: Thermal ellipsoid plot (30\%) of [(BDI) $\left.\mathrm{GaBn}_{2}\right]$. Selected $\mathrm{H}$ atoms have been omitted for clarity. Selected structural data are given in Table 2. 
Table 2: Selected bond lengths and angles for [(BDI)GaBn $\mathrm{G}_{2}$.

\begin{tabular}{|c|c|c|c|}
\hline \multicolumn{2}{|c|}{ Bond Lengths $(\AA)$} & \multicolumn{2}{|c|}{ Bond Angles ( $\left(^{\circ}\right)$} \\
\hline $\mathrm{Ga}(1)-\mathrm{N}(1)$ & $1.970(2)$ & $\mathrm{N}(1)-\mathrm{Ga}(1)-\mathrm{N}(2)$ & $94.69(7)$ \\
\hline $\mathrm{Ga}(1)-\mathrm{N}(2)$ & $1.986(2)$ & $C(30)-G a(1)-C(37)$ & $111.03(9)$ \\
\hline $\mathrm{Ga}(1)-\mathrm{C}(30)$ & $1.992(2)$ & $N(1)-G a(1)-C(30)$ & $115.86(8)$ \\
\hline $\mathrm{Ga}(1)-\mathrm{C}(37)$ & $1.990(2)$ & $N(1)-G a(1)-C(37)$ & $110.33(8)$ \\
\hline$N(1)-C(1)$ & $1.328(3)$ & $N(2)-G a(1)-C(30)$ & $111.64(8)$ \\
\hline$N(2)-C(3)$ & $1.330(3)$ & $N(2)-G a(1)-C(37)$ & $112.40(8)$ \\
\hline$C(1)-C(2)$ & $1.405(3)$ & $\mathrm{Ga}(1)-\mathrm{N}(1)-\mathrm{C}(1)$ & $120.8(1)$ \\
\hline \multirow[t]{4}{*}{$C(2)-C(3)$} & $1.403(3)$ & $\mathrm{Ga}(1)-N(2)-C(3)$ & $120.3(1)$ \\
\hline & & $N(1)-C(1)-C(2)$ & $123.5(2)$ \\
\hline & & $C(1)-C(2)-C(3)$ & $127.9(2)$ \\
\hline & & $C(2)-C(3)-N(2)$ & $123.9(2)$ \\
\hline
\end{tabular}

\subsubsection{Attempted $\alpha$-proton Elimination}

The $\alpha$-proton elimination reaction of $\left[(\mathrm{BDI}) \mathrm{GaBn}_{2}\right]$ was first attempted on a $25 \mathrm{mg}$ scale in deuterated benzene. No reaction was observed by ${ }^{1} \mathrm{H}$ NMR spectroscopy at either room temperature or at $80{ }^{\circ} \mathrm{C}$. In an attempt to facilitate the transfer of the $\alpha$-proton, the Lewis bases DMAP and TMEDA were independently added to the reaction mixture, however only on a $1 \%$ loading to determine if the base could catalytically facilitate the transfer of the $\alpha$-proton without coordinating to the resulting carbene as previously observed with transition metal carbenes ${ }^{41}$ and imides. ${ }^{44}$ The two bases DMAP and TMEDA were independently added to the solution and the samples monitored for two hours, then heated to $80{ }^{\circ} \mathrm{C}$ after no reaction was observed by ${ }^{1} \mathrm{H}$ NMR spectroscopy. Upon the failure of both bases to catalyse proton transfer, the reaction was repeated on a $100 \mathrm{mg}$ scale in THF to determine whether a coordinating solvent could stabilise the resulting carbene complex instead of a coordinating base. No reaction was observed, even when TMEDA or DMAP were added to the reaction mixture. Finally, the reactions were repeated in toluene to increase the reflux temperature to $110^{\circ} \mathrm{C}$, however again no reaction was observed, including when TMEDA or DMAP were added to the reaction mixture. A key difference noted was that the compound showed no signs of the degradation exhibited by [(BDI) $\left.\mathrm{GaMe}_{2}\right]$, even after heating in toluene at $110{ }^{\circ} \mathrm{C}$ for one week both with and without DMAP present. These results are summarised in Table 3. 
Table 3: Reaction conditions for the attempted $\alpha$-proton elimination of [(BDI)GaBn $]$.

\begin{tabular}{|l|l|l|l|l|}
\hline Solvent & Temp. $\left({ }^{\circ} \mathrm{C}\right)$ & Time & Base & Observations \\
\hline $\mathrm{C}_{6} \mathrm{D}_{6}$ & 25 & $2 \mathrm{~h}$ & - & No Reaction \\
\hline $\mathrm{C}_{6} \mathrm{D}_{6}$ & 80 & $12 \mathrm{~h}$ & - & No Reaction \\
\hline $\mathrm{C}_{6} \mathrm{D}_{6}$ & 80 & $168 \mathrm{~h}$ & - & No Reaction \\
\hline $\mathrm{C}_{6} \mathrm{D}_{6}$ & 25 & $2 \mathrm{~h}$ & TMEDA & No Reaction \\
\hline $\mathrm{C}_{6} \mathrm{D}_{6}$ & 80 & $12 \mathrm{~h}$ & TMEDA & No Reaction \\
\hline $\mathrm{C}_{6} \mathrm{D}_{6}$ & 25 & $2 \mathrm{~h}$ & DMAP & No Reaction \\
\hline $\mathrm{C}_{6} \mathrm{D}_{6}$ & 80 & $12 \mathrm{~h}$ & DMAP & No Reaction \\
\hline THF & 25 & $2 \mathrm{~h}$ & - & No Reaction \\
\hline THF & 60 & $12 \mathrm{~h}$ & - & No Reaction \\
\hline THF & 60 & $168 \mathrm{~h}$ & - & No Reaction \\
\hline THF & 25 & $2 \mathrm{~h}$ & TMEDA & No Reaction \\
\hline THF & 60 & $12 \mathrm{~h}$ & TMEDA & No Reaction \\
\hline THF & 25 & $2 \mathrm{~h}$ & DMAP & No Reaction \\
\hline THF & 60 & $12 \mathrm{~h}$ & DMAP & No Reaction \\
\hline Toluene & 25 & $2 \mathrm{~h}$ & - & No Reaction \\
\hline Toluene & 110 & $12 \mathrm{~h}$ & - & No Reaction \\
\hline Toluene & 110 & $168 \mathrm{~h}$ & - & No Reaction \\
\hline Toluene & 25 & $2 \mathrm{~h}$ & DMAP & No Reaction \\
\hline Toluene & 110 & $12 \mathrm{~h}$ & DMAP & No Reaction \\
\hline Toluene & 110 & $168 \mathrm{~h}$ & DMAP & No Reaction \\
\hline Toluene & 25 & $2 \mathrm{~h}$ & TMEDA & No Reaction \\
\hline Toluene & 110 & $12 \mathrm{~h}$ & TMEDA & No Reaction \\
\hline & & Base loaded at 1\% &
\end{tabular}

\subsubsection{Attempted Synthesis of $\beta$-Diketiminato-benzyl-chlorogallium}

During the synthesis of $\left[(\mathrm{BDI}) \mathrm{GaBn}_{2}\right]$, a small amount of a second product was observed by ${ }^{1} \mathrm{H}$ NMR spectroscopy, assumed to be the mono-substituted product, $[(\mathrm{BDI}) \mathrm{Ga}(\mathrm{Bn}) \mathrm{Cl}]$. If the mono-substituted product could be isolated, then theoretically it could be treated with one equivalent of ${ }^{n} \mathrm{BuLi}$ to lithiate the benzyl $\mathrm{CH}_{2}$ position and eliminate $\mathrm{LiCl}$ to form a gallium carbon double bond (Scheme 20).

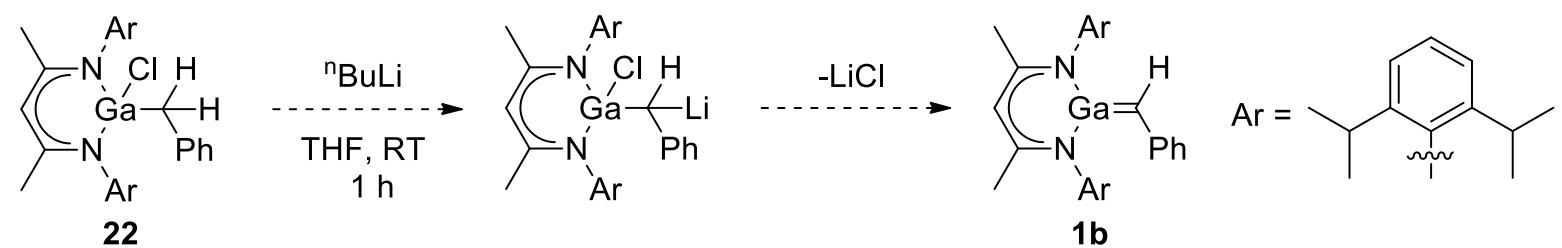

Scheme 20: Possible BDI-gallium-carbene formation reaction. 
The synthesis of $[(\mathrm{BDI}) \mathrm{Ga}(\mathrm{Bn}) \mathrm{Cl}]$ was first attempted via the addition of one equivalent of $\mathrm{BnMgCl}$ to a solution of $\left[(\mathrm{BDI}) \mathrm{GaCl}_{2}\right]$, both of which had been cooled to $-30{ }^{\circ} \mathrm{C}$. This synthesis resulted in a $2: 1: 2$ mixture of $\left[(\mathrm{BDI}) \mathrm{GaBn}_{2}\right]:[(\mathrm{BDI}) \mathrm{Ga}(\mathrm{Bn}) \mathrm{Cl}]:\left[(\mathrm{BDI}) \mathrm{GaCl}_{2}\right]$, as quantified by the BDI $\mathrm{Y}-\mathrm{H}$ resonance in the ${ }^{1} \mathrm{H}$ NMR spectrum, and all attempts to separate the mono-substituted product from the reaction mixture proved unsuccessful. In order to kinetically favour the formation of the mono-substituted product, the reaction was repeated at $-78{ }^{\circ} \mathrm{C}$ with a ten-fold dilution of the $\mathrm{BnMgCl}$ solution, to both reduce the effective concentration of reagent, and favour the product with the lowest formation energy. Unfortunately this resulted in a $1: 1$ ratio of $\left[(\mathrm{BDI}) \mathrm{GaBn}_{2}\right]:\left[(\mathrm{BDI}) \mathrm{GaCl}_{2}\right]$ as quantified by ${ }^{1} \mathrm{H}$ NMR spectroscopy, indicating that the di-substituted product is the kinetically favoured reaction. This could be due to the addition of the first benzyl ligand to the gallium centre activating the remaining $\mathrm{Ga}-\mathrm{Cl}$ bond towards $\sigma$-bond metathesis, resulting in the mono-substituted product to be more reactive with the Grignard reagent than the starting material.

\subsection{Concluding Remarks}

The data collected indicates that $\beta$-diketiminato-gallium-dialkyl compounds do not undergo the same $\alpha$-proton elimination reaction observed in group 3 dialkyl complexes, indicating that the valence $d$ orbitals may play an important role in the rearrangement mechanism. Neither [(BDI)GaMe $\mathrm{Gar}_{2}$ nor [(BDI)GaBn $\mathrm{Gr}_{2}$ showed any signs of $\alpha$-proton elimination under high temperature or in the presence of co-ordinating solvents, and the addition of the sterically hindered bases DMAP or TMEDA did not assist in proton transfer. While other ligands, such as the neopentyl ligand, could be explored in the same manner, a similar lack of reactivity is expected. An alternative route was explored through the isolation of the mono-substituted product, [(BDI) $\mathrm{Ga}(\mathrm{Bn}) \mathrm{Cl}]$, however reaction kinetics favouring the formation of the di-substituted product, [(BDI)GaBn $\left.{ }_{2}\right]$, hindered these attempts. Another possibile method would be to use either the tri-methylbenzyl $\left(\mathrm{Mes}^{-} \mathrm{CH}_{2}-\right)$ or tri-tert-butylbenzyl (Mes*- $\mathrm{CH}_{2}-$ ) Grignard reagents, as these groups possess significantly more steric hinderance, and would therefore increasingly favour the formation of a mono-substituted $\beta$-diketiminato-gallium complex. This complex could then be treated with ${ }^{n} \mathrm{BuLi}$ to investigate if the benzyl proton is abstracted, and if the resulting lithium salt reacts with the adjacent chloride to eliminate $\mathrm{LiCl}$ and form a gallium carbon double bond. 


\section{Chapter 3}

\section{Nitrenes}

The second major synthetic target of this study, $\beta$-diketiminato-gallium-imido complexes (2), have been synthesised previously. Alternative routes to the formation of these complexes are examined, using both previous $\beta$-diketiminato-gallium-imido and transition metal imido complexes as the foundation of the proposed strategies.

\subsection{Introduction}

Nitrenes are the nitrogen analogue of carbenes, possessing a formal nitrogen double bond. These functionalities are better known as either imido ligands (when the nitrogen forms a double bond to another element, such as a transition metal) or imines (when they form a double bond to carbon). Imido complexes typically adopt the structure L-M=NR and can be prepared in a similar manner to carbenes, with thermally assisted extraction of an amide proton by either an alkyl group or another amide ligand bound to the metal giving an alkane and an imido complex such as (23) (Scheme 21). ${ }^{51}$

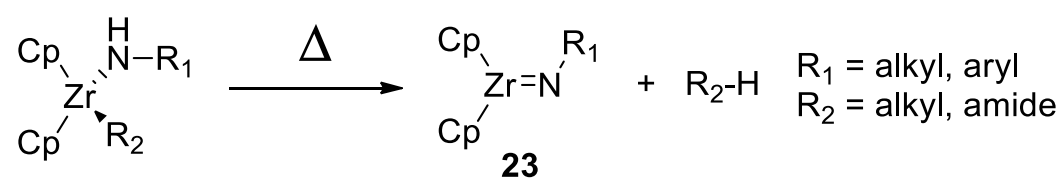

Scheme 21: Formation of an imidozirconocene complex.

As mentioned previously in Section 2.1.4, the extraction of the amide proton can be facilitated by Lewis bases such as DMAP, which results in the formation of a metal-imido complex. However the 
Lewis base typically remains coordinated to the metal centre to stabilise the resulting imido complex (Scheme 14, Section 2.1.4).

\subsubsection{Applications of Nitrenes}

While many terminal metal-imido complexes have been shown to be unreactive, there are several examples of transition metal-imido complexes that show both stoichiometric reactivity and catalytic abilities. Group four metal complexes are a good example, in particular, the imidometallocenes of zirconium produced by Bergman et al. ${ }^{51}$ These complexes undergo a wide range of reactions, including cleavage of $\mathrm{C}-\mathrm{H}$ bonds, cycloadditions of alkenes, alkynes, carbonyls and nitrogen compounds. ${ }^{51}$ In addition they are also effective catalysts for imine metathesis, which is similar to the Shell Higher Olefin Process, where $R=N R$ and $R^{\prime}=N R^{\prime}$ can undergo metathesis to give $\mathrm{R}^{\prime}=\mathrm{NR}$ and $\mathrm{R}=\mathrm{NR}$, and also hydroamination of alkynes (Figure 19). ${ }^{51}$

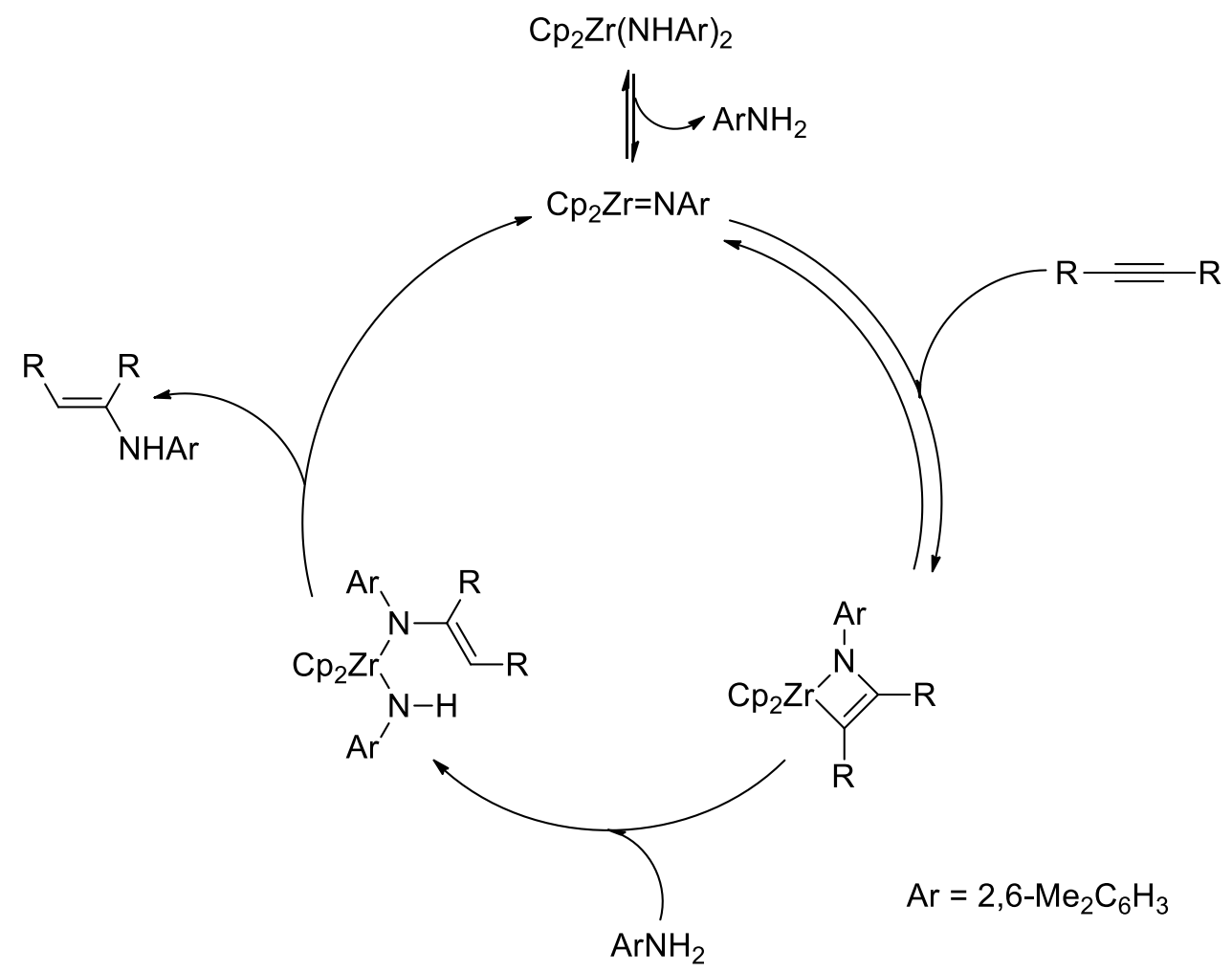

Figure 19: Catalytic cycle of hydroaminiation proposed by Bergman et al. ${ }^{51}$ 
These group four imidometallocenes can be readily prepared through an $\alpha$-proton elimination reaction, observed in the $\mathrm{Cp}_{2} \mathrm{Zr}(\mathrm{NHAr})_{2}$ complex eliminating an amine to form the active imidozirconocene catalyst. They can also be prepared through the reaction of aniline derivatives, such as 2,6-dimethylaniline, with a di-alkyl pre-catalyst complex such as $\mathrm{Cp}_{2} \mathrm{TiMe}_{2}$, which reacts with the amine protons of aniline in the presence of pyridine to eliminate two equivalents of methane and form the imidotitanium complex that is the active catalyst (Scheme 22). ${ }^{52}$

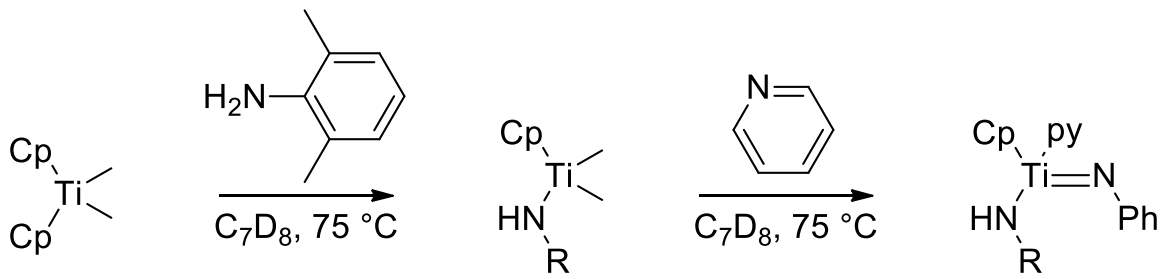

Scheme 22: Formation of an imidotitanocene complex.

\subsubsection{Existing $\beta$-Diketiminatogallium Imido Complexes}

As stated in chapter one, there are many examples of group 13 imido complexes, including those of gallium with the BDI ligand. The synthesis of the first reported $\beta$-diketiminato-gallium imide was achieved through the reaction of a BDI gallene ((BDI)Ga:) with the azide $\mathrm{N}_{3}-2,6-\mathrm{Trip}_{2} \mathrm{C}_{6} \mathrm{H}_{3}$ (Trip $=2,4,6-{ }^{i} \mathrm{Pr}-\mathrm{C}_{6} \mathrm{H}_{2}$ ). The formation of this imide was favoured as the addition of imide ligand increased the amount of steric bulk around the reactive gallene centre of the starting material to stabilise it (Scheme 23). ${ }^{53}$
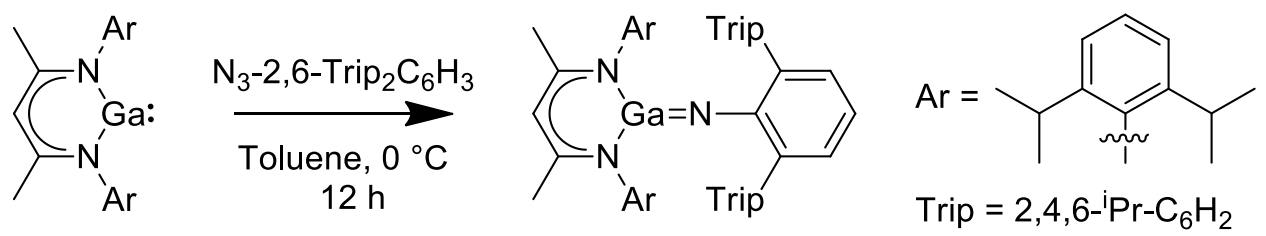

Scheme 23: Formation of a gallium-nitrogen double bond. 


\subsubsection{Existing $\beta$-Diketiminatogallium Diamido Complexes}

The formation of $\beta$-diketiminato-gallium-diamido complexes was previously achieved using short alkyl and aryl groups (Et, 'Pr, $\left.{ }^{\mathrm{n}} \mathrm{Bu}, \mathrm{Ph}\right){ }^{54}$ These compounds could theoretically undergo the same $\alpha$-elimination reaction observed in group 4 alkyl/amide and diamide complexes to form a galliumnitrogen double bond and free amine or aniline, however they lack the steric bulk around the nitrogen atom to stabilise and prevent dimerisation of the resulting gallium imido complex. The formation of these $\beta$-diketiminato-gallium-diamide complexes was achieved through the addition of two equivalents of the lithium salt of the amine to a solution of $\left[(\mathrm{BDI}) \mathrm{GaCl}_{2}\right]$ (Scheme 24), which can be adapted to use more sterically hindered amines that can better stabilise a gallium-nitrogen double bond.<smiles></smiles>

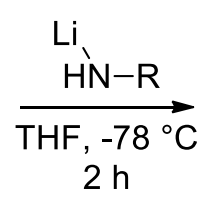<smiles></smiles>

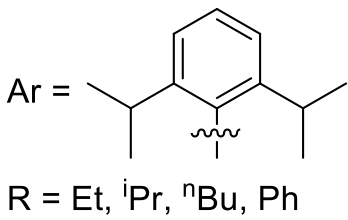

Scheme 24: Formation of $\beta$-diketiminato-gallium-diamide complexes.

\subsection{Synthetic Strategy}

The synthetic strategies of new $\beta$-diketiminato-gallium-imido complexes determined the reactivity of amines or anilines with $\left[(\mathrm{BDI}) \mathrm{GaMe}_{2}\right]$, as the methyl ligand has been observed to react with acidic protons to form methane, ${ }^{27,51}$ and anilide ligands are able to be reduced to imides through this reaction on group four metals. ${ }^{51}$ Other more labile ligands, such as the HMDS ligand, are alternatives to the methyl ligand, used in the deprotonation of an amine or aniline to form an imide complex. The reactivity of $\beta$-diketiminato -gallium-diamido complexes towards $\alpha$-proton elimination to form an amine and an imide is also examined, using bulky aniline derivatives as steric drivers that favour $\alpha$-proton elimination, and stabilise any resulting imido complexes. The known $\beta$-diketiminatogallium-diamido complex using anilide ligands $\left(\left[(\mathrm{BDI}) \mathrm{Ga}(\mathrm{NHPh})_{2}\right]\right)$, and the more sterically demanding analogues using 2,6-dimethylanilide and 2,6-diisopropylanilide ligands have had their reactivity towards $\alpha$-proton elimination tested. Synthetic targets are outlined in Figure 20. 
<smiles></smiles>

24<smiles>[R]N[Ge]1(N[Ga])C([Al])=C(C)C=C(C)N1[Al]</smiles>

25

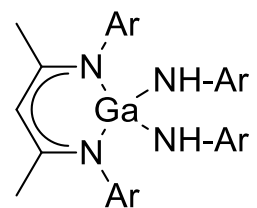

26<smiles>CC(C)c1cccc(C(C)C=[Zn])c1N(C)C</smiles>

$\mathrm{R}=2,6-\mathrm{Me}_{2} \mathrm{C}_{6} \mathrm{H}_{3}$

Figure 20: Targeted $\beta$-diketiminato-gallium-diamido complexes.

\subsection{Results and Discussion}

\subsubsection{Reactivity of $\beta$-Diketiminato-dimethylgallium with Anilines}

The first attempted route to a gallium-nitrogen double bond involved the addition of one equivalent of aniline to $\left[(\mathrm{BDI}) \mathrm{GaMe}_{2}\right]$, as aniline derivatives have been shown to protonate and displace methyl ligands in group 4 metallocene precatalysts to form the active group 4 imidometallocene catalysts used in hydroamination ${ }^{51,52}$ (Scheme 25).<smiles></smiles>

20

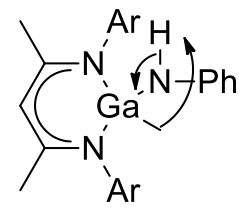
$\mathrm{Ar}$<smiles></smiles>

$2 a$<smiles>CC(C)c1cccc(C(C)C=[Zn])c1N(C)C</smiles>

Scheme 25: Proposed reaction mechanism of [(BDI)GaMe $\left.\mathrm{Ga}_{2}\right]$ and aniline.

The reaction was attempted with three different aniline derivatives: 2,6-diisopropylaniline, 2,6-dimethylaniline, and aniline. Each aniline derivative was added to a solution of [(BDI)GaMe $\left.\mathrm{Ga}_{2}\right]$ in toluene and stirred for $12 \mathrm{~h}$. No reaction was observed by ${ }^{1} \mathrm{H}$ NMR spectroscopy for any of the three aniline derivatives, indicating that the aniline protons were not acidic enough to protonate the methyl ligands. 


\subsubsection{Attempted Synthesis of $\beta$-Diketiminato- bis(hexamethyldisilazane)gallium}

The hexamethyldisilazane (HMDS) ligand was chosen to attempt the synthesis of a gallium nitrene as the HMDS ligand can be readily protonated to eliminate HMDS-H. Reaction of $\left[(\mathrm{BDI}) \mathrm{Ga}(\mathrm{HMDS})_{2}\right]$ with an amine or aniline functionality could lead to the direct formation of a gallium-nitrogen double bond through protonation of both HMDS ligands in the same manner as the proposed [(BDI)GaMe $]$ mechanism (Scheme 26).

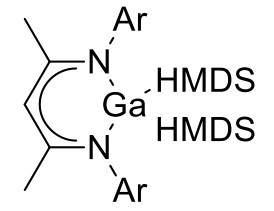

27<smiles>[PH4+]Nc1ccccc1</smiles><smiles></smiles>

$2 a$<smiles>CC(C)c1cccc(C(C)C)c1N(C)C</smiles>

Scheme 26: Proposed reaction of $\left[(\mathrm{BDI}) \mathrm{Ga}(\mathrm{HMDS})_{2}\right]$ with aniline.

The synthesis of $\left[(\mathrm{BDI}) \mathrm{Ga}(\mathrm{HMDS})_{2}\right]$ was attempted via three routes. The first route involved the synthesis of the known compound ${ }^{55} \mathrm{Ga}(\mathrm{HMDS})_{3}$ through the addition of three equivalents of HMDS-Li to $\mathrm{GaCl}_{3}$ to generate the Ga(HMDS) ${ }_{3}$ complex in-situ. This was identified by the presence of a singlet resonance at $\delta 0.24 \mathrm{ppm}$ in the ${ }^{1} \mathrm{H}$ NMR spectrum, which is of similar chemical shift to other L-Ga(HMDS) $)_{x}$ complexes $(\delta 0.09-0.30 \mathrm{ppm}) .{ }^{55,56}$ To this solution of "Ga(HMDS)", one equivalent of $\mathrm{BDI}-\mathrm{H}$ in toluene was added to attempt the elimination of HMDS-H and form [(BDI)Ga(HMDS) $\left.{ }_{2}\right]$. Monitoring of the reaction mixture by ${ }^{1} \mathrm{H}$ NMR spectroscopy showed no reaction occurred at room temperature, $60{ }^{\circ} \mathrm{C}$, or $110{ }^{\circ} \mathrm{C}$. The second route to $\left[(\mathrm{BDI}) \mathrm{Ga}(\mathrm{HMDS})_{2}\right]$ utilised two equivalents of HMDS-Li with $\left[(\mathrm{BDI}) \mathrm{GaCl}_{2}\right.$ ] in toluene. The ${ }^{1} \mathrm{H}$ NMR spectrum revealed that no reaction occurred when the reaction mixture was at room temperature, at $60{ }^{\circ} \mathrm{C}$, or at $110^{\circ} \mathrm{C}$. The third route to [(BDI)Ga(HMDS $)_{2}$ involved addition of two equivalents of $\mathrm{HMDS}-\mathrm{H}$ to $\left[(\mathrm{BDI}) \mathrm{GaMe}_{2}\right]$ in toluene. The ${ }^{1} \mathrm{H}$ NMR spectrum of the reaction mixture showed no reaction had occurred when the reaction mixture was at room temperature, at $60^{\circ} \mathrm{C}$, or at $110^{\circ} \mathrm{C}$. The failure to synthesise [(BDI)Ga(HMDS) $\left.{ }_{2}\right]$ via all three attempted reaction pathways indicates that the HMDS ligand is too sterically bulky to coordinate to a gallium centre containing the BDI ligand, as it can coordinate to some degree to free gallium, evidenced during the in situ formation of $\mathrm{Ga}(\mathrm{HMDS})_{3}$. These reactions are summarised in Scheme 27. 


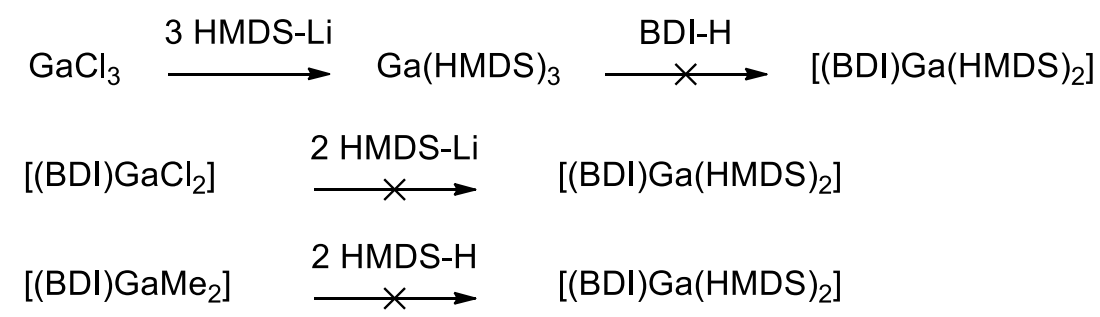

Scheme 27: Attempted formation of [(BDI)Ga(HMDS) 2 .

\subsubsection{Synthesis of $\beta$-Diketiminato-bis(anilato)gallium}

The synthesis of $\left[(\mathrm{BDI}) \mathrm{Ga}(\mathrm{NHPh})_{2}\right]$ was achieved via the literature procedure ${ }^{54}$ through the addition of two equivalents of $\mathrm{PhN}(\mathrm{H}) \mathrm{Li}$ to $\left[(\mathrm{BDI}) \mathrm{GaCl}_{2}\right]$ in toluene at $60^{\circ} \mathrm{C}$ for 72 hours (Scheme 28) to give $\mathbf{2 4}$ in $50 \%$ isolated yield. Following crystallisation from toluene the product (24) was characterised by ${ }^{1} \mathrm{H}$ NMR spectroscopy, which matched reported values. ${ }^{54}$<smiles></smiles>

12

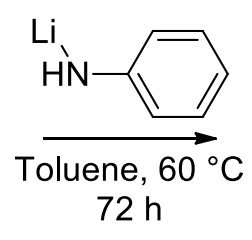

Scheme 28: Synthesis of $\left[(\mathrm{BDI}) \mathrm{Ga}(\mathrm{NHPh})_{2}\right]$.

\subsubsection{Attempted $\alpha$-proton Elimination}

The $\alpha$-proton elimination reaction of $\left[(\mathrm{BDI}) \mathrm{Ga}(\mathrm{NHPh})_{2}\right]$ was first attempted on a $25 \mathrm{mg}$ scale in deuterated benzene. No reaction was observed by ${ }^{1} \mathrm{H}$ NMR spectroscopy at either room temperature or at $80^{\circ} \mathrm{C}$. To attempt to facilitate the transfer of the $\alpha$-proton, the Lewis bases DMAP and TMEDA were independently added to the reaction mixture, however only on a $1 \%$ loading to determine if the base could catalytically facilitate the transfer of the $\alpha$-proton without coordinating to the resulting imide as previously observed with transition metal carbenes ${ }^{41}$ and imides. ${ }^{44}$ The two bases DMAP and TMEDA were independently added to the solution and the samples monitored for two hours, then heated to $80^{\circ} \mathrm{C}$ after no reaction was observed by ${ }^{1} \mathrm{H}$ NMR spectroscopy. Upon the failure of both bases to catalyse proton transfer, the reaction was repeated on a $100 \mathrm{mg}$ scale in THF 
to determine if a coordinating solvent could stabilise the resulting imido complex instead of a coordinating base. No reaction was observed, even when TMEDA or DMAP were added to the reaction mixture. Finally, the reactions were repeated in toluene to increase the reflux temperature to $110^{\circ} \mathrm{C}$, however again no reaction was observed, including when TMEDA or DMAP were added to the reaction mixture. These results are summarised in Table 4.

Table 4: Reaction conditions for the attempted $\alpha$-proton elimination of [(BDI)Ga(NHPh) $\left.)_{2}\right]$.

\begin{tabular}{|l|l|l|l|l|}
\hline Solvent & Temp. $\left({ }^{\circ} \mathrm{C}\right)$ & Time & Base & Observations \\
\hline $\mathrm{C}_{6} \mathrm{D}_{6}$ & 25 & $2 \mathrm{~h}$ & - & No Reaction \\
\hline $\mathrm{C}_{6} \mathrm{D}_{6}$ & 80 & $12 \mathrm{~h}$ & - & No Reaction \\
\hline $\mathrm{C}_{6} \mathrm{D}_{6}$ & 25 & $2 \mathrm{~h}$ & TMEDA & No Reaction \\
\hline $\mathrm{C}_{6} \mathrm{D}_{6}$ & 80 & $12 \mathrm{~h}$ & TMEDA & No Reaction \\
\hline $\mathrm{C}_{6} \mathrm{D}_{6}$ & 25 & $2 \mathrm{~h}$ & DMAP & No Reaction \\
\hline $\mathrm{C}_{6} \mathrm{D}_{6}$ & 80 & $12 \mathrm{~h}$ & DMAP & No Reaction \\
\hline THF & 25 & $2 \mathrm{~h}$ & - & No Reaction \\
\hline THF & 60 & $12 \mathrm{~h}$ & - & No Reaction \\
\hline THF & 25 & $2 \mathrm{~h}$ & TMEDA & No Reaction \\
\hline THF & 60 & $12 \mathrm{~h}$ & TMEDA & No Reaction \\
\hline THF & 25 & $2 \mathrm{~h}$ & DMAP & No Reaction \\
\hline THF & 60 & $12 \mathrm{~h}$ & DMAP & No Reaction \\
\hline Toluene & 25 & $2 \mathrm{~h}$ & - & No Reaction \\
\hline Toluene & 110 & $12 \mathrm{~h}$ & - & No Reaction \\
\hline Toluene & 25 & $2 \mathrm{~h}$ & DMAP & No Reaction \\
\hline Toluene & 110 & $12 \mathrm{~h}$ & DMAP & No Reaction \\
\hline Toluene & 25 & $2 \mathrm{~h}$ & TMEDA & No Reaction \\
\hline Toluene & 110 & $12 \mathrm{~h}$ & TMEDA & No Reaction \\
\hline
\end{tabular}

Base loaded at $1 \%$

\subsubsection{Synthesis of $\beta$-Diketiminato-bis(2,6-dimethylanilato)gallium}

In order to investigate if increasing the steric bulk on the aromatic rings of the anilide ligands would favour the $\alpha$-proton elimination of the anilide ligand, $\left[(\mathrm{BDI}) \mathrm{GaCl}_{2}\right]$ was treated with two equivalents of lithiated 2,6-dimethylaniline in toluene at $60^{\circ} \mathrm{C}$ for 72 hours to give the di-substituted product [(BDI)Ga(NHDMP) $\left.)_{2}\right](\mathbf{2 5})$ in $35 \%$ isolated yield (Scheme 29$)$. 
<smiles></smiles>

12

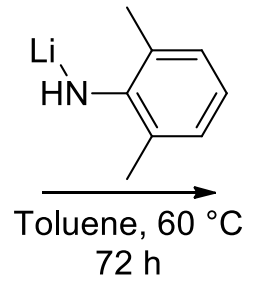

$72 \mathrm{~h}$

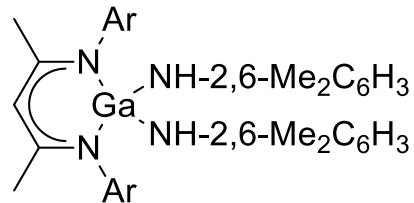<smiles>CC(C)c1cccc(C(C)C)c1C(C)C</smiles>

Scheme 29: Synthesis of [(BDI)Ga(NHDMP) $)_{2}$.

Following purification of the crude reaction mixture by crystallisation from toluene at $-30{ }^{\circ} \mathrm{C}$, the resulting crystals were analysed by ${ }^{1} \mathrm{H}$ and ${ }^{13} \mathrm{C}$ NMR spectroscopy, elemental analysis, and single crystal X-ray diffraction. The main indication that the reaction had proceeded was the loss of the BDI $\mathrm{Y}-\mathrm{H}$ resonance $(\delta 4.75 \mathrm{ppm}, \mathrm{s}, 1 \mathrm{H})$ for $\left[(\mathrm{BDI}) \mathrm{GaCl}_{2}\right]$, and the presence of a new resonance for the BDI $\mathrm{Y}-\mathrm{H}(\delta 4.96 \mathrm{ppm}, \mathrm{s}, 1 \mathrm{H})$. The most notable features of the ${ }^{1} \mathrm{H}$ NMR spectrum were the presence of four doublet resonances $(\delta 1.43,1.19,1.08,0.90)$ and two apparent septet resonances $(\delta 3.53,3.37)$ that corresponded with the isopropyl groups on the $\mathrm{N}$-aryl group of the BDI ligand. COSY spectroscopy showed that each methine resonance coupled to two methyl resonances, indicating that the isopropyl groups on either side of the $\mathrm{C}_{3} \mathrm{~N}_{2}$ ligand backbone plane were in a different environment to each other. The four methyl substituents of the two anilide ligands presented as three distinct resonances $(\delta 2.61 \mathrm{ppm}, \mathrm{s}, 3 \mathrm{H} ; 1.65 \mathrm{ppm}, \mathrm{s}, 3 \mathrm{H} ; 1.44 \mathrm{ppm}, \mathrm{s}, 6 \mathrm{H})$, revealing that one anilide ligand was perpendicular to the approximate plane of symmetry in the molecule formed through the $\mathrm{BDI} \gamma-\mathrm{H}$, gallium, and the anilide ligand nitrogen atoms, while the other was parallel with the plane of symmetry, so that the two methyl groups were not related through symmetry (Figure 21).
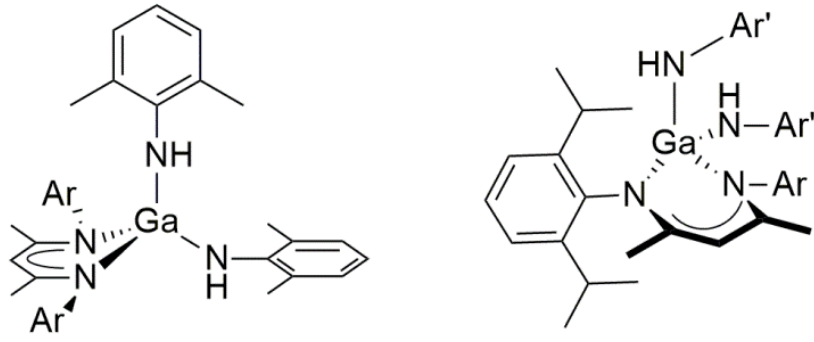<smiles>Cc1ccc(C(C)C)c(C(C)C)c1N(C)c1cccc(C(C)C)c1N</smiles>

Figure 21: 3D Structure of [(BDI)Ga(NHDMP $\left.)_{2}\right]$. 
Further support of this observation is the presence of two $\mathrm{N}-\mathrm{H}$ resonances $(\delta 3.43 \mathrm{ppm}, \mathrm{s}, 1 \mathrm{H}$; $2.37 \mathrm{ppm}, \mathrm{s}, 1 \mathrm{H}$ ) for the anilide ligands, both of which are further upfield compared to [(BDI)Ga(NHPh) $\left.)_{2}\right](\delta 6.14 \mathrm{ppm}$, br. $s, 2 \mathrm{H})$, which has both $\mathrm{N}-\mathrm{H}$ protons in the same environment. The large downfield shift of one methyl resonance to $\delta 2.61 \mathrm{ppm}$ indicates a high amount of deshielding for a methyl substituent, placing it near an electron withdrawing group in the molecule. The possible candidates for this are either the aromatic BDI backbone environment or one of the four aromatic rings on the ligands.

The crystal structure of $\left[(\mathrm{BDI}) \mathrm{Ga}(\mathrm{NHDMP})_{2}\right]$ revealed that one of the anilide methyl substituents sits directly above the BDI backbone, centred between two isopropyl groups of the BDI ligand (Figure 22). The distance between the $C_{3} N_{2}$ backbone plane and the hydrogen atoms of this methyl substituent is $2.33 \AA$, which confirms that this methyl substituent is interacting with the $\pi$-electrons of the aromatic system in the BDI backbone. Similar $\mathrm{C}-\mathrm{H} \cdots \pi$ interactions have been observed in bis(BDI)metal complexes such as $\left[\left(\mathrm{BDI}_{\mathrm{DIPP}}\right)_{2} \mathrm{Ca}\right]$ and $\left[\left(\mathrm{BDI}_{\mathrm{DIPP}}\right)_{2} \mathrm{Sr}\right],^{57}$ albeit these interactions were between the $\pi$ system of the BDI aromatic rings and the isopropyl substituents, rather than the BDI backbone. The $\mathrm{C}-\mathrm{H} \cdots \pi$ interactions observed in the calcium and strontium complexes had average distances of $2.70 \AA$ and $2.76 \AA$ respectively, therefore the $\mathrm{C}-\mathrm{H} \cdots \pi$ distance in [(BDI)Ga(NHDMP) ${ }_{2}$ ] of $2.33 \AA$ is significantly shorter, possibly as the backbone system is only $\eta^{5}$ coordinate as opposed to the $\eta^{6}$ coordination of the BDI aromatic rings in the calcium and strontium complexes. It was also noted that the average distance between this methyl group and the isopropyl hydrogen atoms on the BDI ligand was $2.55 \AA$, signalling that these may also contribute to the deshielding effect on this methyl group. The geometry at gallium is pseudo-tetrahedral, with the BDI ligand possessing a bite angle of $95.57(6)^{\circ}$ compared to $96.4(1)^{\circ}$ in $\left[(\mathrm{BDI}) \mathrm{Ga}(\mathrm{NHPh})_{2}\right]$. The angle between the anilide ligands is $104.07(6)^{\circ}$, compared to $109.3(1)^{\circ}$ in $\left[(\mathrm{BDI}) \mathrm{Ga}(\mathrm{NHPh})_{2}\right]$, showing that increasing the steric bulk on the anilide ligands reduces the angle between the two anilide ligand nitrogen atoms, which could assist in an $\alpha$-proton elimination reaction as the intramolecular distance between the $\mathrm{N}-\mathrm{H}$ functionalities of the anilide ligands is reduced. The Ga-N bond lengths for the BDI ligand (1.938(1) \& $1.953(2) \AA ̊$ ) are of comparable length to those observed in $\left[(\mathrm{BDI}) \mathrm{Ga}(\mathrm{NHPh})_{2}\right](1.945(3)$ \& 1.947(3) $\AA$ ). However the bond lengths for the anilide ligands increased in length, albeit disproportionally, with

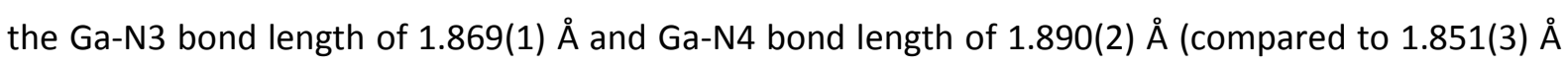
and $1.862(3) \AA$ respectively in $\left.\left[(\mathrm{BDI}) \mathrm{Ga}(\mathrm{NHPh})_{2}\right]\right)$. This implies that the anilide ligand sitting parallel with the symmetry plane may have a slightly stronger bond with gallium, possibly because of the interactions between the BDI backbone and the methyl substituent. Alternatively, it may simply be 
able to have a shorter bond length due to differences in the steric environments of the two substitution positions. These factors may detract from the ability of this anilide ligand to participate in an $\alpha$-proton elimination reaction, as the $\mathrm{C}-\mathrm{H} \cdots \cdot \pi$ interactions between the aromatic system of the $\mathrm{BDI}$ backbone and the methyl group on the anilide ligand will stabilise the complex, countering the effects of steric repulsion between the ligands. The gallium sits $0.38 \AA$ above the $C_{3} N_{2}$ backbone plane, compared to $0.44 \AA$ in $\left[(\mathrm{BDI}) \mathrm{Ga}(\mathrm{NHPh})_{2}\right]$, which is surprising as increasing the steric bulk on the anilide ligands was hypothesised to increase the distance of the gallium above the backbone plane due to the steric repulsion with the BDI ligand. The smaller bite angle of the BDI ligand is also usually indicative of the metal sitting higher above the plane, ${ }^{27}$ however in this case the metal centre has both a smaller BDI bite angle and sits closer to the BDI backbone plane than the less sterically hindered $\left[(\mathrm{BDI}) \mathrm{Ga}(\mathrm{NHPh})_{2}\right]$, achieved through increasing the steric bulk on the ligands. The crystal structure did contain one equivalent of toluene in the crystal lattice, modelled over a 2-fold rotoinversion axis, however, it was determined not to be interacting with the solid state structure of the molecule. The elemental analysis of the crystals was within experimental error of the formula of the proposed structure, indicating the toluene present in the crystal lattice was not part of the compound and had been removed under vacuum during sample preparation. 


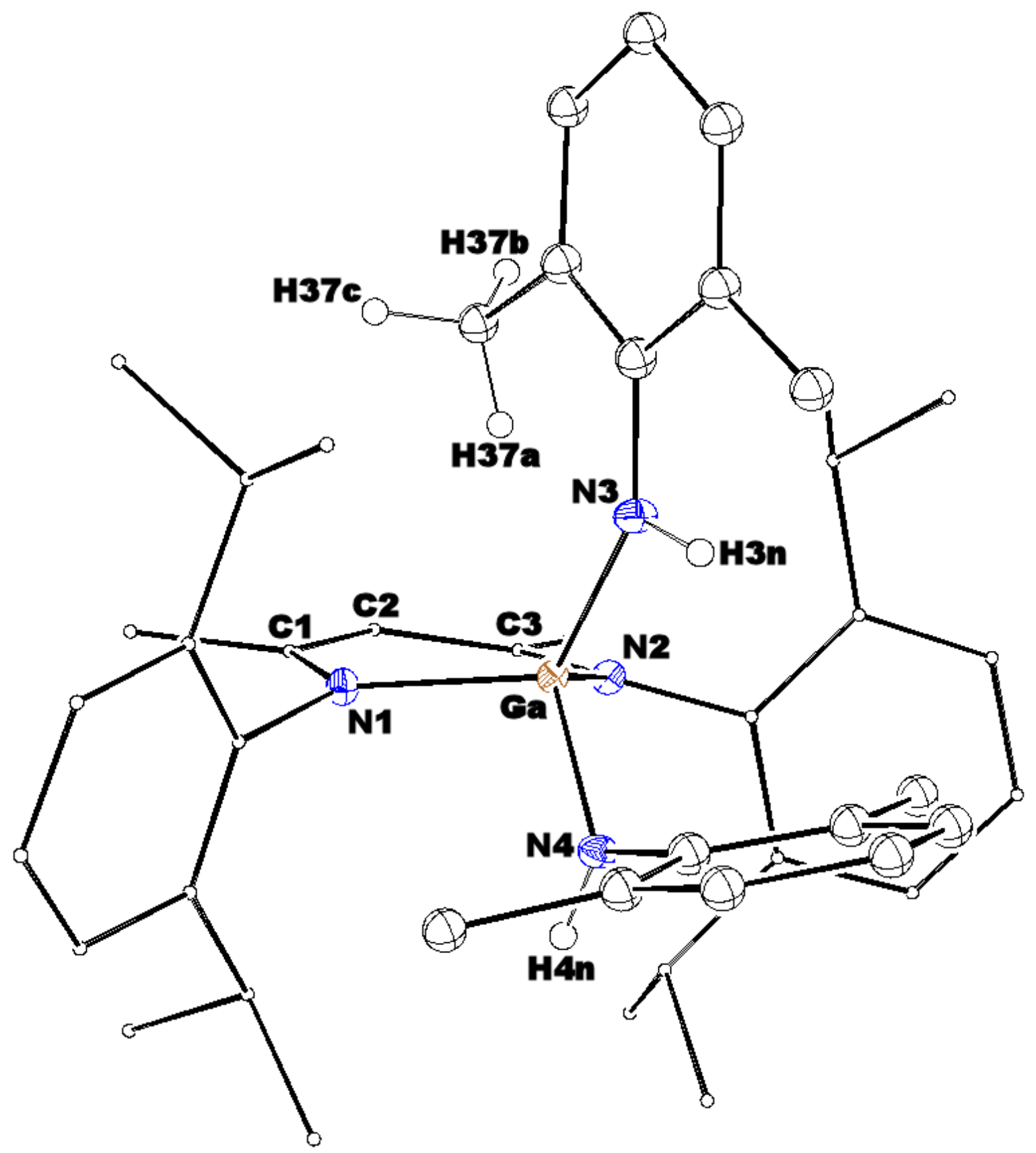

Figure 22: Thermal ellipsoid plot (30\%) of $\left[(\mathrm{BDI}) \mathrm{Ga}(\mathrm{NHDMP})_{2}\right]$. Selected $\mathrm{H}$ atoms have been omitted for clarity. Selected structural data are given in Table 5. 
Table 5: Selected bond lengths and angles for [(BDI)Ga(NHDMP $\left.)_{2}\right]$.

\begin{tabular}{|c|c|c|c|}
\hline \multicolumn{2}{|c|}{ Bond Lengths ( $\AA$ ) } & \multicolumn{2}{|c|}{ Bond Angles ( $\left(^{\circ}\right)$} \\
\hline $\mathrm{Ga}(1)-\mathrm{N}(1)$ & $1.938(1)$ & $\mathrm{N}(1)-\mathrm{Ga}(1)-\mathrm{N}(2)$ & $95.57(6)$ \\
\hline $\mathrm{Ga}(1)-\mathrm{N}(2)$ & $1.953(2)$ & $N(3)-G a(1)-N(4)$ & $104.07(6)$ \\
\hline $\mathrm{Ga}(1)-\mathrm{N}(3)$ & $1.869(1)$ & $N(1)-G a(1)-N(3)$ & $120.70(6)$ \\
\hline $\mathrm{Ga}(1)-\mathrm{N}(4)$ & $1.890(2)$ & $N(1)-G a(1)-N(4)$ & $105.16(6)$ \\
\hline$N(1)-C(1)$ & $1.339(3)$ & $N(2)-G a(1)-N(3)$ & $114.08(6)$ \\
\hline$N(2)-C(3)$ & $1.329(2)$ & $N(2)-G a(1)-N(4)$ & $117.71(6)$ \\
\hline$C(1)-C(2)$ & $1.389(3)$ & $\mathrm{Ga}(1)-\mathrm{N}(1)-\mathrm{C}(1)$ & $122.7(1)$ \\
\hline \multirow[t]{4}{*}{$C(2)-C(3)$} & $1.399(2)$ & $\mathrm{Ga}(1)-\mathrm{N}(2)-\mathrm{C}(3)$ & $122.4(1)$ \\
\hline & & $N(1)-C(1)-C(2)$ & $123.4(1)$ \\
\hline & & $C(1)-C(2)-C(3)$ & $128.2(2)$ \\
\hline & & $C(2)-C(3)-N(2)$ & $124.0(1)$ \\
\hline
\end{tabular}

\subsubsection{Attempted $\alpha$-proton Elimination}

The $\alpha$-proton elimination reaction of $\left[(\mathrm{BDI}) \mathrm{Ga}(\mathrm{NHPh})_{2}\right]$ was first attempted on a $25 \mathrm{mg}$ scale in deuterated benzene. No reaction was observed by ${ }^{1} \mathrm{H}$ NMR spectroscopy at either room temperature or at $80^{\circ} \mathrm{C}$. To attempt to facilitate the transfer of the $\alpha$-proton, the Lewis bases DMAP and TMEDA were independently added to the reaction mixture, however only on a $1 \%$ loading to determine if the base could catalytically facilitate the transfer of the $\alpha$-proton without coordinating to the resulting imide as previously observed with transition metal carbenes ${ }^{41}$ and imides. ${ }^{44}$ The two bases DMAP and TMEDA were independently added to the solution and the samples monitored for two hours, then heated to $80^{\circ} \mathrm{C}$ after no reaction was observed by ${ }^{1} \mathrm{H}$ NMR spectroscopy. Upon the failure of both bases to catalyse proton transfer, the reaction was repeated on a $100 \mathrm{mg}$ scale in THF to determine if a coordinating solvent could stabilise the resulting imido complex instead of a coordinating base. No reaction was observed, even when TMEDA or DMAP were added to the reaction mixture. Finally, the reactions were repeated in toluene to increase the reflux temperature to $110^{\circ} \mathrm{C}$, however again no reaction was observed, including when TMEDA or DMAP were added to the reaction mixture. These results are summarised in Table 6. 
Table 6: Reaction conditions for the attempted $\alpha$-proton elimination of [(BDI)Ga(NHDMP) $\left.{ }_{2}\right]$.

\begin{tabular}{|l|l|l|l|l|}
\hline Solvent & Temp. $\left({ }^{\circ} \mathrm{C}\right)$ & Time & Base & Observations \\
\hline $\mathrm{C}_{6} \mathrm{D}_{6}$ & 25 & $2 \mathrm{~h}$ & - & No Reaction \\
\hline $\mathrm{C}_{6} \mathrm{D}_{6}$ & 80 & $12 \mathrm{~h}$ & - & No Reaction \\
\hline $\mathrm{C}_{6} \mathrm{D}_{6}$ & 25 & $2 \mathrm{~h}$ & TMEDA & No Reaction \\
\hline $\mathrm{C}_{6} \mathrm{D}_{6}$ & 80 & $12 \mathrm{~h}$ & TMEDA & No Reaction \\
\hline $\mathrm{C}_{6} \mathrm{D}_{6}$ & 25 & $2 \mathrm{~h}$ & DMAP & No Reaction \\
\hline $\mathrm{C}_{6} \mathrm{D}_{6}$ & 80 & $12 \mathrm{~h}$ & DMAP & No Reaction \\
\hline THF & 25 & $2 \mathrm{~h}$ & - & No Reaction \\
\hline THF & 60 & $12 \mathrm{~h}$ & - & No Reaction \\
\hline THF & 25 & $2 \mathrm{~h}$ & TMEDA & No Reaction \\
\hline THF & 60 & $12 \mathrm{~h}$ & TMEDA & No Reaction \\
\hline THF & 25 & $2 \mathrm{~h}$ & DMAP & No Reaction \\
\hline THF & 60 & $12 \mathrm{~h}$ & DMAP & No Reaction \\
\hline Toluene & 25 & $2 \mathrm{~h}$ & - & No Reaction \\
\hline Toluene & 110 & $12 \mathrm{~h}$ & - & No Reaction \\
\hline Toluene & 25 & $2 \mathrm{~h}$ & DMAP & No Reaction \\
\hline Toluene & 110 & $12 \mathrm{~h}$ & DMAP & No Reaction \\
\hline Toluene & 25 & $2 \mathrm{~h}$ & TMEDA & No Reaction \\
\hline Toluene & 110 & $12 \mathrm{~h}$ & TMEDA & No Reaction \\
\hline
\end{tabular}

Base loaded at $1 \%$

\subsubsection{Synthesis of $\beta$-Diketiminato-bis(2,6-diisopropylanilato)gallium}

To examine further if the steric bulk on the aromatic ring of the anilide ligands would favour the a-elimination of the anilide ligand, the 2,6-diisopropylanilide analogue was synthesised. This was achieved through the treatment of $\left[(\mathrm{BDI}) \mathrm{GaCl}_{2}\right]$ with two equivalents of lithiated 2,6-diisopropylaniline in toluene at $60{ }^{\circ} \mathrm{C}$ for 72 hours to give $\left[(\mathrm{BDI}) \mathrm{Ga}(\mathrm{NHDIPP})_{2}\right.$ ] (26) in $94.1 \%$ isolated yield (Scheme 30).<smiles></smiles>

12

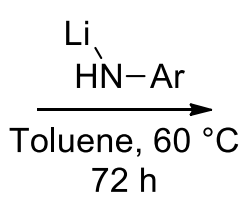
$72 \mathrm{~h}$

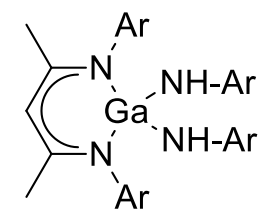

26<smiles>CC(C)c1cccc(C(C)C)c1C(C)(C)C</smiles>

Scheme 30: Synthesis of [(BDI)Ga(NHDIPP $\left.)_{2}\right]$. 
Purification of the crude reaction mixture was achieved through crystallisation from toluene at $-30{ }^{\circ} \mathrm{C}$, and the crystals were analysed through ${ }^{1} \mathrm{H}$ and ${ }^{13} \mathrm{C}$ NMR spectroscopy, elemental analysis, and single crystal X-ray diffraction. Inspection of the ${ }^{1} H$ NMR spectrum revealed the presence of a new $\mathrm{BDI} \mathrm{y}-\mathrm{H}$ resonance $(\delta 5.07 \mathrm{ppm}, \mathrm{s}, 1 \mathrm{H}$ ) and loss of the corresponding starting material resonance $(\delta 4.75 \mathrm{ppm}, \mathrm{s}, 1 \mathrm{H})$, indicating that the reaction had proceeded. The spectrum suggested that the complex possessing the same structural motif as the 2,6-dimethylanilide analogue, with the ${ }^{1} \mathrm{H}$ NMR spectrum exhibiting eight doublet resonances $(\delta 1.51,1.35,1.17,1.10,1.05,1.01,0.89$, $0.73,6 \mathrm{H}$ each) in the methyl region and four methine resonances $(\delta 3.50-3.37, m, 4 \mathrm{H}$ (one of which is an $\mathrm{N}-\mathrm{H}$ resonance); 3.28, app. sept, $2 \mathrm{H} ; 2.07$, app. sept, $2 \mathrm{H} ; 1.88$, sept, $1 \mathrm{H}$ ) for the eight isopropyl groups in the structure. The most notable feature of these resonances was their $3: 2: 2: 1$ ratio of the eight methine protons (the resonance at $\delta 3.50-3.37 \mathrm{ppm}$ contains an $\mathrm{N}-\mathrm{H}$ resonance that accounts for one of the four protons of that resonance). HSQC, COSY and HMBC spectroscopy identified that the methine resonance $\delta 1.88$ was on the same anilide ligand as one of the two methine resonances contained in the multiplet at $\delta 3.50-3.37$. Furthermore, each of these two methine resonances $(\delta 3.50-3.37 \& 1.88)$ had COSY correlations with only one methyl resonance each ( $\delta 1.35 \& 1.01$ respectively), while all other methine resonances had COSY correlations with two methyl resonances each. This indicated that the anilide ligands were in a similar conformation as observed in $\left[(\mathrm{BDI}) \mathrm{Ga}(\mathrm{NHDMP})_{2}\right]$, with one aromatic ring sitting above the BDI backbone in parallel to the plane of symmetry in the molecule, while the other perpendicular to the symmetry plane (Figure 23).

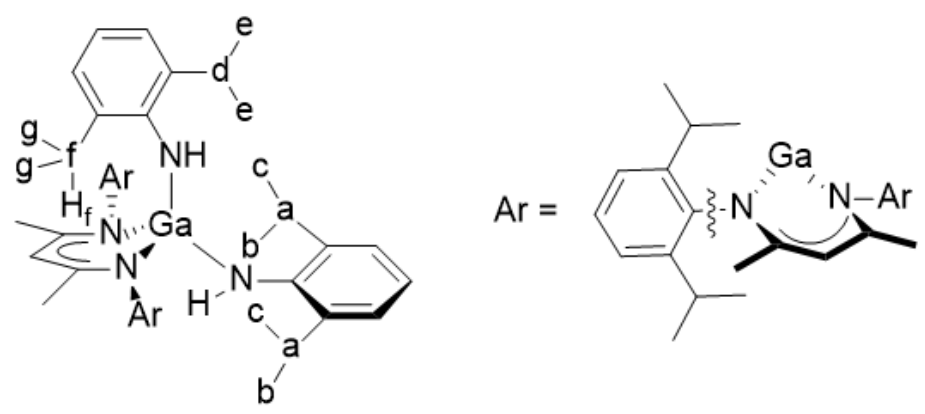

Figure 23: 3D structure of [(BDI)Ga(NHDIPP $\left.)_{2}\right]$.

Due to the large difference in chemical shift between the two isopropyl groups on the same anilide ligand $(\delta 3.50-3.37 \& 1.88$ ), this compound was presumed to be exhibiting similar $\mathrm{C}-\mathrm{H} \cdots \cdots$ 
interactions to those observed in $\left[(\mathrm{BDI}) \mathrm{Ga}(\mathrm{NHDMP})_{2}\right]$. The resonance at $\delta 3.50-3.37$ was assumed to be the proton interacting with the aromatic system $\left(H_{f}\right)$, as the $\pi$ interaction would result in the deshielding of the proton environment. This resonance forms one isopropyl group with the resonance at $\delta 1.35(f, g)$, while the other isopropyl group of this anilide ligand corresponded to the resonances at $\delta 1.88 \& 1.01$ (d,e respectively). The 3D structure was further supported by the second anilide ligand having identical methine proton resonances $(\delta 2.07$, a) that had COSY correlations to two methyl resonances $(\delta 1.05, b ; 0.73, c)$, showing that this anilide ligand was perpendicular to the plane of symmetry. This left the remaining methyl and methine resonances assigned to the BDI ligand. Two separate resonances $(\delta 3.40 \mathrm{ppm}, s, 1 \mathrm{H} ; 2.45 \mathrm{ppm}, s, 1 \mathrm{H})$ were observed for the $\mathrm{N}-\mathrm{H}$ protons. This is similar to $\left[(\mathrm{BDI}) \mathrm{Ga}(\mathrm{NHDMP})_{2}\right]$, further supporting that the two complexes a have very similar chemical environment at the amine functionalities. The elemental analysis of the crystals was within experimental error of the proposed molecular formula.

The crystal structure of $\left[(\mathrm{BDI}) \mathrm{Ga}(\mathrm{NHDIPP})_{2}\right]$ exhibited the same molecular conformation observed in $\left[(\mathrm{BDI}) \mathrm{Ga}(\mathrm{NHDMP})_{2}\right]$, with a pseudo-tetrahedral geometry at gallium (Figure 24). The bite angle of the BDI ligand of $94.39(8)^{\circ}$ is smaller than those observed in both [(BDI)Ga(NHDMP) ${ }_{2}$ ] and [(BDI)Ga(NHPh) $)_{2}\left(95.6^{\circ}\right.$ and $96.4^{\circ}$ respectively), and the Ga-N bond lengths of the BDI ligand are slightly longer (1.989(2) \& 1.955(2) Å), possibly to accommodate the reduction in the bite angle. The Ga-N3 bond length (1.890(2) ̊̊), however, is now nearly identical to the Ga-N4 bond length $(1.893(2) \AA ̊)$ unlike in $\left[(\mathrm{BDI}) \mathrm{Ga}(\mathrm{NHDMP})_{2}\right]$ and $\left[(\mathrm{BDI}) \mathrm{Ga}(\mathrm{NHPh})_{2}\right]$ which observe inequivalent bond lengths in the two anilide substituents. These longer bond lengths, coupled with the N(3)-Ga-N(4) bond angle between the two anilide ligands has increased to $109.5^{\circ}$ from the angle of $104.1^{\circ}$ observed in $\left[(\mathrm{BDI}) \mathrm{Ga}(\mathrm{NHDMP})_{2}\right]$, could reduce the reactivity of the compound towards $\alpha$-proton elimination as the amine $\mathrm{N}-\mathrm{H}$ functionalities are further away from each other than in [(BDI)Ga(NHDMP) $\left.)_{2}\right]$, which was unreactive towards $\alpha$-proton elimination. The gallium sits the highest out of the $\mathrm{C}_{3} \mathrm{~N}_{2}$ backbone plane of the three complexes at $0.55 \AA$, compared to $0.38 \AA$ observed in [(BDI)Ga(NHDMP) $)_{2}$ and $0.44 \AA$ for $\left[(\mathrm{BDI}) \mathrm{Ga}(\mathrm{NHPh})_{2}\right]$, which makes for a very interesting trend as the initial increase in steric bulk brought the gallium centre closer to the BDI backbone plane. The increase in steric bulk from $\left[(\mathrm{BDI}) \mathrm{Ga}(\mathrm{NHPh})_{2}\right]$ to $\left[(\mathrm{BDI}) \mathrm{Ga}(\mathrm{NHDMP})_{2}\right]$ reduces the bite angle of the BDI ligand and shifts the gallium centre closer to the BDI backbone plane, however further increasing the steric bulk to $\left[(\mathrm{BDI}) \mathrm{Ga}(\mathrm{NHDIPP})_{2}\right]$ reduces the bite angle of the BDI ligand and shifts the gallium centre further away from the BDI backbone plane, indicating that $\left[(\mathrm{BDI}) \mathrm{Ga}(\mathrm{NHDMP})_{2}\right]$, or possibly the 2,6-diethylanilide intermediate between these two complexes, would provide the ideal balance 
of sterics and electronics for this system. The large deshielding observed for of one of the isopropyl resonances $(\delta 3.50-3.37)$ can be attributed to the proximity of the hydrogen to the aromatic system of the BDI backbone, being located $2.40 \AA$ above the $C_{3} N_{2}$ backbone plane. While this is slightly further away than in $\left[(\mathrm{BDI}) \mathrm{Ga}(\mathrm{NHDMP})_{2}\right](2.33 \AA)$, it is considerably shorter than the $\mathrm{C}-\mathrm{H} \cdots \pi$ interactions observed in $\left[\left(\mathrm{BDI}_{\mathrm{DIPP}}\right)_{2} \mathrm{Ca}\right]$ and $\left[\left(\mathrm{BDI}_{\mathrm{DIPP}}\right)_{2} \mathrm{Sr}\right](2.70 \AA \AA 2.76 \AA$ respectively $) .{ }^{57}$ Together with the deshielding observed in the ${ }^{1} \mathrm{H}$ NMR spectrum, we can conclude that it is interacting with the $\pi$-electrons of the aromatic system in the BDI backbone. This interaction likely stabilises the complex, as proposed for $\left[(\mathrm{BDI}) \mathrm{Ga}(\mathrm{NHDMP})_{2}\right]$, and may therefore detract from the ability of the complex to undergo $\alpha$-proton elimination. 


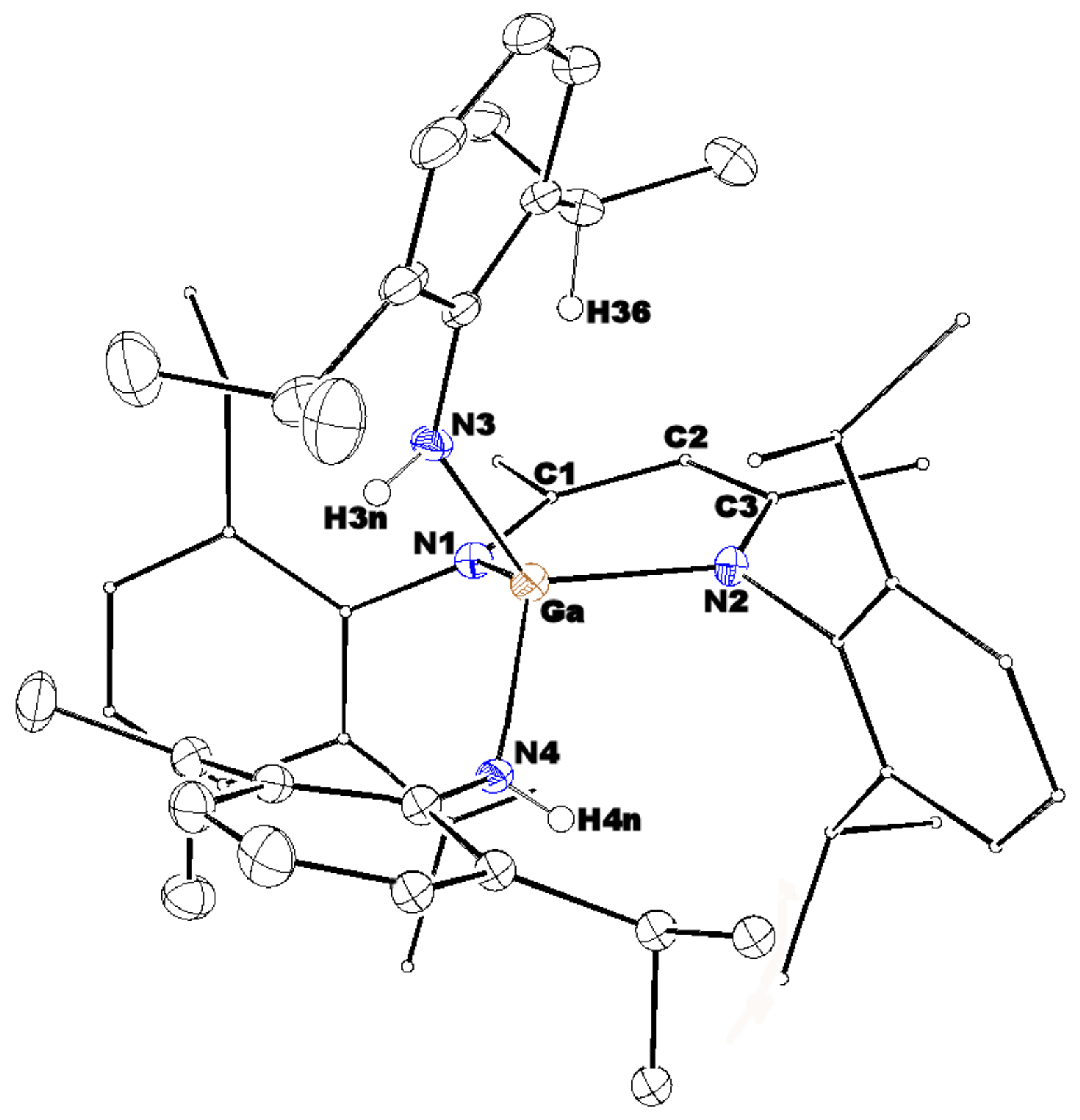

Figure 24: Thermal ellipsoid plot (30\%) of [(BDI)Ga(NHDIPP $\left.)_{2}\right]$. Selected $\mathrm{H}$ atoms have been omitted for clarity. Selected structural data are given in Table 7. 
Table 7: Selected bond lengths and angles for [(BDI)Ga(NHDIPP $\left.)_{2}\right]$.

\begin{tabular}{|c|c|c|c|}
\hline \multicolumn{2}{|c|}{ Bond Lengths ( $(̊)$} & \multicolumn{2}{|c|}{ Bond Angles ( $\left.{ }^{\circ}\right)$} \\
\hline $\mathrm{Ga}(1)-\mathrm{N}(1)$ & $1.989(2)$ & $N(1)-G a(1)-N(2)$ & $94.39(8)$ \\
\hline $\mathrm{Ga}(1)-\mathrm{N}(2)$ & $1.955(2)$ & $N(3)-G a(1)-N(4)$ & $109.48(9)$ \\
\hline $\mathrm{Ga}(1)-\mathrm{N}(3)$ & $1.890(2)$ & $\mathrm{N}(1)-\mathrm{Ga}(1)-\mathrm{N}(3)$ & $109.20(9)$ \\
\hline $\mathrm{Ga}(1)-\mathrm{N}(4)$ & $1.893(2)$ & $\mathrm{N}(1)-\mathrm{Ga}(1)-\mathrm{N}(4)$ & $115.33(8)$ \\
\hline$N(1)-C(1)$ & $1.321(3)$ & $N(2)-G a(1)-N(3)$ & $121.42(9)$ \\
\hline$N(2)-C(3)$ & $1.340(2)$ & $N(2)-G a(1)-N(4)$ & $106.67(9)$ \\
\hline$C(1)-C(2)$ & $1.410(5)$ & $\mathrm{Ga}(1)-\mathrm{N}(1)-\mathrm{C}(1)$ & $121.1(2)$ \\
\hline \multirow[t]{4}{*}{$C(2)-C(3)$} & $1.392(4)$ & $\mathrm{Ga}(1)-\mathrm{N}(2)-\mathrm{C}(3)$ & $121.8(2)$ \\
\hline & & $N(1)-C(1)-C(2)$ & $123.9(2)$ \\
\hline & & $C(1)-C(2)-C(3)$ & $128.2(2)$ \\
\hline & & $C(2)-C(3)-N(2)$ & $123.4(2)$ \\
\hline
\end{tabular}

\subsubsection{Attempted $\alpha$-proton Elimination}

The $\alpha$-proton elimination reaction of $\left[(\mathrm{BDI}) \mathrm{Ga}(\mathrm{NHDIPP})_{2}\right]$ was first attempted on a $25 \mathrm{mg}$ scale in deuterated benzene. No reaction was observed by ${ }^{1} \mathrm{H}$ NMR spectroscopy at either room temperature or at $80^{\circ} \mathrm{C}$. To attempt to facilitate the transfer of the $\alpha$-proton, the Lewis bases DMAP and TMEDA were independently added to the reaction mixture, however only on a $1 \%$ loading to determine if the base could catalytically facilitate the transfer of the $\alpha$-proton without coordinating to the resulting imide as previously observed with transition metal carbenes ${ }^{41}$ and imides. ${ }^{44}$ The two bases DMAP and TMEDA were independently added to the solution and the samples monitored for two hours, then heated to $80^{\circ} \mathrm{C}$ after no reaction was observed by ${ }^{1} \mathrm{H}$ NMR spectroscopy. Upon the failure of both bases to catalyse proton transfer, the reaction was repeated on a $100 \mathrm{mg}$ scale in THF to determine if a coordinating solvent could stabilise the resulting imido complex instead of a coordinating base. No reaction was observed, even when TMEDA or DMAP were added to the reaction mixture. Finally, the reactions were repeated in toluene to increase the reflux temperature to $110^{\circ} \mathrm{C}$, however again no reaction was observed, including when TMEDA or DMAP were added to the reaction mixture. These results are summarised in Table 8. 
Table 8: Reaction conditions for the attempted $\alpha$-proton elimination of [(BDI)Ga(NHDIPP) $\left.)_{2}\right]$.

\begin{tabular}{|l|l|l|l|l|}
\hline Solvent & Temp. $\left({ }^{\circ} \mathrm{C}\right)$ & Time & Base & Observations \\
\hline $\mathrm{C}_{6} \mathrm{D}_{6}$ & 25 & $2 \mathrm{~h}$ & - & No Reaction \\
\hline $\mathrm{C}_{6} \mathrm{D}_{6}$ & 80 & $12 \mathrm{~h}$ & - & No Reaction \\
\hline $\mathrm{C}_{6} \mathrm{D}_{6}$ & 25 & $2 \mathrm{~h}$ & TMEDA & No Reaction \\
\hline $\mathrm{C}_{6} \mathrm{D}_{6}$ & 80 & $12 \mathrm{~h}$ & TMEDA & No Reaction \\
\hline $\mathrm{C}_{6} \mathrm{D}_{6}$ & 25 & $2 \mathrm{~h}$ & DMAP & No Reaction \\
\hline $\mathrm{C}_{6} \mathrm{D}_{6}$ & 80 & $12 \mathrm{~h}$ & DMAP & No Reaction \\
\hline THF & 25 & $2 \mathrm{~h}$ & - & No Reaction \\
\hline THF & 60 & $12 \mathrm{~h}$ & - & No Reaction \\
\hline THF & 25 & $2 \mathrm{~h}$ & TMEDA & No Reaction \\
\hline THF & 60 & $12 \mathrm{~h}$ & TMEDA & No Reaction \\
\hline THF & 25 & $2 \mathrm{~h}$ & DMAP & No Reaction \\
\hline THF & 60 & $12 \mathrm{~h}$ & DMAP & No Reaction \\
\hline Toluene & 25 & $2 \mathrm{~h}$ & - & No Reaction \\
\hline Toluene & 110 & $12 \mathrm{~h}$ & - & No Reaction \\
\hline Toluene & 25 & $2 \mathrm{~h}$ & DMAP & No Reaction \\
\hline Toluene & 110 & $12 \mathrm{~h}$ & DMAP & No Reaction \\
\hline Toluene & 25 & $2 \mathrm{~h}$ & TMEDA & No Reaction \\
\hline Toluene & 110 & $12 \mathrm{~h}$ & TMEDA & No Reaction \\
\hline
\end{tabular}

\subsubsection{Synthesis of $\beta$-Diketiminato-anilato-chlorogallium Complexes}

One of the by-products present in the crude reaction mixture during the synthesis of the di-substituted $\beta$-diketiminato-gallium-anilido complexes was postulated to be the mono-substituted [(BDI)Ga(NHAr)Cl] complex (Ar = Ph, DMP, DIPP). This assumption was based on the presence of a $\mathrm{BDI} \mathrm{Y}-\mathrm{H}$ resonance in the ${ }^{1} \mathrm{H}$ NMR spectrum that did not correspond to either the starting material or di-substituted product. Isolation of this complex followed by treatment with ${ }^{\mathrm{n}} \mathrm{BuLi}$ to lithiate the anilide ligand could potentially result in the elimination of $\mathrm{LiCl}$ to form a gallium-nitrogen double bond (Scheme 31).

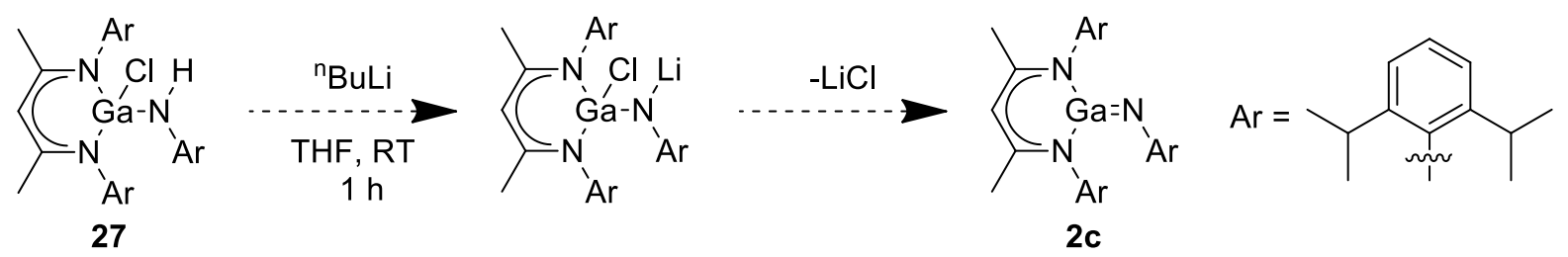

Scheme 31: Possible $\beta$-diketiminato-gallium-imide formation reaction. 
The synthesis of $[(\mathrm{BDI}) \mathrm{Ga}(\mathrm{NHAr}) \mathrm{Cl}]$ was achieved through the addition of one equivalent of $\operatorname{ArN}(\mathrm{H}) \mathrm{Li}(\mathrm{Ar}=\mathrm{Ph}, \mathrm{DMP}, \mathrm{DIPP})$ in toluene to a solution of $\left[(\mathrm{BDI}) \mathrm{GaCl}_{2}\right]$ in toluene at $-30{ }^{\circ} \mathrm{C}$. The solution was allowed to warm to room temperature and stirred for 12 hours. Qualitative assessment through the integreal of the $\mathrm{BDI} \mathrm{y}-\mathrm{H}$ resonances in the crude reaction mixtures showed the presence of the mono-substituted products as $62 \%, 54 \%$ and $56 \%$ for Ph, DMP and DIPP respectively, with 10-20 \% di-substituted product and the remainder as [(BDI $\left.\mathrm{GaCl}_{2}\right]$. Fractional crystallisation of these crude reaction mixtures in toluene/hexane was successful for the DMP and DIPP (27) complexes, however the quantity of pure sample isolated of both complexes was only 5-10 mg each, allowing for characterisation of both complexes by ${ }^{1} \mathrm{H}$ NMR spectroscopy and one attempt at a reaction with

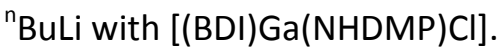

The two isolated compounds [(BDI)Ga(NHAr)Cl] (Ar = DMP, DIPP) were characterised by ${ }^{1} \mathrm{H}$ NMR spectroscopy, which hinted at some interesting structural features. The spectrum of [(BDI)Ga(NHDIPP)CI] possessed five doublet resonances $(\delta 1.34(6 \mathrm{H}), 1.31(6 \mathrm{H}), 1.13(6 \mathrm{H}), 1.06$ $(6 \mathrm{H}), 0.94(12 \mathrm{H}))$ corresponding to the isopropyl methyl environments, with one of the resonances representing four methyl groups and the other four each representing two. The presence of only two methine resonances $(\delta 3.57-3.49(m, 3 \mathrm{H}), 3.36-3.26(m, 3 \mathrm{H}))$ for all six isopropyl groups indicates that the anilide ligand of this complex does not possess the same geometry as either of the anilide ligands of the di-substituted complex $\left[(\mathrm{BDI}) \mathrm{Ga}(\mathrm{NHDIPP})_{2}\right]$. In the $[(\mathrm{BDI}) \mathrm{Ga}(\mathrm{NHDMP}) \mathrm{Cl}]$ analogue, one resonance at $\delta 1.60$ accounted for both methyl groups on the anilide ligand. This indicates that the anilide ligand did not substitute in parallel with the plane of symmetry as observed in $\left[(\mathrm{BDI}) \mathrm{Ga}(\mathrm{NHDMP})_{2}\right]$.

\subsubsection{Addition of $\boldsymbol{n}$-Butyllithium to $\boldsymbol{\beta}$-Diketiminato-chloro- (2,6-dimethylanilato)gallium}

The addition of $10 \mu \mathrm{L}$ of $1.6 \mathrm{M}{ }^{\mathrm{n}} \mathrm{BuLi}$ in hexanes to a solution of $10 \mathrm{mg}$ of [(BDI)Ga(NHDMP)Cl] in $0.5 \mathrm{~mL} \mathrm{C}_{6} \mathrm{D}_{6}$ was followed by ${ }^{1} \mathrm{H}$ NMR spectroscopy. Qualitative assessment of the spectrum indicated that a reaction had occurred, with two new resonances appearing that were assigned to the $\mathrm{BDI} \mathrm{\gamma}-\mathrm{H}$ environment ( $\delta 4.67 \mathrm{ppm}, s ; 4.18 \mathrm{ppm}, s$ ), and that could correspond to [(BDI)Ga(NLiDMP)Cl] and [(BDI)GaNDMP]. While a good indicator of whether the reaction had occurred would be the presence or lack of the $\mathrm{N}-\mathrm{H}$ peak $(\delta 2.71 \mathrm{ppm}, \mathrm{s}, 1 \mathrm{H})$, the presence of starting 
material in the reaction mixture meant this resonance remained in the ${ }^{1} \mathrm{H}$ NMR spectrum, along with trace amounts of $\left[(\mathrm{BDI}) \mathrm{Ga}(\mathrm{NHDMP})_{2}\right]$ that were present in the starting material, however these impurities could not be separated from the reaction mixture to allow for full characterisation of the products. As only $5 \mathrm{mg}$ of [(BDI)Ga(NHDIPP)Cl] was isolated, addition of a stoichiometric equivalent of ${ }^{\mathrm{n}} \mathrm{BuLi}$ was not feasible, as the $4 \mu \mathrm{L}$ required could not be measured and administered accurately.

\subsection{Concluding Remarks}

The formation of a gallium-nitrogen double bond was attempted via three different routes. The first method attempted to react aniline with either [(BDI)GaMe $\left.{ }_{2}\right]$ or $\left[(\mathrm{BDI}) \mathrm{Ga}(\mathrm{HMDS})_{2}\right]$, however the methyl groups were not basic enough to abstract the aniline protons and the synthesis of the $\left[(\mathrm{BDI}) \mathrm{Ga}(\mathrm{HMDS})_{2}\right]$ complex was unsucessful, likely due to steric effects. The next route attempted $\alpha$-proton elimination in the $\beta$-diketiminato-gallium di-substituted anilido complex, [(BDI)Ga(NHAr $\left.)_{2}\right]$, however this complex showed no reactivity towards $\alpha$-proton elimination at high temperatures and/or with Lewis base catalysts in both toluene and THF. Increasing the size of the substituents at the two and six position of the aromatic rings of the anilide ligands to methyl and isopropyl groups did not improve the reactivity of the corresponding complexes towards $\alpha$-proton elimination under identical conditions. The final route involved the reaction of a mono-substituted anilide-chloride complex, [(BDI)Ga(NHAr)Cl], with ${ }^{n} \mathrm{BuLi}$ to remove the anilide proton and eliminate LiCl. Difficulty in isolating a pure sample of the mono-substituted complex resulted in the reaction only being attempted once with [(BDI)Ga(NHDMP)Cl], on a $10 \mathrm{mg}$ scale. While a qualitative assessment of the

${ }^{1} \mathrm{H}$ NMR spectrum indicated that a reaction had occurred, the products could not be separated from the reaction mixture and therefore could not be conclusively characterised. Future work on purifying the mono-substituted complexes, or using the more sterically hindered 2,4,6-tri-tert-butylaniline (Mes*-NH ${ }_{2}$ ) to selectively form a mono-substituted complex, would give further insight into whether this reaction pathway does form a gallium-nitrogen double bond. Alternatively a ligand redistribution reaction could be attempted to improve the isolation of the mono-substituted complexes, mixing one equivalent each of $\left[(\mathrm{BDI}) \mathrm{GaCl}_{2}\right]$ and $\left[(\mathrm{BDI}) \mathrm{Ga}(\mathrm{NHAr})_{2}\right]$ to form two equivalents of [(BDI)Ga(NHAr)Cl]. 


\section{Chapter 4}

\section{Phosphinidenes}

Another major synthetic target of this study is the formation of a $\beta$-diketiminato-gallium phosphinidene complex (3), as a formal gallium-phosphorus double bond has never been reported to date. Previous attempts at the synthesis of gallium phosphinidene complexes have been reviewed, along with transition metal phosphinidene complexes, and the insights from those studies used to design new synthetic strategies.

\subsection{Introduction}

The phosphorus analogues of carbenes (possessing a formal phosphorus double bond) are very reactive compounds and are consequently difficult to isolate. Nonetheless they form very stable compounds with carbon ( $\mathrm{R}_{2} \mathrm{C}=\mathrm{PR}^{\prime}$ phosphenes) which are used in organic chemistry as alkene analogues. ${ }^{14}$ Phosphorus double bonds with transition metal or p-block elements typically take the form of $L-M=P R_{2}$, where the phosphorus lone pair has donated electron density into an empty orbital on its bonding partner. One recent synthesis by Rotter et al. came close to isolating gallium and indium complexes with formal double bonds to phosphorus. However, they readily formed dimers due to insufficient steric bulk stabilising the gallium/indium centres (Scheme 32). ${ }^{25}$

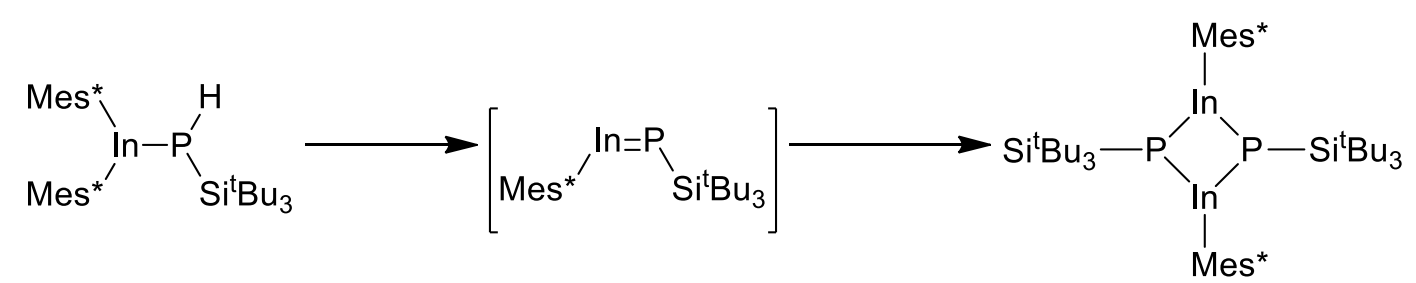

Scheme 32: Dimer formation of an indium phosphinidene. ${ }^{25}$ 


\subsubsection{Transition Metal Phosphinidenes}

Phosphinidene complexes involving transition metals can be generated in a variety of different ways, with varying degrees of stability. Tantalum phosphinidene complexes synthesised by Rankin and Cummins were generated through the addition of three equivalents of $\mathrm{PhP}(\mathrm{H}) \mathrm{Li}$ to $\mathrm{L}_{3}-\mathrm{Ta}-\mathrm{Cl}$ $\left(\mathrm{L}=\operatorname{Ar}\left(\mathrm{CH}_{2}{ }^{\mathrm{t}} \mathrm{Bu}\right) \mathrm{N}, \mathrm{Ar}=2,5-\mathrm{Me}_{2} \mathrm{C}_{6} \mathrm{H}_{3}\right)$ to form the $\mathrm{L}_{3}-\mathrm{Ta}-\mathrm{P}(\mathrm{H})-\mathrm{Ph}$ complex which, upon addition of 0.5 equivalents of $\mathrm{PhP}(\mathrm{H}) \mathrm{Li}$, formed the phosphinidene $\mathrm{L}_{3}-\mathrm{Ta}=\mathrm{P}-\mathrm{Ph}$. This was revised to a direct route from $\mathrm{L}_{3}-\mathrm{Ta}-\mathrm{Cl}$ treated with 1.5 equivalents of $\mathrm{PhP}(\mathrm{H}) \mathrm{Li}$ to give $\mathrm{L}_{3}-\mathrm{Ta}=\mathrm{P}-\mathrm{Ph}$ (Scheme 33 ). ${ }^{58}$

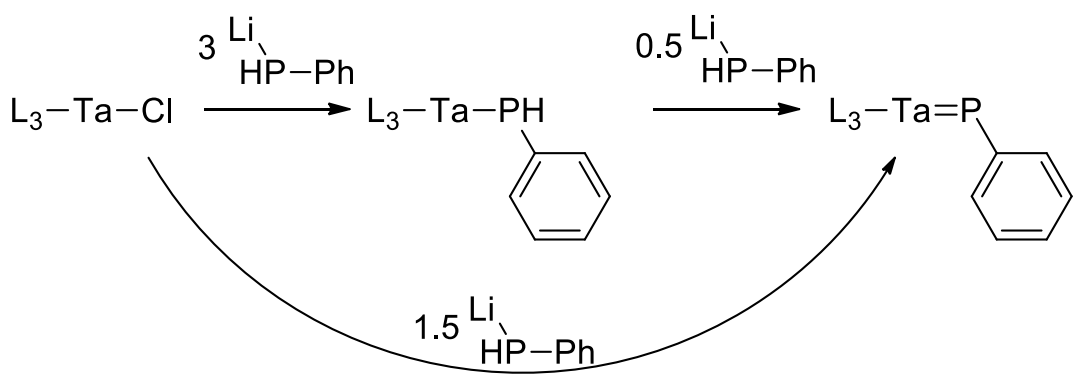

Scheme 33: Formation of a tantalum phosphinidene.

This tantalum phosphinidene was found to be highly reactive as a phospha-Wittig reagent, creating a $\mathrm{C}=\mathrm{P}$ bond instead of the analogous $\mathrm{C}=\mathrm{C}$ bond formed in the standard Wittig reaction. ${ }^{58}$

\subsection{Synthetic Strategy}

Rotter et al. have previously shown that Mes*-gallium-phosphanido complexes will undergo a-proton elimination of Mes*-H to potentially form a gallium-phosphinidene that rearranged to form the dimer. ${ }^{25}$ The proposed synthetic strategy investigates if $\beta$-diketiminato-galliumdiphosphanido complexes also undergo this $\alpha$-proton elimination reaction with phosphanide ligands, as the phosphorus-hydrogen bond is weaker than both the $\mathrm{C}-\mathrm{H}$ and $\mathrm{N}-\mathrm{H}$ bonds examined previously. ${ }^{59}$ The second strategy examines the BDI analogue of the method used by Rotter et al., forming a $\beta$-diketiminato-gallium-alkyl-phosphanide and eliminating the alkyl ligand to leave either a $\beta$-diketiminato-gallium phosphinidene or a dimer. Synthetic targets are outlined in Figure 25. 
<smiles></smiles>

28<smiles></smiles>

29<smiles></smiles>

30<smiles>CC(C)c1cccc(C(C)C=[Zn])c1N(C)C</smiles>

$\mathrm{R}=\mathrm{a}) \mathrm{Me}, \mathrm{b}) \mathrm{Bu}$

Figure 25: Targeted $\beta$-diketiminato-gallium -diphosphido and -alkylphosphido complexes.

\subsection{Results and Discussion}

\subsubsection{Attempted Synthesis of $\beta$-Diketiminato- bis(dicyclohexylphosphanido)gallium}

The first attempted route towards a gallium phosphorous double bond was the synthesis of $\left[(\mathrm{BDI}) \mathrm{Ga}\left(\mathrm{PCy}_{2}\right)_{2}\right](\mathbf{2 8})$, with the aim being that the steric repulsion of the cyclohexane rings leading to the elimination of $\mathrm{PCy}_{3}$ and the formation of $[(\mathrm{BDI}) \mathrm{Ga}=\mathrm{PCy}]$. The attempted synthesis involved the addition of two equivalents of $\mathrm{Cy}_{2} \mathrm{PLi}$ to a solution of $\left[(\mathrm{BDI}) \mathrm{GaCl}_{2}\right]$ in toluene (Scheme 34), however no reaction was observed by ${ }^{1} \mathrm{H}$ NMR spectroscopy at either room temperature or reflux in toluene or THF. This is most likely because the steric repulsion between the BDI ligand and the cyclohexane groups prevented the two reagents getting close enough to undergo salt metathesis.<smiles></smiles>

12

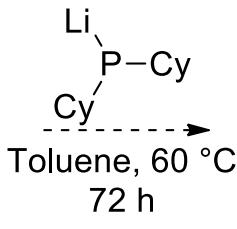
$72 \mathrm{~h}$<smiles></smiles>

28<smiles>CC(C)c1cccc(C(C)C=[Zn])c1N(C)C</smiles>

Scheme 34: Attempted synthesis of [(BDI)Ga(PCy $\left.)_{2}\right]$. 


\subsubsection{Synthesis of $\beta$-Diketiminato-bis(phenylphosphanido)gallium}

The next attempted route was the synthesis of $\left[(\mathrm{BDI}) \mathrm{Ga}(\mathrm{PHPh})_{2}\right]$ to attempt $\alpha$-proton elimination of phenylphosphine and the formation of $[(\mathrm{BDI}) \mathrm{Ga}=\mathrm{PPh}]$. The synthesis was achieved using [(BDI) $\mathrm{GaCl}_{2}$ ] and two equivalents of $\mathrm{PhP}(\mathrm{H}) \mathrm{Li}$ in THF by heating at $60{ }^{\circ} \mathrm{C}$ for 72 hours (Scheme 35) to give the novel compound $\left[(\mathrm{BDI}) \mathrm{Ga}(\mathrm{PHPh})_{2}\right](\mathbf{2 9})$ in $78 \%$ isolated yield.<smiles></smiles>

12

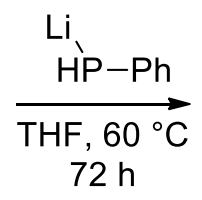

Scheme 35: Synthesis of [(BDI)Ga(PHPh $\left.)_{2}\right]$.

The crude sample was purified by crystallisation from toluene/hexane at $-30^{\circ} \mathrm{C}$ and the crystals were analysed by ${ }^{1} \mathrm{H},{ }^{13} \mathrm{C}$ and ${ }^{31} \mathrm{P}$ NMR spectroscopy, single crystal $\mathrm{X}$-ray diffraction, and elemental analysis. The presence of a BDI $\mathrm{y}-\mathrm{H}$ resonance $(\delta 4.83 \mathrm{ppm}, \mathrm{s}, 1 \mathrm{H})$ and loss of the corresponding starting material resonance $(\delta 4.75 \mathrm{ppm}, \mathrm{s}, 1 \mathrm{H})$ indicated that a reaction had occurred. The ${ }^{1} \mathrm{H}$ NMR spectrum of $\left[(\mathrm{BDI}) \mathrm{Ga}(\mathrm{PHPh})_{2}\right]$ showed three broad resonances $(\delta 3.44,4 \mathrm{H} ; 1.40,12 \mathrm{H} ; 1.03,12 \mathrm{H})$ that corresponded to the isopropyl groups on the BDI ligand. The presence of the P-H was identified through the resonance at $\delta 3.25 \mathrm{ppm}\left(d, J_{\mathrm{PH}}=203.5 \mathrm{~Hz}, 2 \mathrm{H}\right)$, though the coupling could not be compared in the ${ }^{31} \mathrm{P}$ NMR spectrum as the only signal present was a broad resonance at $\delta$-127.3 ppm. The ${ }^{13} \mathrm{C}$ spectrum also showed several broad resonances, but also revealed P-C through space scalar coupling ${ }^{60}$ between the $B D I ~ \gamma-C$ of $13.8 \mathrm{~Hz}$, reinforcing the proposal that both the BDI ligand and the phosphide ligand were bound to the gallium centre.

The X-Ray crystal structure of $\left[(\mathrm{BDI}) \mathrm{Ga}(\mathrm{PHPh})_{2}\right]$ confirms that the lone pairs on the phosphorus atoms are stereochemically active, with both adopting a distorted trigonal pyramidal geometry (Figure 26). The phosphorus hydrogen atoms are syn to each other, and both phosphorus phenyl rings lie on the same side of the $\mathrm{BDI} \mathrm{C}_{3} \mathrm{~N}_{2}$ plane, which contrasts with [(BDI)Ga(NHPh) ${ }_{2}$ ] where the nitrogen phenyl rings are on different sides of the plane. One of the gallium-phosphorus bond lengths $(2.3539(7) \AA)$ is identical to that reported by Rotter et al. for $\left(\mathrm{Mes}^{*}\right)_{2} \mathrm{GaP}(\mathrm{H}) \mathrm{Si}(\mathrm{Pr})_{3}$ 
$(2.353(3) \AA)$ while the second $(2.3419(7) \AA)$ is slightly shorter. The gallium-nitrogen bond lengths $(1.968(2) \& 1.985(2) \AA ̊$ ) are comparable to the other BDI-gallium complexes synthesised in chapters two and three (average $1.97 \AA$ A). The BDI bite angle of $95.10(8)^{\circ}$ is smaller than in [(BDI)Ga(NHPh) $\left.{ }_{2}\right]$ $\left(96.4(1)^{\circ}\right)$, the closest analogue. The gallium sits $0.59 \AA$ above the $C_{3} N_{2}$ plane, which is a comparable distance to both [(BDI)Ga(NHDIPP) $\left.)_{2}\right](0.55 \AA)$ and [(BDI)GaBn $\left.{ }_{2}\right](0.60 \AA)$. The crystal structure did contain one equivalent of toluene in the crystal lattice, modelled over a centre of inversion, however it was determined not to be interacting with the solid state structure of the molecule.

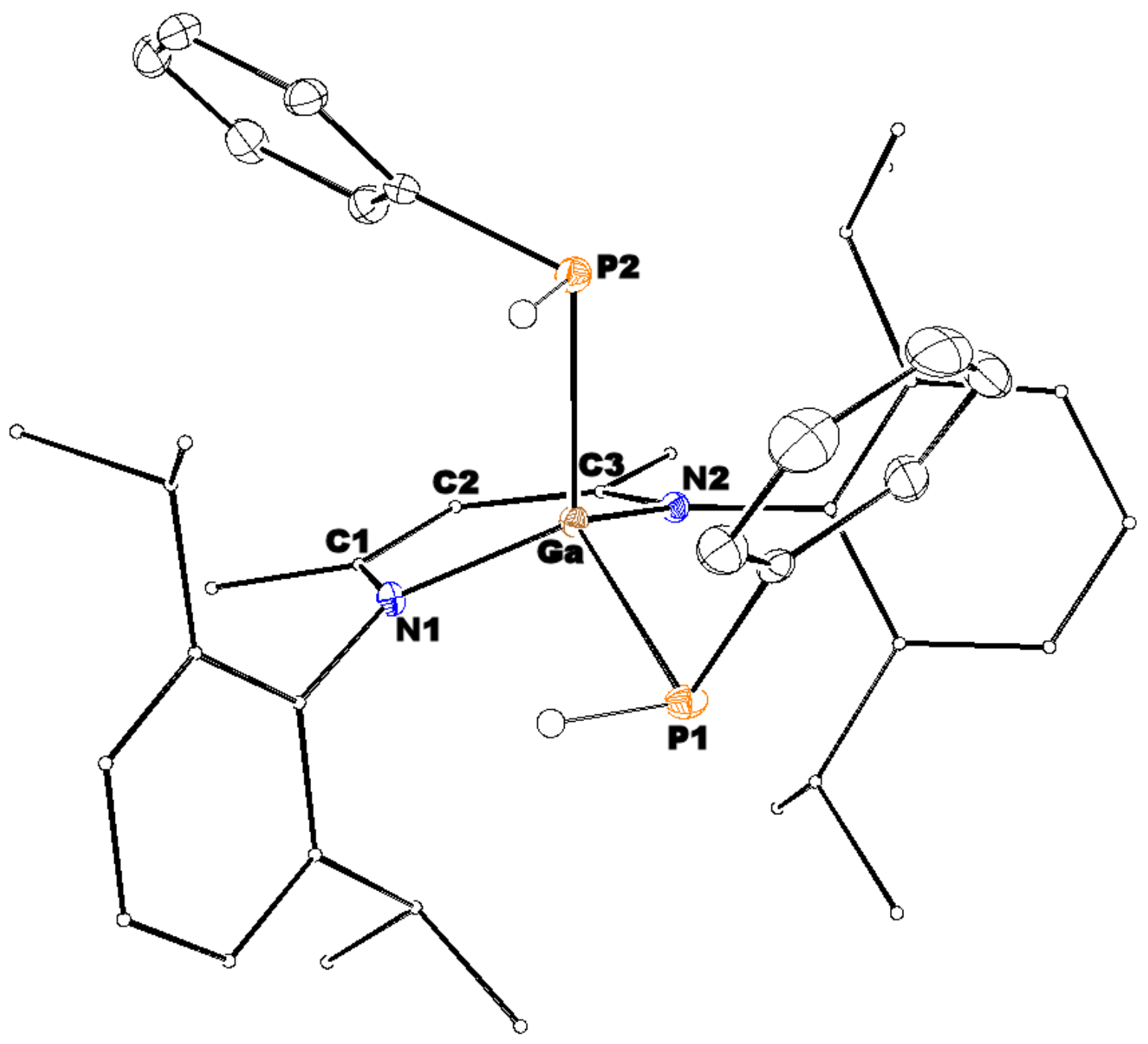

Figure 26: Thermal ellipsoid plot (30\%) of [(BDI)Ga(PHPh) $)_{2}$. Selected $\mathrm{H}$ atoms have been omitted for clarity. Selected structural data are given in Table 9. 
Table 9: Selected bond lengths and angles for $\left[(\mathrm{BDI}) \mathrm{Ga}(\mathrm{PHPh})_{2}\right]$.

\begin{tabular}{|c|c|c|c|}
\hline \multicolumn{2}{|c|}{ Bond Lengths $(\AA)$} & \multicolumn{2}{|c|}{ Bond Angles $\left({ }^{\circ}\right)$} \\
\hline $\mathrm{Ga}(1)-\mathrm{N}(1)$ & $1.968(2)$ & $N(1)-G a(1)-N(2)$ & $95.10(8)$ \\
\hline $\mathrm{Ga}(1)-\mathrm{N}(2)$ & $1.985(2)$ & $P(1)-G a(1)-P(2)$ & $111.71(3)$ \\
\hline $\mathrm{Ga}(1)-\mathrm{P}(1)$ & $2.3419(7)$ & $N(1)-G a(1)-P(1)$ & $110.46(6)$ \\
\hline $\mathrm{Ga}(1)-\mathrm{P}(2)$ & $2.3539(7)$ & $N(1)-G a(1)-P(2)$ & $118.90(6)$ \\
\hline$N(1)-C(1)$ & $1.334(3)$ & $N(2)-G a(1)-P(1)$ & $112.87(6)$ \\
\hline$N(2)-C(3)$ & $1.325(3)$ & $N(2)-G a(1)-P(2)$ & $106.64(6)$ \\
\hline$C(1)-C(2)$ & $1.397(4)$ & $\mathrm{Ga}(1)-\mathrm{N}(1)-\mathrm{C}(1)$ & $120.3(2)$ \\
\hline \multirow[t]{6}{*}{$C(2)-C(3)$} & $1.408(4)$ & $\mathrm{Ga}(1)-\mathrm{N}(2)-\mathrm{C}(3)$ & $120.2(2)$ \\
\hline & & $N(1)-C(1)-C(2)$ & $123.5(2)$ \\
\hline & & $C(1)-C(2)-C(3)$ & $128.7(2)$ \\
\hline & & $C(2)-C(3)-N(2)$ & $123.7(2)$ \\
\hline & & $G a(1)-P(1)-C(30)$ & $97.85(9)$ \\
\hline & & $G a(1)-P(2)-C(36)$ & $105.86(9)$ \\
\hline
\end{tabular}

In $\left[(\mathrm{BDI}) \mathrm{Ga}(\mathrm{PHPh})_{2}\right]$, each of the phosphorus centres is chiral. This leads to the potential of having both RR \& SS, as well as SR \& RS diastereomeric pairs in both solution and solid state. With regards to the latter, the unit cell consists of four molecules of $\left[(\mathrm{BDI}) \mathrm{Ga}(\mathrm{PHPh})_{2}\right]$. Two of these have an RR configuration, while the other two have an SS configuration. As only 'one crystal' was used in the determination of the RR-SS structure, it is unknown if the other diastereomeric pair RS-SR also crystallised.

To investigate this, a variable temperature NMR study was performed on $\left[(\mathrm{BDI}) \mathrm{Ga}(\mathrm{PHPh})_{2}\right]$ $d_{8}$-toluene. At $50{ }^{\circ} \mathrm{C}$, the ${ }^{31} \mathrm{P}$ NMR spectrum consisted of a singlet at $\delta-126.8 \mathrm{ppm}$, while the ${ }^{1} \mathrm{H}$ NMR spectrum showed the BDI $\mathrm{Y}-\mathrm{H}$ resonance as a singlet $(\delta 4.88,1 \mathrm{H})$, the $\mathrm{P}-\mathrm{H}$ resonance as a doublet $\left(\delta 3.16, J_{\mathrm{PH}}=201 \mathrm{~Hz}, 2 \mathrm{H}\right)$, the isopropyl methine resonance as a broad resonance with three resolved peaks $(\delta 3.44,3.42,3.40,4 \mathrm{H})$, the BDI backbone methyl resonance as a singlet $(\delta 1.56$, $6 \mathrm{H})$, and two doublets for the isopropyl methyl resonances $(\delta 1.35, J=6.3 \mathrm{~Hz}, 12 \mathrm{H} ; 1.03, J=6.6 \mathrm{~Hz}$, $12 \mathrm{H})$. At room temperature $\left(24^{\circ} \mathrm{C}\right)$, the ${ }^{31} \mathrm{P}$ NMR spectrum now possessed a broad resonance from $-125 \mathrm{ppm}$ to $-130 \mathrm{ppm}$, the ${ }^{1} \mathrm{H}$ NMR spectrum now possessed three broad resonances for the isopropyl methine and methyl protons $(\delta 3.41,4 \mathrm{H} ; 1.37,12 \mathrm{H} ; 1.03,12 \mathrm{H})$, with all other signals unchanged. Cooling of the sample to $-40{ }^{\circ} \mathrm{C}$ showed that the ${ }^{31} \mathrm{P}$ NMR spectrum now possessed two resonances $\left(\delta-119.0, s ;-126.0, b r\right.$.) and the corresponding ${ }^{1} \mathrm{H}$ NMR spectrum also showed some resonances splitting. The BDI $\mathrm{\gamma}-\mathrm{H}$ resonance split into either a doublet $(\delta 4.81, J=6 \mathrm{~Hz})$ or two 
singlets $(\delta 4.82,4.80)$, as the ${ }^{13} \mathrm{C}$ NMR spectrum showed that there is through space scalar coupling between the BDI $\gamma$-carbon and a phosphorus, this may extend to the proton at low temperature. The methine resonances for the isopropyl groups split into 3-4 broad resonances, with the THF impurity potentially masking the fourth. The methyl substituents on the BDI backbone has become a broad resonance $(\delta 1.57)$, while the isopropyl methyl resonances are now a doublet $(\delta 1.44, J=10.8 \mathrm{~Hz})$ and a broad singlet $(\delta 1.15)$. Upon further cooling to $-80^{\circ} \mathrm{C}$, the ${ }^{31} \mathrm{P}$ NMR spectrum now showed two broad resonances $(\delta-116.5,-138.2)$, while the ${ }^{1} \mathrm{H}$ NMR spectrum showed further splitting of resonances. The BDI $\mathrm{Y}-\mathrm{H}$ resonance remained either two singlets $(\delta 4.77,4.74)$ or a doublet $(\delta 4.76, J$ $=8.1 \mathrm{~Hz}$ ), and methine resonances for the isopropyl groups remained as 3-4 broad resonances, with the THF impurity still potentially masking the fourth. The P-H resonance had broadened slightly, as had the methyl resonance for the BDI backbone. The isopropyl methyl resonances now consisted of one split into a broad resonance $(\delta 1.47)$ and a singlet $(\delta 1.38)$, while the other remained as one broad resonance $(\delta 1.13)$.

These observations indicate that the phosphide ligands freely rotate in the solution phase at high temperature on an NMR timescale; however two conformations can be trapped at low temperatures. The presence of $\mathrm{P}-\mathrm{C}$ through space scalar coupling between the phosphide ligands and the isopropyl methyl substituents of the BDI ligand provides the basis of these two conformations. The two lone pairs on the two phosphide ligands can each interact with one of the four isopropyl groups of the BDI ligand, and these P-Me interactions can be in either the syn- or anticonformations. These two conformations are trapped out separately at low temperature as the rotation of the Ga-P bond is slow relative to the NMR timescale. The approximate energy barrier for this rotation can be calculated using the equation denoted below, ${ }^{61}$ where $T_{c}$ is the temperature of coalescence of the NMR resonances, and $\Delta v$ is the hertz difference between the two resonances at low temperature.

$$
\begin{gathered}
\Delta G_{c}=19.14 T_{c}\left(10.32+\log \frac{T_{c}}{k_{c}}\right) \mathrm{J} \mathrm{mol}^{-1} \\
k_{c}=2.2 \times \Delta v
\end{gathered}
$$


Using the one of the isopropyl methyl resonances ( $\delta 1.44)$ of the BDI ligand splitting of $10.8 \mathrm{~Hz}$ at $-40{ }^{\circ} \mathrm{C}$, and a coalescence temperature of $298 \mathrm{~K}$, the approximate value of $\Delta \mathrm{G}_{\mathrm{c}}=65 \mathrm{~kJ} \mathrm{~mol}^{-1}$ is the energy barrier to the rotation of the Ga-P bond.

\subsubsection{Attempted $\alpha$-proton elimination}

The $\alpha$-proton elimination reaction of $\left[(\mathrm{BDI}) \mathrm{Ga}(\mathrm{PHPh})_{2}\right]$ was first attempted on a $25 \mathrm{mg}$ scale in deuterated benzene. No reaction was observed by ${ }^{1} \mathrm{H}$ NMR spectroscopy at either room temperature or at $80^{\circ} \mathrm{C}$. To attempt to facilitate the transfer of the $\alpha$-proton, the Lewis bases DMAP and TMEDA were independently added to the reaction mixture, however only on a $1 \%$ loading to determine if the base could catalytically facilitate the transfer of the $\alpha$-proton without coordinating to the resulting phosphinidene as previously observed with transition metal carbenes ${ }^{41}$ and imides. ${ }^{44}$ The two bases DMAP and TMEDA were independently added to the solution and the samples monitored for two hours, then heated to $80{ }^{\circ} \mathrm{C}$ after no reaction was observed by ${ }^{1} \mathrm{H}$ NMR spectroscopy. Upon the failure of both bases to catalyse proton transfer, the reaction was repeated on a $100 \mathrm{mg}$ scale in THF to determine if a coordinating solvent could stabilise the resulting phosphinidene complex instead of a coordinating base. No reaction was observed, even when TMEDA or DMAP were added to the reaction mixture. Finally, the reactions were repeated in toluene to increase the reflux temperature to $110^{\circ} \mathrm{C}$, however again no reaction was observed, including when TMEDA or DMAP were added to the reaction mixture. These results are summarised in Table 10. 
Table 10: Reaction conditions for the attempted $\alpha$-proton elimination of $\left[(\mathrm{BDI}) \mathrm{Ga}(\mathrm{PHPh})_{2}\right]$.

\begin{tabular}{|l|l|l|l|l|}
\hline Solvent & Temp. $\left({ }^{\circ} \mathrm{C}\right)$ & Time & Base & Observations \\
\hline $\mathrm{C}_{6} \mathrm{D}_{6}$ & 25 & $2 \mathrm{~h}$ & - & No Reaction \\
\hline $\mathrm{C}_{6} \mathrm{D}_{6}$ & 80 & $12 \mathrm{~h}$ & - & No Reaction \\
\hline $\mathrm{C}_{6} \mathrm{D}_{6}$ & 25 & $2 \mathrm{~h}$ & TMEDA & No Reaction \\
\hline $\mathrm{C}_{6} \mathrm{D}_{6}$ & 80 & $12 \mathrm{~h}$ & TMEDA & No Reaction \\
\hline $\mathrm{C}_{6} \mathrm{D}_{6}$ & 25 & $2 \mathrm{~h}$ & DMAP & No Reaction \\
\hline $\mathrm{C}_{6} \mathrm{D}_{6}$ & 80 & $12 \mathrm{~h}$ & DMAP & No Reaction \\
\hline THF & 25 & $2 \mathrm{~h}$ & - & No Reaction \\
\hline THF & 60 & $12 \mathrm{~h}$ & - & No Reaction \\
\hline THF & 25 & $2 \mathrm{~h}$ & TMEDA & No Reaction \\
\hline THF & 60 & $12 \mathrm{~h}$ & TMEDA & No Reaction \\
\hline THF & 25 & $2 \mathrm{~h}$ & DMAP & No Reaction \\
\hline THF & 60 & $12 \mathrm{~h}$ & DMAP & No Reaction \\
\hline Toluene & 25 & $2 \mathrm{~h}$ & - & No Reaction \\
\hline Toluene & 110 & $12 \mathrm{~h}$ & - & No Reaction \\
\hline Toluene & 25 & $2 \mathrm{~h}$ & DMAP & No Reaction \\
\hline Toluene & 110 & $12 \mathrm{~h}$ & DMAP & No Reaction \\
\hline Toluene & 25 & $2 \mathrm{~h}$ & TMEDA & No Reaction \\
\hline Toluene & 110 & $12 \mathrm{~h}$ & TMEDA & No Reaction \\
\hline
\end{tabular}

Base loaded at $1 \%$

\subsubsection{Synthesis of $\beta$-Diketiminato-chloro-phenylphosphanidogallium}

Once again, the mono-substituted product was observed as a minor component in the ${ }^{1} \mathrm{H}$ NMR spectrum of the crude reaction mixture of the di-substituted product. Synthesis of [(BDI)Ga(PHPh)Cl] through the addition of one equivalent of $\mathrm{PhP}(\mathrm{H}) \mathrm{Li}$ to a solution of $\left[(\mathrm{BDI}) \mathrm{GaCl}_{2}\right]$, both cooled to $-30{ }^{\circ} \mathrm{C}$, resulted in a reaction mixture consisting of $70 \%[(\mathrm{BDI}) \mathrm{Ga}(\mathrm{PHPh}) \mathrm{Cl}]$ with the remaining $30 \%$ an equal amount of $\left[(\mathrm{BDI}) \mathrm{Ga}(\mathrm{PHPh})_{2}\right]$ and $\left[(\mathrm{BDI}) \mathrm{GaCl}_{2}\right]$ (Scheme 36$)$. Purification of the reaction mixture through crystallisation from toluene/hexane yielded a small amount ( $38 \mathrm{mg}, 30 \%$ ) of pure [(BDI)Ga(PHPh)Cl] (31) for characterisation and experimentation.<smiles></smiles>

12

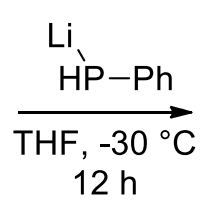

$12 \mathrm{~h}$<smiles></smiles>

31<smiles>CC(C)c1cccc(C(C)C)c1C(C)C</smiles>

Scheme 36: Synthesis of [(BDI)Ga(PHPh)Cl]. 
The crystallised product was characterised by ${ }^{1} \mathrm{H},{ }^{13} \mathrm{C}$ and ${ }^{31} \mathrm{P}$ NMR spectroscopy. The change in the $\mathrm{BDI} \mathrm{\gamma}-\mathrm{H}$ resonance $(\delta 4.88 \mathrm{ppm}, s, 1 \mathrm{H})$ from the corresponding starting material resonance ( $\delta 4.75 \mathrm{ppm}, \mathrm{s}, 1 \mathrm{H}$ ) indicated that a reaction had occurred, but the compound formed was not $\left[(\mathrm{BDI}) \mathrm{Ga}(\mathrm{PHPh})_{2}\right](\delta 4.83 \mathrm{ppm})$. The most notable feature of the ${ }^{1} \mathrm{H}$ NMR spectrum was that there are eight distinct doublet resonances $(\delta 1.58-1.56,1.48,1.33,1.19,1.14,1.10-1.06,1.03)$ and four methine resonances $(\delta 3.77,3.60,3.48-3.37,3.30)$ for the isopropyl groups of the BDI ligand, indicating that the molecule was non-symmetric. The resonance corresponding to the $\mathrm{P}-\mathrm{H}$ hydrogen was observed at $\delta 3.09 \mathrm{ppm}\left(d, J_{\mathrm{PH}}=195 \mathrm{~Hz}, 1 \mathrm{H}\right)$. The ${ }^{1} \mathrm{H}$ coupled ${ }^{31} \mathrm{P}$ NMR spectrum revealed a doublet of triplets at $\delta-151.7 \mathrm{ppm}\left(J_{\mathrm{PH}}=195,7.1 \mathrm{~Hz}\right)$, which is comparable coupling to $\mathrm{P}(\mathrm{H})_{2} \mathrm{Ph}$ $\left(\delta 125.9, t t, J_{\mathrm{PH}}=198.5,7.2 \mathrm{~Hz}\right.$ ). The ${ }^{13} \mathrm{C}$ NMR spectrum confirmed that both the BDI ligand and the phenylphosphide ligand were bound to gallium, as the BDI $\gamma$-carbon and the methyl carbons of the isopropyl groups showed through space scalar coupling to phosphorus of 5-9 Hz. ${ }^{60}$

\subsubsection{Addition of $\boldsymbol{n}$-Butyllithium to $\boldsymbol{\beta}$-Diketiminato-chloro- phenylphosphanidogallium}

The isolated sample of [(BDI)Ga(PHPh)Cl] $(38 \mathrm{mg}, 55 \mu \mathrm{mol})$ was dissolved in THF $(5 \mathrm{~mL})$ and cooled to $-30{ }^{\circ} \mathrm{C}$, ${ }^{\mathrm{n}} \mathrm{BuLi}(40 \mu \mathrm{L}, 60 \mu \mathrm{mol})$ was added slowly and the solution allowed to warm to room temperature and stirred for $12 \mathrm{~h}$ to give an orange solution. The solvent was removed under vacuum and the resulting solid extracted into hexane to give a yellow solution and white precipitate. The solution was filtered through celite to remove the solid and the product was crystallised from hexane at $-30{ }^{\circ} \mathrm{C}$ to give orange crystals $(20 \mathrm{mg})$.

The recrystallised product was characterised by ${ }^{1} \mathrm{H},{ }^{13} \mathrm{C}$ and ${ }^{31} \mathrm{P}$ NMR spectroscopy, and a reaction was deemed to have occurred due to the upfield shift of the BDI $\mathrm{Y}-\mathrm{H}$ resonance $(\delta 4.66 \mathrm{ppm}, \mathrm{s}, 1 \mathrm{H}$ ) from the starting material $(\delta 4.88)$. Unfortunately, the sample contained $17 \%$ of the starting material after recrystallisation, making full characterisation difficult. The presence of a $\mathrm{P}-\mathrm{H}$ resonance $\left(\delta 2.95, d, J_{P H}=192 \mathrm{~Hz}, 1 \mathrm{H}\right)$, and the corresponding ${ }^{1} \mathrm{H}$ coupled ${ }^{31} \mathrm{P}$ resonance $\left(\delta-145.2, d, J_{\mathrm{PH}}=192 \mathrm{~Hz}\right)$ indicated that the product contains a P-H bond. As the chemical shift of the phosphorus resonance is similar to both $\left[(\mathrm{BDI}) \mathrm{Ga}(\mathrm{PHPh})_{2}\right]$ and $[(\mathrm{BDI}) \mathrm{Ga}(\mathrm{PHPh}) \mathrm{Cl}]$, it is doubted that the compound contains a gallium-phosphorus double bond. However the presence of three overlapping doublet resonances in a $1: 1: 1$ ratio $(\delta 1.19,1.16,1.13,6 \mathrm{H}$ each) accounted for only 
three of the four expected isopropyl methyl environments of the BDI ligand. Two singlet resonances $(\delta 1.55,6 \mathrm{H} ; 1.52,6 \mathrm{H})$ were also observed, one of which can be assigned to the methyl substituents of the BDI backbone. Thus the remaining resonance must be assigned to the fourth 'isopropyl' group. The change in multiplicity from a doublet to a singlet indicates the loss of the methine proton on this group, though this could not be confirmed as the methine resonances for the product overlap with those of the starting material, making integrals unreliable. If the methine proton has indeed been abstracted as hypothesised, the lack of $\mathrm{Li}-\mathrm{H}$ coupling in the corresponding methyl groups would indicate that the isolated product is not the lithium salt, and that the observed precipitate was likely lithium chloride. The presence of a carbon resonance at $\delta 14.0 \mathrm{ppm}$ could indicate the presence of a metal-carbon bond, as it is similar to the $\mathrm{Ga}-\mathrm{CH}_{2}-\mathrm{Ph}$ resonance in [(BDI) $\mathrm{GaBn}_{2}$ ] of $\delta 21.6 \mathrm{ppm}$. Together this spectroscopic data indicates that a bond has formed between a former isopropyl group of the BDI ligand and the gallium (Scheme 37).

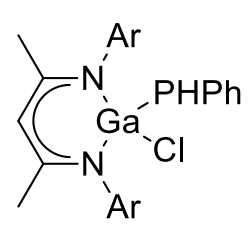

31

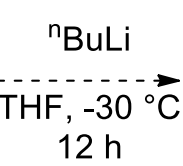

$12 \mathrm{~h}$

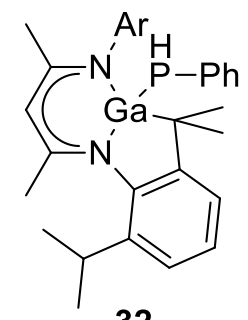

32

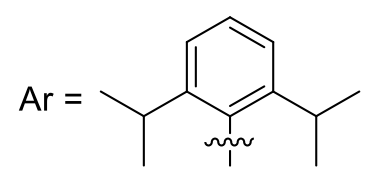

Scheme 37: Possible gallium-carbon bond formation.

This proposed product (32), however, is unlikely to have been formed due to the abstraction of the methine proton by ${ }^{\mathrm{n}} \mathrm{BuLi}$, as the only reported example of the BDI methine protons being abstracted is in the complex $\mathrm{BDI}-\mathrm{Ti}(\mathrm{X})=\mathrm{C}(\mathrm{H}){ }^{\mathrm{t}}{ }^{\mathrm{t}} \mathrm{Bu}(\mathrm{X}=\mathrm{OTf}, \mathrm{I})$. In this complex, the titanium carbene activated the methine $\mathrm{C}-\mathrm{H}$ bonds of the $\mathrm{BDI}$ ligand, abstracting two of them to eliminate neopentane and form two titanium-carbon bonds (Scheme 38 ). ${ }^{62}$ 

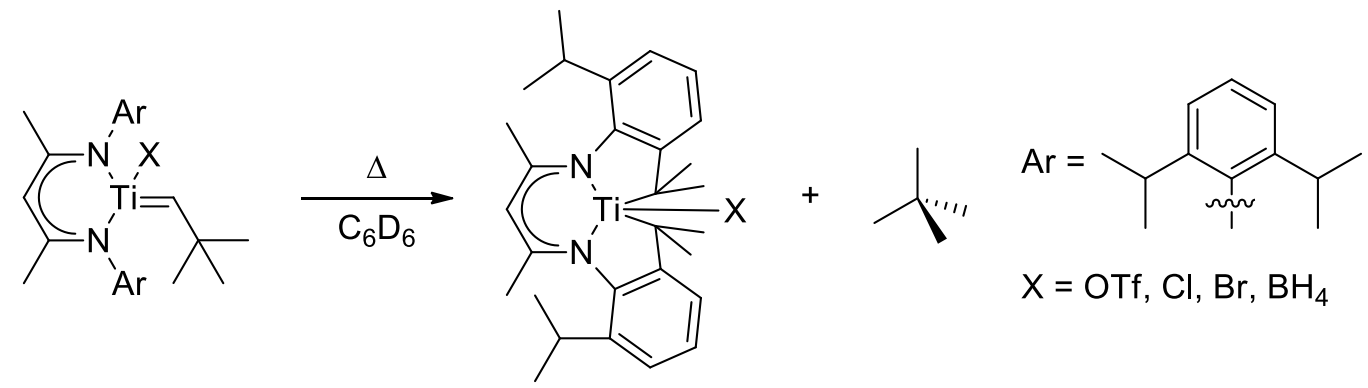

Scheme 38: Formation of titanium-carbon bonds using the BDI ligand.

This activation of the methine $\mathrm{C}-\mathrm{H}$ bond by a metal-carbon double bond could be exhibited by a gallium-phosphorus double bond, as their reactivity is unknown. It is possible that the gallium phosphorus double bond was formed in this reaction as planned; however, it may then have reacted with the nearby isopropyl groups of the BDI ligand (Scheme 39). Repeating this reaction with the 2,6-di-tert-butyl analogue of the BDI ligand would remove the methine protons from the reaction and increase the likelihood of trapping any potential gallium-phosphinidene intermediate.

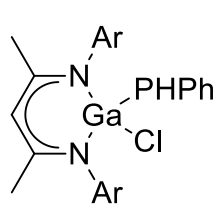

31

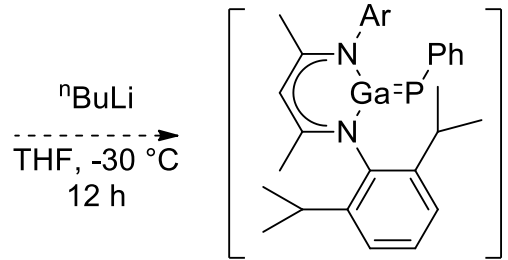

1b

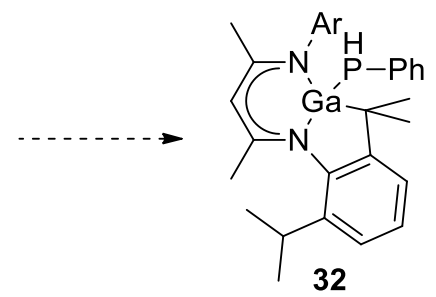

32<smiles>CC(C)c1cccc(C(C)C)c1N(C)C</smiles>

Scheme 39: Possible gallium-phophinidene intermediate.

This mechanism could also be investigated through the use of deuterated reagents. Substituting the PHPh ligand for a PDPh ligand would remove the phosphide resonance from the starting material, and if the phosphinidene intermediate is formed as proposed, a phosphide $\mathrm{P}-\mathrm{H}$ resonance would appear after the proposed abstraction of the $\mathrm{C}-\mathrm{H}$ proton. Another potential reaction mechanism is that, upon addition of ${ }^{n} \mathrm{BuLi}, \sigma$-bond metathesis occurred at the gallium-chlorine bond to form $\mathrm{LiCl}$ and add a butyl chain to the gallium centre. This butyl chain then abstracted the nearby methine proton of the BDI ligand to eliminate butane and form the theorised gallium-carbon bond 
to the isopropyl group. Investigation of these potential reaction pathways using mechanistic NMR spectroscopy studies, such as repeating the reaction in $d_{8}$-tolune at low temperatures, would identify which of these possible mechanisms is occurring, or possibly identify a completely different mechanism to those proposed.

\subsection{Concluding Remarks}

The synthesis of $\beta$-diketiminato-gallium phosphinidene complexes was attempted through both $\alpha$-proton elimination reactions and addition of ${ }^{\mathrm{n}} \mathrm{BuLi}$ to $[(\mathrm{BDI}) \mathrm{Ga}(\mathrm{PHPh}) \mathrm{Cl}]$. The diphosphido complex, $\left[(\mathrm{BDI}) \mathrm{Ga}(\mathrm{PHPh})_{2}\right]$, was unreactive to $\alpha$-proton elimination reactions at high temperatures and/or with Lewis base catalysts in both toluene and THF. While this reactivity could be examined using more sterically hindered phosphanide ligands, such as $\mathrm{H}_{2} \mathrm{P}\left(2,4,6{ }^{\mathrm{t}} \mathrm{BuPh}\right)$, increasing the steric bulk of the analide ligand did not affect the $\alpha$-proton elimination reaction in the analogous dianilido complexes, therefore a similar result would be expected. The second route determined that $[(\mathrm{BDI}) \mathrm{Ga}(\mathrm{PHPh}) \mathrm{Cl}]$ does undergo a reaction with ${ }^{\mathrm{n}} \mathrm{BuLi}$, however the product has been tentatively identified as forming a gallium-carbon bond to an isopropyl group on the BDI ligand (32) (Figure 27). While this product could have been mechanistically formed through a BDI-gallium phosphinidene intermediate, the desired phosphinidene target $\mathbf{2} \mathbf{b}$ was not isolated. Future studies utilising the 2,6-di-tert-butyl analogue of the BDI ligand would remove these methine protons from the vicinity of the potential gallium-phosphorus double bond, potentially allowing for its isolation and characterisation. Alternatively, mechanistic studies using either a deuterated phosphanide ligand or deuterated BDI ligand would determine if a phosphinidene intermediate was formed during the reaction.

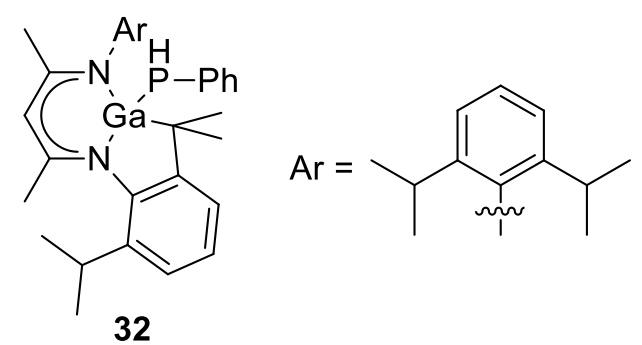

Figure 27: Proposed product of gallium-carbon bond formation. 


\section{Chapter 5}

\section{Alkoxides}

Alkoxide complexes of p-block elements are useful polymerisation catalysts, and as such synthetic strategies towards $\beta$-diketiminatogallium alkoxide complexes have been examined. The BDI ligand may impart useful stereochemical control on any polymerisation activity possessed by gallium alkoxides, and merits investigation.

\subsection{Introduction}

As stated in chapter one, $\mathrm{p}$-block alkoxides have been used for the polymerisation of lactic acid and glycolic acid, but also for $\varepsilon$-caprolactone, another biodegradable, renewable polymer. ${ }^{63}$ The alkoxide ligands on the metal centre readily form hydrogen bonds with an alcohol used to initiate the ring opening metathesis polymerisation reaction. These hydrogen bonds help bind the polymer chain to the metal centre, and facilitate the nucleophilic attack on the monomer by the alcohol functionality. Upon ring opening of the monomer, the alcohol reforms and the hydrogen bond to the alkoxide ligand causes the polymer chain to orientate away from the metal centre, allowing the coordination of another monomer unit to the metal centre (Figure $28, \mathrm{~L}=$ identical mechanism with the second Oct ligand). ${ }^{63}$ 


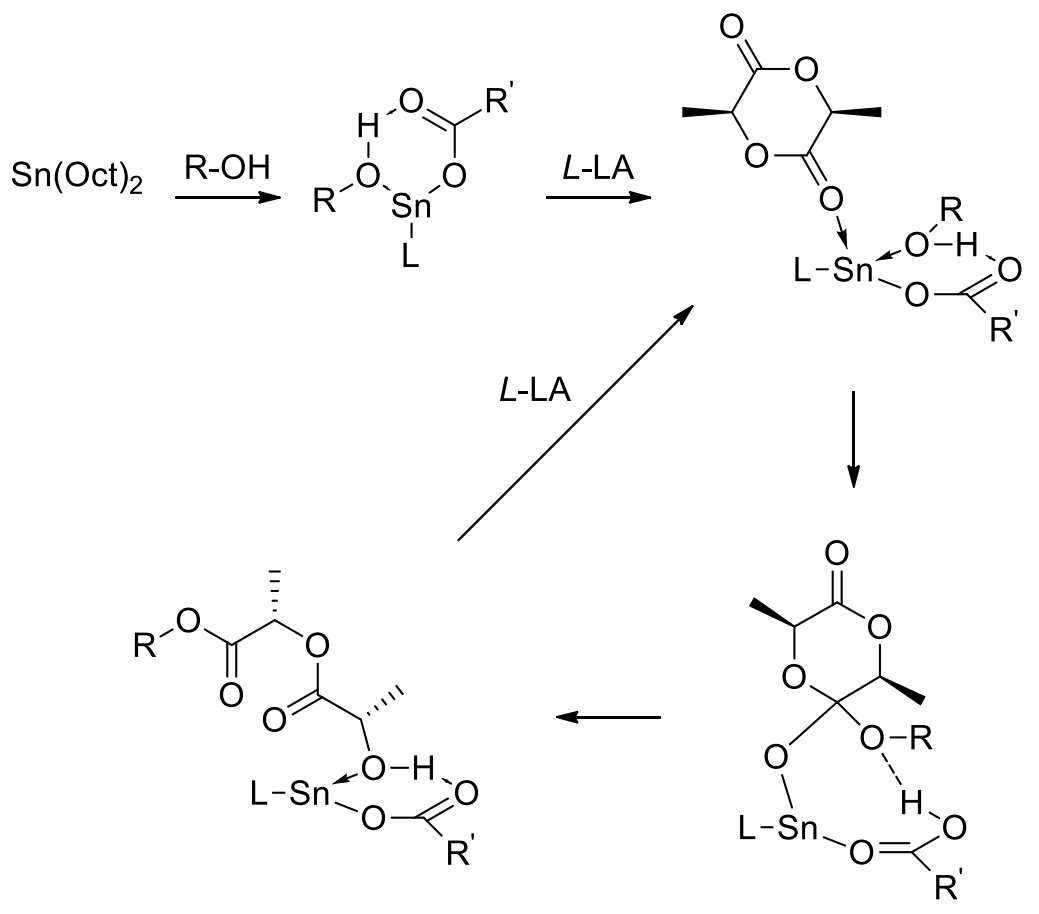

Figure 28: Polymerisation of the $L$-lactic acid dimer by $\operatorname{Sn}(\mathrm{Oct})_{2}$. Figure redrawn from Chen et al. ${ }^{63}$

\subsection{1 p-Block Alkoxides}

The BDI ligand has previously been coordinated to tin(II) to create the lactide polymerisation catalyst [(BDI)Sn(O'Pr)], which can be readily formed through the addition of 'Pr-OLi to a solution of [(BDI)SnCl], forming the alkoxide through salt metathesis. ${ }^{64}$ Other $\beta$-diketiminato-metal alkoxide complexes used for polymerisation catalysts are prepared using the same reaction, for example the preparation of $\left[(\mathrm{BDI}) \mathrm{Zn}\left(\mathrm{O}^{\mathrm{i}} \mathrm{Pr}\right)\right]$ is achieved through salt metathesis. ${ }^{65}$ Simple aluminium ${ }^{66}$ and germanium ${ }^{67}$ alkoxides used as polymerisation catalysts are also prepared in this manner, such as $\mathrm{Al}\left(\mathrm{O}^{\mathrm{i} P r}\right)_{3}$ and $\mathrm{Ge}\left(\mathrm{O}^{\mathrm{i} P r}\right)_{4}$ (Figure 29).<smiles>CC(C)O[Al](OC(C)C)OC(C)C</smiles><smiles>CC(C)O[Ge](OC(C)C)(OC(C)C)OC(C)C</smiles><smiles></smiles><smiles>CC(C)c1cccc(C(C)C)c1C(C)(C)C</smiles>

Figure 29: Known p-block alkoxide catalysts. 


\subsection{Synthetic Strategy}

The synthesis of $\beta$-diketiminato-gallium-alkoxide complexes was investigated through two main routes. The first involved the addition of alkoxide potassium salts (R-O-K) to $\left[(\mathrm{BDI}) \mathrm{GaCl}_{2}\right]$, to attempt formation through salt metathesis. The second explored the reactivity of alcohols (R-O-H) with [(BDI) $\left.\mathrm{GaMe}_{2}\right]$, attempting formation through the elimination of methane (Scheme 40).

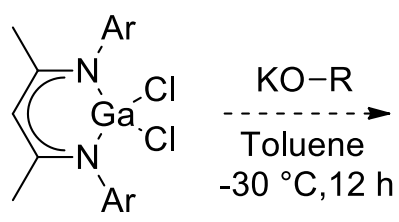

12

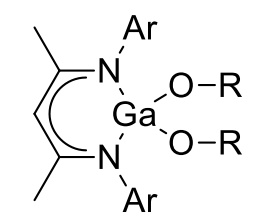

$33 \mathrm{R}={ }^{\mathrm{i}} \mathrm{Pr}$

$34 \mathrm{R}={ }^{\mathrm{t}} \mathrm{Bu}$

$35 \mathrm{R}=\mathrm{Ph}$

$36 \mathrm{R}=2,6-{ }^{\mathrm{t}} \mathrm{BuC}_{6} \mathrm{H}_{3}$

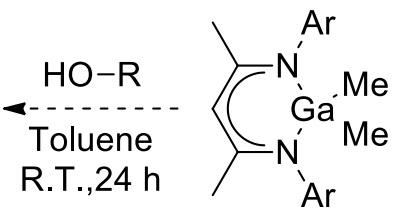

20

Scheme 40: Two potential routes to $\beta$-diketiminato-gallium alkoxides.

\subsection{Results and Discussion}

\subsubsection{Attempted Synthesis of $\beta$-Diketiminato- bis(isopropoxido)gallium}

The synthesis of $\left[(\mathrm{BDI}) \mathrm{Ga}\left(\mathrm{O}^{\mathrm{i}} \mathrm{Pr}\right)_{2}\right]$ (33) was first attempted through the addition of two equivalents of ${ }^{\mathrm{i}} \mathrm{PrOK}$ to a solution of $\left[(\mathrm{BDI}) \mathrm{GaCl}_{2}\right]$. This resulted in the formation of a large volume of white precipitate after 12 hours. ${ }^{1} \mathrm{H}$ NMR spectroscopy of the reaction mixture showed the presence of $\left[(\mathrm{BDI}) \mathrm{GaCl}_{2}\right], \mathrm{BDI}-\mathrm{H}$ and three other resonances for the $\mathrm{BDI} \gamma-\mathrm{H}(\delta 4.84,4.78,4.74)$, indicating that several reactions had occurred giving different products. An interesting resonance was present at $\delta 0.01 \mathrm{ppm}(\mathrm{s}, 3 \mathrm{H})$ which implied there was a methyl group bound to gallium, as it was in the region of the resonance observed in the spectrum of $\left[(\mathrm{BDI}) \mathrm{GaMe}_{2}\right](\delta-0.17 \mathrm{ppm}, \mathrm{s}, 6 \mathrm{H})$, though it is uncertain as to exactly what this resonance corresponded to. While the major product of the reaction $(\delta 4.78 \mathrm{ppm}, s)$ did appear to be $\left[(\mathrm{BDI}) \mathrm{Ga}\left(\mathrm{O}^{\mathrm{i} P r}\right)_{2}\right]$ based on the ${ }^{1} \mathrm{H}$ NMR spectrum, this was unable to be isolated, as purification of the crude reaction mixture yielded only $\left[(\mathrm{BDI}) \mathrm{GaCl}_{2}\right]$ and 
$\mathrm{BDI}-\mathrm{H}$ when extracted into toluene, hexane and diethyl ether. Attempts to purify in THF were also unsuccessful as the $\mathrm{KCl}$ by-product could not be removed from the reaction mixture.

The second attempt at the synthesis of $\left[(\mathrm{BDI}) \mathrm{Ga}\left(\mathrm{O}^{\mathrm{i}} \mathrm{Pr}\right)_{2}\right]$ involved mixing two equivalents of ' $\mathrm{PrOH}$ with a solution of [(BDI)GaMe $\mathrm{Ge}_{2}$, which after 24 hours resulted in the presence of a large quantity of a rubbery white solid that possessed a mild blue fluorescence. This solid was insoluble in both $\mathrm{C}_{6} \mathrm{D}_{6}$ and $\mathrm{CDCl}_{3}$, however the ${ }^{1} \mathrm{H}$ NMR spectrum of the crude reaction mixture showed that the major product of the reaction was $\mathrm{BDI}-\mathrm{H}$, indicating that the BDI ligand had been preferentially protonated over the methyl ligands. The mildly-fluorescent solid could potentially be the dimer, $\left(\mathrm{Me}_{2} \mathrm{Ga}\left(\mathrm{O}^{\mathrm{i}} \mathrm{Pr}\right)\right)_{2}$, described in a patent application as being formed through the addition of $\mathrm{Cp}-\mathrm{GaMe}_{2}$ to ${ }^{\mathrm{i}} \mathrm{PrOH}^{68}{ }^{6}$ with other dimeric complexes $\left(\left(R_{a}\right)\left(R_{b}\right) G a\left(O R_{c}\right)\right)_{2}\left(R_{a} \& R_{b}=M e\right.$, Et; $R_{c}=M e$, Et, 'Pr, $\left.{ }^{t} B u\right)$ also being described. However the patent application describes these dimers to be mainly liquids at room temperature, and does not differentiate between the properties of the individual complexes such as fluorescence. Alternatively the white solid could potentially be the polymeric form of the monomer - $\left(\mathrm{Me}_{2} \mathrm{Ga}\left(\mathrm{O}^{\mathrm{P} P r}\right)\right)$ - (Figure 30), as the reaction time of 24 hours is much longer than the one hour used to generate the dimer, and the dimer is generated using diethyl ether as the solvent as opposed to toluene. Further investigation of the solid by mass spectrometry would differentiate between these two likely possibilities, however due to time constraints this avenue was not pursued further.

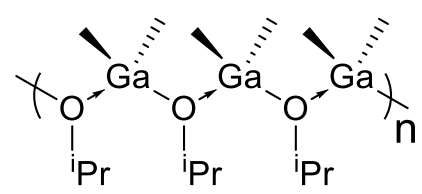

Figure 30: Dialkyl gallium alkoxide polymer.

\subsubsection{Attempted Synthesis of $\beta$-Diketiminato- bis(tert-butoxido)gallium}

The first attempted synthesis of [(BDI)Ga( $\left.\left(\mathrm{O}^{\mathrm{t}} \mathrm{Bu}\right)_{2}\right](34)$ utilised the addition of two equivalents of ${ }^{\mathrm{t}} \mathrm{BuOK}$ to a solution of $\left[(\mathrm{BDI}) \mathrm{GaCl}_{2}\right]$, which resulted in the formation of a large volume of white precipitate after 12 hours. ${ }^{1} \mathrm{H}$ NMR spectroscopy of the reaction mixture showed the presence of 
[(BDI) $\left.\mathrm{GaCl}_{2}\right], \mathrm{BDI}-\mathrm{H}$ and two other resonances for the $\mathrm{BDI} \gamma-\mathrm{H}(\delta 4.73,4.61)$, indicating that multiple products were formed. Again, the solubility of the product hindered purification efforts, with extraction of the two products into toluene, hexane and diethyl ether all only isolating [(BDI) $\left.\mathrm{GaCl}_{2}\right]$ and $\mathrm{BDI}-\mathrm{H}$ from the reaction mixture. The insolubility of the white precipitate could be attributed to the formation of a gallium alkoxide polymer, as the presence of $\mathrm{BDI}-\mathrm{H}$ in the reaction mixture indicates that the BDI ligand was protonated to some extent, though this could just be due to a possible residual ${ }^{\mathrm{t}} \mathrm{BuOH}$ impurity in the ${ }^{\mathrm{t}} \mathrm{BuOK}$. More polar solvents such as chloroform could be used to attempt the extraction of both the $\left[(\mathrm{BDI}) \mathrm{Ga}\left(\mathrm{O}^{\mathrm{t}} \mathrm{Bu}\right)_{2}\right]$ and $\left[(\mathrm{BDI}) \mathrm{Ga}\left(\mathrm{O}^{i} \mathrm{Pr}\right)_{2}\right]$ crude reaction mixtures to determine if the products can be purified for full characterisation.

The second attempted synthesis of $\left[(\mathrm{BDI}) \mathrm{Ga}\left(\mathrm{O}^{\mathrm{t}} \mathrm{Bu}\right)_{2}\right]$ combined two equivalents of ${ }^{\mathrm{t}} \mathrm{BuOH}$ to a solution of $\left[(\mathrm{BDI}) \mathrm{GaMe}_{2}\right]$, which resulted in the formation of a white solid after 24 hours. This solid was insoluble in both $\mathrm{C}_{6} \mathrm{D}_{6}$ and $\mathrm{CDCl}_{3}$, and the ${ }^{1} \mathrm{H}$ NMR spectrum of the crude reaction mixture showed that the major isolated product of the reaction was BDI-H, as observed in the attempted synthesis of $\left[(\mathrm{BDI}) \mathrm{Ga}\left(\mathrm{O}^{\mathrm{i} P r}\right)_{2}\right]$ using this route, indicating that the $\mathrm{BDI}$ ligand had again been preferentially protonated over the methyl ligands. It was therefore assumed that the product of the reaction was $\left(\mathrm{Me}_{2} \mathrm{Ga}\left(\mathrm{O}^{t} \mathrm{Bu}\right)\right)$, either in dimer form as previously reported ${ }^{68}$ or polymer form that could potentially arise from either ring opening polymerisation of the dimer or direct polymer formation due to different reaction conditions, which could be confirmed by mass spectrometry.

\subsubsection{Attempted Synthesis of $\beta$-Diketiminato-bis(phenoxido)gallium}

The synthesis of $\left[(\mathrm{BDI}) \mathrm{Ga}(\mathrm{OPh})_{2}\right](35)$ was attempted through the addition of two equivalents of $\mathrm{PhOH}$ to a solution of [(BDI)GaMe $\mathrm{Ga}_{2}$, which resulted in the formation of a white solid after 24 hours. This solid was insoluble in both $\mathrm{C}_{6} \mathrm{D}_{6}$ and $\mathrm{CDCl}_{3}$, and the only observed resonances in the ${ }^{1} \mathrm{H}$ NMR spectrum of the crude reaction were those of $\mathrm{BDI}-\mathrm{H}$, as observed in the attempted synthesis of $\left[(\mathrm{BDI}) \mathrm{Ga}\left(\mathrm{O}^{\prime} \mathrm{Pr}\right)_{2}\right]$ using this route, indicating that the $\mathrm{BDI}$ ligand had again been preferentially protonated over the methyl ligands. It was assumed that this solid consisted mainly of $\left(\mathrm{Me}_{2} \mathrm{Ga}(\mathrm{OPh})\right)$, possibly in the same dimer form observed for $\left(\mathrm{Me}_{2} \mathrm{Ga}\left(\mathrm{O}^{\prime} \mathrm{Pr}\right)\right)$ and $\left(\mathrm{Me}_{2} \mathrm{Ga}\left(\mathrm{O}^{\mathrm{t}} \mathrm{Bu}\right)\right)$ as the phenoxy ligand is of similar bulk. 


\subsubsection{Attempted Synthesis of $\beta$-Diketiminato-bis(2,6-di-tert- butylphenoxido)gallium}

The attempted synthesis of $\left[(\mathrm{BDI}) \mathrm{Ga}\left(\mathrm{O}-2,6-{ }^{\mathrm{t}} \mathrm{Bu}_{2} \mathrm{C}_{6} \mathrm{H}_{3}\right)_{2}\right]$ (36) involved the addition of two equivalents of $\left(2,6{ }^{\mathrm{t}} \mathrm{Bu}_{2} \mathrm{C}_{6} \mathrm{H}_{3}\right) \mathrm{OH}$ to a solution of $\left[(\mathrm{BDI}) \mathrm{GaMe}_{2}\right]$, which resulted in the formation of a dark brown solid after 24 hours. This solid was insoluble in both $\mathrm{C}_{6} \mathrm{D}_{6}$ and $\mathrm{CDCl}_{3}$, and the only resonances observed in the ${ }^{1} \mathrm{H}$ NMR spectrum of the crude reaction were those that corresponded to $\mathrm{BDI}-\mathrm{H}$, as in the attempted synthesis of $\left[(\mathrm{BDI}) \mathrm{Ga}\left(\mathrm{O}^{\mathrm{i}} \mathrm{Pr}\right)_{2}\right]$, indicating that increasing the steric restrictions around the alcohol functionality does not prevent the BDI ligand from being preferentially protonated over the methyl ligands, which are much less sterically hindered. It was assumed that this solid consisted mainly of $\left(\mathrm{Me}_{2} \mathrm{Ga}\left(\mathrm{O}-2,6-{ }^{\mathrm{t}} \mathrm{Bu}_{2} \mathrm{C}_{6} \mathrm{H}_{3}\right)\right)$, potentially in the same dimer form that has been previously observed for $\left(\mathrm{Me}_{2} \mathrm{Ga}-\left(\mathrm{O}^{\mathrm{i}} \mathrm{Pr}\right)\right)$ and $\left(\mathrm{Me}_{2} \mathrm{Ga}\left(\mathrm{O}^{\mathrm{t}} \mathrm{Bu}\right)\right)$, though the extra steric bulk of the tert-butyl substituents may prevent dimerisation.

\subsection{Concluding Remarks}

The synthesis of $\beta$-diketiminato-gallium alkoxides and aryloxides was attempted through two main routes. The first route targeted the formation of $\beta$-diketiminato-gallium alkoxides using salt metathesis between $\left[(\mathrm{BDI}) \mathrm{GaCl}_{2}\right]$ and the potassium salt of an alcohol (R-OK). The target alkoxide complexes were potentially formed, however their minimal solubility in the available purification solvents of toluene, hexane, diethyl ether, and THF resulted in the products being unable to be purified and characterised to confirm their identities. Purification using alternative solvent systems, such as dichloromethane, chloroform or acetonitrile, could help isolate the products of these reactions and allow for full characterisation. The second route attempted formation of $\beta$ diketiminato-gallium alkoxides and aryloxides using [(BDI)GaMe $\mathrm{Gand}_{2}$ and alcohol to protonate the methyl ligand and eliminate methane. Addition of each the attempted alcohols to [(BDI)GaMe $\left.\mathrm{G}_{2}\right]$ resulted in the formation of solids that were insoluble in both $\mathrm{C}_{6} \mathrm{D}_{6}$ and $\mathrm{CDCl}_{3}$, and the major product of the reaction was $\mathrm{BDI}-\mathrm{H}$, indicating that the $\mathrm{BDI}$ ligand is more labile than the methyl ligands. The products were tentatively identified as $\left(\left(\mathrm{Me}_{2}\right) \mathrm{Ga}(\mathrm{O}-\mathrm{R})\right)$ complexes, which have previously been reported as dimers where $\mathrm{R}={ }^{\mathrm{t}} \mathrm{Bu} \&{ }^{\mathrm{i}} \mathrm{Pr}$, though this could not be confirmed due to solubility issues. 


\section{Chapter 6}

\section{Concluding Remarks}

The change in the behaviour of the heavier elements of the p-block from their lighter counterparts allows them to form a diverse range of coordination complexes that possess both stoichiometric and catalytic reactivity in a wide range of situations. Further investigation into the coordination complexes of the p-block will uncover new reactive functionalities potentially useful in industry and biological systems. This study identified seven new coordination complexes of $\beta$-diketiminatogallium with carbon, nitrogen, and phosphorus bound ligands, consisting of [(BDI)GaBn ${ }_{2}$ ], [(BDI)Ga(NHDMP) $\left.)_{2}\right],\left[(B D I) G a(N H D I P P)_{2}\right],[(B D I) G a(N H D M P) C l],[(B D I) G a(N H D I P P) C l]$, $\left[(\mathrm{BDI}) \mathrm{Ga}(\mathrm{PHPh})_{2}\right]$, and [(BDI)Ga(PHPh)Cl]. Other potentially synthesised but not isolated complexes were $[(\mathrm{BDI}) \mathrm{Ga}(\mathrm{NHPh}) \mathrm{Cl}],\left[(\mathrm{BDI}) \mathrm{Ga}\left(\mathrm{O}^{\mathrm{t}} \mathrm{Bu}\right)_{2}\right]$ and $\left[(\mathrm{BDI}) \mathrm{Ga}\left(\mathrm{O}^{\mathrm{i} P r}\right)_{2}\right]$.

It was determined that $\beta$-diketiminatogallium complexes that have been di-substituted with benzyl-, anilato-, and phenylphosphanido- ligands are unreactive to the $\alpha$-proton elimination reactions observed in transition metal complexes. These compounds remained unreactive in the presence of coordinating solvents, strong bases, and at temperatures of up to $110^{\circ} \mathrm{C}$. Increasing the steric bulk of the ligand substituents at the two and six positions from $-\mathrm{H}$, to $-\mathrm{Me}$, to - $\mathrm{Pr}$ also had no effect on the reactivity of $\beta$-diketiminatogallium bis-anilato complexes towards $\alpha$-proton elimination. Future work would involve examining the effect of increasing the steric bulk on the $\beta$-diketiminatogallium bis-benzyl and bis-phenylphosphanido analogues. Also, increasing the steric bulk of the substituents examined to include ${ }^{\mathrm{t}} \mathrm{Bu}$ substituents.

The addition of ${ }^{\mathrm{n}} \mathrm{BuLi}$ to solutions of [(BDI)Ga(NHDMP)Cl] and [(BDI)Ga(PHPh)Cl] indicated that a reaction had occurred as observed by ${ }^{1} \mathrm{H}$ NMR spectroscopy, though the products in the reaction mixture of $[(\mathrm{BDI}) \mathrm{Ga}(\mathrm{NHDMP}) \mathrm{Cl}]$ could not be separated. The product of the addition of ${ }^{\mathrm{n}} \mathrm{BuLi}$ to [(BDI)Ga(PHPh)Cl] was isolated, albeit with a small starting material impurity that hindered full characterisation. Preliminary assignment of the ${ }^{1} \mathrm{H}$ NMR spectrum of this product indicates that a bond has formed between gallium and the methine carbon of an isopropyl group of the BDI ligand, which could have occurred through a gallium phosphinidene intermediate. Future work would 
involve further purification and full characterisation of this product coupled with mechanistic studies. Provided the proposed structure is correct, isotopically labelled ligands would determine if a gallium phosphinidene intermediate is formed. This would then allow the reaction conditions to be modified to improve the possibilities of trapping this potential intermediate.

The formation of $\beta$-diketiminatogallium alkoxides was potentially achieved for the complexes $\left[(\mathrm{BDI}) \mathrm{Ga}\left(\mathrm{O}^{\mathrm{t}} \mathrm{Bu}\right)_{2}\right]$ and $\left[(\mathrm{BDI}) \mathrm{Ga}\left(\mathrm{O}^{\mathrm{i}} \mathrm{Pr}\right)_{2}\right]$ utilising a salt metathesis mechanism, however solubility issues meant a pure sample could not be isolated for characterisation. The attempted formation of [(BDI)Ga( $\left.\left(\mathrm{O}^{\mathrm{t}} \mathrm{Bu}\right)_{2}\right],\left[(\mathrm{BDI}) \mathrm{Ga}\left(\mathrm{O}^{\mathrm{i} P r}\right)_{2}\right],\left[(\mathrm{BDI}) \mathrm{Ga}(\mathrm{OPh})_{2}\right]$ and $\left[(\mathrm{BDI}) \mathrm{Ga}\left(\mathrm{O}-2,6{ }^{\mathrm{t}}{ }^{\mathrm{BuPh}}\right)_{2}\right]$ using [(BDI)GaMe $\left.{ }_{2}\right]$ as a starting material presumably resulted in the formation of $\left(\mathrm{Me}_{2} \mathrm{Ga}(\mathrm{O}-\mathrm{R})\right)_{\mathrm{x}}$, where $\mathrm{x} \geq 2$. These solids were insoluble in NMR solvents, preventing their characterisation, though in future mass spectrometry could be employed to determine if the solid is monomeric, dimeric, or polymeric.

Overall, none of the targeted structures were isolated using the methods proposed, though the addition of ${ }^{\mathrm{n}} \mathrm{BuLi}$ to the mixed $\beta$-diketiminato-chloro-phenylphosphanidogallium complex is still being investigated for the potential formation of target compound $\mathbf{3} \mathbf{b}$ as an intermediate, which if successful in the isolation of $\mathbf{3 b}$ would give a methodology for investigation of the analogous carbon (1a-c) and nitrogen (2a-c) containing target complexes. 


\section{Appendix A: Experimental}

\section{General}

All manipulations were carried out under dry nitrogen using standard Schlenk-line and cannula techniques, or in a conventional nitrogen-filled glovebox. Solvents were dried using a PureSolv. system (Innovative Technologies). NMR spectra were recorded in $\mathrm{C}_{6} \mathrm{D}_{6}$ at $298 \mathrm{~K}$ (unless otherwise stated), using a Varian INOVA system at $300 \mathrm{MHz}\left({ }^{1} \mathrm{H}\right), 75 \mathrm{MHz}\left({ }^{13} \mathrm{C}\left\{{ }^{1} \mathrm{H}\right\}\right)$ or $121 \mathrm{MHz}\left({ }^{31} \mathrm{P}\left\{{ }^{1} \mathrm{H}\right\}\right)$. Proton and carbon chemical shifts were referenced internally to residual solvent resonances. Elemental analyses were performed by S. Boyer at London Metropolitan University. All compounds were purchased from Sigma-Aldrich chemical company. Anilines were distilled before use. Liquids were subjected to $3 \times$ freeze-pump-thaw cycles, and stored under nitrogen in the glovebox.

\section{$\left.\mathrm{CH}\left\{\mathrm{C}(\mathrm{Me}) \mathrm{NH}\left(\mathrm{C}_{6} \mathrm{H}_{3}-2,6-{ }^{\mathrm{i}} \mathrm{Pr}_{2}\right)\right\} \mathrm{C}(\mathrm{Me}) \mathrm{N}\left(\mathrm{C}_{6} \mathrm{H}_{3}-2,6-{ }^{\mathrm{i}} \mathrm{Pr}_{2}\right)\right\}\left(\mathrm{BDI}_{\mathrm{DIPP}}-\mathrm{H}\right)$ (11)}

This compound was prepared following literature procedure. ${ }^{69}$ Acetylacetone $(10.2 \mathrm{~mL}$, $100 \mathrm{mmol}$ ) and 2,6-diisopropylaniline $(37.8 \mathrm{~mL}, 200 \mathrm{mmol})$ were added to a stirring solution of ethanol $(100 \mathrm{~mL})$ in a $250 \mathrm{~mL}$ round bottom flask open to air fitted with a reflux condenser. $\mathrm{HCl}$ $(9.0 \mathrm{~mL}, 100 \mathrm{mmol}$ ) was added drop-wise to the solution, and the mixture was then refluxed for $72 \mathrm{~h}$ to give a white precipitate. The solution was neutralised and extracted with $3 \times 50 \mathrm{~mL}$ of $1: 1$ sat. sodium carbonate solution : dichloromethane. The organic layer was isolated, and the solvent was reduced in vacuo till precipitation was observed. The solution was cooled to $0{ }^{\circ} \mathrm{C}$ and the resulting white crystals filtered off and recrystallised from dichloromethane/methanol to give $\mathrm{BDI}_{\mathrm{DIPP}} \mathrm{H}$ as colourless needles (31.65 g, 75.4\%). ${ }^{1} \mathrm{H}$ NMR (299.741 MHz, $\left.\mathrm{C}_{6} \mathrm{D}_{6}, 298 \mathrm{~K}\right) \delta 12.48(s, 1 \mathrm{H}, \mathrm{NH})$, 7.18-7.14 (m, $6 \mathrm{H}, \mathrm{ArH}), 4.89(\mathrm{~s}, 1 \mathrm{H}, \mathrm{CH}), 3.32$ (app. sept, J = 4.2 Hz, $\left.4 \mathrm{H}, \mathrm{CH}\left(\mathrm{CH}_{3}\right)_{2}\right), 1.67(s, 6 \mathrm{H}$, $\left.\mathrm{C}\left(\mathrm{CH}_{3}\right)\right), 1.22\left(d, J=4.2 \mathrm{~Hz}, 12 \mathrm{H}, \mathrm{CH}\left(\mathrm{CH}_{3}\right)_{2}\right), 1.17\left(d, J=4.2 \mathrm{~Hz}, 12 \mathrm{H}, \mathrm{CH}\left(\mathrm{CH}_{3}\right)_{2}\right)$. The compound was also measured in $\mathrm{CDCl}_{3}$ to compare with literature values of: $\delta 12.12,7.12,4.84,3.10,1.72,1.22$, 1.12. ${ }^{69}$ When run in $\mathrm{CDCl}_{3}$, the resonances were of comparable chemical shift to the literature. 


\section{$\mathrm{CH}\left\{\mathrm{C}(\mathrm{Me}) \mathrm{N}\left(\mathrm{C}_{6} \mathrm{H}_{3}-2,6-\mathrm{Pr}_{2}\right)\right\}_{2} \mathrm{GaCl}_{2}\left[\left(\mathrm{BDI}_{\mathrm{DIPP}}\right) \mathrm{GaCl}_{2}\right](12)$}

This compound was prepared following literature procedure. ${ }^{27} \mathrm{BuLi}(1.6 \mathrm{~mL}, 3.1 \mathrm{mmol})$ in hexane was added drop-wise to a stirring solution of $\mathrm{BDI}_{\mathrm{DIPP}} \mathrm{H}(1.19 \mathrm{~g}, 2.8 \mathrm{mmol})$ in toluene $(10 \mathrm{~mL})$ that had been cooled to $-30^{\circ} \mathrm{C}$. The solution rapidly turned yellow in colour. After $1 \mathrm{~h}$ this solution was added drop-wise to a solution of $\mathrm{GaCl}_{3}(500 \mathrm{mg}, 2.8 \mathrm{mmol})$ in toluene $(10 \mathrm{~mL})$ that had been cooled to $-30{ }^{\circ} \mathrm{C}$. This resulted in the rapid formation of a white precipitate. The slurry was stirred for $12 \mathrm{~h}$, filtered through celite, and the solvent removed in vacuo. The resulting solid was crystallised from toluene at $-30{ }^{\circ} \mathrm{C}$ to give $\left[\left(\mathrm{BDI}_{\mathrm{DIPP}}\right) \mathrm{GaCl}_{2}\right.$ ] as white needles $(1.56 \mathrm{~g}, 65 \%) .{ }^{1} \mathrm{H} \mathrm{NMR}(299.741 \mathrm{MHz}$, $\left.\mathrm{C}_{6} \mathrm{D}_{6}, 298 \mathrm{~K}\right) \delta$ 7.13-7.07 (m, $\left.6 \mathrm{H}, \mathrm{ArH}\right), 4.75(\mathrm{~s}, 1 \mathrm{H}, \mathrm{CH}), 3.44$ (app. sept, J = 6.8 Hz, $4 \mathrm{H}, \mathrm{CH}\left(\mathrm{CH}_{3}\right)_{2}$ ), $1.50\left(s, 6 \mathrm{H}, \mathrm{C}\left(\mathrm{CH}_{3}\right)\right), 1.44\left(d, J=6.9 \mathrm{~Hz}, 12 \mathrm{H}, \mathrm{CH}\left(\mathrm{CH}_{3}\right)_{2}\right), 1.11\left(d, J=6.6 \mathrm{~Hz}, 12 \mathrm{H}, \mathrm{CH}\left(\mathrm{CH}_{3}\right)_{2}\right)$. These values are in accordance with literature values of: $\delta 7.10,4.7,3.42,1.58,1.43,1.13 .{ }^{27}$

\section{$\mathrm{CH}\left\{\mathrm{C}(\mathrm{Me}) \mathrm{N}\left(\mathrm{C}_{6} \mathrm{H}_{3}-2,6^{\mathrm{i}} \mathrm{Pr}_{2}\right)\right\}_{2} \mathrm{GaMe}_{2}\left[\left(\mathrm{BDI}_{\mathrm{DIPP}}\right) \mathrm{GaMe}_{2}\right](20)$}

This compound was prepared following adapted literature procedure. ${ }^{27} \mathrm{MeMgBr}(1.2 \mathrm{~mL}$, $3.5 \mathrm{mmol})$ in $\mathrm{Et}_{2} \mathrm{O}$ was added drop-wise to a stirring solution of $\left[\left(\mathrm{BDI}_{\mathrm{DIPP}}\right) \mathrm{GaCl}_{2}\right](0.92 \mathrm{~g}, 1.6 \mathrm{mmol})$ in toluene $(10 \mathrm{~mL})$ at $-30{ }^{\circ} \mathrm{C}$. The solution was allowed to warm to room temperature then refluxed overnight. The solvents were removed in vacuo, the product extracted into toluene and filtered through celite to remove the precipitate. The crude product was crystallised from toluene at $-30{ }^{\circ} \mathrm{C}$ to give [(BDI $\left.\mathrm{BIPP}) \mathrm{GaMe}_{2}\right]$ as colourless crystals $(680 \mathrm{mg}, 81.6 \%) .{ }^{1} \mathrm{H}$ NMR $\left(299.741 \mathrm{MHz}, \mathrm{C}_{6} \mathrm{D}_{6}, 298 \mathrm{~K}\right)$ 6 7.11-7.09 (m, $6 \mathrm{H}, \mathrm{ArH}), 4.79(\mathrm{~s}, 1 \mathrm{H}, \mathrm{CH}), 3.42$ (app. sept, J = 6.8 Hz, $\left.4 \mathrm{H}, \mathrm{CH}\left(\mathrm{CH}_{3}\right)_{2}\right), 1.56(s, 6 \mathrm{H}$, $\left.\mathrm{C}\left(\mathrm{CH}_{3}\right)\right), 1.30\left(d, J=6.9 \mathrm{~Hz}, 12 \mathrm{H}, \mathrm{CH}\left(\mathrm{CH}_{3}\right)_{2}\right), 1.15\left(d, J=6.6 \mathrm{~Hz}, 12 \mathrm{H}, \mathrm{CH}\left(\mathrm{CH}_{3}\right)_{2}\right),-0.17(s, 6 \mathrm{H}$, $\left.\mathrm{Ga}\left(\mathrm{CH}_{3}\right)_{2}\right)$. These values are in accordance with literature values of $\delta 7.12,4.80,3.43,1.58,1.30$, $1.15,-0.18 .^{27}$

\section{$\left[\mathrm{C}_{6} \mathrm{H}_{5} \mathrm{CH}_{2} \mathrm{MgCl}\right]$}

This reagent was prepared following literature procedure. ${ }^{70}$ Magnesium turnings $(1.94 \mathrm{~g}$, $79.9 \mathrm{mmol})$, were activated by sequential rinsing in a frit with $0.2 \mathrm{M} \mathrm{HCl}(20 \mathrm{~mL})$, water $(3 \times 20 \mathrm{~mL})$, acetone $(2 \times 20 \mathrm{~mL})$ and diethyl ether $(2 \times 20 \mathrm{~mL})$. The activated magnesium turnings were dried at $100{ }^{\circ} \mathrm{C}$ under vacuum then cooled under a nitrogen atmosphere. Benzyl chloride ( $\left.4.6 \mathrm{~mL}, 39.9 \mathrm{mmol}\right)$ in THF (75 mL) was prepared separately and $\sim 10 \mathrm{~mL}$ cannulated onto the activated magnesium while 
stirring. Once boiling of the ethereal solution was observed, the reaction mixture was cooled in an ice-water bath and the remaining benzyl chloride solution was cannulated in over 30 mins. The reaction mixture was stirred at $0{ }^{\circ} \mathrm{C}$ for a further $60 \mathrm{~min}$, the remaining solid filtered off via cannula to give an orange solution of $\mathrm{BnMgCl}$ in $\mathrm{THF}(\sim 0.7 \mathrm{M})$.

\section{$\mathrm{CH}\left\{\mathrm{C}(\mathrm{Me}) \mathrm{N}\left(\mathrm{C}_{6} \mathrm{H}_{3}-2,6-{ }^{\mathrm{i}} \mathrm{Pr}_{2}\right)\right\}_{2} \mathrm{Ga}\left(\mathrm{CH}_{2}\left(\mathrm{C}_{6} \mathrm{H}_{5}\right)\right)_{2}\left[\left(\mathrm{BDI}_{\mathrm{DIPP}}\right) \mathrm{GaBn}_{2}\right](21)$}

To a stirring solution of $\left[\left(\mathrm{BDI}_{\mathrm{DIPP}}\right) \mathrm{GaCl}_{2}\right](200 \mathrm{mg}, 0.4 \mathrm{mmol})$ in THF $(10 \mathrm{~mL}), \mathrm{BnMgCl}$ in THF $\left(1.2 \mathrm{~mL}, 0.8 \mathrm{mmol}\right.$ ) was added drop-wise. The solution was heated to $60^{\circ} \mathrm{C}$ for $72 \mathrm{~h}$, the solvent was removed in vacuo and the product extracted into toluene to give a bright red solution. This solution was filtered through celite to remove the precipitate. The volatiles were removed in vacuo and the resulting white powder crystallised from toluene/hexane at $-30{ }^{\circ} \mathrm{C}$ to give $\left[\left(\mathrm{BDI}_{\mathrm{DIPP}}\right) \mathrm{GaBn}_{2}\right]$ as colourless crystals (157 mg, $65.8 \%$ ). Anal. calcd for $\mathrm{C}_{43} \mathrm{H}_{55} \mathrm{GaN}_{2}$ : C, 77.13; $\mathrm{H}, 8.28 ; \mathrm{N}, 4.18$. Found: C, 76.86; H, 8.11; N, 4.30. ${ }^{1} \mathrm{H}$ NMR (299.741 MHz, $\left.\mathrm{C}_{6} \mathrm{D}_{6}, 298 \mathrm{~K}\right) \delta$ 7.21-7.19 (m, $\left.2 \mathrm{H}, p-\mathrm{Ar}\right), 7.14-7.05$ $(m, 8 \mathrm{H}, m-\mathrm{Ar} ; m-\mathrm{Ph}), 6.92(t, J=7.5 \mathrm{~Hz}, 2 \mathrm{H}, p-\mathrm{Ph}), 6.86(d, J=7.5 \mathrm{~Hz}, 4 \mathrm{H}, o-\mathrm{Ph}), 4.93(s, 1 \mathrm{H}, \mathrm{CH})$, 3.31 (app. sept, J = 6.8 Hz, $\left.4 \mathrm{H}, \mathrm{CH}\left(\mathrm{CH}_{3}\right)_{2}\right), 2.03\left(s, 4 \mathrm{H}, \mathrm{CH}_{2}\right), 1.54\left(s, 6 \mathrm{H}, \mathrm{C}\left(\mathrm{CH}_{3}\right)\right), 1.20(d, J=6.6 \mathrm{~Hz}$, $\left.12 \mathrm{H}, \mathrm{CH}\left(\mathrm{CH}_{3}\right)_{2}\right), 1.05\left(d, J=6.9 \mathrm{~Hz}, 12 \mathrm{H}, \mathrm{CH}\left(\mathrm{CH}_{3}\right)_{2}\right) .{ }^{13} \mathrm{C} \mathrm{NMR}\left(75.378 \mathrm{MHz}, \mathrm{C}_{6} \mathrm{D}_{6}, 298 \mathrm{~K}\right) \delta 168.9$ $C\left(\mathrm{CH}_{3}\right), 144.4$ i-Ph, 144.1 o-Ar, 141.8 i-Ar, 129.2 p-Ph, 126.8 m-Ar; m-Ph, 124.4 p-Ar, 122.7 i-Ph, 97.2 $\gamma-\mathrm{CH}, 27.9 \mathrm{CH}\left(\mathrm{CH}_{3}\right)_{2}, 24.5 \mathrm{CH}\left(\mathrm{CH}_{3}\right)_{2}, 24.4 \mathrm{CH}\left(\mathrm{CH}_{3}\right)_{2}, 23.5 \mathrm{C}\left(\mathrm{CH}_{3}\right), 21.6 \mathrm{CH}_{2}-\mathrm{Ph}$.

\section{$\operatorname{PhN}(\mathrm{H}) \mathrm{Li}$}

${ }^{\mathrm{n}} \mathrm{BuLi}(6 \mathrm{~mL}, 12 \mathrm{mmol})$ in hexane was added drop-wise to a stirring solution of aniline $(1.0 \mathrm{~g}$, $10.7 \mathrm{mmol})$ in hexane $(10 \mathrm{~mL})$ at $-30{ }^{\circ} \mathrm{C}$. The solution was warmed to room temperature and stirred for $1 \mathrm{~h}$, the volatiles were removed in vacuo to give $\mathrm{PhN}(\mathrm{H}) \mathrm{Li}$ as a pale yellow powder $(1.0 \mathrm{~g}, 94 \%)$.

\section{2,6- $\mathrm{Me}_{2} \mathrm{C}_{6} \mathrm{H}_{3} \mathrm{~N}(\mathrm{H}) \mathrm{Li}$}

${ }^{\mathrm{n}}$ BuLi $(4.5 \mathrm{~mL}, 9.1 \mathrm{mmol})$ in hexane was added drop-wise to a stirring solution of 2,6-dimethylphenylaniline $(1.0 \mathrm{~g}, 8.3 \mathrm{mmol})$ in hexane $(10 \mathrm{~mL})$ at $-30^{\circ} \mathrm{C}$. The solution was warmed to room temperature and stirred for $1 \mathrm{~h}$, the volatiles were removed in vacuo to give 2,6- $\mathrm{Me}_{2} \mathrm{C}_{6} \mathrm{H}_{3} \mathrm{~N}(\mathrm{H}) \mathrm{Li}$ as a pale yellow powder (1.0 g, 95.3\%). 


\section{2,6-' $\mathrm{Pr}_{2} \mathrm{C}_{6} \mathrm{H}_{3} \mathrm{~N}(\mathrm{H}) \mathrm{Li}$}

${ }^{\mathrm{n}}$ BuLi (1.6 mL, $3.1 \mathrm{mmol}$ ) in hexane was added drop-wise to a stirring solution of 2,6-diisopropylphenylaniline $(0.5 \mathrm{~g}, 2.8 \mathrm{mmol})$ in hexane $(10 \mathrm{~mL})$ at $-30^{\circ} \mathrm{C}$. The solution was warmed to room temperature and stirred for $1 \mathrm{~h}$, the volatiles were removed in vacuo to give 2,6- ${ }^{\mathrm{i}} \mathrm{Pr}_{2} \mathrm{C}_{6} \mathrm{H}_{3} \mathrm{~N}(\mathrm{H}) \mathrm{Li}$ as a pale yellow powder (0.5 g, 92\%).

\section{Attempted Syntheses of [(BDI)Ga(HMDS) $\left.)_{2}\right]$}

1. A solution of HMDS-Li (588 mg, $3.5 \mathrm{mmol})$ in toluene $(20 \mathrm{~mL})$ was added drop-wise to a stirring solution of $\mathrm{GaCl}_{3}(200 \mathrm{mg}, 1.1 \mathrm{mmol})$ in toluene $(10 \mathrm{~mL})$ at $-30{ }^{\circ} \mathrm{C}$, the reaction mixture was allowed to warm to room temperature for $12 \mathrm{~h}$. The resulting solution was filtered through celite to remove the precipitate and the ${ }^{1} \mathrm{H}$ NMR spectrum showed the presence of a product with a singlet resonance at $\delta 0.24 \mathrm{ppm}$. BDI-H (477 $\mathrm{mg}, 1.1 \mathrm{mmol}$ ) was added to the solution and stirred at room temperature for $12 \mathrm{~h}$. The ${ }^{1} \mathrm{H}$ NMR spectrum of this solution showed BDI-H and the resonance at $\delta 0.24 \mathrm{ppm}$ as the only compounds present, the solution was heated to $60^{\circ} \mathrm{C}$ for a further $12 \mathrm{~h}$, then to $110^{\circ} \mathrm{C}$ for a further $12 \mathrm{~h}$, but still no reaction was observed.

2. A solution of HMDS-Li $(63 \mathrm{mg}, 0.4 \mathrm{mmol})$ in toluene $(5 \mathrm{~mL})$ was added drop-wise to a stirring solution of $\left[(\mathrm{BDI}) \mathrm{GaCl}_{2}\right](100 \mathrm{mg}, 0.2 \mathrm{mmol})$ in toluene $(5 \mathrm{~mL})$ and stirred at room temperature for $12 \mathrm{~h}$, after no reaction was observed by ${ }^{1} \mathrm{H}$ NMR spectroscopy the solution was heated at $60{ }^{\circ} \mathrm{C}$ for a further $12 \mathrm{~h}$, then at $110{ }^{\circ} \mathrm{C}$ for a further $12 \mathrm{~h}$, but still no reaction was observed.

3. A solution of HMDS-H ( $32 \mathrm{mg}, 0.2 \mathrm{mmol})$ in toluene $(5 \mathrm{~mL})$ was added drop-wise to a stirring solution of $\left[(\mathrm{BDI}) \mathrm{GaMe}_{2}\right](50 \mathrm{mg}, 0.1 \mathrm{mmol})$ in toluene $(5 \mathrm{~mL})$ and stirred at room temperature for $12 \mathrm{~h}$, after no reaction was observed by ${ }^{1} \mathrm{H}$ NMR spectroscopy the solution was heated at $60^{\circ} \mathrm{C}$ for a further $12 \mathrm{~h}$, then at $110^{\circ} \mathrm{C}$ for a further $12 \mathrm{~h}$, but still no reaction was observed.

\section{$\mathrm{CH}\left\{\mathrm{C}(\mathrm{Me}) \mathrm{N}\left(\mathrm{C}_{6} \mathrm{H}_{3}-2,6-\mathrm{-Pr}_{2}\right)\right\}_{2} \mathrm{Ga}\left(\mathrm{NH}\left(\mathrm{C}_{6} \mathrm{H}_{5}\right)\right)_{2}\left[\left(\mathrm{BDI}_{\mathrm{DIPP}}\right) \mathrm{Ga}(\mathrm{NHPh})_{2}\right](24)$}

$\mathrm{PhN}(\mathrm{H}) \mathrm{Li}(120 \mathrm{mg}, 1.2 \mathrm{mmol})$ in toluene $(30 \mathrm{~mL})$, was added to a stirring solution of $\left[\left(\mathrm{BDI}_{\mathrm{DIPP}}\right) \mathrm{GaCl}_{2}\right](300 \mathrm{mg}, 0.5 \mathrm{mmol})$ in toluene $(10 \mathrm{~mL})$ and heated at $60{ }^{\circ} \mathrm{C}$ for $72 \mathrm{~h}$. The resulting solution was filtered through celite to remove the precipitate. The volatiles were removed in vacuo and the product crystallised from toluene at $-30{ }^{\circ} \mathrm{C}$ to give $\left[\left(\mathrm{BDI}_{\mathrm{DIPP}}\right) \mathrm{Ga}(\mathrm{NHPh})_{2}\right]$ as a white powder 
(180 mg, 50\%). Anal. Calcd for $\mathrm{C}_{41} \mathrm{H}_{53} \mathrm{GaN}_{4}$ : C, 73.32; H, 7.95; N, 8.34. Found: C, 73.47; H, 8.10; $\mathrm{N}$, 8.25. ${ }^{1} \mathrm{H}$ NMR (299.741 MHz, $\left.\mathrm{C}_{6} \mathrm{D}_{6}, 298 \mathrm{~K}\right) \delta$ 7.14-7.09 (m, $\left.8 \mathrm{H}, o-, m-\mathrm{Ph}-\boldsymbol{H}\right)$, 7.04-6.98 $(m, 6 \mathrm{H}$, $m$-, p-Ar-H), 6.56 (br. s, $2 \mathrm{H}, p$-Ph-H), 6.14 (br., $2 \mathrm{H}, \mathrm{NH}$ ), $4.98(s, 1 \mathrm{H}, \mathrm{CH}$ ), 3.31 (app. sept, J = $6.6 \mathrm{~Hz}$, $\left.4 \mathrm{H}, \mathrm{CH}\left(\mathrm{CH}_{3}\right)_{2}\right), 1.53\left(s, 6 \mathrm{H}, \mathrm{C}\left(\mathrm{CH}_{3}\right)\right), 1.18\left(d, J=6.3 \mathrm{~Hz}, 12 \mathrm{H}, \mathrm{CH}\left(\mathrm{CH}_{3}\right)_{2}\right), 1.03(d, J=6.9 \mathrm{~Hz}, 12 \mathrm{H}$, $\left.\mathrm{CH}\left(\mathrm{CH}_{3}\right)_{2}\right)$. These values are in accordance with literature values of: 7.15-7.12, 7.08-7.05, 6.57, 6.16, $4.98,3.32,1.54,1.19,1.03 . .^{54}$

\section{$\mathrm{CH}\left\{\mathrm{C}(\mathrm{Me}) \mathrm{N}\left(\mathrm{C}_{6} \mathrm{H}_{3}-2,6-{ }^{\mathrm{i}} \mathrm{Pr}_{2}\right)\right\}_{2} \mathrm{Ga}\left(\mathrm{NH}\left(\mathrm{C}_{6} \mathrm{H}_{3}-2,6-\mathrm{Me}_{2}\right)\right)_{2}\left[\left(\mathrm{BDI}_{\mathrm{DIPP}}\right) \mathrm{Ga}(\mathrm{NHDMP})_{2}\right](25)$}

2,6- $\mathrm{Me}_{2} \mathrm{C}_{6} \mathrm{H}_{3} \mathrm{~N}(\mathrm{H}) \mathrm{Li}(142 \mathrm{mg}, 1.1 \mathrm{mmol})$ in toluene $(30 \mathrm{~mL})$, was added to a stirring solution of $\left[\left(\mathrm{BDI}_{\mathrm{DIPP}}\right) \mathrm{GaCl}_{2}\right](300 \mathrm{mg}, 0.5 \mathrm{mmol})$ in toluene $(10 \mathrm{~mL})$ and heated at $60{ }^{\circ} \mathrm{C}$ for $72 \mathrm{~h}$. The resulting solution was filtered through celite to remove the precipitate. The volatiles were removed in vacuo and the product crystallised from toluene at $-30{ }^{\circ} \mathrm{C}$ to give $\left[\left(\mathrm{BDI}_{\mathrm{DIPP}}\right) \mathrm{Ga}\left(\mathrm{NH}\left(\mathrm{C}_{6} \mathrm{H}_{3}-2,6-\mathrm{Me}_{2}\right)\right)_{2}\right]$ as pale yellow crystals (136 mg, 35\%). Anal. Calcd for $\mathrm{C}_{45} \mathrm{H}_{61} \mathrm{GaN}_{4}: \mathrm{C}, 74.27 ; \mathrm{H}, 8.45 ; \mathrm{N}, 7.70$. Found: $\mathrm{C}, 74.40$; $\mathrm{H}, 8.56 ; \mathrm{N}, 7.62 .{ }^{1} \mathrm{H}$ NMR $\left(299.741 \mathrm{MHz}, \mathrm{C}_{6} \mathrm{D}_{6}, 298 \mathrm{~K}\right) \delta$ 7.21-7.19 $\left(m, 2 \mathrm{H}, p-\mathrm{Ar}_{\mathrm{BD}} \mathrm{H}\right), 7.12-7.11(m, 5 \mathrm{H}$, $\left.4 m-\mathrm{Ar}_{\mathrm{BD}} \boldsymbol{H} ; 1 \mathrm{~m}-\mathrm{Ar} \boldsymbol{H}\right), 6.94-6.88(m, 3 \mathrm{H}, m-\mathrm{Ar} \boldsymbol{H}), 6.73-6.65(m, 2 \mathrm{H}, p-\operatorname{Ar} \boldsymbol{H}), 4.96(s, 1 \mathrm{H}, \mathrm{CH}), 3.53$ (app. sept, J = 6.8 Hz, $2 \mathrm{H}, \mathrm{CH}\left(\mathrm{CH}_{3}\right)_{2}$ ), $3.43\left(\mathrm{~s}, 1 \mathrm{H}, \mathrm{NH}\right.$ ), 3.37 (app. sept, $\mathrm{J}=6.8 \mathrm{~Hz}, 2 \mathrm{H}, \mathrm{CH}\left(\mathrm{CH}_{3}\right)_{2}$ ), 2.61 $\left(s, 3 \mathrm{H}, \mathrm{ArCH}_{3}\right), 2.37(s, 1 \mathrm{H}, \mathrm{NH}), 1.65\left(\mathrm{~s}, 3 \mathrm{H}, \mathrm{ArCH}_{3}\right), 1.56\left(s, 6 \mathrm{H}, \mathrm{C}\left(\mathrm{CH}_{3}\right)\right), 1.44-1.42(m, 12 \mathrm{H}$, $\left.\mathrm{CH}\left(\mathrm{CH}_{3}\right)_{2} ; 2 \mathrm{ArCH}_{3}\right), 1.19\left(d, J=6.6 \mathrm{~Hz}, 12 \mathrm{H}, \mathrm{CH}\left(\mathrm{CH}_{3}\right)_{2}\right), 1.08\left(d, J=6.9 \mathrm{~Hz}, 12 \mathrm{H}, \mathrm{CH}\left(\mathrm{CH}_{3}\right)_{2}\right), 0.90(d$, $\left.J=6.6 \mathrm{~Hz}, 12 \mathrm{H}, \mathrm{CH}\left(\mathrm{CH}_{3}\right)_{2}\right) .{ }^{13} \mathrm{C} \mathrm{NMR}\left(75.378 \mathrm{MHz}, \mathrm{C}_{6} \mathrm{D}_{6}, 298 \mathrm{~K}\right) \delta 171.0 \mathrm{C}\left(\mathrm{CH}_{3}\right), 148.6 i-\mathrm{Ar}, 148.4 i-\mathrm{Ar}$,

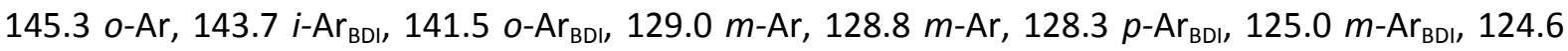
m-Ar, $118.1 p$-Ar, $115.4 p$-Ar, 98.1 - $\mathrm{CH}, 28.5 \mathrm{CH}\left(\mathrm{CH}_{3}\right)_{2}, 27.9 \mathrm{CH}\left(\mathrm{CH}_{3}\right)_{2}, 24.9 \mathrm{CH}\left(\mathrm{CH}_{3}\right)_{2}, 24.6 \mathrm{CH}\left(\mathrm{CH}_{3}\right)_{2}$, $24.2 \mathrm{CH}\left(\mathrm{CH}_{3}\right)_{2}, 23.1 \mathrm{C}\left(\mathrm{CH}_{3}\right), 19.3 \mathrm{ArCH}_{3}, 18.0 \mathrm{ArCH}_{3}, 17.8 \mathrm{ArCH}_{3}$.

\section{$\mathrm{CH}\left\{\mathrm{C}(\mathrm{Me}) \mathrm{N}\left(\mathrm{C}_{6} \mathrm{H}_{3}-2,6-\mathrm{-}^{\mathrm{i}} \mathrm{Pr}_{2}\right)\right\}_{2} \mathrm{Ga}\left(\mathrm{NH}\left(\mathrm{C}_{6} \mathrm{H}_{3}-2,6-\mathrm{-Pr}_{2}\right)\right)_{2}\left[\left(\mathrm{BDI}_{\mathrm{DIPP}}\right) \mathrm{Ga}(\mathrm{NHDIPP})_{2}\right]$ (26)}

2,6- ${ }^{\mathrm{i}} \mathrm{Pr}_{2} \mathrm{C}_{6} \mathrm{H}_{3} \mathrm{~N}(\mathrm{H}) \mathrm{Li}(132 \mathrm{mg}, 0.7 \mathrm{mmol})$ in toluene $(10 \mathrm{~mL})$ was added to a stirring solution of $\left[\left(\mathrm{BDI}_{\mathrm{DIPP}}\right) \mathrm{GaCl}_{2}\right](200 \mathrm{mg}, 0.4 \mathrm{mmol})$ in toluene $(10 \mathrm{~mL})$ and the solution refluxed for $72 \mathrm{~h}$. The solution was then filtered through celite to remove the precipitate, the volatiles removed in vacuo and the resulting solid crystallised from hexane at $-30{ }^{\circ} \mathrm{C}$ to give $\left[\left(\mathrm{BDI}_{\mathrm{DIPP}}\right) \mathrm{Ga}(\mathrm{NHDIPP})_{2}\right]$ as vivid yellow crystals (284 mg, $94.1 \%$ ). Anal. calcd for $\mathrm{C}_{53} \mathrm{H}_{77} \mathrm{GaN}_{4}$ : C, 75.79; $\mathrm{H}, 9.24 ; \mathrm{N}, 6.67$. Found: C, 75.85; H, 9.35; N, 6.81. ${ }^{1} \mathrm{H}$ NMR (299.741 MHz, C $\left.{ }_{6} \mathrm{D}_{6}, 298 \mathrm{~K}\right) \delta$ 7.21-7.18 (m, $\left.2 \mathrm{H}, p-\mathrm{Ar}_{\mathrm{BD}} \boldsymbol{H}\right)$, 7.15-7.03 (m, $8 \mathrm{H}, 4 m-\mathrm{Ar}_{\mathrm{BD}} \boldsymbol{H}$; $\left.4 \mathrm{~m}-\mathrm{Ar} \boldsymbol{H}\right), 6.98-6.91(m, 2 \mathrm{H}, p-\operatorname{Ar} \boldsymbol{H}), 5.07(s, 1 \mathrm{H}, \mathrm{CH}), 3.50-3.37$ 
$\left(m, 4 \mathrm{H}, 2 \mathrm{C}_{\mathrm{BD}} \boldsymbol{H}\left(\mathrm{CH}_{3}\right)_{2} ; \mathrm{CH}\left(\mathrm{CH}_{3}\right)_{2} ; \mathrm{NH}\right), 3.28$ (app. sept, J = $\left.6.8 \mathrm{~Hz}, 2 \mathrm{H}, \mathrm{C}_{\mathrm{BD} I} \boldsymbol{H}\left(\mathrm{CH}_{3}\right)_{2}\right), 2.45(\mathrm{~s}, 1 \mathrm{H}, \mathrm{NH})$, 2.07 (app. sept, J = 6.5 Hz, $\left.2 \mathrm{H}, \mathrm{CH}\left(\mathrm{CH}_{3}\right)_{2}\right), 1.88$ (sept, J = $\left.6.6 \mathrm{~Hz}, 1 \mathrm{H}, \mathrm{CH}\left(\mathrm{CH}_{3}\right)_{2}\right), 1.60\left(\mathrm{~s}, 6 \mathrm{H}, \mathrm{C}\left(\mathrm{CH}_{3}\right)\right.$ ), $1.51\left(d, J=6.6 \mathrm{~Hz}, 6 \mathrm{H}, \mathrm{C}_{\mathrm{BDI}} \mathrm{H}\left(\mathrm{CH}_{3}\right)_{2}\right), 1.35\left(d, J=6.6 \mathrm{~Hz}, 6 \mathrm{H}, \mathrm{CH}\left(\mathrm{CH}_{3}\right)_{2}\right), 1.17(d, J=6.9 \mathrm{~Hz}, 6 \mathrm{H}$, $\left.\mathrm{C}_{\mathrm{BDI}} \mathrm{H}\left(\mathrm{CH}_{3}\right)_{2}\right), 1.10\left(d, J=6.9 \mathrm{~Hz}, 6 \mathrm{H}, \mathrm{C}_{\mathrm{BD} I} \mathrm{H}\left(\mathrm{CH}_{3}\right)_{2}\right), 1.05\left(d, J=6.9 \mathrm{~Hz}, 6 \mathrm{H}, \mathrm{CH}\left(\mathrm{CH}_{3}\right)_{2}\right), 1.01(d, J=6.9 \mathrm{~Hz}$, $\left.6 \mathrm{H}, \mathrm{CH}\left(\mathrm{CH}_{3}\right)_{2}\right), 0.89\left(d, J=6.6 \mathrm{~Hz}, 6 \mathrm{H}, \mathrm{C}_{\mathrm{BDI}} \mathrm{H}\left(\mathrm{CH}_{3}\right)_{2}\right), 0.73\left(d, J=6.3 \mathrm{~Hz}, 6 \mathrm{H}, \mathrm{CH}\left(\mathrm{CH}_{3}\right)_{2}\right) .{ }^{13} \mathrm{C} \mathrm{NMR}$ (75.378 MHz, $\left.\mathrm{C}_{6} \mathrm{D}_{6}, 298 \mathrm{~K}\right) \delta 170.9 \mathrm{C}\left(\mathrm{CH}_{3}\right), 145.4 \mathrm{i}-\mathrm{Ar}, 145.3 \mathrm{i}-\mathrm{Ar}, 145.0 \mathrm{i}-\mathrm{Ar}_{\mathrm{BDI}}, 143.0$ o- $\mathrm{Ar}_{\mathrm{BDI}}, 141.7$

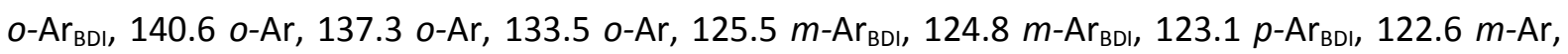

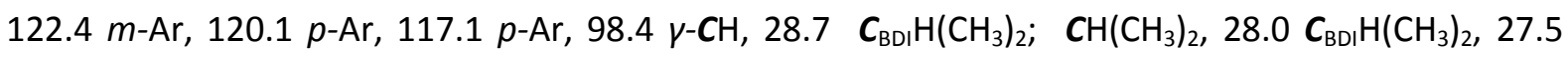
$\mathrm{CH}\left(\mathrm{CH}_{3}\right)_{2}, 27.2 \mathrm{CH}\left(\mathrm{CH}_{3}\right)_{2}, 26.4 \mathrm{CH}\left(\mathrm{CH}_{3}\right)_{2}, 26.3 \mathrm{CH}\left(\mathrm{CH}_{3}\right)_{2}, 25.0 \mathrm{C}_{\mathrm{BDI}} \mathrm{H}\left(\mathrm{CH}_{3}\right)_{2}, 24.6 \mathrm{C}_{\mathrm{BD} I} \mathrm{H}\left(\mathrm{CH}_{3}\right)_{2}, 24.5 \mathrm{C}\left(\mathrm{CH}_{3}\right)$; $\mathrm{C}_{\mathrm{BD}} \mathrm{H}\left(\mathrm{CH}_{3}\right)_{2}, 24.0 \mathrm{CH}\left(\mathrm{CH}_{3}\right)_{2}, 22.5 \mathrm{CH}\left(\mathrm{CH}_{3}\right)_{2}$.

\section{$\mathrm{CH}\left\{\mathrm{C}(\mathrm{Me}) \mathrm{N}\left(\mathrm{C}_{6} \mathrm{H}_{3}-2,6-{ }^{\mathrm{i}} \mathrm{Pr} \mathrm{r}_{2}\right)\right\}_{2} \mathrm{Ga}\left(\mathrm{NH}\left(\mathrm{C}_{6} \mathrm{H}_{5}\right)\right) \mathrm{Cl}\left[\left(\mathrm{BDI}_{\mathrm{DIPP}}\right) \mathrm{Ga}(\mathrm{NHPh}) \mathrm{Cl}\right]$}

$\mathrm{PhN}(\mathrm{H}) \mathrm{Li}(40 \mathrm{mg}, 0.4 \mathrm{mmol})$ in toluene $(30 \mathrm{~mL})$ was added to a stirring solution of [( $\left(\mathrm{BDI}_{\mathrm{DIPP}}\right) \mathrm{GaCl}_{2}$ ] (200 mg, $0.4 \mathrm{mmol})$ in toluene $\left(10 \mathrm{~mL}\right.$ ) at $-30^{\circ} \mathrm{C}$. The resulting solution was allowed to warm to room temperature and stirred for $12 \mathrm{~h}$, then filtered through celite to remove the precipitate. While the ${ }^{1} \mathrm{H}$ NMR spectrum of the crude material indicated the reaction had succeeded based on the presence of a BDI $\mathrm{p}-\mathrm{H}$ resonance at $\delta 4.96 \mathrm{ppm}(s, 1 \mathrm{H})$, the sample could not be purified for full characterisation.

\section{$\mathrm{CH}\left\{\mathrm{C}(\mathrm{Me}) \mathrm{N}\left(\mathrm{C}_{6} \mathrm{H}_{3}-2,6-{ }^{\mathrm{i}} \mathrm{Pr} \mathrm{r}_{2}\right)\right\}_{2} \mathrm{Ga}\left(\mathrm{NH}\left(\mathrm{C}_{6} \mathrm{H}_{3}-2,6-\mathrm{Me}_{2}\right)\right) \mathrm{Cl}\left[\left(\mathrm{BDI}_{\mathrm{DIPP}}\right) \mathrm{Ga}(\mathrm{NHDMP}) \mathrm{Cl}\right]$}

2,6- $-\mathrm{Me}_{2} \mathrm{C}_{6} \mathrm{H}_{3} \mathrm{~N}(\mathrm{H}) \mathrm{Li}(51 \mathrm{mg}, 0.4 \mathrm{mmol})$ in toluene $(30 \mathrm{~mL}$ ) was added to a stirring solution of $\left[\left(\mathrm{BDI}_{\mathrm{DIPP}}\right) \mathrm{GaCl}_{2}\right](200 \mathrm{mg}, 0.4 \mathrm{mmol})$ in toluene $(10 \mathrm{~mL})$ at $-30{ }^{\circ} \mathrm{C}$. The resulting solution was allowed to warm to room temperature and stirred for $12 \mathrm{~h}$, then filtered through celite to remove the precipitate. The volatiles were remove in vacuo and the product was crystallised from toluene/hexane at $-30{ }^{\circ} \mathrm{C}$ to give $\left[\left(\mathrm{BDI}_{\mathrm{DIPP}}\right) \mathrm{Ga}\left(\mathrm{NH}\left(\mathrm{C}_{6} \mathrm{H}_{3}-2,6-\mathrm{Me}_{2}\right)\right) \mathrm{Cl}\right]$ as yellow crystals $(10 \mathrm{mg}, 3.9 \%)$.

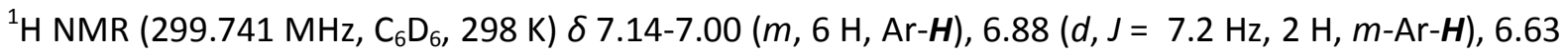
$\left(t, J=7.2 \mathrm{~Hz}, 1 \mathrm{H}, p-\mathrm{Ar}-\mathrm{H}\right.$ ), $4.84\left(\mathrm{~s}, 1 \mathrm{H}, \mathrm{CH}\right.$ ), 3.60 (app. sept, J = $6.8 \mathrm{~Hz}, 2 \mathrm{H}, \mathrm{CH}\left(\mathrm{CH}_{3}\right)_{2}$ ), 3.36 (app. sept, $\left.J=6.8 \mathrm{~Hz}, 2 \mathrm{H}, \mathrm{CH}\left(\mathrm{CH}_{3}\right)_{2}\right), 2.73(s, 1 \mathrm{H}, \mathrm{NH}), 1.60\left(\mathrm{~s}, 6 \mathrm{H}, \mathrm{Ar}-\mathrm{CH}_{3}\right), 1.54\left(s, 6 \mathrm{H}, \mathrm{C}\left(\mathrm{CH}_{3}\right)\right) 1.37(d$, $\left.J=6.6 \mathrm{~Hz}, \mathrm{CH}\left(\mathrm{CH}_{3}\right)_{2}\right), 1.27\left(d, J=6.9 \mathrm{~Hz}, 6 \mathrm{H}, \mathrm{CH}\left(\mathrm{CH}_{3}\right)_{2}\right), 1.16\left(d, J=6.6 \mathrm{~Hz}, 6 \mathrm{H}, \mathrm{CH}\left(\mathrm{CH}_{3}\right)_{2}\right), 1.07(d$, $\left.J=6.6 \mathrm{~Hz}, \mathrm{CH}\left(\mathrm{CH}_{3}\right)_{2}\right)$. 


\section{$\mathrm{CH}\left\{\mathrm{C}(\mathrm{Me}) \mathrm{N}\left(\mathrm{C}_{6} \mathrm{H}_{3}-2,6-{ }^{\mathrm{i}} \mathrm{Pr}_{2}\right)\right\}_{2} \mathrm{Ga}\left(\mathrm{NH}\left(\mathrm{C}_{6} \mathrm{H}_{3}-2,6-{ }^{\mathrm{i}} \mathrm{Pr}_{2}\right)\right) \mathrm{Cl}\left[\left(\mathrm{BDI}_{\mathrm{DIPP}}\right) \mathrm{Ga}(\mathrm{NHDIPP}) \mathrm{Cl}\right]$ (27)}

2,6- ${ }^{\mathrm{i}} \mathrm{Pr}_{2} \mathrm{C}_{6} \mathrm{H}_{3} \mathrm{~N}(\mathrm{H}) \mathrm{Li}(73 \mathrm{mg}, 0.4 \mathrm{mmol})$ in toluene $(10 \mathrm{~mL})$ was added to a stirring solution of $\left[\left(\mathrm{BDI}_{\mathrm{DIPP}}\right) \mathrm{GaCl}_{2}\right](200 \mathrm{mg}, 0.4 \mathrm{mmol})$ in toluene $(10 \mathrm{~mL})$ at $-30^{\circ} \mathrm{C}$. The resulting solution was allowed to warm to room temperature and stirred for $12 \mathrm{~h}$, then filtered through celite to remove the precipitate. The volatiles were remove in vacuo and the resulting solid crystallised from toluene/hexane to give $\left[\left(\mathrm{BDI}_{\mathrm{DIPP}}\right) \mathrm{Ga}(\mathrm{NHDIPP}) \mathrm{Cl}\right]$ as yellow crystals $(5 \mathrm{mg}, 1.8 \%) .{ }^{1} \mathrm{H} \mathrm{NMR}$ (299.741 MHz, $\left.\mathrm{C}_{6} \mathrm{D}_{6}, 298 \mathrm{~K}\right) \delta$ 7.13-7.05 (m, $\left.6 \mathrm{H}, \mathrm{Ar}-\boldsymbol{H}\right), 6.94-6.89(\mathrm{~m}, 3 \mathrm{H}, \mathrm{Ar}-\boldsymbol{H}), 4.88(\mathrm{~s}, 1 \mathrm{H}, \mathrm{CH})$, 3.57-3.49 (m, $\left.3 \mathrm{H}, \mathrm{CH}\left(\mathrm{CH}_{3}\right)_{2}\right), 3.36-3.26\left(m, 3 \mathrm{H}, \mathrm{CH}\left(\mathrm{CH}_{3}\right)_{2}\right), 2.74(b r ., 1 \mathrm{H}, \mathrm{NH}), 1.52\left(s, 6 \mathrm{H}, \mathrm{C}\left(\mathrm{CH}_{3}\right)\right)$, $1.34\left(d, J=6.9 \mathrm{~Hz}, 6 \mathrm{H}, \mathrm{CH}\left(\mathrm{CH}_{3}\right)_{2}\right), 1.31\left(d, J=6.3 \mathrm{~Hz}, 6 \mathrm{H}, \mathrm{CH}\left(\mathrm{CH}_{3}\right)_{2}\right), 1.13\left(d, J=6.9 \mathrm{~Hz}, 6 \mathrm{H}, \mathrm{CH}\left(\mathrm{CH}_{3}\right)_{2}\right)$, $1.06\left(d, J=6.9 \mathrm{~Hz}, 6 \mathrm{H}, \mathrm{CH}\left(\mathrm{CH}_{3}\right)_{2}\right), 0.94\left(d, J=6.6 \mathrm{~Hz}, 12 \mathrm{H}, \mathrm{CH}\left(\mathrm{CH}_{3}\right)_{2}\right)$.

\section{PhP(H)Li}

${ }^{\mathrm{n}}$ BuLi $(1.5 \mathrm{~mL}, 2.3 \mathrm{mmol})$ in hexane was added drop-wise to a stirring solution of phenylphosphine $(0.25 \mathrm{~g}, 2.3 \mathrm{mmol})$ in hexane $(10 \mathrm{~mL})$ at $-30^{\circ} \mathrm{C}$. The solution was warmed to room temperature and stirred for $1 \mathrm{~h}$, the volatiles removed in vacuo to give $\mathrm{PhP}(\mathrm{H}) \mathrm{Li}$ as a yellow powder (0.25 g, 94.8\%).

\section{Attempted synthesis of $\mathrm{CH}\left\{\mathrm{C}(\mathrm{Me}) \mathrm{N}\left(\mathrm{C}_{6} \mathrm{H}_{3}-2,6-\mathrm{Pr}_{2}\right)\right\}_{2} \mathrm{Ga}\left(\mathrm{P}\left(\mathrm{C}_{6} \mathrm{H}_{11}\right)_{2}\right)_{2}\left[\left(\mathrm{BDI}_{\mathrm{DIPP}}\right) \mathrm{Ga}\left(\mathrm{PCy}_{2}\right)_{2}\right]$}

A solution of $\mathrm{LiPCy}_{2}(37 \mathrm{mg}, 0.2 \mathrm{mmol}$ ) in toluene $(5 \mathrm{~mL})$ was added drop-wise to a stirring solution of $\left[\left(\mathrm{BDI}_{\mathrm{DIPP}}\right) \mathrm{GaCl}_{2}\right](50 \mathrm{mg}, 0.1 \mathrm{mmol})$ in toluene $(5 \mathrm{~mL})$. The resulting yellow solution/white suspension was filtered through celite to remove the precipitate, the volatiles removed in vacuo and the crude product analysed. This crude material contained only $\left[(\mathrm{BDI}) \mathrm{GaCl}_{2}\right]$ determined by the $\mathrm{BDI}$ ligand $\mathrm{\gamma}$-H resonance in the ${ }^{1} \mathrm{H}$ NMR spectrum.

\section{$\mathrm{CH}\left\{\mathrm{C}(\mathrm{Me}) \mathrm{N}\left(\mathrm{C}_{6} \mathrm{H}_{3}-2,6-\mathrm{Pr}_{2}\right)\right\}_{2} \mathrm{Ga}\left(\mathrm{PH}\left(\mathrm{C}_{6} \mathrm{H}_{5}\right)\right)_{2}\left[\left(\mathrm{BDI}_{\mathrm{DIPP}}\right) \mathrm{Ga}(\mathrm{PHPh})_{2}\right](29)$}

A solution of $\mathrm{PhP}(\mathrm{H}) \mathrm{Li}(39 \mathrm{mg}, 0.4 \mathrm{mmol})$ in THF $(10 \mathrm{~mL})$ was added drop-wise to a solution of [(BDI $\left.\left.\mathrm{BDP}_{\mathrm{DP}}\right) \mathrm{GaCl}_{2}\right](100 \mathrm{mg}, 0.2 \mathrm{mmol})$ in THF $(5 \mathrm{~mL})$. The solution was heated at $60{ }^{\circ} \mathrm{C}$ for $72 \mathrm{~h}$, the volatiles removed in vacuo and the product extracted into toluene to give a cloudy orange solution. This solution was filtered through celite to remove the precipitate. The volatiles were removed in 
vacuo and the resulting orange oil crystallised from toluene/hexane at $-30{ }^{\circ} \mathrm{C}$ to give $\left[\left(\mathrm{BDI}_{\mathrm{DIPP}}\right) \mathrm{Ga}(\mathrm{PHPh})_{2}\right]$ as yellow-orange crystals $(98 \mathrm{mg}, 78.0 \%)$. Anal. calcd for $\mathrm{C}_{41} \mathrm{H}_{53} \mathrm{GaN}_{2} \mathrm{P}_{2}: \mathrm{C}, 69.80$; $\mathrm{H}, 7.57 ; \mathrm{N}, 3.97$. Found: $\mathrm{C}, 69.54 ; \mathrm{H}, 7.52 ; \mathrm{N}, 3.86 .{ }^{1} \mathrm{H}$ NMR $\left(299.741 \mathrm{MHz}, \mathrm{C}_{6} \mathrm{D}_{6}, 298 \mathrm{~K}\right) \delta$ 7.20-7.17 ( $m, 2 \mathrm{H}, p$-Ar), 7.12-7.07 (m, $6 \mathrm{H}, 4$ o-Ph, $2 m-\mathrm{Ar}), 7.01(t, J=6.75 \mathrm{~Hz}, 2 \mathrm{H}, p-\mathrm{Ph}), 6.94-6.84(m, 6 \mathrm{H}$, $4 m$-Ph, $2 m-A r), 4.83(s, 1 \mathrm{H}, \mathrm{CH}), 3.44\left(\right.$ br. $\left., 4 \mathrm{H}, \mathrm{CH}\left(\mathrm{CH}_{3}\right)_{2}\right), 3.25\left(d, J_{\mathrm{PH}}=201.9 \mathrm{~Hz}, 2 \mathrm{H}, \mathrm{PH}\right), 1.50$ (s, $\left.6 \mathrm{H}, \mathrm{C}\left(\mathrm{CH}_{3}\right)\right), 1.40$ (br. s, $\left.12 \mathrm{H}, \mathrm{CH}\left(\mathrm{CH}_{3}\right)_{2}\right), 1.03$ (br. s, $\left.12 \mathrm{H}, \mathrm{CH}\left(\mathrm{CH}_{3}\right)_{2}\right) .{ }^{13} \mathrm{C}$ NMR (75.378 MHz, $\mathrm{C}_{6} \mathrm{D}_{6}$, $298 \mathrm{~K}) \delta 169.7 \mathrm{C}\left(\mathrm{CH}_{3}\right), 144.4$ o-Ar, $141.2 \mathrm{i}-\mathrm{Ar}, 136.8\left(d, J_{\mathrm{PC}}=23 \mathrm{~Hz}, i-\mathrm{Ph}\right), 133.5\left(d, J_{\mathrm{PC}}=13.9 \mathrm{~Hz}, o-\mathrm{Ph}\right)$, 129.0128 .2127 .2125 .3 m-Ph m-Ar, 125.0 p-Ph, $124.7 p$-Ar, $97.9\left(d, J_{\mathrm{PC}}=13.8 \mathrm{~Hz}, \gamma-\mathrm{CH}\right), 28.4 \mathrm{br}$ $\mathrm{CH}\left(\mathrm{CH}_{3}\right)_{2}, 25.1$ br $\mathrm{CH}\left(\mathrm{CH}_{3}\right)_{2}, 24.7$ (br. d, J $\left.=4 \mathrm{~Hz}, \mathrm{CH}\left(\mathrm{CH}_{3}\right)_{2}\right), 23.6 \mathrm{C}\left(\mathrm{CH}_{3}\right) .{ }^{31} \mathrm{P} \mathrm{NMR}\left(121.318 \mathrm{MHz}, \mathrm{C}_{6} \mathrm{D}_{6}\right.$, 298 K) $\delta$-127.3 br PH; (121.318 MHz, C $\left.7 \mathrm{D}_{8}, 328 \mathrm{~K}\right) \delta-126.8 \mathrm{~s} ;\left(121.318 \mathrm{MHz}, \mathrm{C}_{7} \mathrm{D}_{8}, 298 \mathrm{~K}\right) \delta-127.2 \mathrm{br}$; (121.318 MHz, $\left.\mathrm{C}_{7} \mathrm{D}_{8}, 238 \mathrm{~K}\right) \delta$-119.0 s, -127.0 br; (121.318 MHz, $\left.\mathrm{C}_{7} \mathrm{D}_{8}, 198 \mathrm{~K}\right) \delta$-116.5 br, -138.2 br.

\section{$\mathrm{CH}\left\{\mathrm{C}(\mathrm{Me}) \mathrm{N}\left(\mathrm{C}_{6} \mathrm{H}_{3}-2,6-\mathrm{Pr}_{2}\right)\right\}_{2} \mathrm{Ga}\left(\mathrm{PH}\left(\mathrm{C}_{6} \mathrm{H}_{5}\right)\right) \mathrm{Cl}\left[\left(\mathrm{BDI}_{\mathrm{DIPP}}\right) \mathrm{Ga}(\mathrm{PHPh}) \mathrm{Cl}\right](31)$}

A solution of $\mathrm{PhP}(\mathrm{H}) \mathrm{Li}(20 \mathrm{mg}, 0.2 \mathrm{mmol})$ in THF $(10 \mathrm{~mL})$ was added drop-wise to a solution of $\left[\left(\mathrm{BDI}_{\mathrm{DIPP}}\right) \mathrm{GaCl}_{2}\right](100 \mathrm{mg}, 0.2 \mathrm{mmol})$ in THF $(5 \mathrm{~mL})$ at $-30{ }^{\circ} \mathrm{C}$. The solution was allowed to warm to room temperature and stirred for $12 \mathrm{~h}$, the solvent was removed in vacuo and the product extracted into toluene to give a cloudy yellow solution. This solution was filtered through celite to remove the precipitate. The volatiles were removed in vacuo and the resulting yellow solid crystallised from toluene/hexane at $-30{ }^{\circ} \mathrm{C}$ to give $\left[\left(\mathrm{BDI}_{\mathrm{DIPP}}\right) \mathrm{Ga}(\mathrm{PHPh}) \mathrm{Cl}\right]$ as yellow crystals $(38 \mathrm{mg}, 30.0 \%) .{ }^{1} \mathrm{H} \mathrm{NMR}$ (299.741 MHz, $\left.\mathrm{C}_{6} \mathrm{D}_{6}, 298 \mathrm{~K}\right) \delta$ 7.22-7.17 ( $m, 3 \mathrm{H}, 2 \mathrm{~m}$-Ar; 1 p-Ar), 7.12-7.09 ( $m, 2 \mathrm{H}, m-\mathrm{Ar}$ ), 7.06-7.02 ( $m, 1 \mathrm{H}, p-\mathrm{Ar}), 6.95-6.89(m, 1 \mathrm{H}, p-\mathrm{Ph}), 6.86-6.78(m, 2 \mathrm{H}, m-\mathrm{Ph}), 6.76-6.71(m, 2 \mathrm{H}, o-\mathrm{Ph}), 4.88$ $\left(s, 1 \mathrm{H}, \mathrm{CH}\right.$ ), 3.77 (app. sept, J = 6.8 Hz, $1 \mathrm{H}, \mathrm{CH}\left(\mathrm{CH}_{3}\right)_{2}$ ), 3.60 (app. sept, J $=6.8 \mathrm{~Hz}, 1 \mathrm{H}, \mathrm{CH}\left(\mathrm{CH}_{3}\right)_{2}$ ), 3.48$3.37\left(m, 1.5 \mathrm{H}, \mathrm{CH}\left(\mathrm{CH}_{3}\right)_{2} ; 0.5 \mathrm{PH}\right), 3.30$ (app. sept, J = $\left.6.8 \mathrm{~Hz}, 1 \mathrm{H}, \mathrm{CH}\left(\mathrm{CH}_{3}\right)_{2}\right), 3.09\left(d, J_{\mathrm{PH}}=195 \mathrm{~Hz}, 1 \mathrm{H}\right.$, $\mathrm{PH}), 1.58-1.56\left(m, 9 \mathrm{H}, 2 \mathrm{C}\left(\mathrm{CH}_{3}\right) ; 1 \mathrm{CH}\left(\mathrm{CH}_{3}\right)_{2}\right), 1.48\left(d, J=6.6 \mathrm{~Hz}, 3 \mathrm{H}, \mathrm{CH}\left(\mathrm{CH}_{3}\right)_{2}\right), 1.33(d, J=6.9 \mathrm{~Hz}$, $\left.3 \mathrm{H}, \mathrm{CH}\left(\mathrm{CH}_{3}\right)_{2}\right), 1.19\left(d, J=6.9 \mathrm{~Hz}, 3 \mathrm{H}, \mathrm{CH}\left(\mathrm{CH}_{3}\right)_{2}\right), 1.14\left(d, J=6.9 \mathrm{~Hz}, 3 \mathrm{H}, \mathrm{CH}\left(\mathrm{CH}_{3}\right)_{2}\right), 1.10-1.06(m, 6 \mathrm{H}$, $\left.\mathrm{CH}\left(\mathrm{CH}_{3}\right)_{2}\right), 1.03\left(d, J=6.9 \mathrm{~Hz}, 3 \mathrm{H}, \mathrm{CH}\left(\mathrm{CH}_{3}\right)_{2}\right) .{ }^{13} \mathrm{C} \mathrm{NMR}\left(75.378 \mathrm{MHz}, \mathrm{C}_{6} \mathrm{D}_{6}, 298 \mathrm{~K}\right) \delta 169.3 \mathrm{C}\left(\mathrm{CH}_{3}\right)$, $169.1 \mathrm{C}\left(\mathrm{CH}_{3}\right), 145.8$ o-Ar, 145.7 o-Ar, $142.7 \mathrm{i}-\mathrm{Ar}, 142.6 \mathrm{i}-\mathrm{Ar}, 140.2$ (d, $J_{\mathrm{PC}}=12.6 \mathrm{~Hz}, i-\mathrm{Ph}$ ), 134.2 $\left(\mathrm{d}, J_{\mathrm{PC}}=13.8 \mathrm{~Hz}, o-\mathrm{Ph}\right), 129.0 \mathrm{Ar}, 128.2 \mathrm{~m}-\mathrm{Ph}, 127.8 \mathrm{p}-\mathrm{Ph}, 127.4 \mathrm{Ar}, 125.8 \mathrm{~m}-\mathrm{Ph}, 125.4 \mathrm{~m}-\mathrm{Ar}, 125.2$ p-Ar, 123.8 Ar, $123.7 m-\mathrm{Ar}, 97.2\left(\mathrm{~d}, \mathrm{~J}_{\mathrm{PC}}=8.6 \mathrm{~Hz}, \gamma-\mathrm{CH}\right), 29.3 \mathrm{br} \mathrm{CH}\left(\mathrm{CH}_{3}\right)_{2}, 29.1 \mathrm{br} \mathrm{CH}\left(\mathrm{CH}_{3}\right)_{2}, 27.7 \mathrm{br}$ $\mathrm{CH}\left(\mathrm{CH}_{3}\right)_{2}, 26.5 \mathrm{CH}\left(\mathrm{CH}_{3}\right)_{2}, 25.9 \mathrm{CH}\left(\mathrm{CH}_{3}\right)_{2}, 24.7 \mathrm{CH}\left(\mathrm{CH}_{3}\right)_{2}, 24.2\left(d, J_{\mathrm{PC}}=5.7 \mathrm{~Hz}, \mathrm{CH}\left(\mathrm{CH}_{3}\right)_{2}\right), 24.0$ $\left(d, J_{\mathrm{PC}}=5.8 \mathrm{~Hz}, \mathrm{CH}\left(\mathrm{CH}_{3}\right)_{2}\right), 23.8\left(d, J_{\mathrm{PC}}=6.9 \mathrm{~Hz}, \mathrm{CH}\left(\mathrm{CH}_{3}\right)_{2}\right), 23.1 \mathrm{C}\left(\mathrm{CH}_{3}\right), 23.0 \mathrm{C}\left(\mathrm{CH}_{3}\right) .{ }^{31} \mathrm{P} \mathrm{NMR}$ (121.318 MHz, $\mathrm{C}_{6} \mathrm{D}_{6}, 298 \mathrm{~K},{ }^{1} \mathrm{H}$ coupled) $\delta-151.7\left(d t, J_{\mathrm{PH}}=195,7.1 \mathrm{~Hz}, P \mathrm{PH}\right) ;\left(121.318 \mathrm{MHz}, \mathrm{C}_{6} \mathrm{D}_{6}, 298\right.$ $\mathrm{K},{ }^{1} \mathrm{H}$ decoupled) $\delta-151.7(s, \mathrm{PH})$. 
Attempted Synthesis of [(BDI $\left.\mathrm{DIPP}) \mathrm{Ga}\left(\mathrm{O}^{\mathrm{i} P r}\right)_{2}\right](33)$

1. A solution of ${ }^{i} \operatorname{PrOK}(38 \mathrm{mg}, 0.4 \mathrm{mmol})$ in toluene $(5 \mathrm{~mL})$ was added drop-wise to a stirring solution of $\left[\left(\mathrm{BDI}_{\mathrm{DIPP}}\right) \mathrm{GaCl}_{2}\right](100 \mathrm{mg}, 0.2 \mathrm{mmol})$ in toluene $(5 \mathrm{~mL})$ and stirred at room temperature for $12 \mathrm{~h}$, resulting in the formation of a white solid. The solution was filtered through celite to remove the precipitate and the volatiles removed in vacuo. The resulting solid contained two new resonances in the ${ }^{1} \mathrm{H}$ NMR spectrum corresponding to the BDI $\mathrm{y}-\mathrm{H}$ at $\delta 4.73$ and 4.71 , however in subsequent purification steps only BDI-H was isolated.

2. A solution of ${ }^{\mathrm{i}} \mathrm{PrOH}(25 \mathrm{mg}, 0.4 \mathrm{mmol})$ in toluene $(5 \mathrm{~mL})$ was added drop-wise to a stirring solution of $\left[\left(\mathrm{BDI}_{\mathrm{DIPP}}\right) \mathrm{GaMe}_{2}\right](100 \mathrm{mg}, 0.2 \mathrm{mmol})$ in toluene $(5 \mathrm{~mL})$ and stirred at room temperature for $24 \mathrm{~h}$. This resulted in the formation of a mildly fluorescent (purple/blue) white precipitate that was insoluble in $\mathrm{C}_{6} \mathrm{D}_{6}$ and $\mathrm{CDCl}_{3}$ and the ${ }^{1} \mathrm{H}$ NMR spectrum signalled the only compound soluble was BDI-H.

\section{Attempted Synthesis of $\left[\left(\mathrm{BDI}_{\mathrm{DIPP}}\right) \mathrm{Ga}\left(\mathrm{O}^{\mathrm{t}} \mathrm{Bu}\right)_{2}\right](34)$}

1. A solution of ${ }^{\mathrm{t}} \mathrm{BuOK}(43 \mathrm{mg}, 0.4 \mathrm{mmol})$ in toluene $(5 \mathrm{~mL}$ ) was added drop-wise to a stirring solution of $\left[\left(\mathrm{BDI}_{\mathrm{DIPP}}\right) \mathrm{GaCl}_{2}\right](100 \mathrm{mg}, 0.2 \mathrm{mmol})$ in toluene $(5 \mathrm{~mL})$ and stirred at room temperature for $12 \mathrm{~h}$, resulting in the formation of a white solid. The solution was filtered through celite to remove the precipitate and the solvent removed in vacuo. The resulting solid contained two new resonances in the ${ }^{1} \mathrm{H}$ NMR spectrum corresponding to the BDI $y-\mathrm{H}$ at $\delta 4.71$ and 4.59 , however in subsequent purification steps only BDI-H was isolated.

2. A solution of ${ }^{\mathrm{t}} \mathrm{BuOH}(29 \mathrm{mg}, 0.4 \mathrm{mmol})$ in toluene $(5 \mathrm{~mL})$ was added drop-wise to a stirring solution of $\left[\left(\mathrm{BDI}_{\mathrm{DIPP}}\right) \mathrm{GaMe}_{2}\right](100 \mathrm{mg}, 0.2 \mathrm{mmol})$ in toluene $(5 \mathrm{~mL})$ and stirred at room temperature for $24 \mathrm{~h}$, resulting in the formation of a white precipitate that was insoluble in $\mathrm{C}_{6} \mathrm{D}_{6}$ and $\mathrm{CDCl}_{3}$ and the only compound soluble was BDI-H, indicated by the ${ }^{1} \mathrm{H}$ NMR spectrum.

\section{Attempted Synthesis of BDIGa(OPh) 2 (35)}

A solution of $\mathrm{PhOH}(40 \mathrm{mg}, 0.4 \mathrm{mmol})$ in toluene $(5 \mathrm{~mL})$ was added drop-wise to a stirring solution of $\left[\left(\mathrm{BDI}_{\mathrm{DIPP}}\right) \mathrm{GaMe}_{2}\right](100 \mathrm{mg}, 0.2 \mathrm{mmol})$ in toluene $(5 \mathrm{~mL})$ and stirred at room temperature 
for $24 \mathrm{~h}$, resulting unexpectedly in the formation of a white precipitate that was insoluble in $\mathrm{C}_{6} \mathrm{D}_{6}$ and $\mathrm{CDCl}_{3}$ and the NMR spectrum signalled the only compound soluble was BDI-H.

\section{Attempted Synthesis of BDIGa(O-2,6- $\left.{ }^{\mathrm{t}} \mathrm{Bu}-\mathrm{Ph}\right)_{2}(33)$}

A solution of 2,6-ditbuphenol (40 mg, $0.2 \mathrm{mmol})$ in toluene $(10 \mathrm{~mL})$ was added drop-wise to a stirring solution of $\left[\left(\mathrm{BDI}_{\mathrm{DIPP}}\right) \mathrm{GaMe}_{2}\right](100 \mathrm{mg}, 0.2 \mathrm{mmol})$ in toluene $(5 \mathrm{~mL})$ and stirred at room temperature for $24 \mathrm{~h}$, resulting in the formation of a brown solid that was insoluble in $\mathrm{C}_{6} \mathrm{D}_{6}$ and $\mathrm{CDCl}_{3}$ and the NMR spectrum signalled the only compound soluble was BDI-H. 


\section{Appendix B: NMR Spectra of Known Compounds}

\section{B.1 BDI-H}

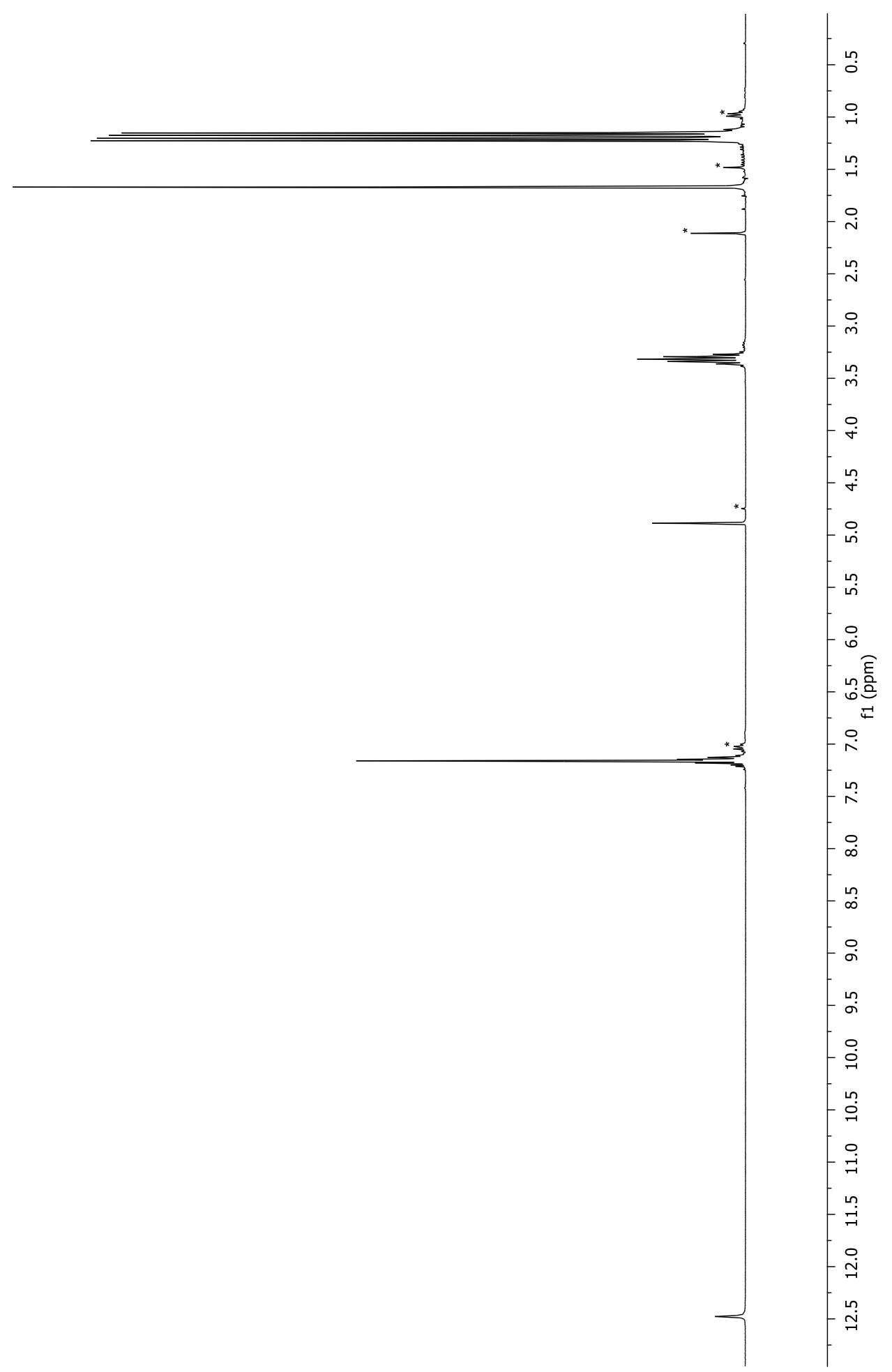

${ }^{1} \mathrm{H}$ NMR spectrum of BDI-H (299.741 MHz, $\left.\mathrm{C}_{6} \mathrm{D}_{6}\right)$

$$
* \text { contamination }
$$




\section{B.2 [(BDI)GaCl 2$]$}

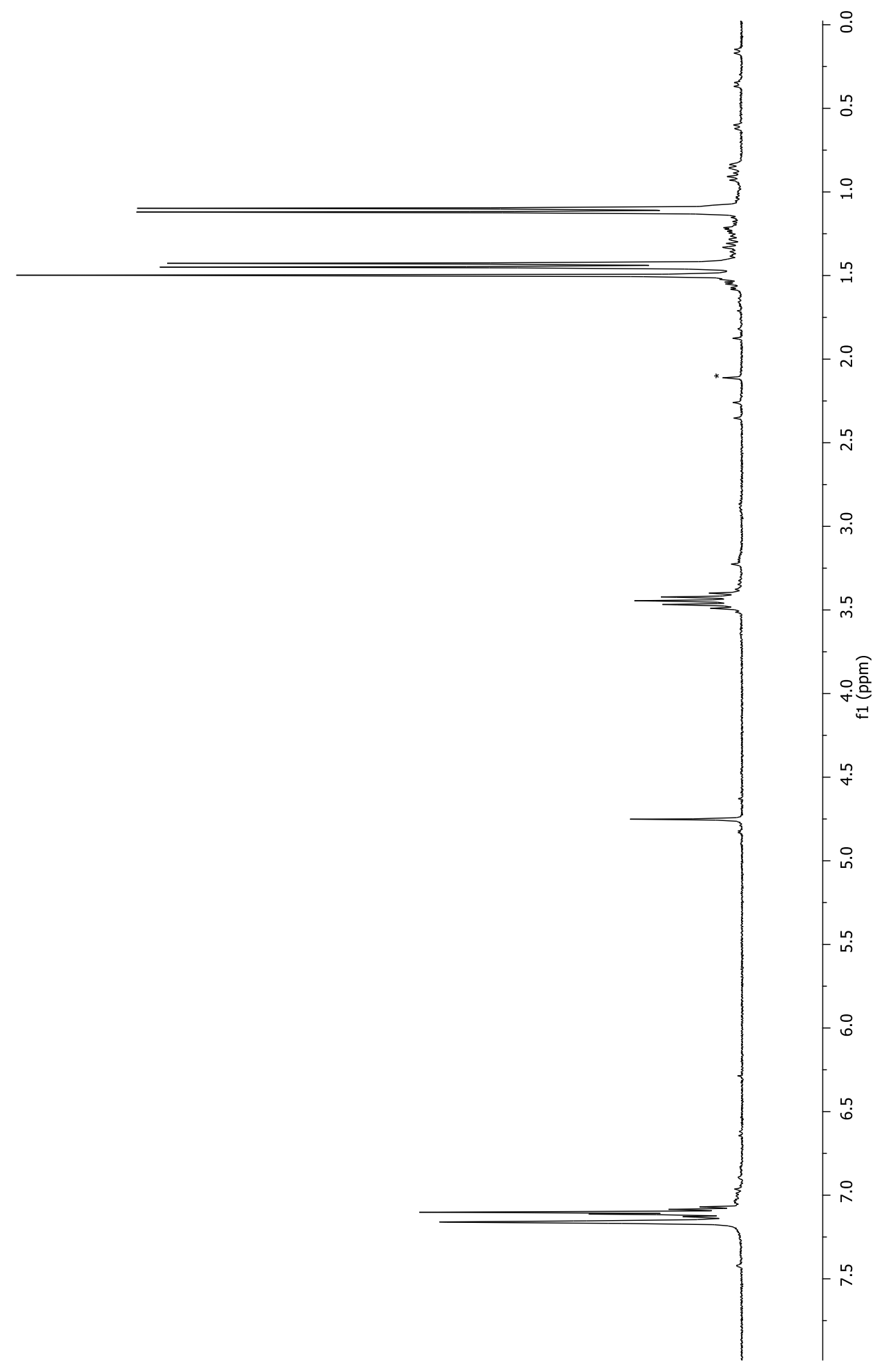

${ }^{1} \mathrm{H}$ NMR spectrum of $\left[(\mathrm{BDI}) \mathrm{GaCl}_{2}\right]\left(299.741 \mathrm{MHz}, \mathrm{C}_{6} \mathrm{D}_{6}\right)$

$*$ = contamination 


\section{B.3 [(BDI)GaMe 2$]$}

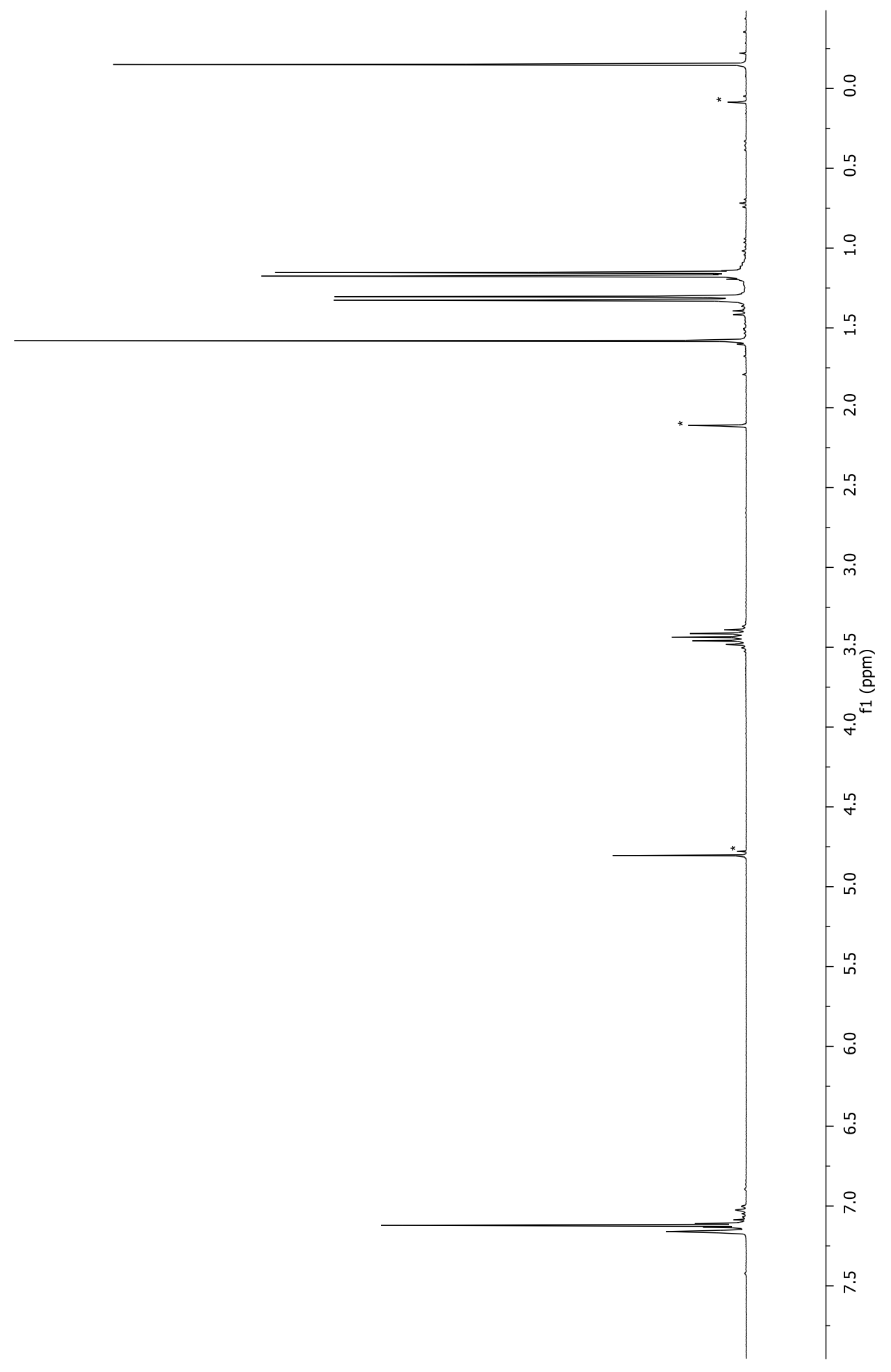

${ }^{1} \mathrm{H}$ NMR spectrum of [(BDI)GaMe 2 (299.741 MHz, $\left.\mathrm{C}_{6} \mathrm{D}_{6}\right)$

$*$ = contamination 


\section{B.4 [(BDI)Ga(NHPh) 2$]$}

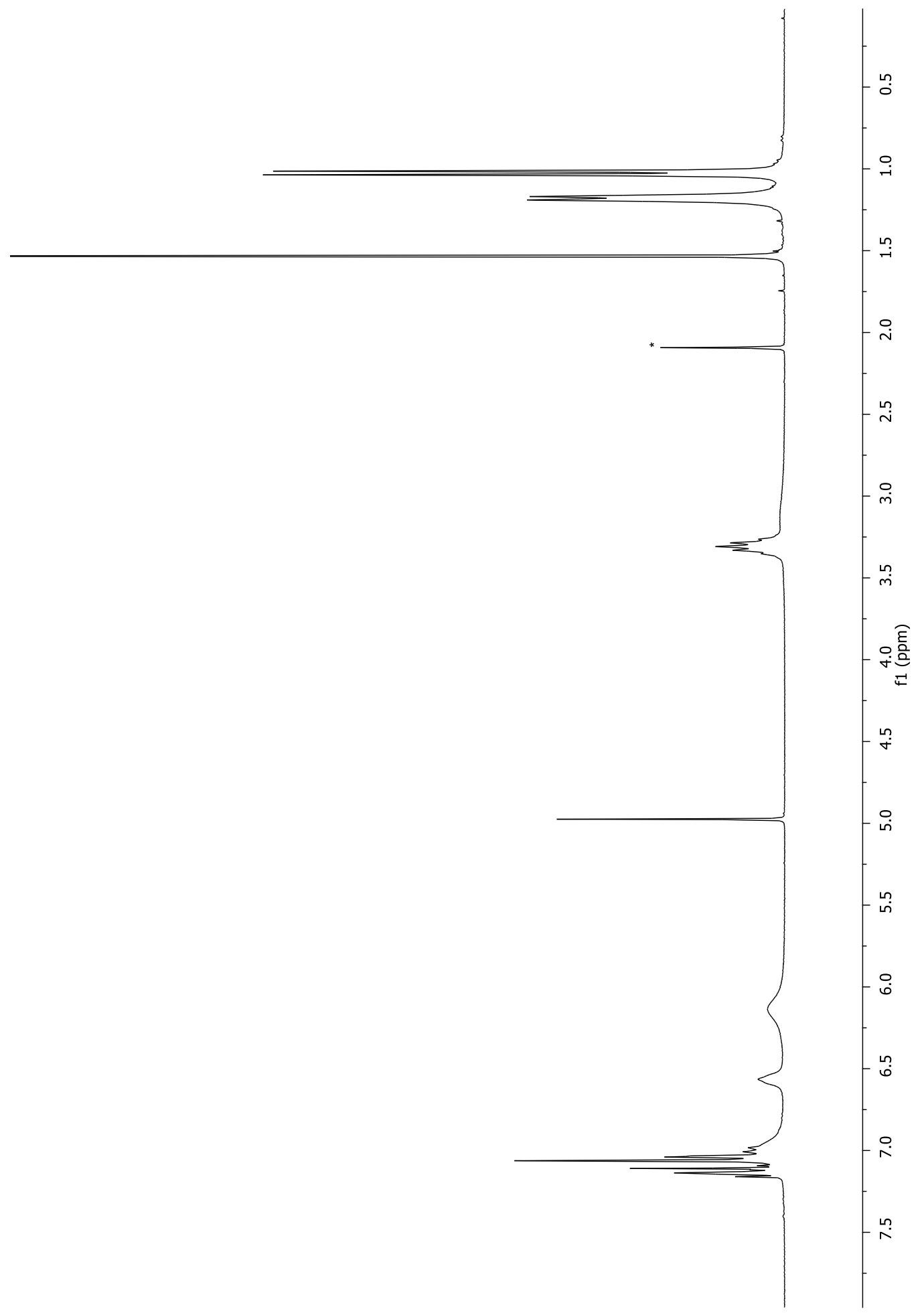

${ }^{1} \mathrm{H}$ NMR spectrum of [(BDI)Ga(NHPh) $\left.{ }_{2}\right]\left(299.741 \mathrm{MHz}, \mathrm{C}_{6} \mathrm{D}_{6}\right)$

$*$ = contamination 


\section{Appendix C: NMR Spectra of Novel Compounds}

\section{C.1 [(BDI)GaBn 2$]$}

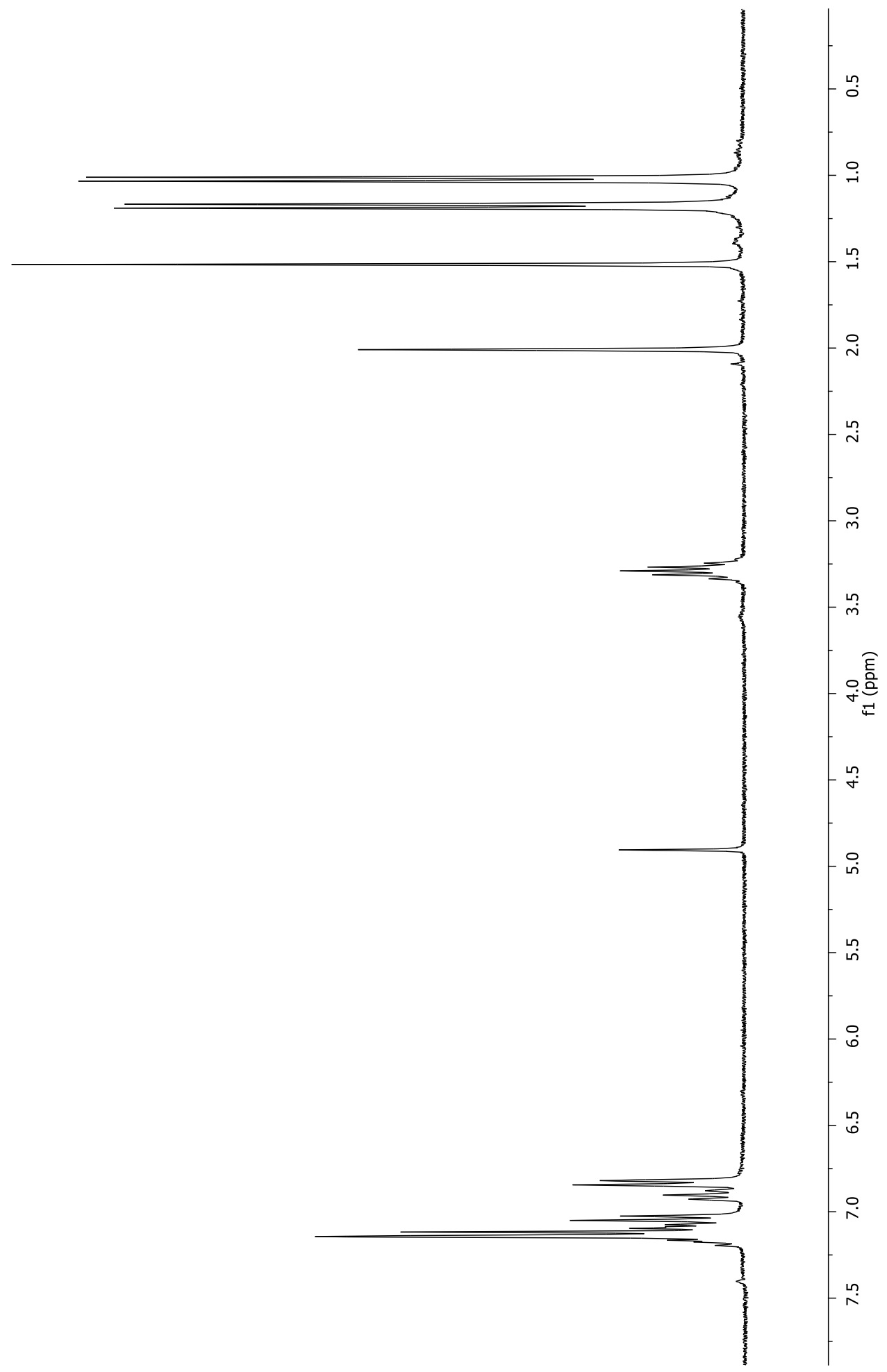

${ }^{1} \mathrm{H}$ NMR spectrum of [(BDI)GaBn $\left.{ }_{2}\right]\left(299.741 \mathrm{MHz}, \mathrm{C}_{6} \mathrm{D}_{6}\right)$ 


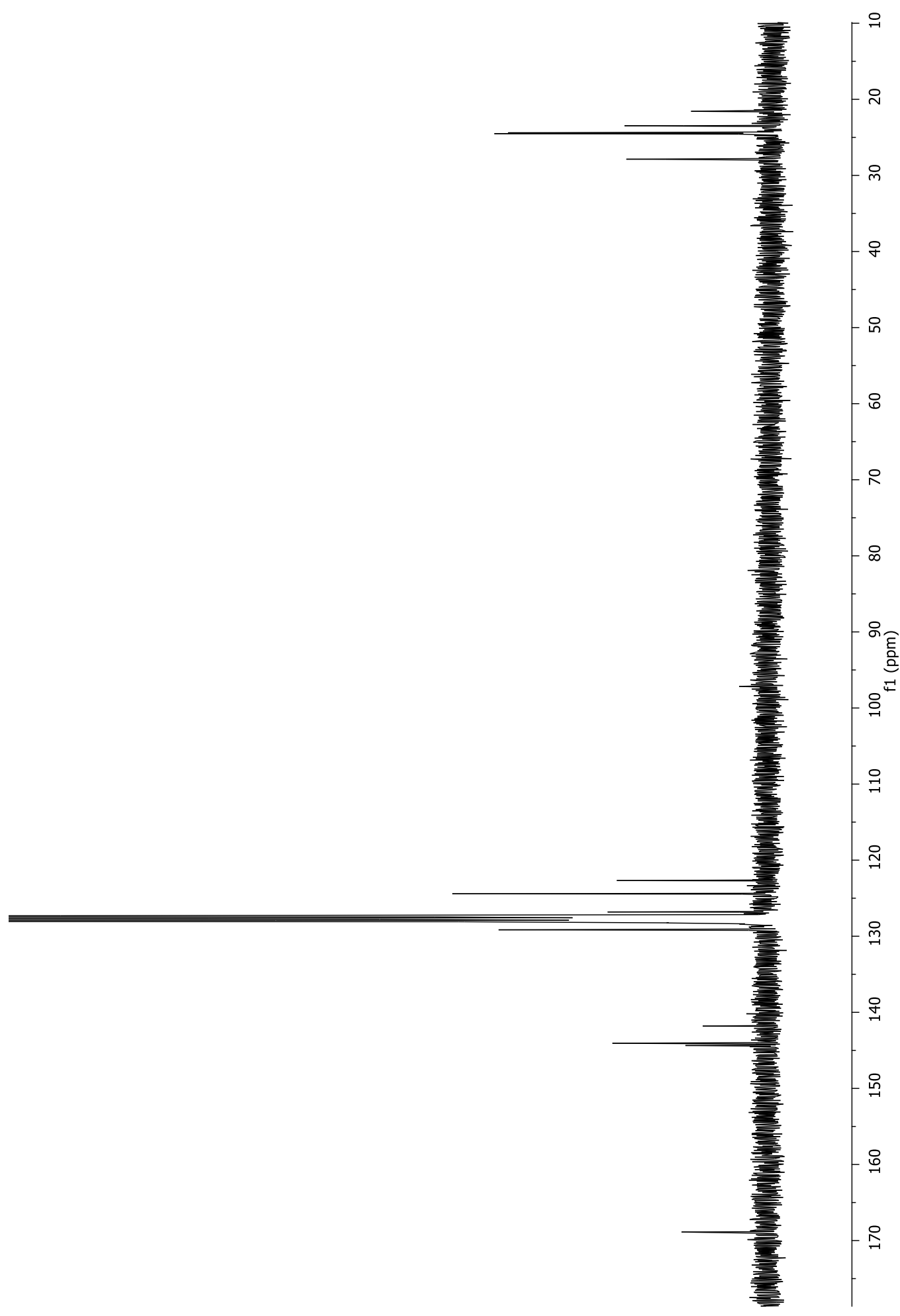

${ }^{13} \mathrm{C}$ NMR spectrum of $\left[(\mathrm{BDI}) \mathrm{GaBn}_{2}\right]\left(75.378 \mathrm{MHz}, \mathrm{C}_{6} \mathrm{D}_{6}\right)$ 


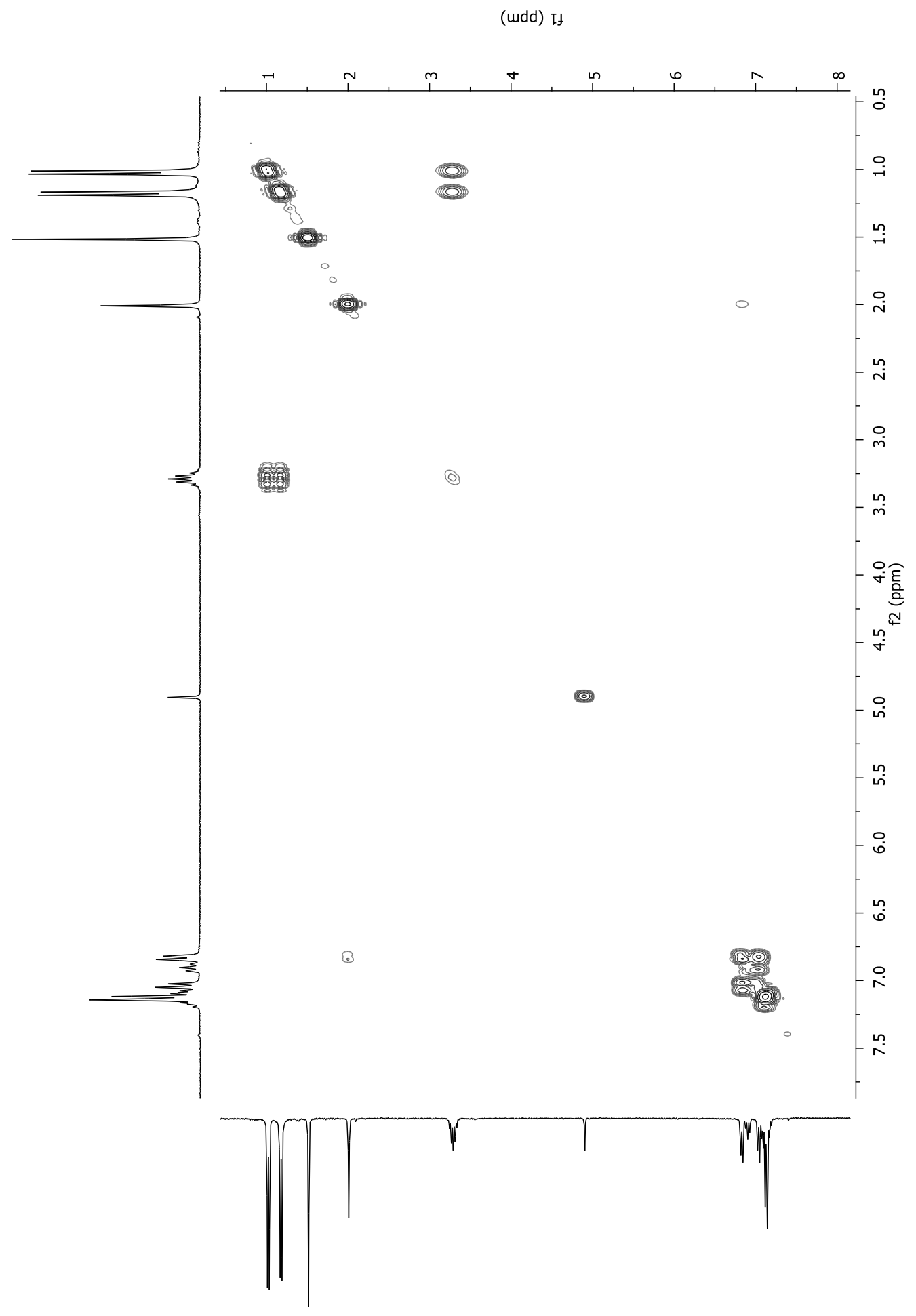

COSY spectrum of [(BDI) $\left.\mathrm{GaBn}_{2}\right]\left(299.741 \mathrm{MHz}, \mathrm{C}_{6} \mathrm{D}_{6}\right)$ 
(udd) If

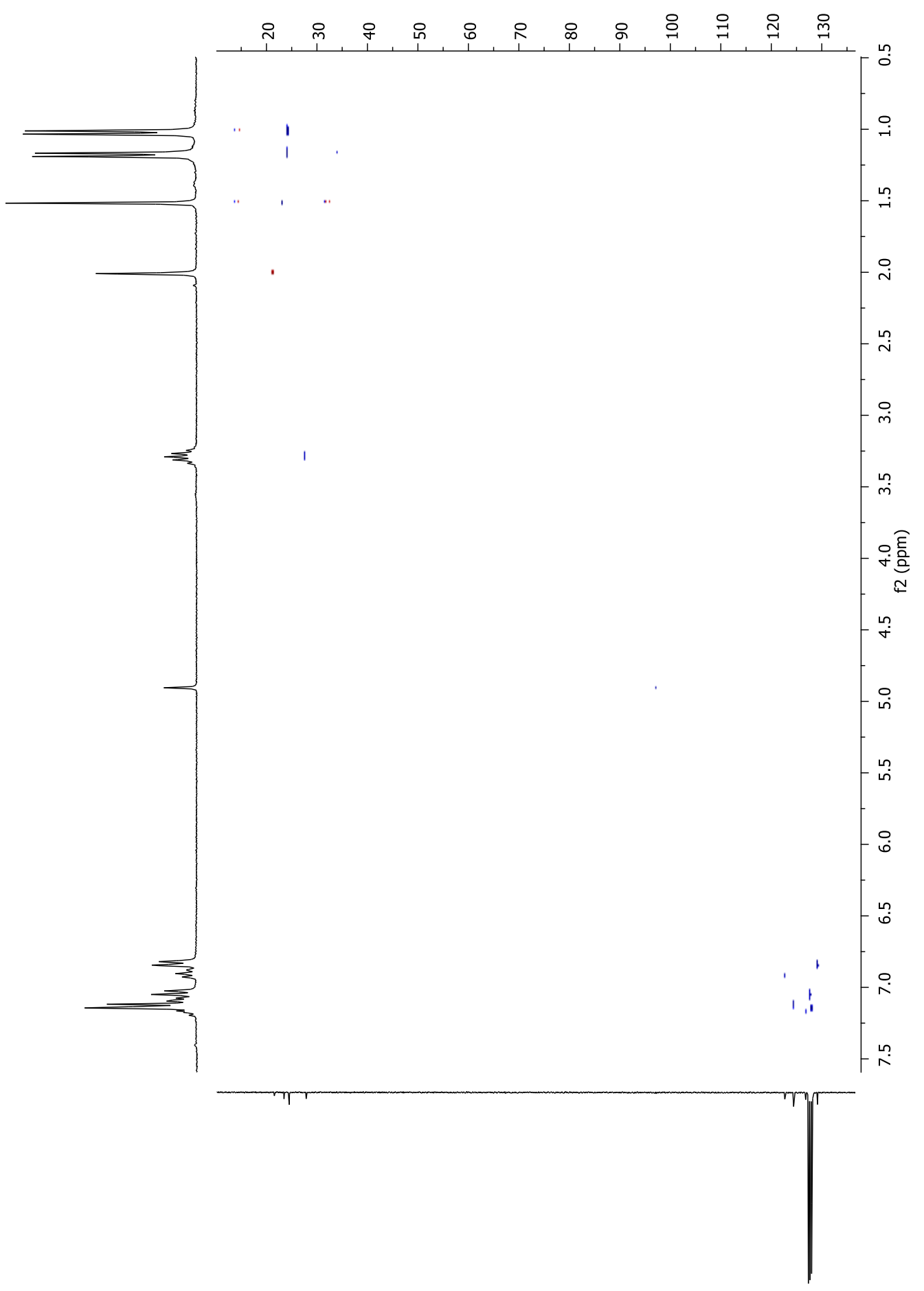

Multiplicity-edited HSQC spectrum of [(BDI)GaBn $\mathrm{Ga}_{2}$, showing methyls and methines in blue and methylenes in red $\left(299.741 \mathrm{MHz}, \mathrm{C}_{6} \mathrm{D}_{6}\right)$ 
(udd) It

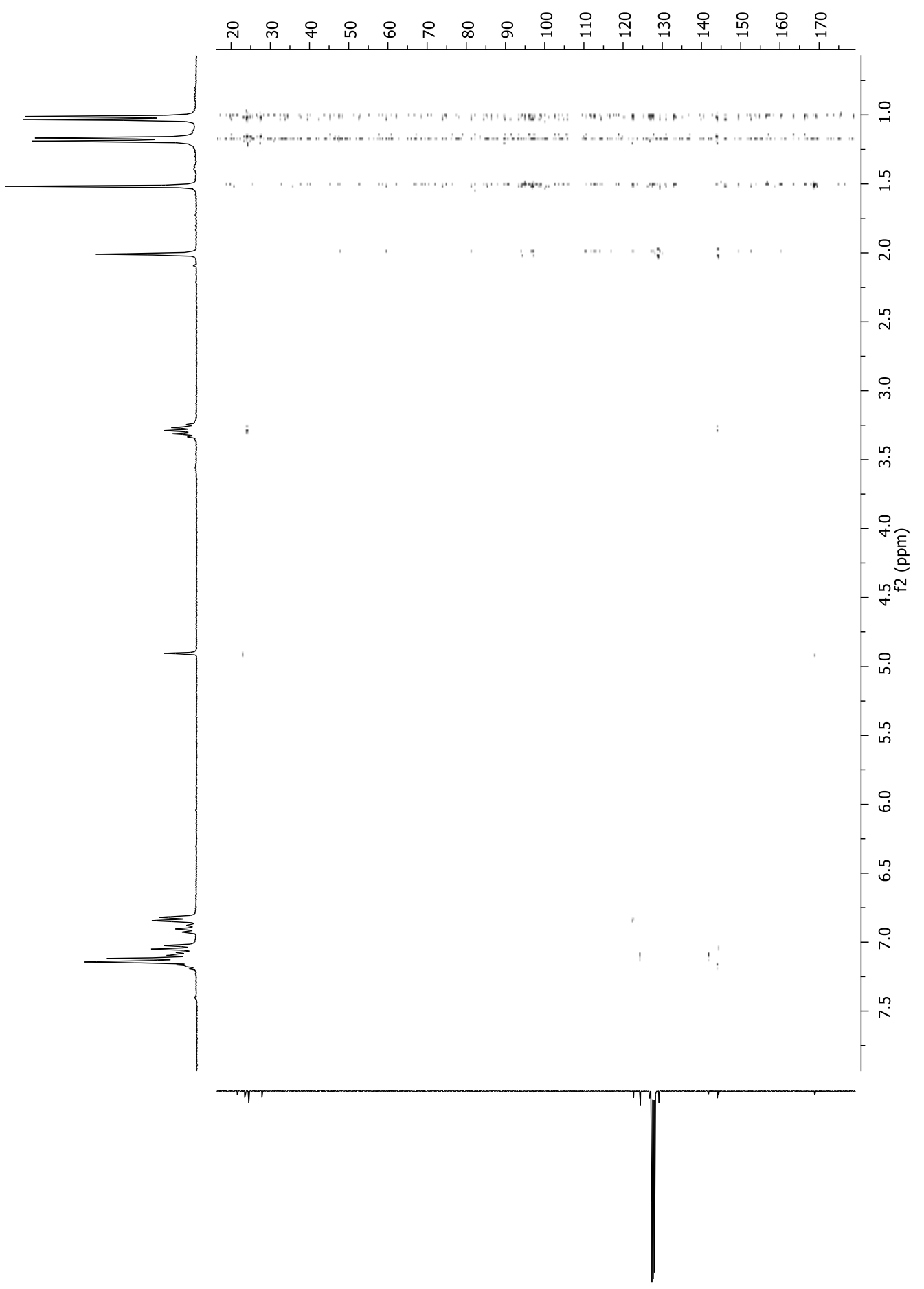

HMBC spectrum of [(BDI) $\left.\mathrm{GaBn}_{2}\right]\left(299.741 \mathrm{MHz}, \mathrm{C}_{6} \mathrm{D}_{6}\right)$ 


\section{C.2 [(BDI)Ga(NHDMP) 2$]$}

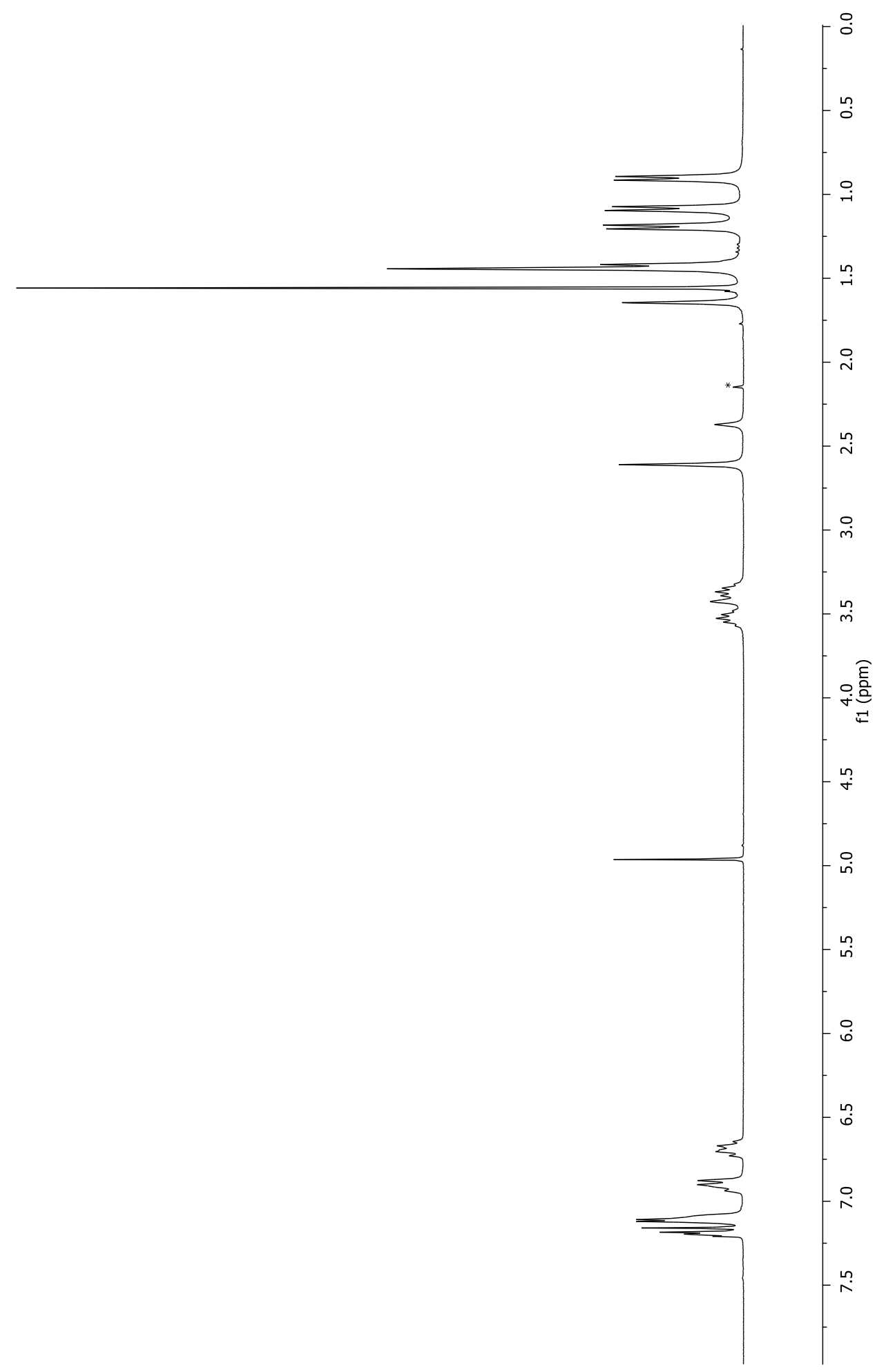

${ }^{1} \mathrm{H}$ NMR spectrum of $\left[(\mathrm{BDI}) \mathrm{Ga}(\mathrm{NHDMP})_{2}\right]\left(299.741 \mathrm{MHz}, \mathrm{C}_{6} \mathrm{D}_{6}\right)$

$*$ = contamination 


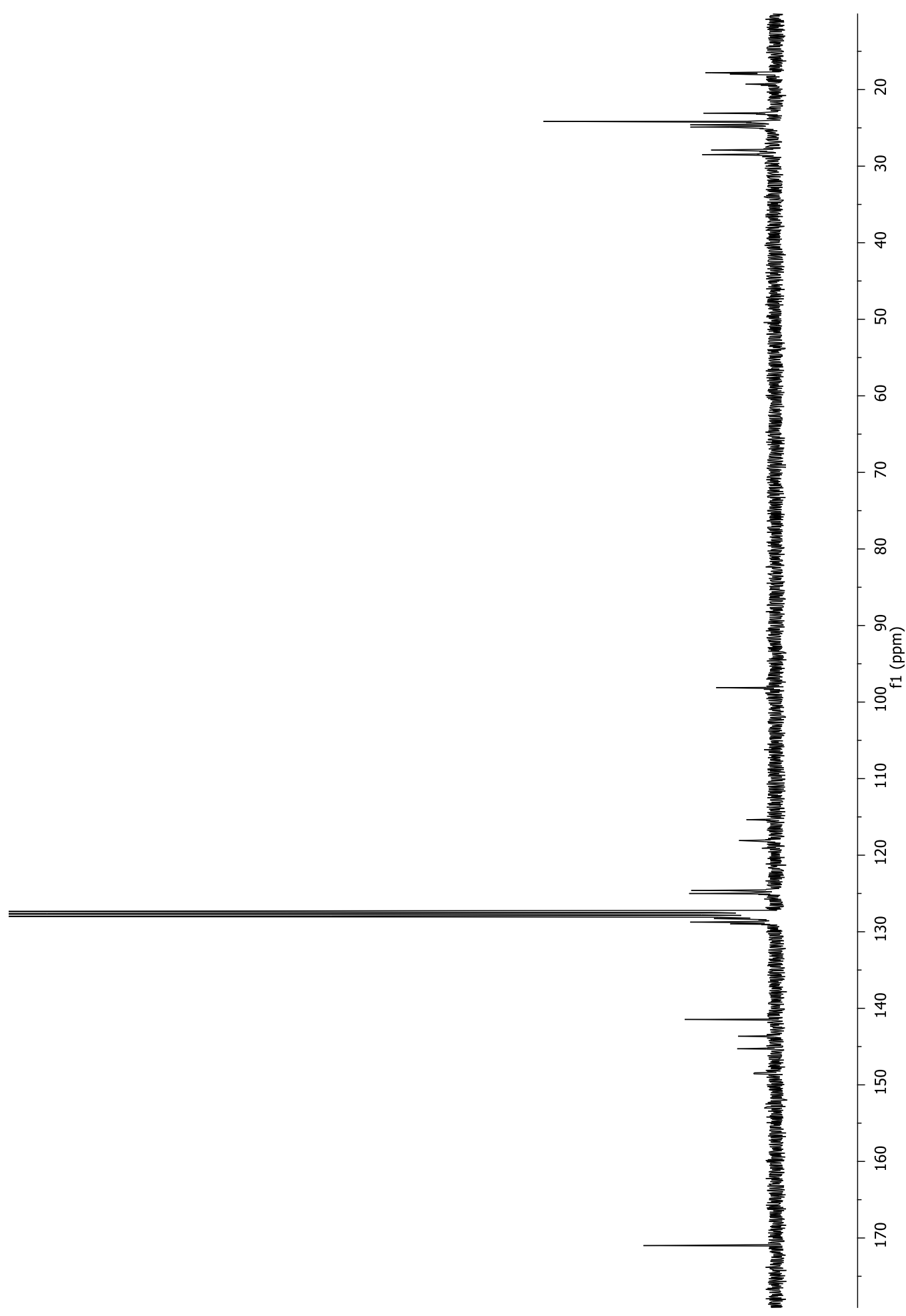

${ }^{13} \mathrm{C}$ NMR spectrum of $\left[(\mathrm{BDI}) \mathrm{Ga}(\mathrm{NHDMP}){ }_{2}\right]\left(75.378 \mathrm{MHz}, \mathrm{C}_{6} \mathrm{D}_{6}\right)$ 
(udd) If

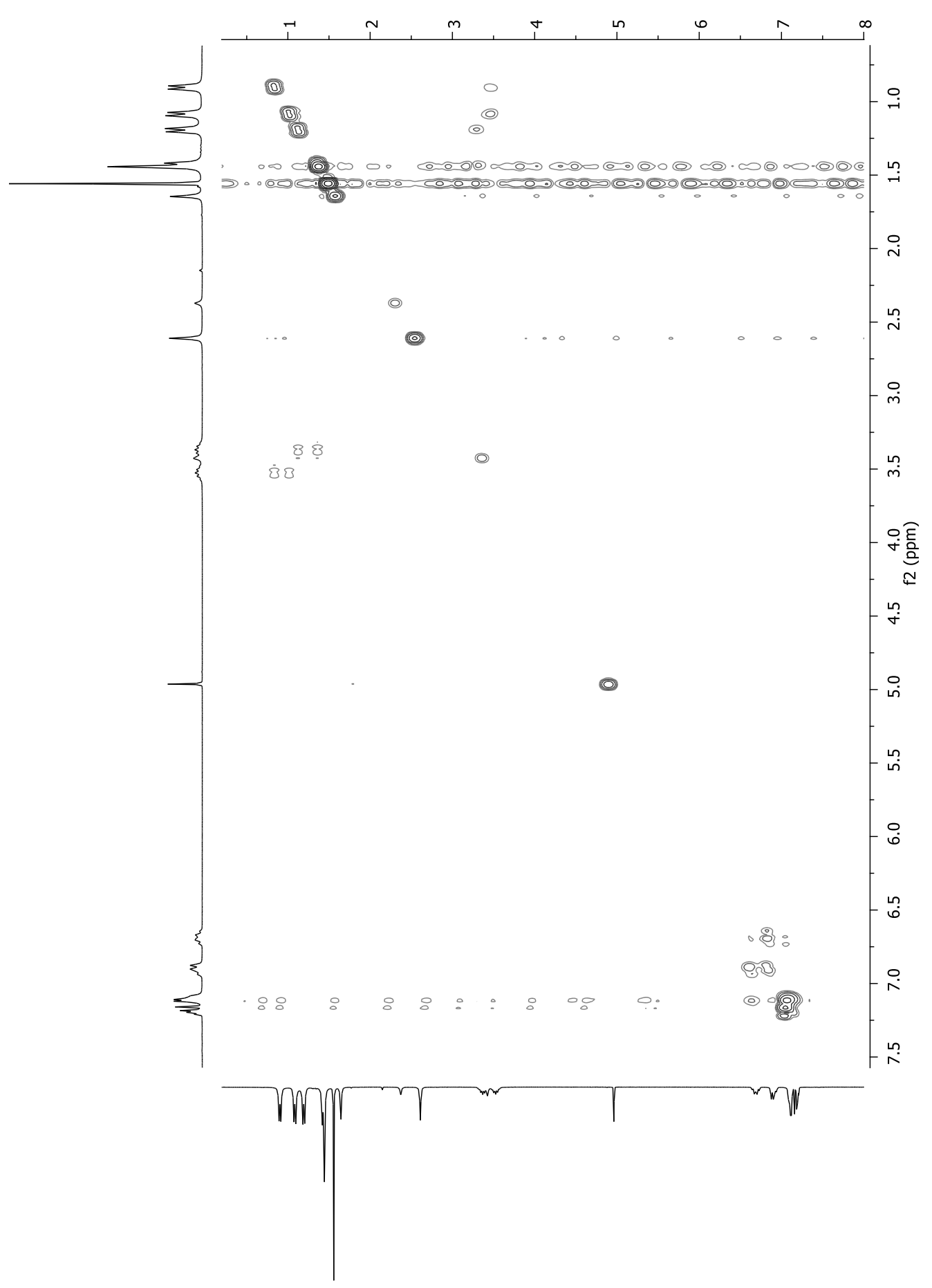

COSY spectrum of [(BDI)Ga(NHDMP) $)_{2}$ (299.741 MHz, $\left.\mathrm{C}_{6} \mathrm{D}_{6}\right)$ 
(udd) If

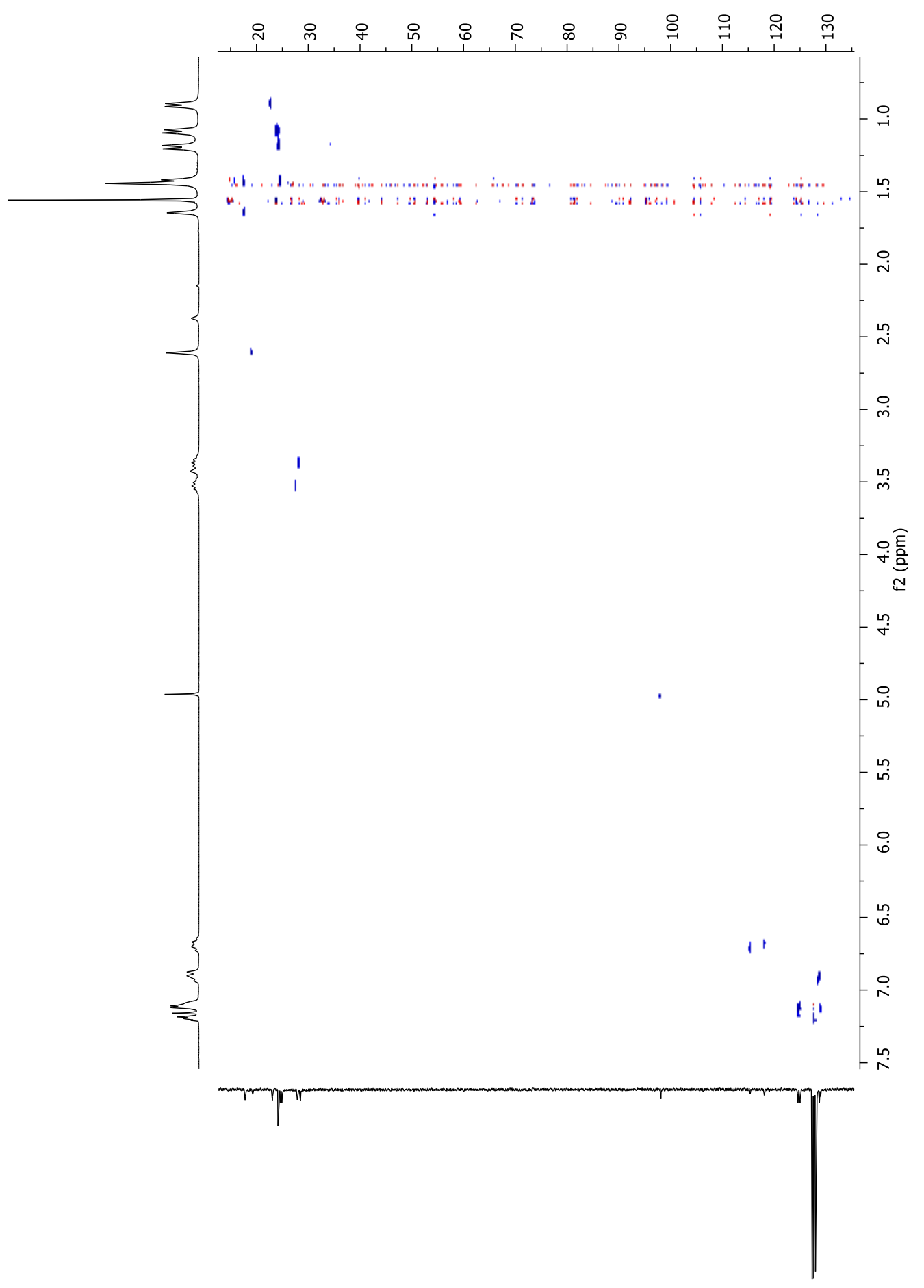

Multiplicity-edited $\mathrm{HSQC}$ spectrum of [(BDI)Ga(NHDMP $\left.)_{2}\right]$, showing methyls and methines in blue and methylenes in red $\left(299.741 \mathrm{MHz}, \mathrm{C}_{6} \mathrm{D}_{6}\right)$ 
(udd) If

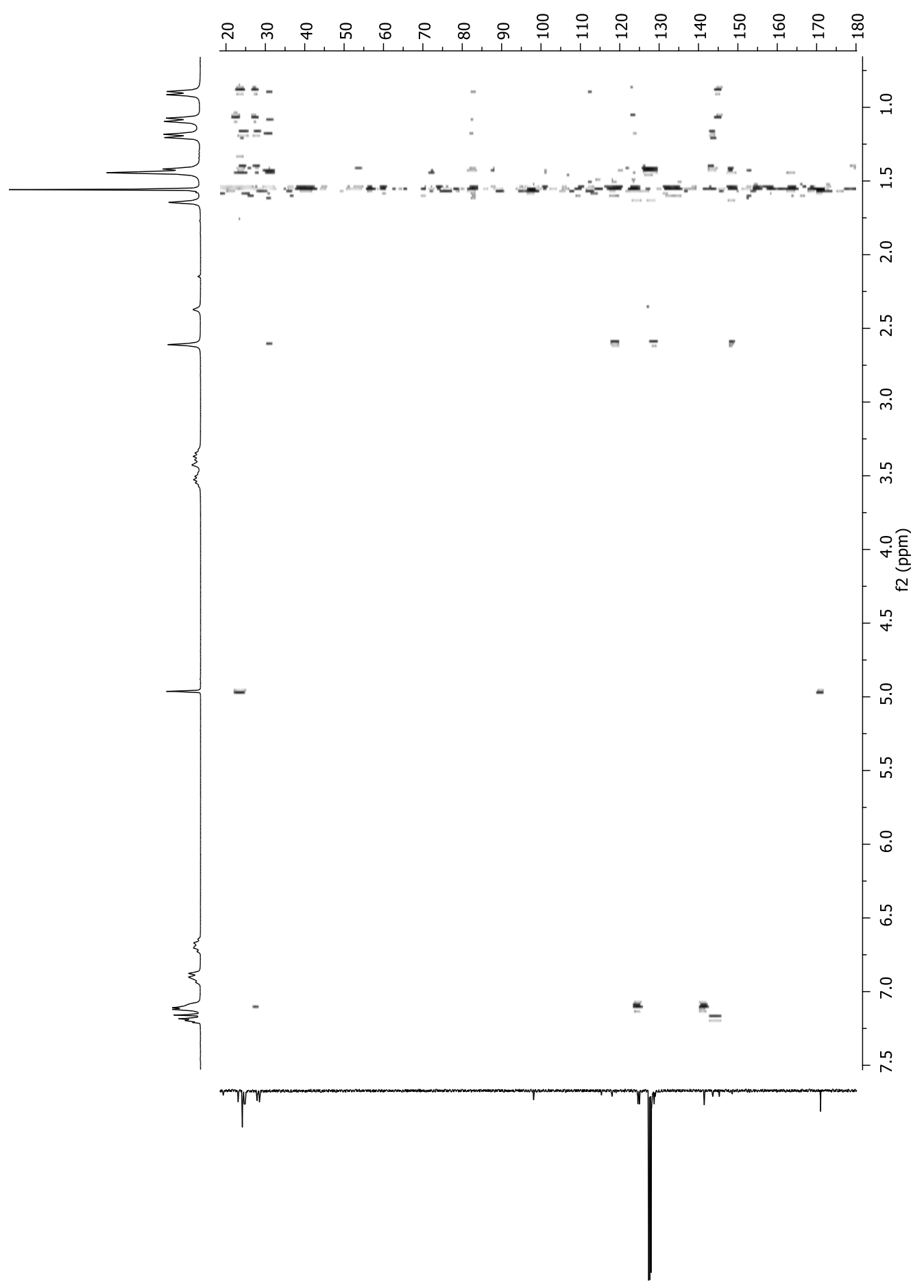

HMBC spectrum of [(BDI)Ga(NHDMP) $)_{2}\left(299.741 \mathrm{MHz}, \mathrm{C}_{6} \mathrm{D}_{6}\right)$ 


\section{C.3 [(BDI)Ga(NHDIPP) $\left.)_{2}\right]$}

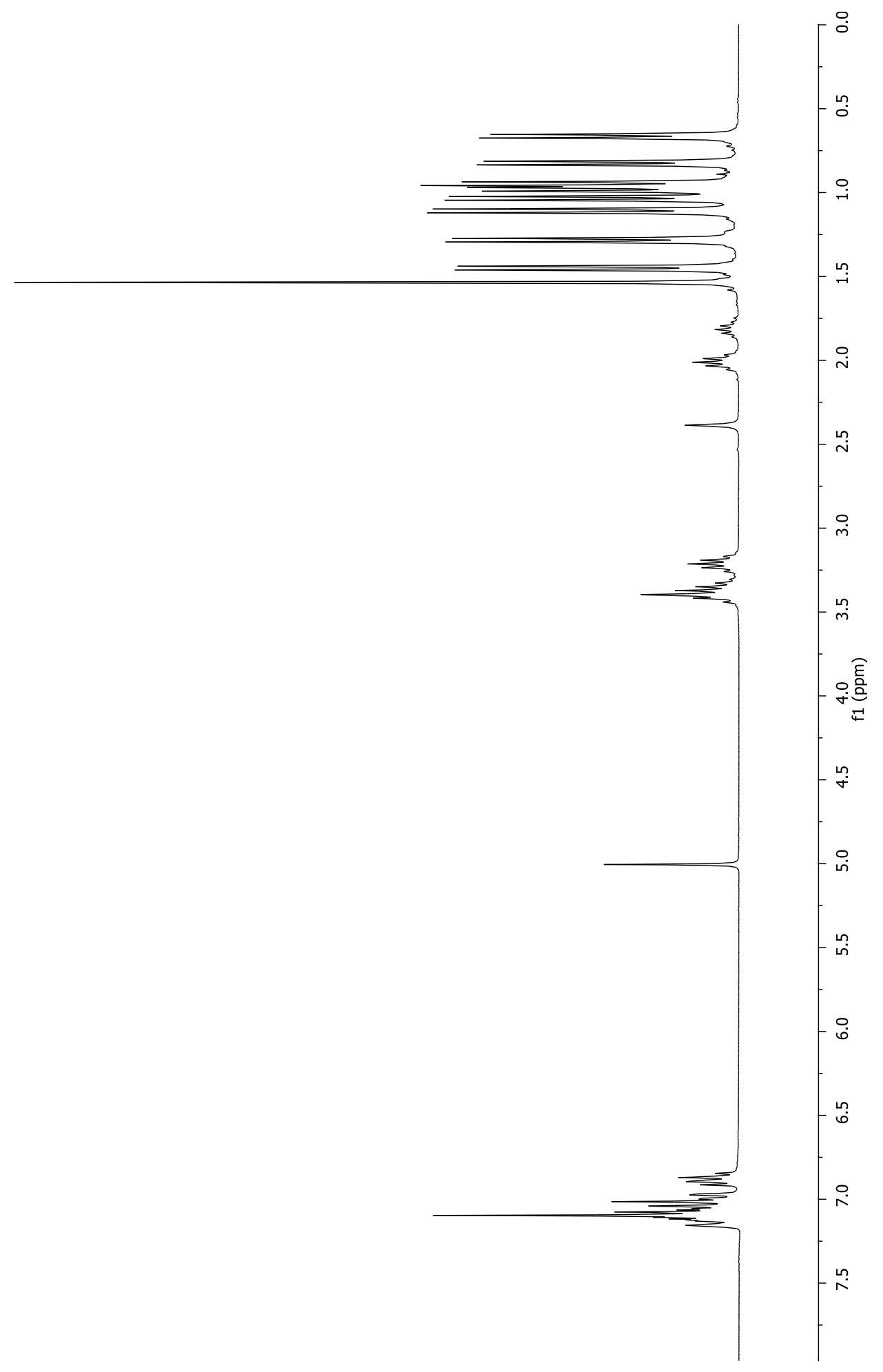

${ }^{1} \mathrm{H}$ NMR spectrum of [(BDI)Ga(NHDIPP) $\left.{ }_{2}\right]\left(299.741 \mathrm{MHz}, \mathrm{C}_{6} \mathrm{D}_{6}\right)$ 


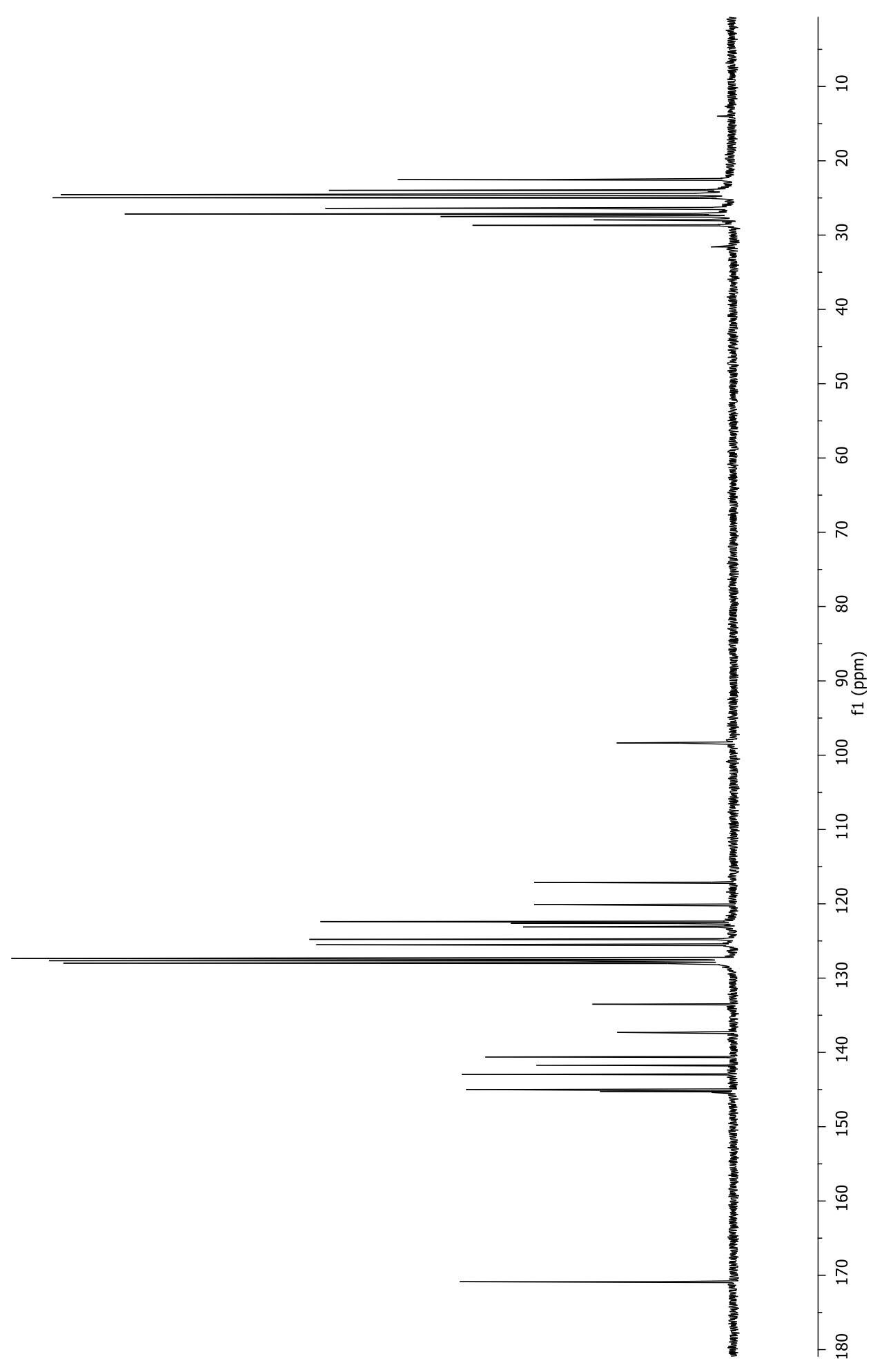

${ }^{13} \mathrm{C}$ NMR spectrum of [(BDI)Ga(NHDIPP) $\left.)_{2}\right]\left(75.378 \mathrm{MHz}, \mathrm{C}_{6} \mathrm{D}_{6}\right)$ 
(udd) If

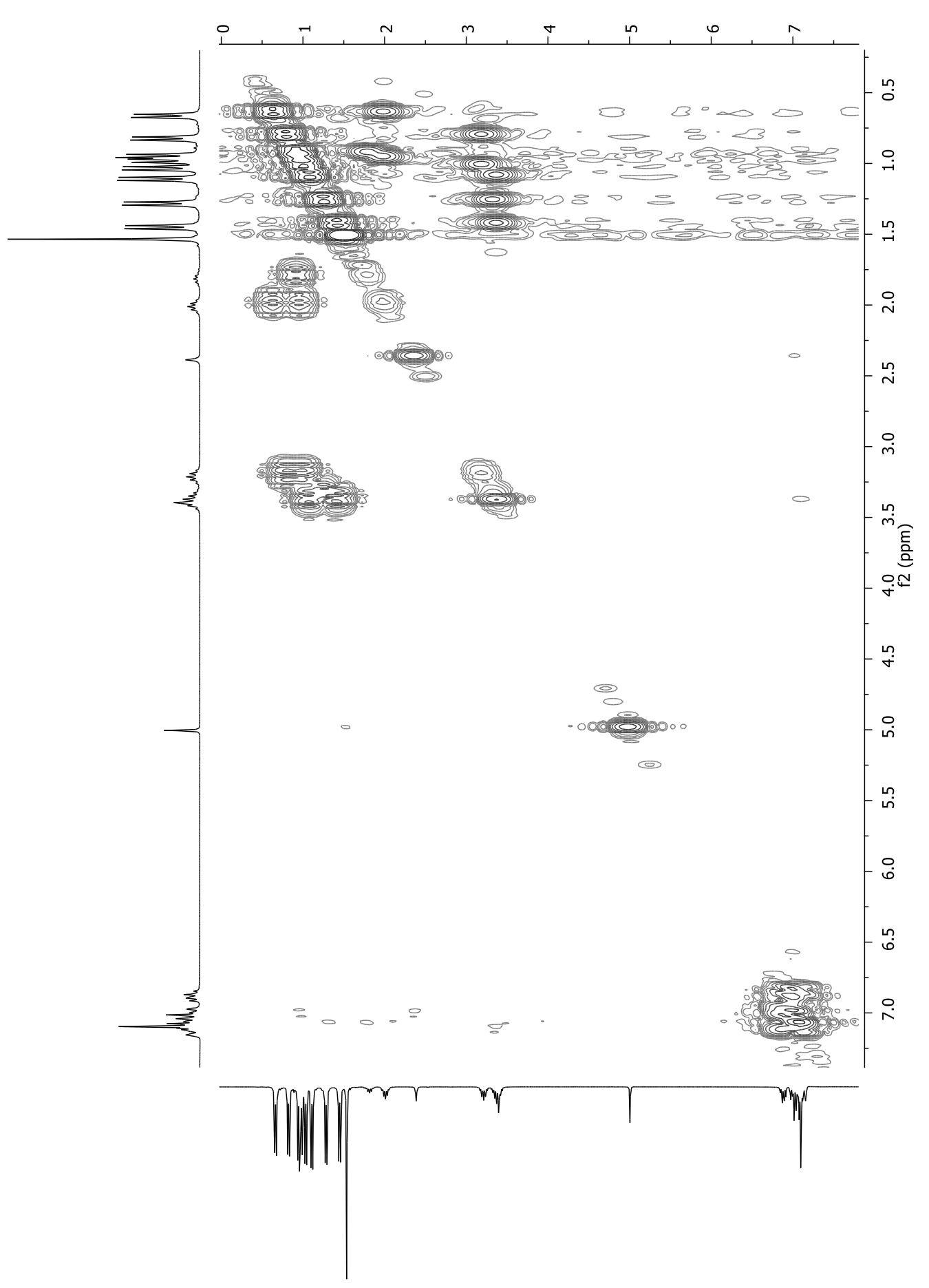

COSY spectrum of [(BDI)Ga(NHDIPP) $\left.{ }_{2}\right]\left(299.741 \mathrm{MHz}, \mathrm{C}_{6} \mathrm{D}_{6}\right)$ 
(udd) It

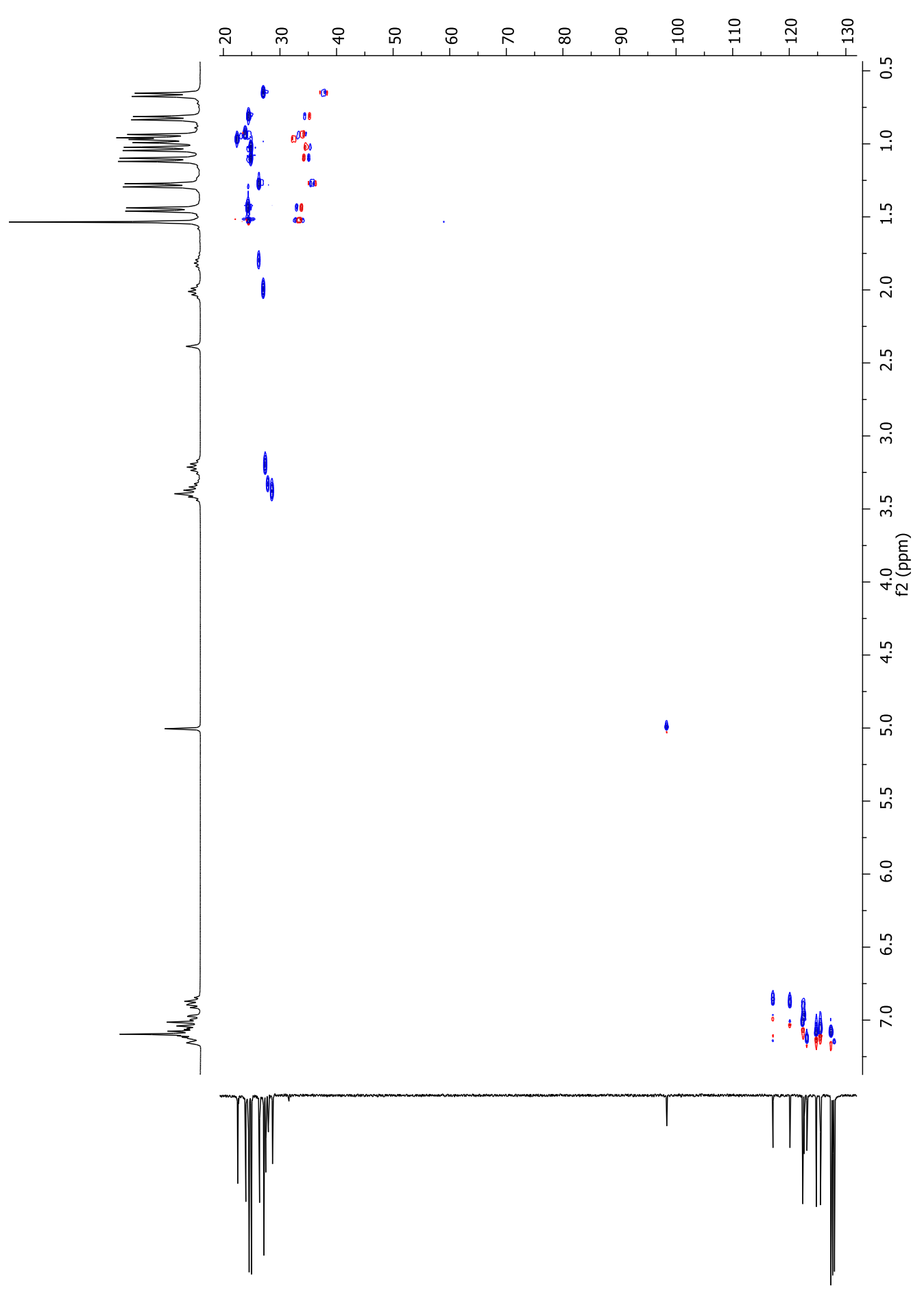

Multiplicity-edited $\mathrm{HSQC}$ spectrum of [(BDI)Ga(NHDIPP) $)_{2}$, showing methyls and methines in blue and methylenes in red $\left(299.741 \mathrm{MHz}, \mathrm{C}_{6} \mathrm{D}_{6}\right)$ 
(udd) It

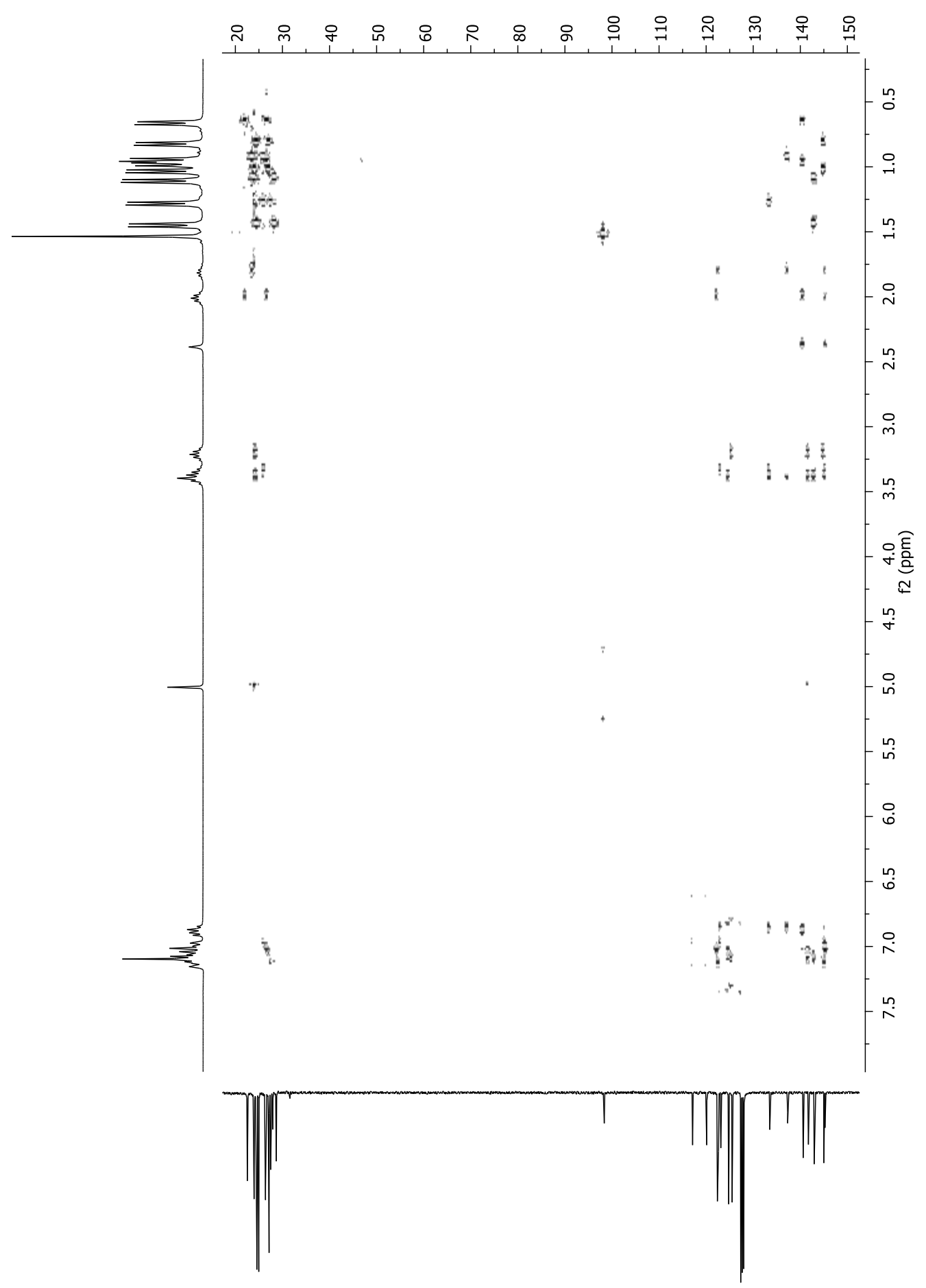

HMBC spectrum of [(BDI)Ga(NHDIPP) $)_{2}$ (299.741 MHz, $\left.\mathrm{C}_{6} \mathrm{D}_{6}\right)$ 


\section{C.4 [(BDI)Ga(NHDMP)Cl]}

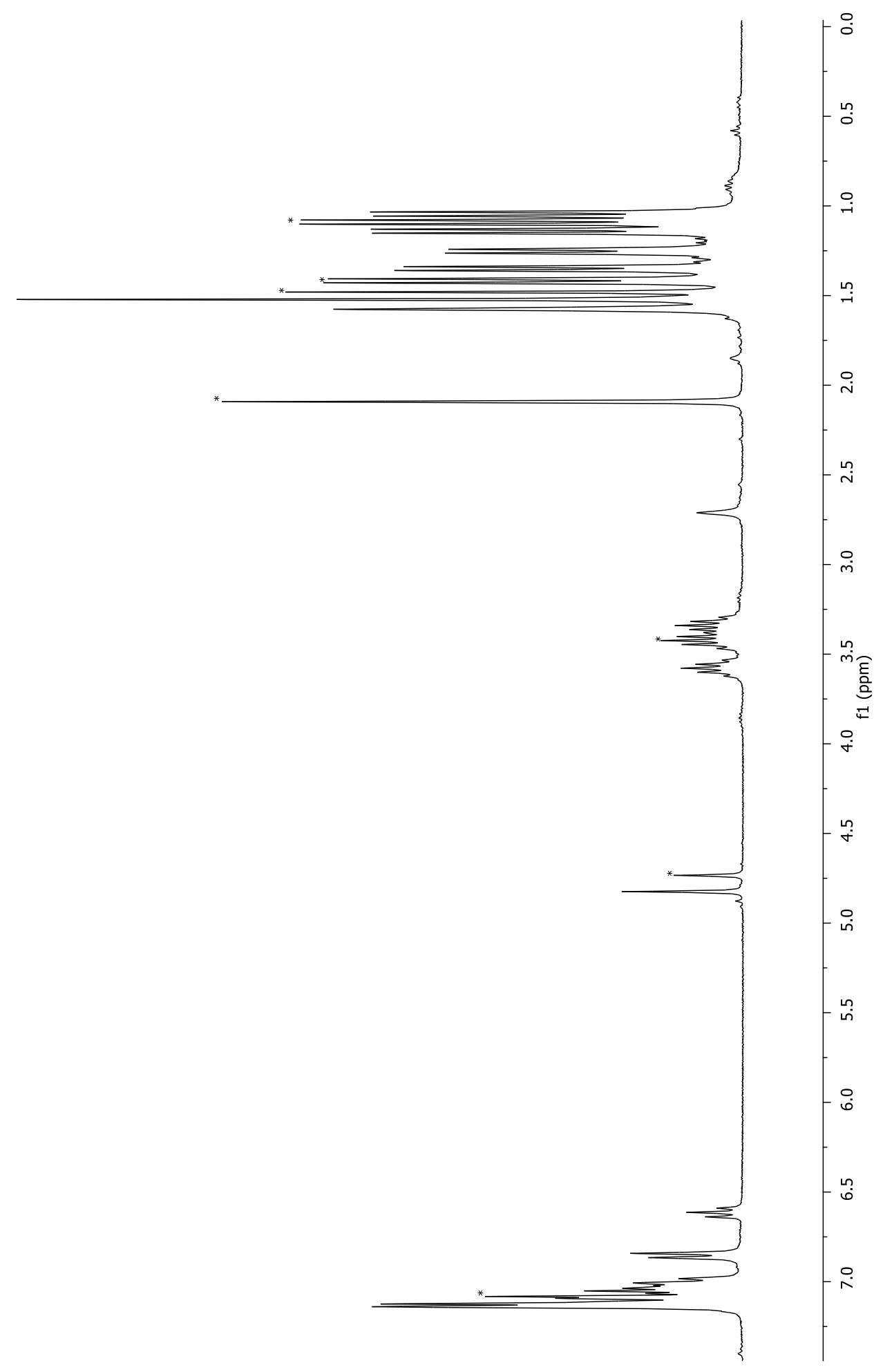

${ }^{1} \mathrm{H}$ NMR spectrum of [(BDI)Ga(NHDMP)Cl] $\left(299.741 \mathrm{MHz}, \mathrm{C}_{6} \mathrm{D}_{6}\right)$

$*=$ contamination 


\section{C.5 [(BDI)Ga(NHDIPP)Cl]}

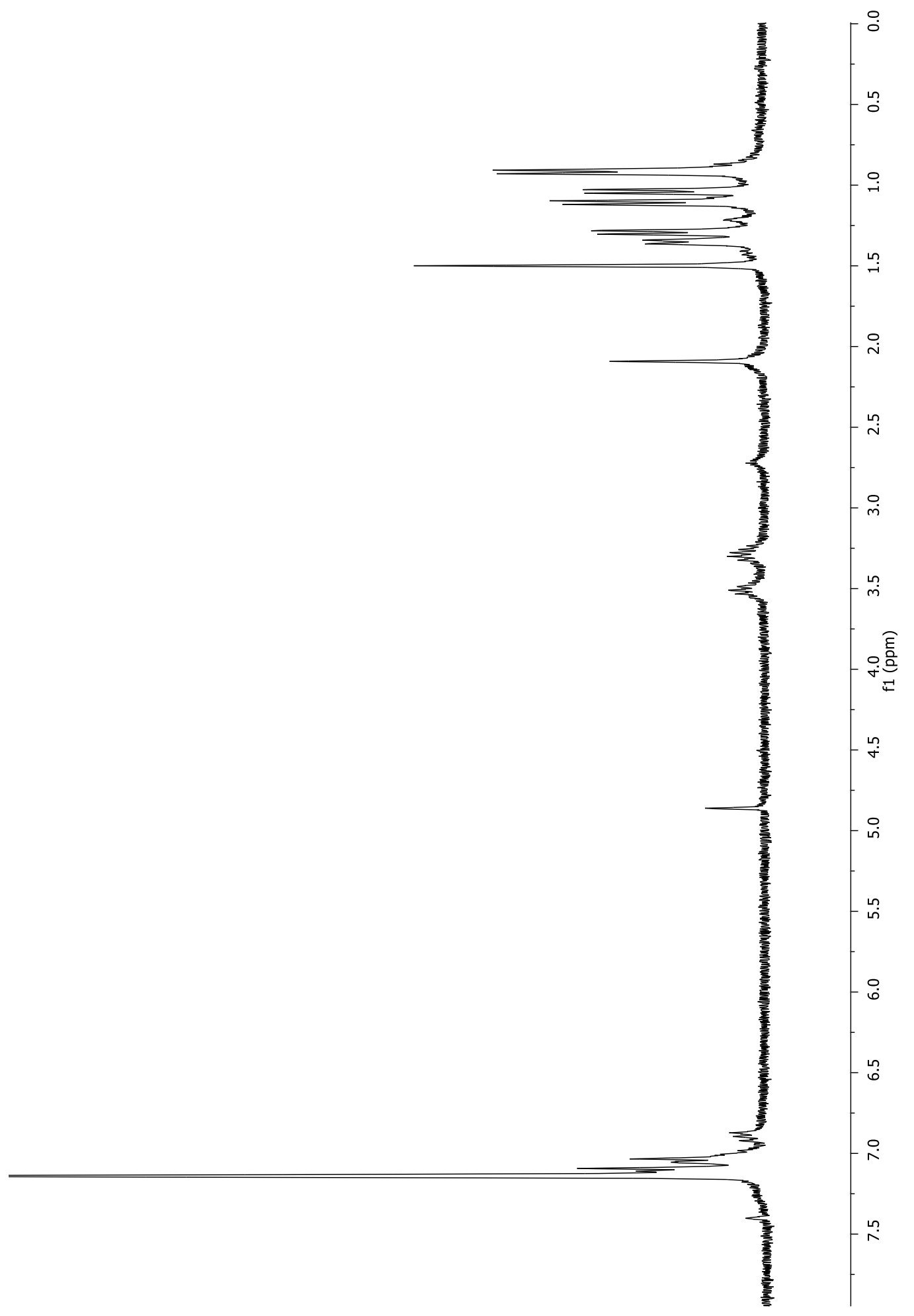

${ }^{1} \mathrm{H}$ NMR spectrum of [(BDI)Ga(NHDIPP)Cl] (299.741 MHz, $\left.\mathrm{C}_{6} \mathrm{D}_{6}\right)$ 


\section{C.6 [(BDI)Ga(PHPh) 2$]$}

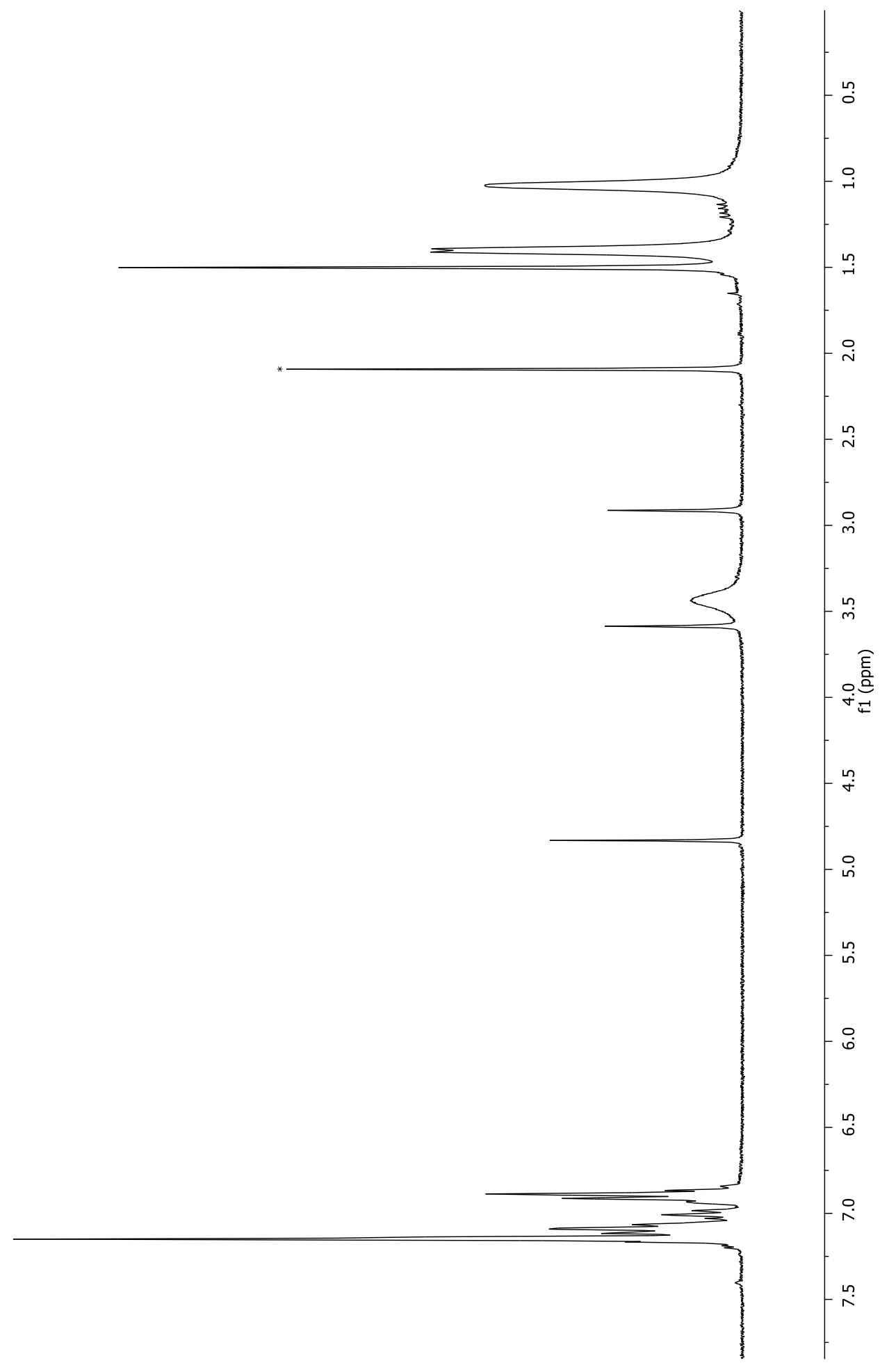

${ }^{1} \mathrm{H}$ NMR spectrum of [(BDI)Ga(PHPh) $\left.{ }_{2}\right]\left(299.741 \mathrm{MHz}, \mathrm{C}_{6} \mathrm{D}_{6}\right)$

$*$ = contamination 


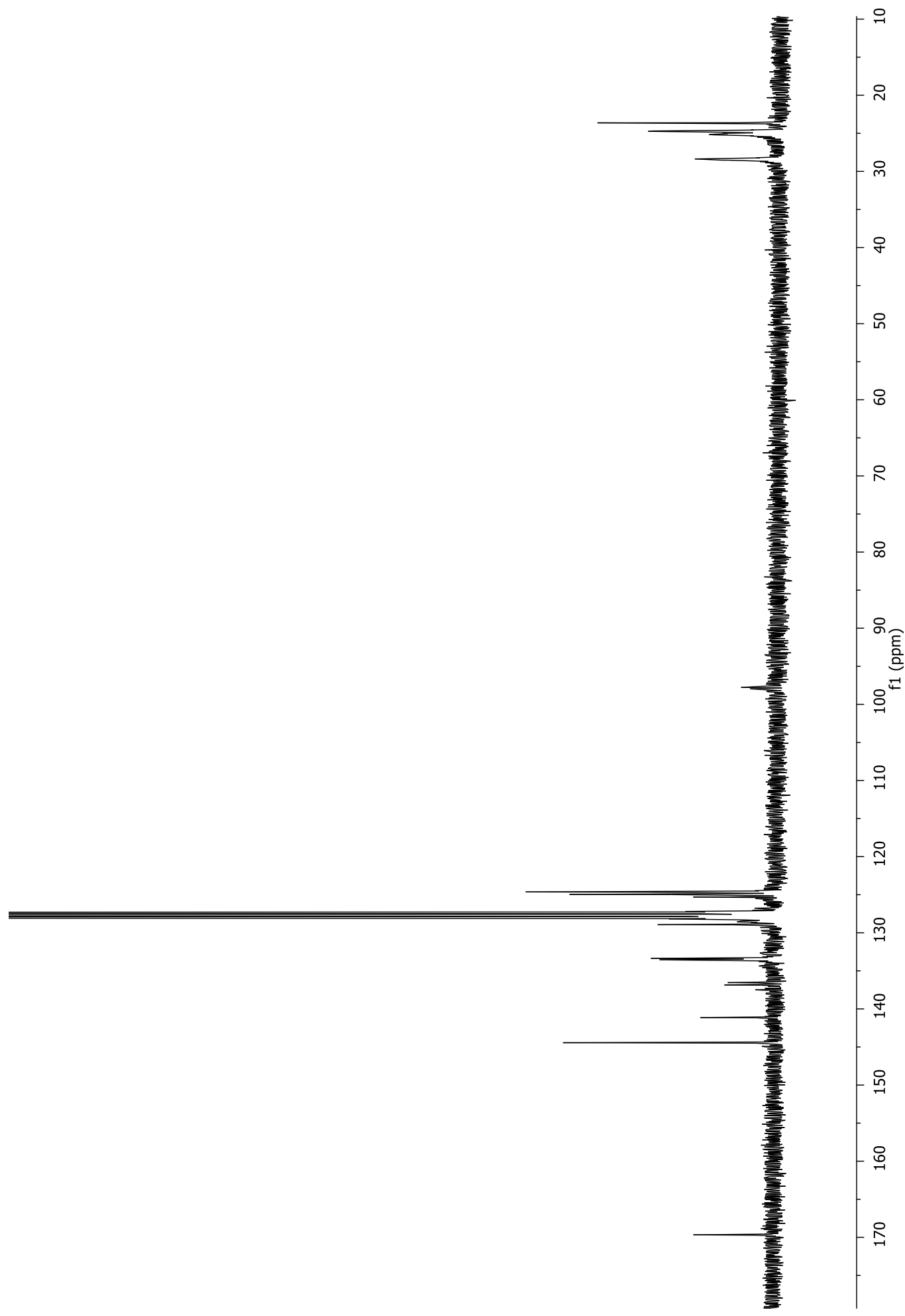

${ }^{13} \mathrm{C}$ NMR spectrum of $\left[(\mathrm{BDI}) \mathrm{Ga}(\mathrm{PHPh})_{2}\right]\left(75.378 \mathrm{MHz}, \mathrm{C}_{6} \mathrm{D}_{6}\right)$ 


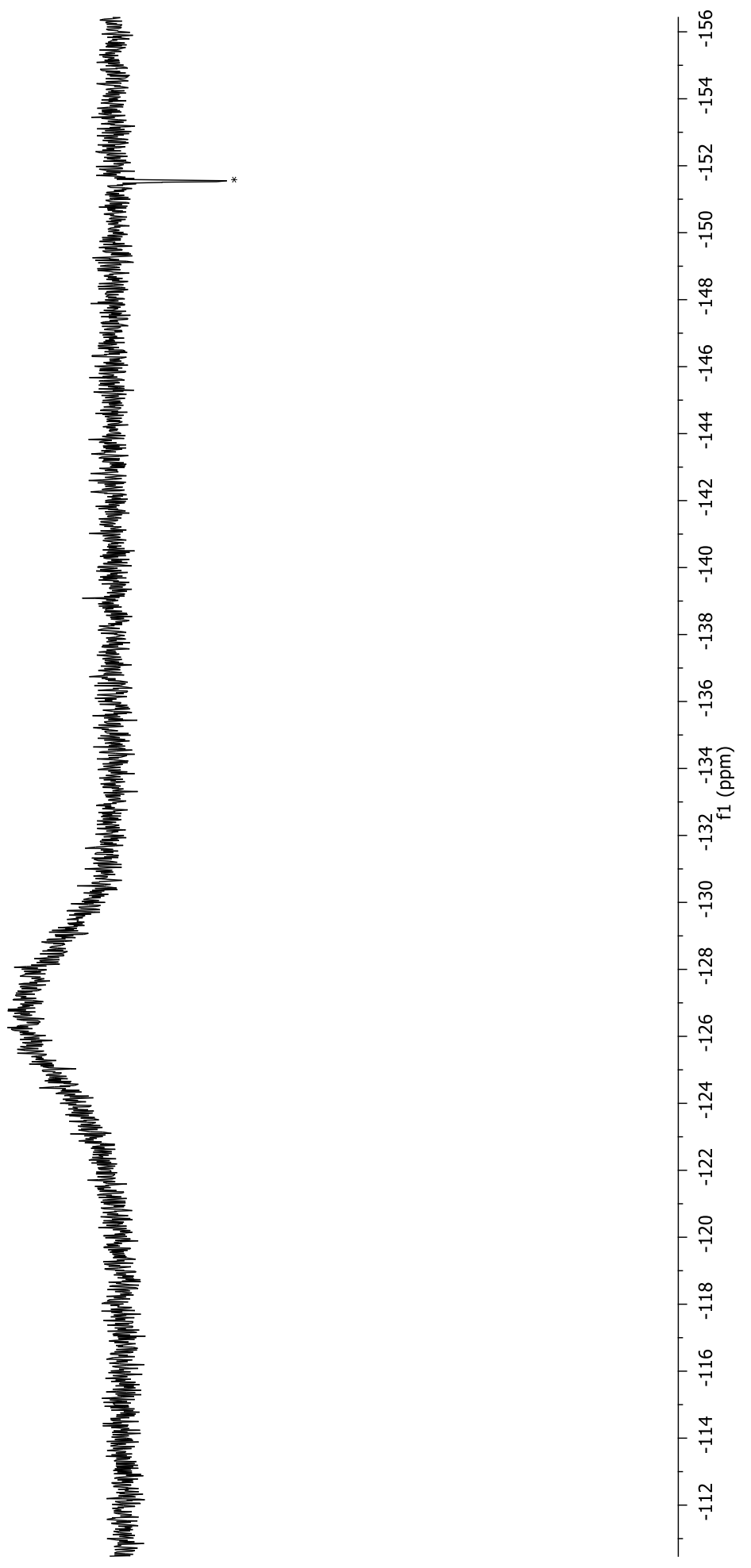

\footnotetext{
${ }^{31} \mathrm{P}$ NMR spectrum of $\left[(\mathrm{BDI}) \mathrm{Ga}(\mathrm{PHPh})_{2}\right]\left(121.318 \mathrm{MHz}, \mathrm{C}_{6} \mathrm{D}_{6}\right)$

$*=$ contamination
} 


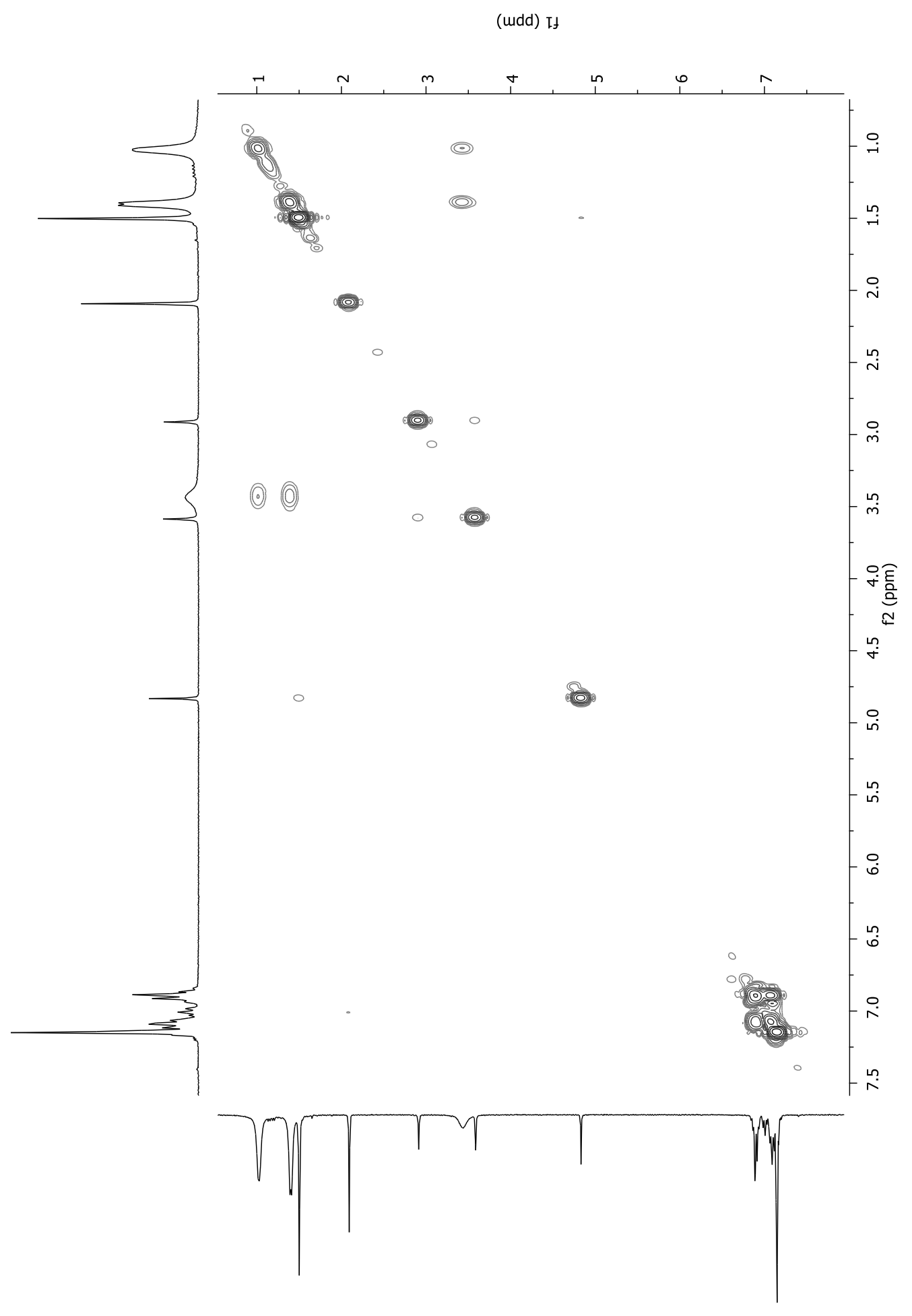

COSY spectrum of $\left[(\mathrm{BDI}) \mathrm{Ga}(\mathrm{PHPh})_{2}\right]\left(299.741 \mathrm{MHz}, \mathrm{C}_{6} \mathrm{D}_{6}\right)$ 
(udd) It

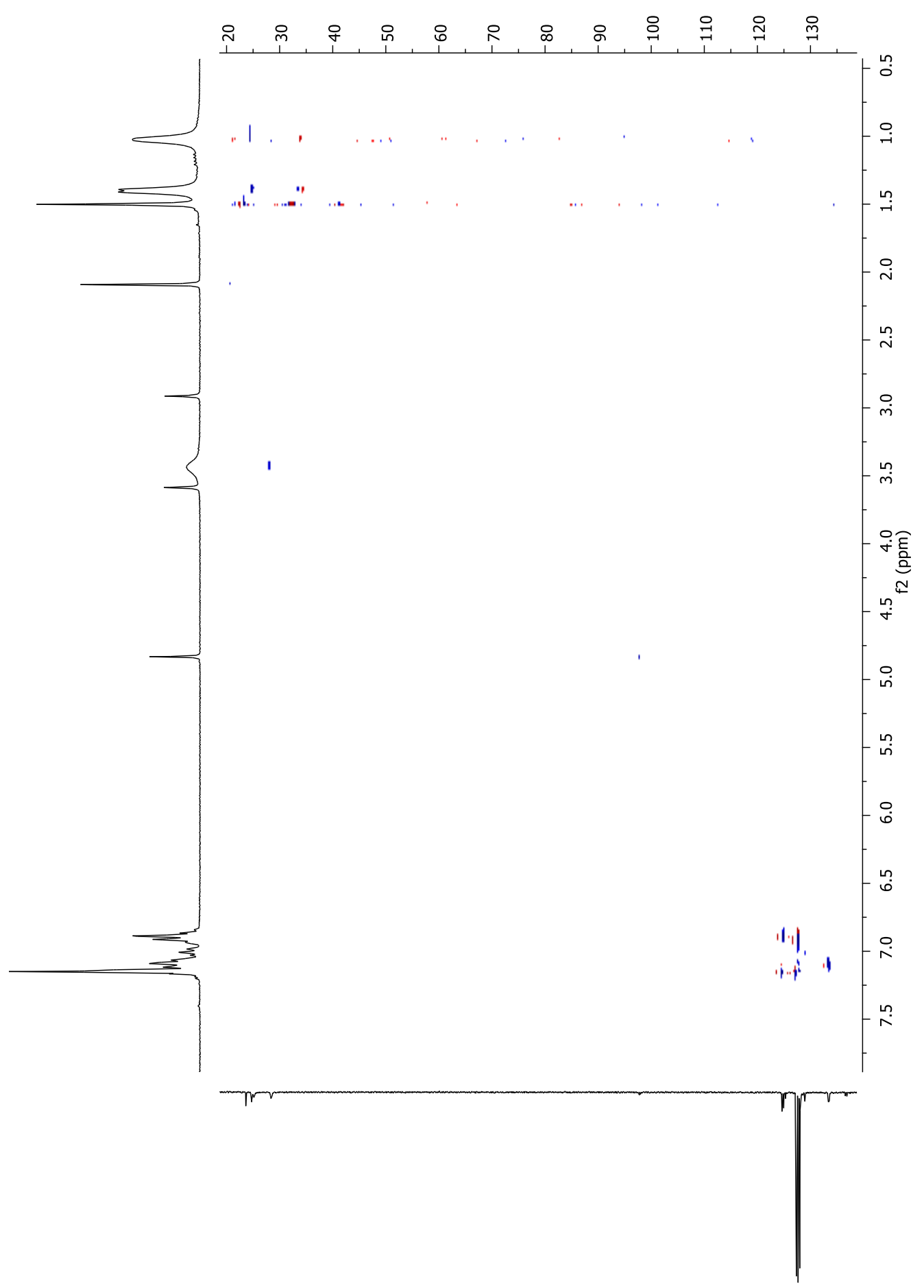

Multiplicity-edited $\mathrm{HSQC}$ spectrum of [(BDI)Ga(PHPh $\left.)_{2}\right]$, showing methyls and methines in blue and methylenes in red $\left(299.741 \mathrm{MHz}, \mathrm{C}_{6} \mathrm{D}_{6}\right)$ 


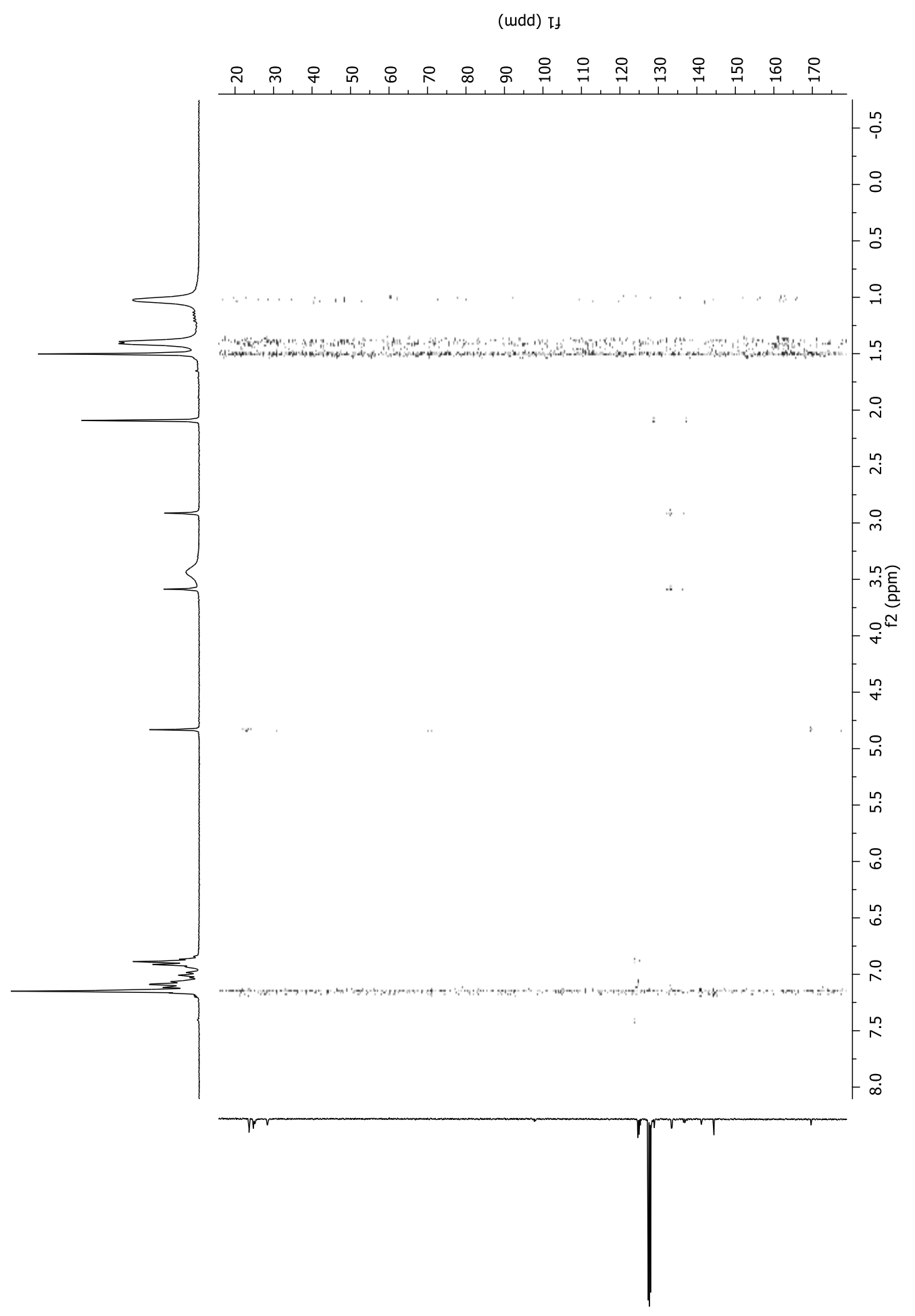

HMBC spectrum of [(BDI)Ga(PHPh) $)_{2}\left(299.741 \mathrm{MHz}, \mathrm{C}_{6} \mathrm{D}_{6}\right)$ 


\section{C.7 [(BDI)Ga(PHPh)Cl]}

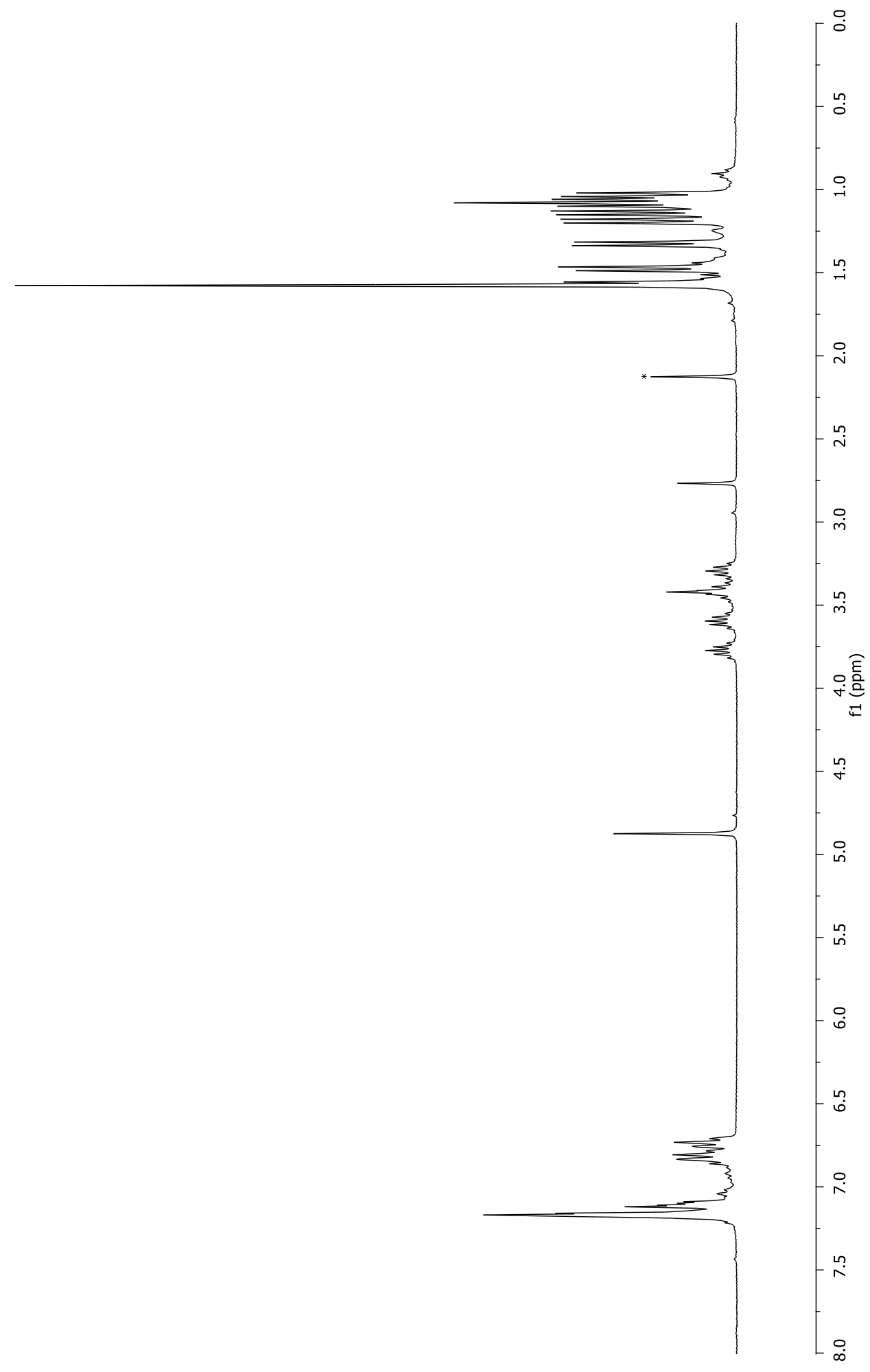

${ }^{1} \mathrm{H}$ NMR spectrum of $[(\mathrm{BDI}) \mathrm{Ga}(\mathrm{PHPh}) \mathrm{Cl}]\left(299.741 \mathrm{MHz}, \mathrm{C}_{6} \mathrm{D}_{6}\right)$

$*$ = contamination 


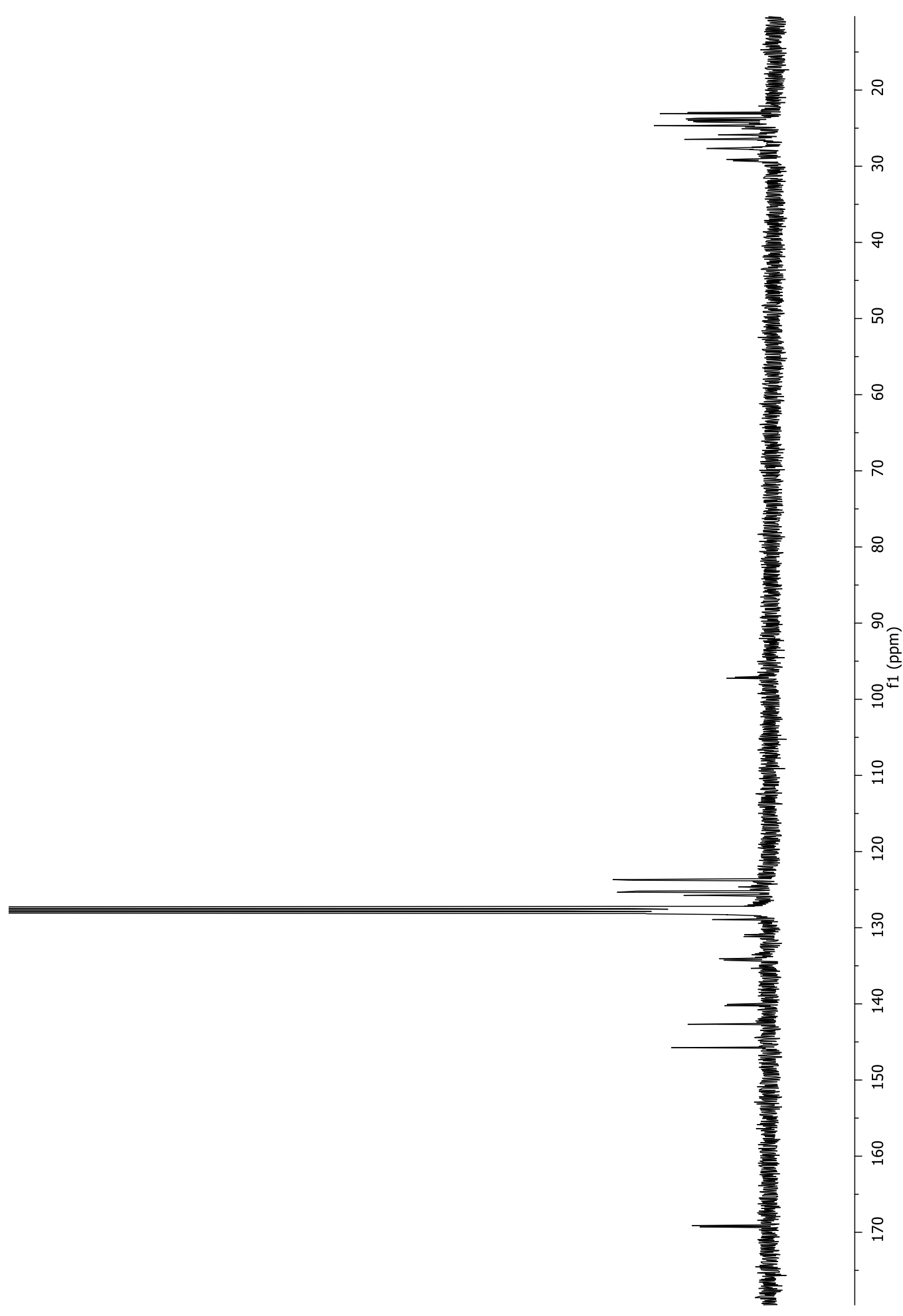

${ }^{13} \mathrm{C}$ NMR spectrum of $[(\mathrm{BDI}) \mathrm{Ga}(\mathrm{PHPh}) \mathrm{Cl}]\left(75.378 \mathrm{MHz}, \mathrm{C}_{6} \mathrm{D}_{6}\right)$ 


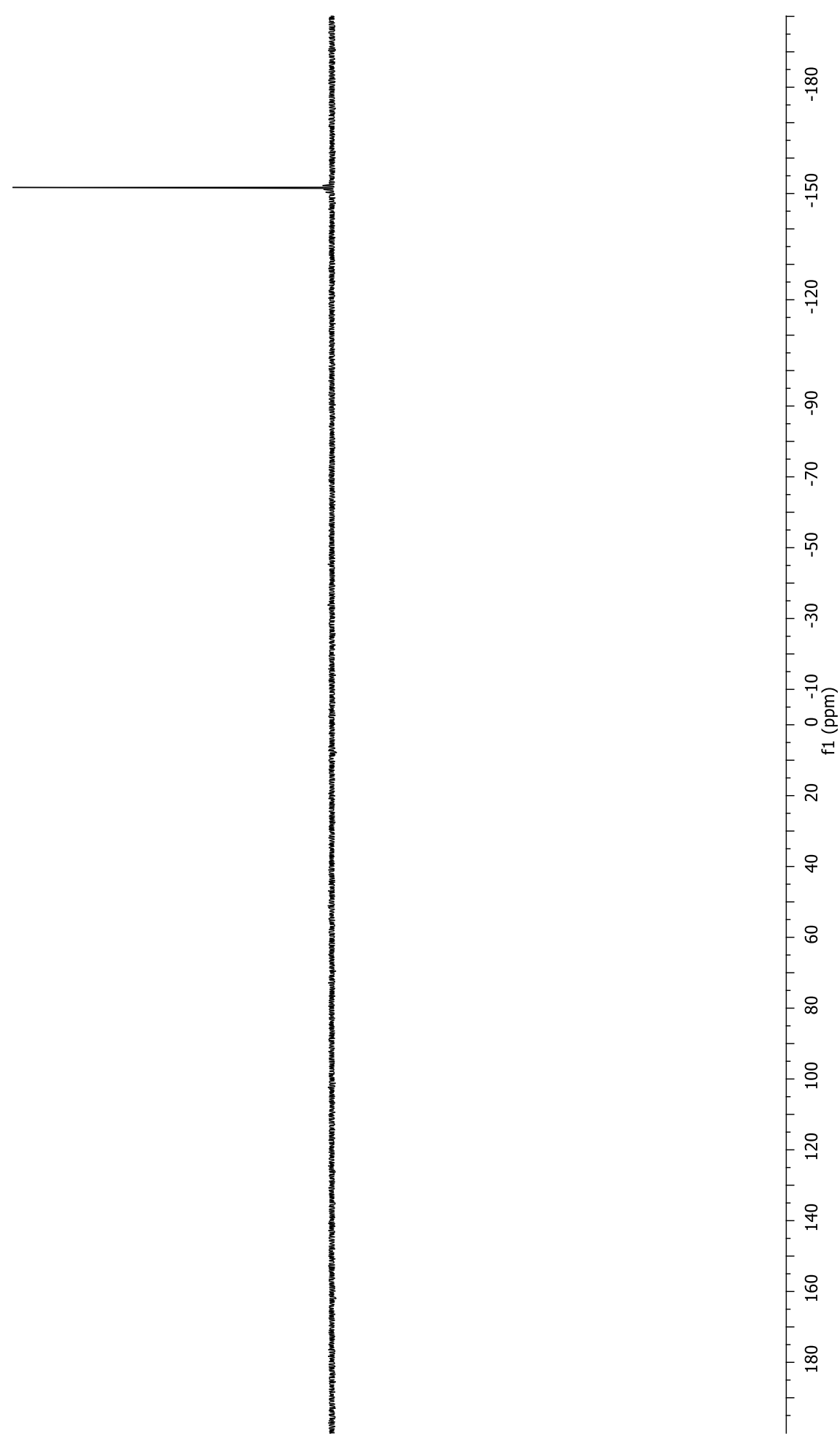

${ }^{31} \mathrm{P}$ NMR spectrum of [(BDI)Ga(PHPh)Cl] $\left(121.318 \mathrm{MHz}, \mathrm{C}_{6} \mathrm{D}_{6}\right)$ 


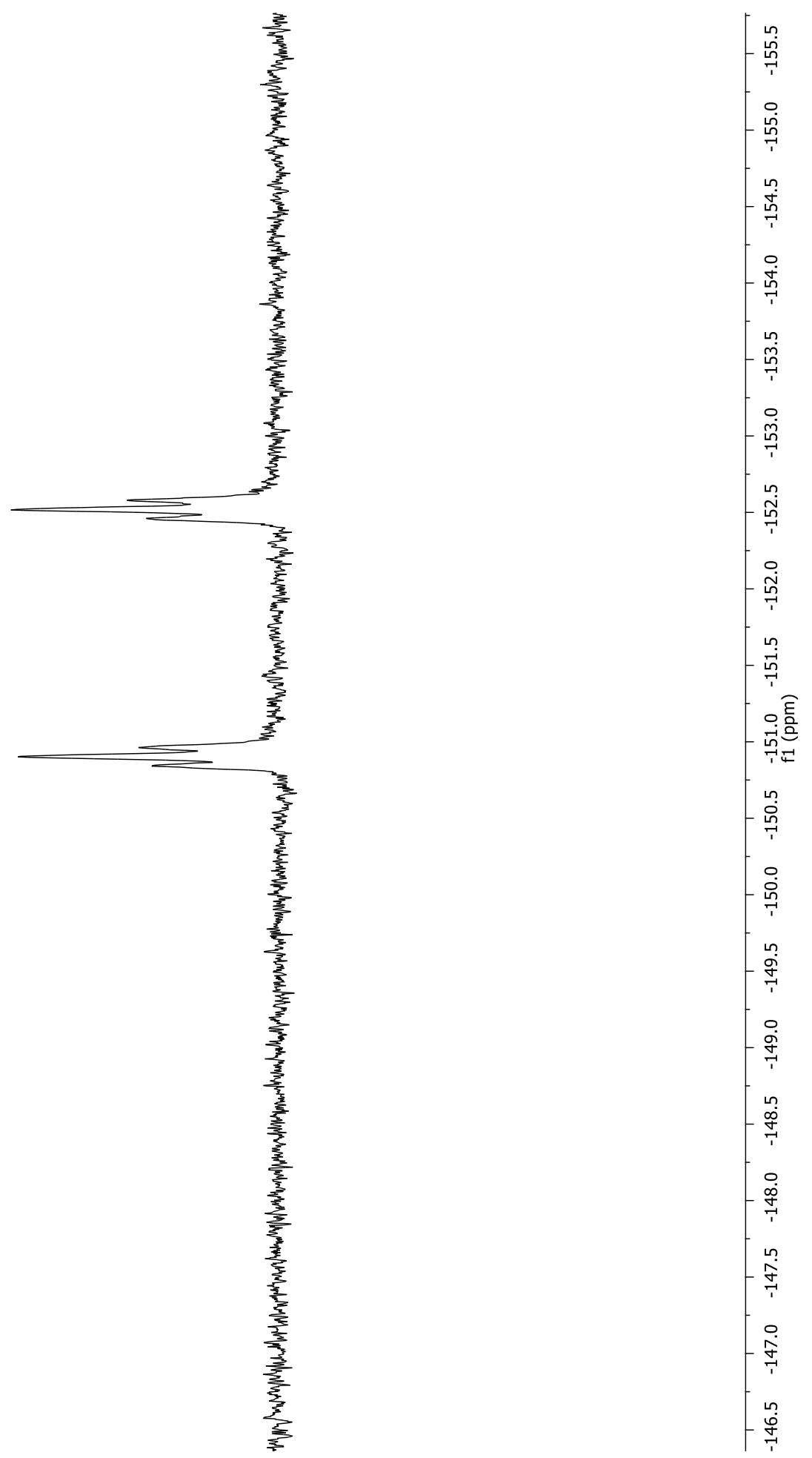

${ }^{31} \mathrm{P}$ NMR spectrum $\left({ }^{1} \mathrm{H}\right.$ coupled) of [(BDI)Ga(PHPh)Cl] (121.318 MHz, $\left.\mathrm{C}_{6} \mathrm{D}_{6}\right)$ 


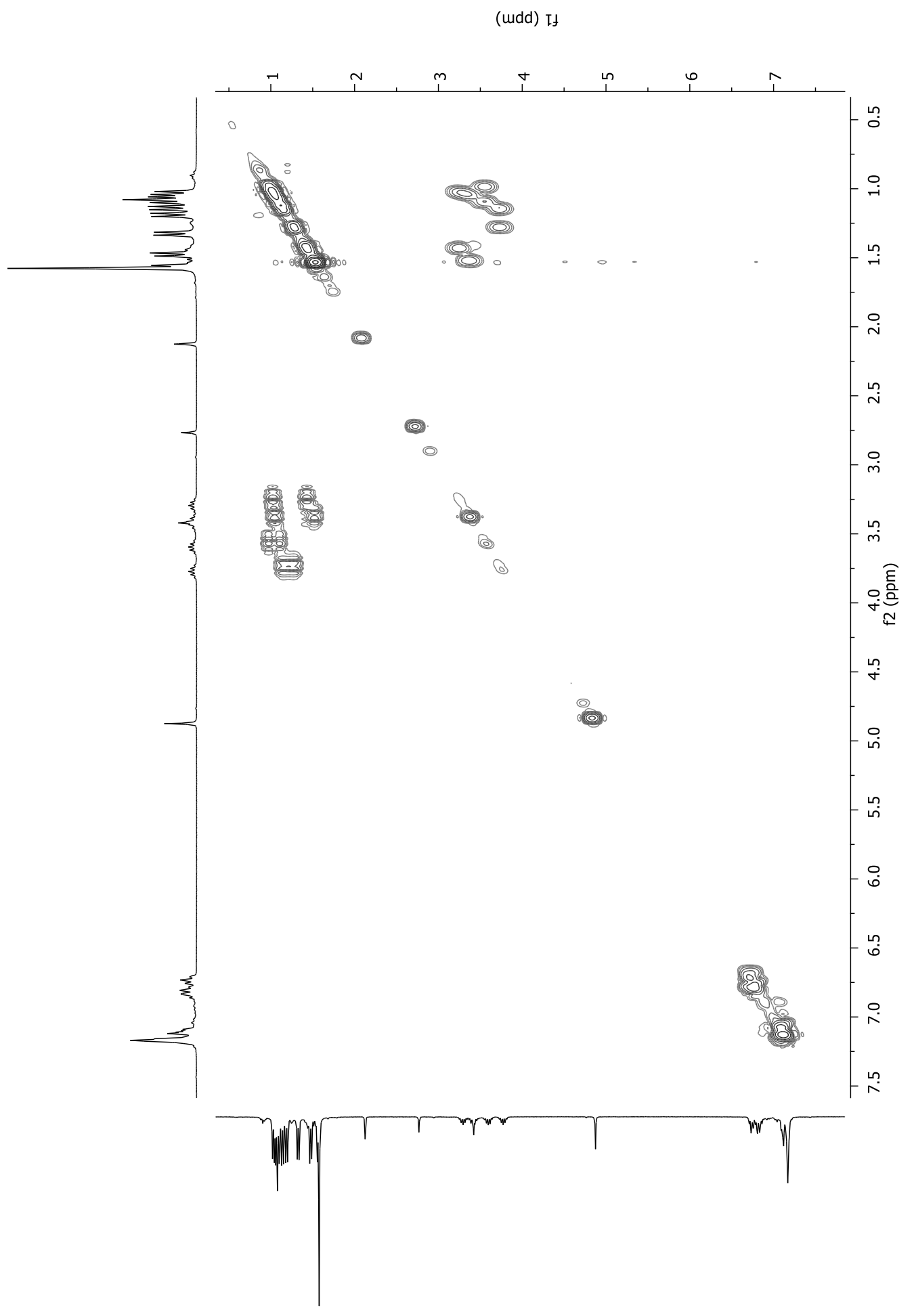

COSY spectrum of [(BDI)Ga(PHPh)Cl] (299.741 MHz, $\left.\mathrm{C}_{6} \mathrm{D}_{6}\right)$ 
(udd) It

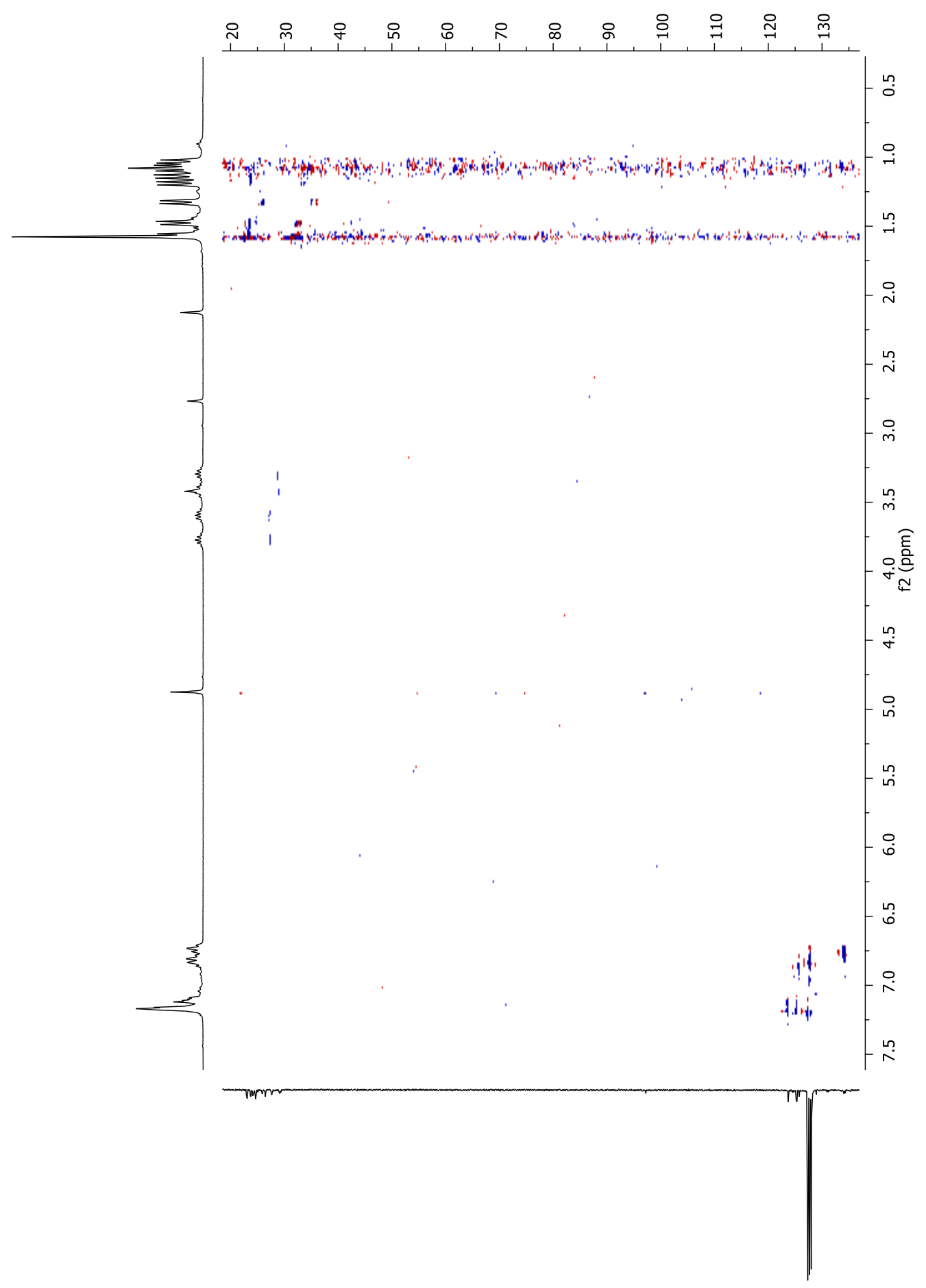

Multiplicity-edited HSQC spectrum of [(BDI)Ga(PHPh)Cl], showing methyls and methines in blue and methylenes in red $\left(299.741 \mathrm{MHz}, \mathrm{C}_{6} \mathrm{D}_{6}\right)$ 
(udd) If

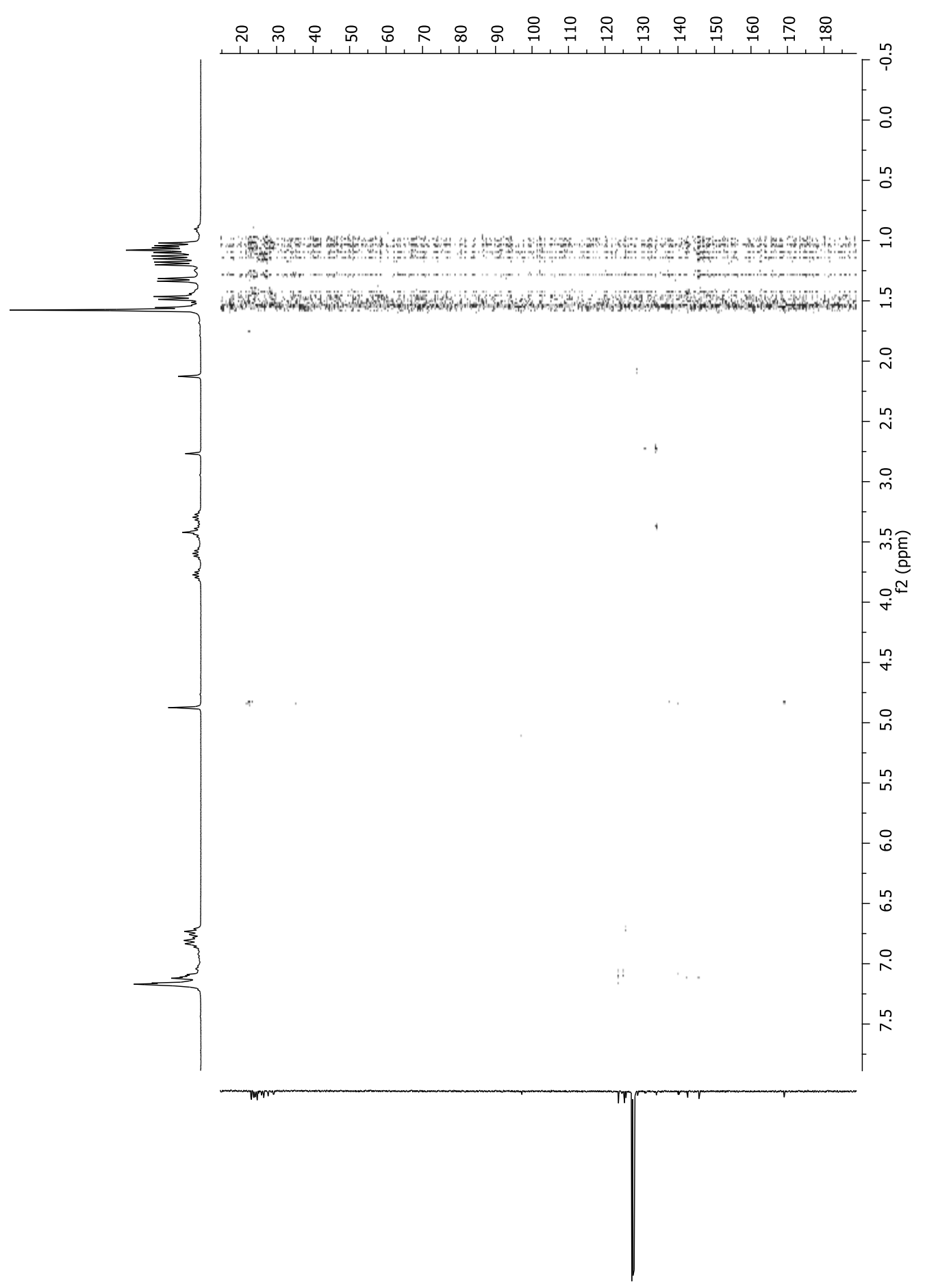

HMBC spectrum of [(BDI)Ga(PHPh)Cl] (299.741 MHz, $\left.\mathrm{C}_{6} \mathrm{D}_{6}\right)$ 


\section{C.8 SJC02_071j}

SJC02_071 is the impure product of the addition of ${ }^{n} \mathrm{BuLi}$ to $[(\mathrm{BDI}) \mathrm{Ga}(\mathrm{PHPh}) \mathrm{Cl}]$.

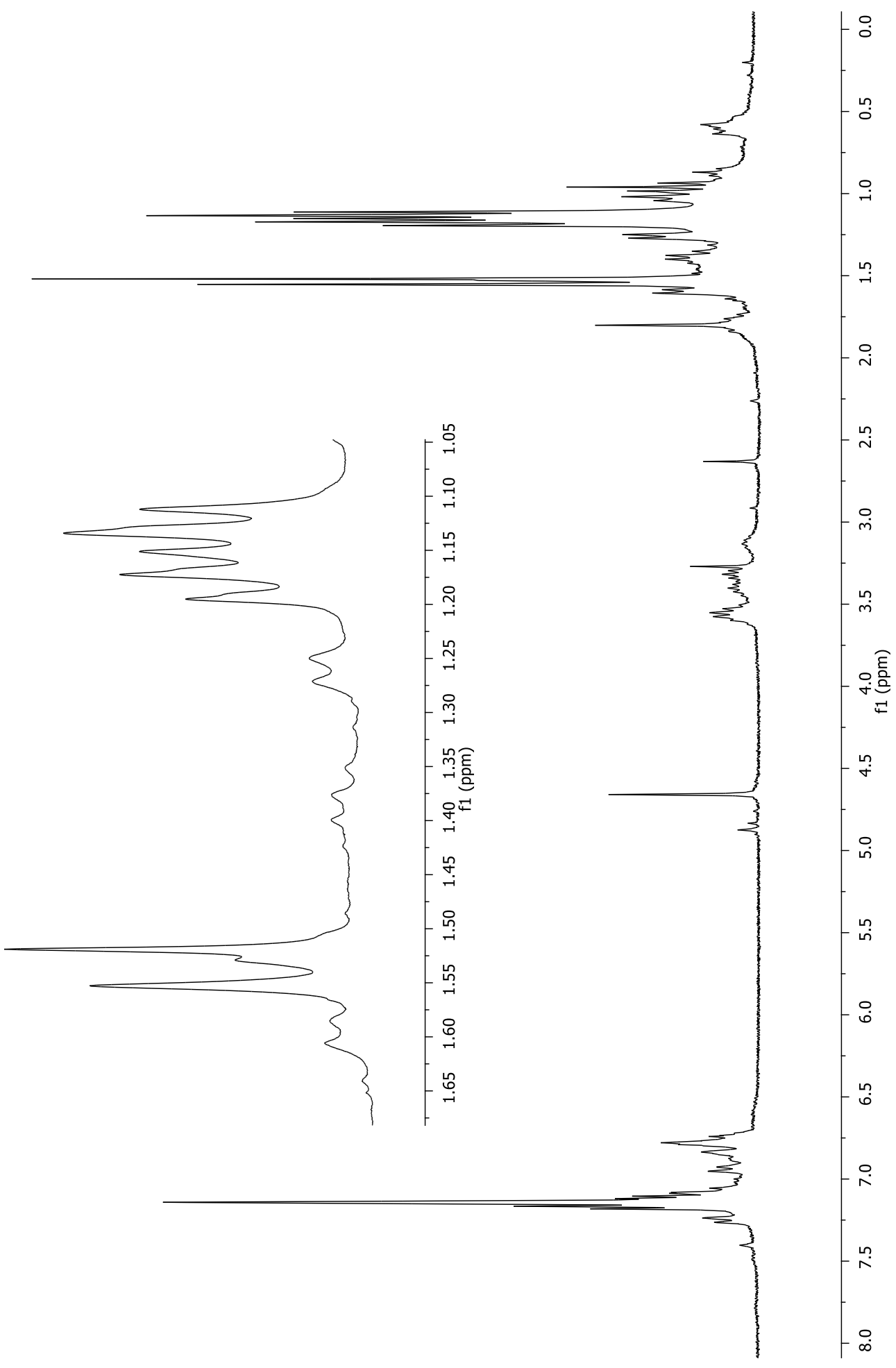

${ }^{1} \mathrm{H}$ NMR spectrum of SJC02_071j (299.741 MHz, $\left.\mathrm{C}_{6} \mathrm{D}_{6}\right)$ 


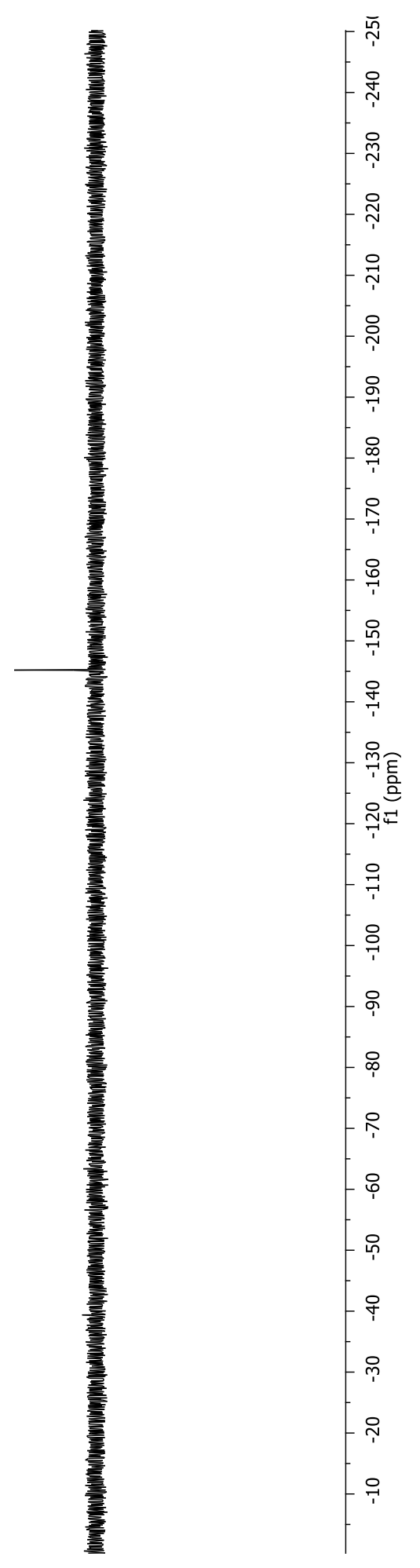

${ }^{31}$ P NMR spectrum of SJC02_071j (121.318 MHz, $\left.C_{6} D_{6}\right)$ 


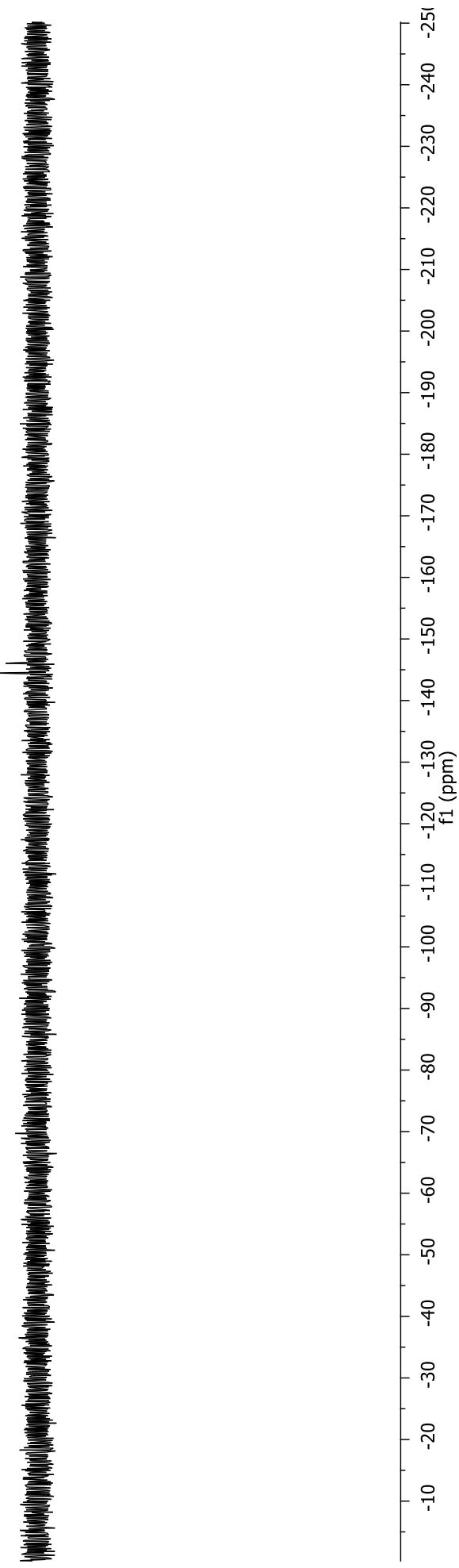

${ }^{31} \mathrm{P}$ NMR spectrum $\left({ }^{1} \mathrm{H}\right.$ coupled) of SJC02_071j $\left(121.318 \mathrm{MHz}, \mathrm{C}_{6} \mathrm{D}_{6}\right)$ 


\section{Appendix D: Crystallography Tables}

Crystal structure and refinement data for $\mathbf{2 1 , 2 5 ,} 26$ and 29.

\begin{tabular}{|c|c|c|c|c|}
\hline & {$\left[(\mathrm{BDI}) \mathrm{Ga}(\mathrm{Bn})_{2}\right](\mathbf{2 1})$} & {$\left[(\mathrm{BDI}) \mathrm{Ga}(\mathrm{DMP})_{2}\right](25)$} & {$\left[(\mathrm{BDI}) \mathrm{Ga}(\mathrm{DIPP})_{2}\right](26)^{\mathrm{a}}$} & {$\left[(\mathrm{BDI}) \mathrm{Ga}(\mathrm{PHPh})_{2}\right](29)$} \\
\hline Chemical formula & $\mathrm{C}_{43} \mathrm{H}_{55} \mathrm{GaN}_{2}$ & $\mathrm{C}_{45} \mathrm{H}_{61} \mathrm{GaN}_{4} \bullet\left(\mathrm{C}_{7} \mathrm{H}_{8}\right)$ & $\mathrm{C}_{53} \mathrm{H}_{77} \mathrm{GaN}_{4}$ & $\left.\mathrm{C}_{41} \mathrm{H}_{53} \mathrm{GaN}_{2} \mathrm{P}_{2}\right] \bullet 0.5\left(\mathrm{C}_{7} \mathrm{H}_{8}\right)$ \\
\hline Formula weight & 669.61 & 819.83 & 839.91 & 747.55 \\
\hline Temperature (K) & $120.02(10)$ & $120.01(10)$ & $120.0(1)$ & $120.01(10)$ \\
\hline Wavelength (Å) & 0.7107 & 0.7107 & 1.54180 & 0.7107 \\
\hline Crystal size $\left(\mathrm{mm}^{3}\right)$ & $0.65 \times 0.64 \times 0.59$ & $0.24 \times 0.23 \times 0.23$ & $0.49 \times 0.36 \times 0.27$ & $0.71 \times 0.5 \times 0.39$ \\
\hline Crystal system & orthorhombic & monoclinic & monoclinic & monoclinic \\
\hline Space group & $P 2{ }_{1} 2_{1} 2_{1}$ (No.19) & $P 2_{1} / c$ (No.14) & $P 2_{1} / c$ (No.14) & $\mathrm{P} 2_{1} / \mathrm{c}$ \\
\hline$a(\AA ̊)$ & $11.2164(3)$ & $11.4582(6)$ & $19.3161(4)$ & $21.0474(7)$ \\
\hline$b(\AA ̊)$ & $13.0869(4)$ & $24.2105(5)$ & $12.1190(2)$ & $8.7732(3)$ \\
\hline$c(\AA ̊)$ & $25.6526(8)$ & $20.5888(10)$ & $23.5884(7)$ & $23.1270(10)$ \\
\hline 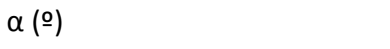 & 90 & 90 & 90 & 90 \\
\hline 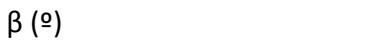 & 90 & $126.345(7)$ & $119.899(2)$ & $107.993(4)$ \\
\hline$\gamma(\underline{0})$ & 90 & 90 & 90 & 90 \\
\hline$V\left(\AA^{3}\right)$ & $3765.51(19)$ & $4600.4(5)$ & $4786.92(19)$ & $4061.6(3)$ \\
\hline$z$ & 4 & 4 & 4 & 4 \\
\hline$p_{\mathrm{c}}\left(\mathrm{Mg} \mathrm{m}^{-3}\right)$ & 1.18 & 1.18 & 1.17 & 1.222 \\
\hline Absorption coefficient $\left(\mathrm{mm}^{-1}\right)$ & 0.761 & 0.636 & 1.061 & 0.788 \\
\hline$\theta$ range for data collection ( $(9)$ & 5.692 to 60 & 5.192 to 59.998 & 2.64 to 73.83 & 5.61 to 54.998 \\
\hline measured / indep rflns & 29269/10989/0.029 & $39672 / 13402 / 0.029$ & $32419 / 9470 / 0.046$ & $24650 / 9327 / 0.0326$ \\
\hline Data / restraints / & $10989 / 0 / 425$ & $13402 / 0 / 529$ & 9470 / 6 / 561 & $9327 / 45 / 487$ \\
\hline Goodness-of-fit on $\mathrm{F}^{2}$ & 1.045 & 1.040 & 1.020 & 1.031 \\
\hline Final $R$ indices [I>2sigma(I)] & $R_{1}=0.029, w R_{2}=0.066$ & $R_{1}=0.035, w R_{2}=0.087$ & $\mathrm{R} 1=0.050, w R 2=0.136$ & $R_{1}=0.0459, w_{2}=0.1203$ \\
\hline $\mathrm{R}$ indices (all data) & $R_{1}=0.032, w R_{2}=0.068$ & $R_{1}=0.044, w R_{2}=0.092$ & $\mathrm{R} 1=0.056, w R 2=0.144$ & $\mathrm{R}_{1}=0.0549, \mathrm{wR}_{2}=0.1262$ \\
\hline Lrgst diff. peak \& hole $\left(\mathrm{e} \AA^{3}\right)$ & $0.43 /-0.36$ & $0.81 /-0.73$ & 0.58 and -0.63 & $2.04 /-1.00$ \\
\hline
\end{tabular}

${ }^{a}$ One isopropyl group on the BDI ligand was disordered and modelled over two positions. 


\section{Appendix E: Bibliography}

(1) March, J. Advanced Organic Chemistry: Reactions, Mechanisms, and Structure, Fourth Edition; Wiley, 1992.

(2) Inorganic Chemistry; Pearson Education, 1981.

(3) Dechy-Cabaret, O.; Martin-Vaca, B.; Bourissou, D. Chem. Rev. 2004, 104, 6147.

(4) Dijkstra, P. J.; Du, H.; Feijen, J. Polymer Chemistry 2011, 2, 520.

(5) Coles, M. P.; Jordan, R. F. J. Am. Chem. Soc. 1997, 119, 8125.

(6) Welch, G. C.; Cabrera, L.; Chase, P. A.; Hollink, E.; Masuda, J. D.; Wei, P.; Stephan, D. W. Dalton Trans. 2007, 3407.

(7) Jakupec, M. A.; Keppler, B. K. Curr. Top. Med. Chem. (Sharjah, United Arab Emirates) 2004, 4, 1575.

(8) Power, P. P. Chem. Rev. 1999, 99, 3463.

(9) Jacobsen, H.; Ziegler, T. J. Am. Chem. Soc. 1994, 116, 3667.

(10) Kutzelnigg, W. Angew. Chem. 1984, 96, 262.

(11) Kaltsoyannis, N. J. Chem. Soc., Dalton Trans. 1997, 1.

(12) Chen, M.; Fulton, J. R.; Hitchcock, P. B.; Johnstone, N. C.; Lappert, M. F.; Protchenko, A. V. Dalton Trans. 2007, 2770.

(13) Wu, C. S.; Su, M. D. J. Comput. Chem. 2012, 33, 103.

(14) Fischer, R. C.; Power, P. P. Chem Rev 2010, 110, 3877.

(15) Power, P. P. Nature 2010, 463, 171.

(16) Pearson, R. G. Proc. Natl. Acad. Sci. U. S. A. 1975, 72, 2104.

(17) Stürmann, M.; Saak, W.; Weidenbruch, M.; Klinkhammer, K. W. Eur. J. Inorg. Chem. 1999, 1999, 579.

(18) Davidson, P. J.; Lappert, M. F. J. Chem. Soc., Chem. Commun. 1973, 317a.

(19) Präsang, C.; Sahin, Y.; Hofmann, M.; Geiseler, G.; Massa, W.; Berndt, A. Eur. J. Inorg. Chem. 2008, 2008, 5046.

(20) Nakata, N.; Sekiguchi, A. J. Am. Chem. Soc. 2006, 128, 422.

(21) Nakata, N.; Izumi, R.; Lee, V. Y.; Ichinohe, M.; Sekiguchi, A. J. Am. Chem. Soc. 2004, $126,5058$.

(22) Nakata, N.; Izumi, R.; Lee, V. Y.; Ichinohe, M.; Sekiguchi, A. Chem. Lett. 2008, 37, 1146.

(23) Breen, T. L.; Stephan, D. W. J. Am. Chem. Soc. 1995, 117, 11914.

(24) Piro, N. A.; Cummins, C. C. J. Am. Chem. Soc. 2009, 131, 8764.

(25) Rotter, T.; Kneifel, A. N.; Mayer, P.; Westerhausen, M. Inorg. Chem. Commun. 2005, $8,809$.

(26) Bourget-Merle, L.; Lappert, M. F.; Severn, J. R. Chem. Rev. 2002, 102, 3031.

(27) Stender, M.; Eichler, B. E.; Hardman, N. J.; Power, P. P.; Prust, J.; Noltemeyer, M.; Roesky, H. W. Inorg. Chem. 2001, 40, 2794.

(28) Kuhn, N.; Fahl, J.; Fuchs, S.; Steimann, M.; Henkel, G.; Maulitz, A. H. Z. Anorg. Allg. Chem. 1999, 625, 2108.

(29) Gornitzka, H.; Stalke, D. Organometallics 1994, 13, 4398.

(30) Trathen, N., M. Chem, $\beta$-diketiminate gallium complexes: synthesis of $\beta$ diketiminate gallium alkyls, aryls and cations, University of Sussex, 2010

(31) Hardman, N. J.; Eichler, B. E.; Power, P. P. Chem. Commun. (Cambridge, U. K.) 2000, 1991.

(32) Prabusankar, G.; Gonzalez-Gallardo, S.; Doddi, A.; Gemel, C.; Winter, M.; Fischer, R. A. Eur. J. Inorg. Chem. 2010, 2010, 4415.

(33) Arduengo, A. J.; Harlow, R. L.; Kline, M. J. Am. Chem. Soc. 1991, 113, 361. 
(34) Bellemin, L. S.; Guichard, G.; Chardon, E.; Centre National de la Recherche Scientifique, Fr.; Universite de Strasbourg . 2012, p 71pp.; Chemical Indexing Equivalent to 157:133924 (WO).

(35) Pan, Y.; Xu, T.; Ge, Y.-S.; Lu, X.-B. Organometallics 2011, 30, 5687.

(36) Casey, C. P.; Burkhardt, T. J. J. Am. Chem. Soc. 1973, 95, 5833.

(37) Schrock, R. R. J. Am. Chem. Soc. 1974, 96, 6796.

(38) Cowley, A. H.; Gabbai, F. P.; Carrano, C. J.; Mokry, L. M.; Bond, M. R.; Bertrand, G. Angew. Chem. 1994, 106, 584.

(39) Stasch, A.; Singh, S.; Roesky, Herbert W.; Noltemeyer, M.; Schmidt, H.-G. Eur. J. Inorg. Chem. 2004, 2004, 4052.

(40) Dolgoplosk, B. A.; Tinyakova, E. I.; Guzman, I. S.; Vollerstein, E. L.; Chigir, N. N.; Bondarenko, G. N.; Sharaev, O. K.; Yakovlev, V. A. J. Organomet. Chem. 1980, $201,249$.

(41) Meinhart, J. D.; Anslyn, E. V.; Grubbs, R. H. Organometallics 1989, 8, 583.

(42) de Heisteeg, B. J. J. v.; Schat, G.; Akkerman, O. S.; Bickelhaupt, F. Tetrahedron Lett. $1987,28,6493$.

(43) Lu, E.; Li, Y.; Chen, Y. Chem Commun (Camb) 2010, 46, 4469.

(44) Chu, T.; Piers, W. E.; Dutton, J. L.; Parvez, M. Organometallics 2013, 32, 1159.

(45) Fuchibe, K.; Iwasawa, N. Chemistry 2003, 9, 905.

(46) Schrock, R. R.; Hoveyda, A. H. Angew. Chem., Int. Ed. Engl. 2003, 42, 4592.

(47) Chatterjee, A. K.; Grubbs, R. H. Org. Lett. 1999, 1, 1751.

(48) Schrock, R. R. Acc. Chem. Res. 1986, 19, 342.

(49) Singh, S.; Ahn, H. J.; Stasch, A.; Jancik, V.; Roesky, H. W.; Pal, A.; Biadene, M.; HerbstIrmer, R.; Noltemeyer, M.; Schmidt, H. G. Inorg. Chem. 2006, 45, 1853.

(50) Singh, S.; Jancik, V.; Roesky, H. W.; Herbst-Irmer, R. Inorg. Chem. 2006, 45, 949.

(51) Duncan, A. P.; Bergman, R. G. Chem. Rec. 2002, 2, 431.

(52) Johnson, J. S.; Bergman, R. G. J. Am. Chem. Soc. 2001, 123, 2923.

(53) Hardman, N. J.; Cui, C.; Roesky, H. W.; Fink, W. H.; Power, P. P. Angew. Chem., Int. Ed. 2001, 40, 2172.

(54) Solis-Ibarra, D.; Gómora-Figueroa, A. P.; Zavala-Segovia, N.; Jancik, V. Eur. J. Inorg. Chem. 2009, 2009, 4564.

(55) Hansmann, M. M.; Melen, R. L.; Wright, D. S. Chemical Science 2011, 2, 1554.

(56) Seifert, A.; Linti, G. Eur. J. Inorg. Chem. 2007, 2007, 5080.

(57) Harder, S. Organometallics 2002, 21, 3782.

(58) Rankin, M. A.; Cummins, C. C. Dalton Trans. 2012, 41, 9615.

(59) Aylward, G. H.; Findlay, T. J. T. J. V. SI Chemical Data; John Wiley \& Sons Australia, Limited, 2007.

(60) Tam, E. C.; Maynard, N. A.; Apperley, D. C.; Smith, J. D.; Coles, M. P.; Fulton, J. R. Inorg. Chem. 2012, 51, 9403.

(61) Zimmer, K. D.; Shoemaker, R.; Ruminski, R. R. Inorg. Chim. Acta 2006, 359, 1478.

(62) Basuli, F.; Bailey, B. C.; Watson, L. A.; Tomaszewski, J.; Huffman, J. C.; Mindiola, D. J. Organometallics 2005, 24, 1886.

(63) Chen, Y.-J.; Fang, H.-J.; Hsu, S. C. N.; Jheng, N.-Y.; Chang, H.-C.; Ou, S.-W.; Peng, W.T.; Lai, Y.-C.; Chen, J.-Y.; Chen, P.-L.; Kao, C.-H.; Zeng, Z.-X.; Chen, J.-L.; Chen, H.-Y. Polymer Bulletin 2012, 70, 993.

(64) Dove, A. P.; Gibson, V. C.; Marshall, E. L.; White, A. J. P.; Williams, D. J. Chem. Commun. (Cambridge, U. K.) 2001, 283.

(65) Cheng, M.; Moore, D. R.; Reczek, J. J.; Chamberlain, B. M.; Lobkovsky, E. B.; Coates, G. W. J. Am. Chem. Soc. 2001, 123, 8738.

(66) Degée, P.; Dubois, P.; Jérǒme, R.; Jacobsen, S.; Fritz, H.-G. Macromol. Symp. 1999, $144,289$.

(67) Kricheldorf, H. R.; Langanke, D. Polymer 2002, 43, 1973. 
(68) Lachaud, C.; Zauner, A.; Leplat, A.; Lahootun, V.; L'Air Liquide, Societe Anonyme pour I'Etude et l'Exploitation des Procedes Georges Claude, Fr. . 2013, p 12pp.

(69) Feldman, J.; McLain, S. J.; Parthasarathy, A.; Marshall, W. J.; Calabrese, J. C.; Arthur, S. D. Organometallics 1997, 16, 1514.

(70) Snyder, S. A.; Treitler, D. S. In Org. Synth.; John Wiley \& Sons, Inc.: 2003. 